\title{
Actual and Estimated Energy Savings Comparison for Deep Energy Retrofits in the Pacific Northwest
}
J Blanchard
E Giever
S Widder
M Baechler

October 2012

Pacific Northwest

NATIONAL LABORATORY

Proudly Operated by Battelle Since 1965 


\title{
DISCLAIMER
}

This report was prepared as an account of work sponsored by an agency of the United States Government. Neither the United States Government nor any agency thereof, nor Battelle Memorial Institute, nor any of their employees, makes any warranty, express or implied, or assumes any legal liability or responsibility for the accuracy, completeness, or usefulness of any information, apparatus, product, or process disclosed, or represents that its use would not inf ringe privately owned rights. Reference herein to any specific commercial product, process, or service by trade name, trademark, manufacturer, or otherwise does not necessarily constitute or imply its endorsement, recommendation, or favoring by the United States Government or any agency thereof, or Battelle Memorial Institute. The views and opinions of authors expressed herein do not necessarily state or reflect those of the United States Government or any agency thereof.

\author{
PACIFIC NORTHWEST NATIONAL LABORATORY \\ operated by \\ BATTELLE \\ for the \\ UNITED STATES DEPARTMENT OF ENERGY \\ under Contract DE-AC05-76RL01830
}

Printed in the United States of America
Available to DOE and DOE contractors from the
Office of Scientific and Technical Information
P.O. Box 62, Oak Ridge, TN 37831-0062;
ph: (865) 576-8401
fax: $(865) 576-5728$
email: reports@adonis.osti.gov

Available to the public from the National Technical Information Service

5301 Shawnee Rd., Alexandria, VA 22312

ph: (800) 553-NTIS (6847)

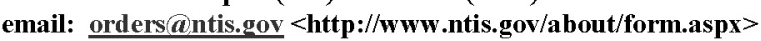

Online ordering: http://www.ntis.gov

This document was printed on recycled paper. 


\title{
Actual and Estimated Energy Savings Comparison for Deep Energy Retrofits in the Pacific Northwest
}

\author{
J Blanchard \\ E Giever \\ S Widder \\ M Baechler
}

October 2012

Prepared for

the U.S. Department of Energy

under Contract DE-AC05-76RL01830

Pacific Northwest National Laboratory

Richland, Washington 99352 


\section{Summary}

Seven homes from the Pacific Northwest were selected to evaluate the differences between estimated and actual energy savings achieved from deep energy retrofits. The energy savings resulting from these retrofits were estimated, using energy modeling software, to save at least $30 \%$ on a whole-house basis. Modeled pre-retrofit energy use was trued against monthly utility bills. After retrofits were completed, each of the homes was extensively monitored, with the exception of one home that was only monitored pre-retrofit. This work is being conducted by Pacific Northwest National Laboratory (PNNL) for the U.S. Department of Energy Building Technologies Program as part of the Building America Program.

Previous research has shown that realized savings from retrofit measures may not be consistent with energy savings estimates produced by modeling software (Lancaster et al. 2012; Parker et al. 2012; Polly et al. 2011). In previous studies, research has generally shown models to over-predict energy savings and energy use, especially in older, less efficient homes (Polly et al. 2011). Modeling occupant behavior has proved to be especially important for improved model accuracy and have found that detailed audit inputs, including operational behavior, can successfully increase the accuracy of models to within $\pm 25 \%$ on a whole house basis (Parker et al. 2012).

However, this study found that by truing models based on whole-house energy consumption and utility bills, offsetting errors can give the illusion of accuracy when in fact individual end-uses are substantially different than the model predicts. This can make determining the fundamental accuracy of the model (e.g., how well model predicts energy use at the component level) and identifying the root cause of inaccuracies difficult because sources of error can act simultaneously and confound one another (Polly et al. 2011). Sub-metered energy usage data are required for robust calibration of individualized models of a single home and homeowner (Parker et al. 2012). In this research project, seven homes in the Pacific Northwest that have undergone extensive energy retrofits and were sub-metered. For six homes the monitored post-retrofit energy usage was compared to energy models that were trued based on preretrofit utility bills. The seventh home was monitored pre-retrofit, however, post-retrofit analysis was not completed because the retrofits were not completed in time for this report. With sub-metered data, the accuracy of the overall whole-house model as well as the accuracy of specific equipment profiles can be examined.

This work found many discrepancies between actual and estimated energy savings and identified the potential causes for the discrepancies. The differences between actual energy use and modeled energy use also suggest improvements that could be made to enhance model accuracy. The difference between whole-house actual and estimated energy savings on a monthly basis ranged from $75 \%$ more energy saved than predicted by the model to $16 \%$ less energy saved for all the monitored homes. Similarly, the annual energy savings difference was between $36 \%$ and $-14 \%$, which was estimated based on existing monitored savings because an entire year of data was not available. Thus, on average, for all six monitored homes the actual energy use was consistently less than estimates, indicating homeowners were saving more energy than estimated. The average actual savings for the 8-month monitoring period was $43 \%$, compared to a modeled savings average of $31 \%$. Although this average difference is only $12 \%$, the range of inaccuracies found for specific end-uses is far greater and are the values used to directly estimate energy savings from specific retrofits. Specifically, the monthly post-retrofit energy use differences for specific end-uses (i.e., heating, cooling, hot water, appliances, etc.) ranged from 131\% under-predicted to $77 \%$ over-predicted by the model with respect to monitored energy use. In addition, for the single home 
where pre-retrofit data were collected the domestic hot water, dryer, and miscellaneous energy use were over-estimated by $45 \%, 47 \%$, and $175 \%$, respectively. Unfortunately, only a single complete month of data was collected so broader impacts regarding improved pre-retrofit model generation were not evaluated. Many of the discrepancies were associated with the following:

- Occupant behavior influences energy use, dramatically in some cases.

- Differences between actual and modeled "typical" weather can be significant.

- Modeling inputs can be limited and inflexible, making it difficult to adapt the model for various homeowners.

- Complex homes are difficult to model accurately.

- Occupants involved in this study are more likely to conserve energy because they volunteered for this study and paid for the retrofits without non-energy related financial incentives.

The discrepancy between actual and estimated energy use indicates a need for better modeling tools and assumptions. Despite the best efforts of researchers, the modeled energy savings were too inaccurate to determine reliable paybacks for retrofit projects. While monitored data allow researchers to understand why differences between modeled and actual savings exist, it is not cost effective to monitor each home with the level of detail presented here. Therefore, an appropriate balance between modeling and monitoring must be determined for more widespread application in retrofit programs and the home performance industry. Recommendations to address these deficiencies include the following:

- Improve the tuning process for pre-retrofit energy use. The current process uses broad-based monthly utility bills.

- Develop simple occupant-based energy models that better address the many different occupant types and their impacts on energy use. For example, inputs should be generalized and simple (e.g., low, medium, high) and flexible to account for various occupant types and behavior.

- Incorporate actual weather inputs to increase accuracy of the tuning process, which uses utility bills from a specific time period.

- Develop simple, cost-effective monitoring solutions for improved model tuning such as non-intrusive load monitoring technology, which may be able to obtain disaggregated energy use at a significantly reduced cost. 


\section{Acknowledgments}

The authors acknowledge the guidance and support of David Lee, Eric Werling, Sam Rashkin, and Chris Early of the U.S. Department of Energy Building Technologies Program in sponsoring this work and providing helpful feedback and guidance.

The team is most appreciative of the homeowners who have chosen to invest in energy performance and comfort for their homes and have decided to participate in this study. This work would not be possible without these motivated individuals who have opened up their homes to the research team, answered numerous questions, and shown incredible patience in participating in the research study.

The PNNL research team was assisted by local home performance contractors Jonathan Cohen of Imagine Energy and Tyler Coke and Andrew Morphis of Green Hammer. We appreciate the efforts and

collaboration of Dave Chasar and Janet McIlvaine from the Florida Solar Energy Center, especially with regard to EnergyGauge ${ }^{\circledR}$ modeling. We also thank Roderick Jackson of Oak Ridge National Laboratory who led work in Metro Atlanta area and provided helpful data and feedback, and Brent Singer of Lawrence Berkeley National Laboratory, who provided input on the indoor air-quality monitoring approach.

Finally, this report is compiled in honor and memory of Subrato Chandra. This research would not have been possible without his vision, motivation, guidance, and individual effort. Subrato devoted most of his professional life to the pursuit of energy efficient residential housing and this report summarizes some of his final work. 


\section{Acronyms and Abbreviations}

\begin{tabular}{|c|c|}
\hline $\mathrm{A} / \mathrm{C}$ & air conditioner (or air conditioning) \\
\hline $\mathrm{AHU}$ & air handling unit (or air handling unit) \\
\hline amp & ampere \\
\hline AMY & Actual Meteorological Year \\
\hline $\mathrm{BA}$ & Building America \\
\hline $\mathrm{BIN}$ & binary \\
\hline CDD & cooling degree day \\
\hline $\mathrm{cfm}$ & cubic feet per minute \\
\hline $\operatorname{cfm} 25$ & cubic feet per minute at 25 Pascals of depressurization \\
\hline $\operatorname{cfm} 50$ & cubic feet per minute at 50 Pascals of depressurization \\
\hline $\mathrm{CH}_{2} \mathrm{O}$ & formaldehyde \\
\hline $\mathrm{CO}$ & carbon monoxide \\
\hline $\mathrm{CO}_{2}$ & carbon dioxide \\
\hline CSV & comma-separated value \\
\hline CT & current transformer \\
\hline d & $\operatorname{day}(\mathrm{s})$ \\
\hline DNI & direct normal irradiance \\
\hline DOE & U.S. Department of Energy \\
\hline DHW & domestic hot water \\
\hline EPA & U.S. Environmental Protection Agency \\
\hline${ }^{\circ} \mathrm{F}$ & degree Fahrenheit \\
\hline $\mathrm{ft}^{2}$ & square foot(feet) \\
\hline GHZ & global horizontal irradiance \\
\hline HDD & heating degree day \\
\hline HERS & home energy rating system \\
\hline HP & heat pump \\
\hline $\mathrm{hr}$ & hour(s) \\
\hline HRV & heat recovery ventilator \\
\hline HSPF & heating seasonal performance factor \\
\hline HVAC & heating, ventilation, and air conditioning \\
\hline IAQ & indoor air quality \\
\hline kBtu & one thousand British thermal unit(s) \\
\hline $\mathrm{kW}$ & kilowatt(s) \\
\hline $\mathrm{kWh}$ & kilowatt-hour(s) \\
\hline LBNL & Lawrence Berkeley National Laboratory \\
\hline NA & not available or not applicable \\
\hline
\end{tabular}


$\mathrm{NO}_{\mathrm{x}}$

$\mathrm{pCi} / \mathrm{L}$

$\mathrm{PM}$

PNNL

ppm

$\mathrm{RH}$

SEER

TMY

TVOC

VAC nitrogen oxides

picocuries per liter

particulate matter

Pacific Northwest National Laboratory

parts per million

relative humidity

Seasonal Energy Efficiency Ratio

typical meteorological year

total volatile organic compound

volt(s) alternating current 


\section{Contents}

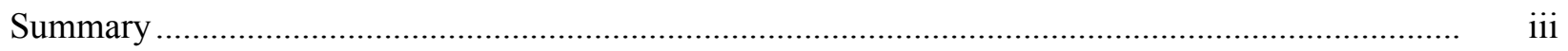

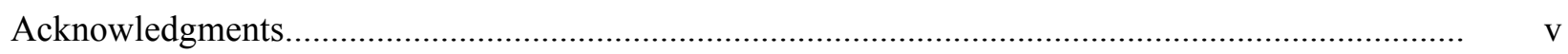

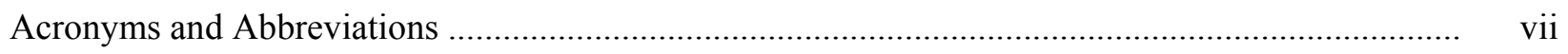

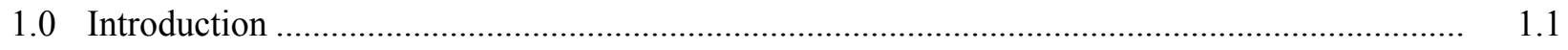

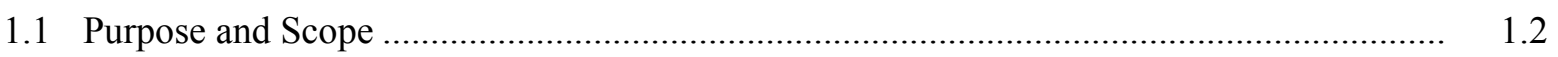

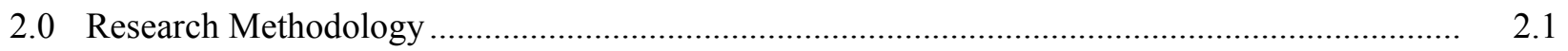

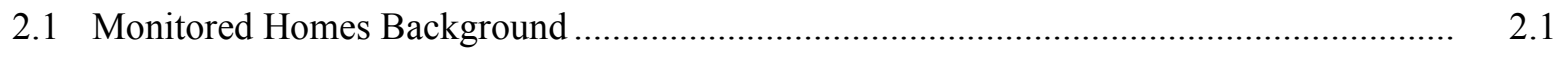

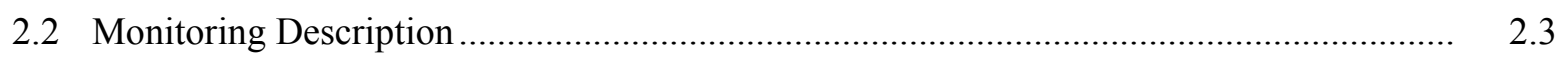

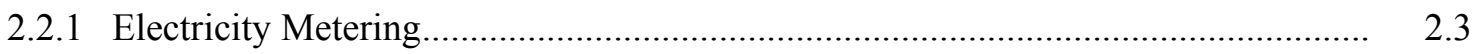

2.2.2 Undersized Current Transformers ................................................................... 2.5

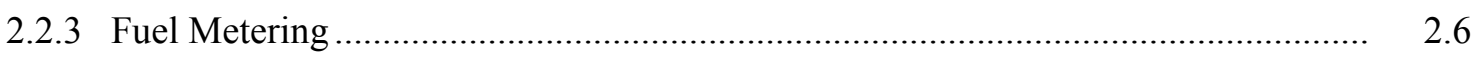

2.2.4 Environmental and Indoor Air Quality Measurements ...................................... 2.7

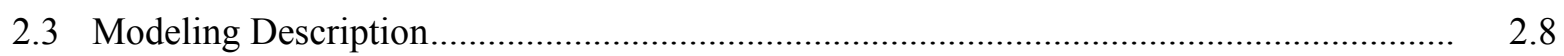

2.3.1 Typical and Actual Meteorological Year Approach ......................................... 2.10

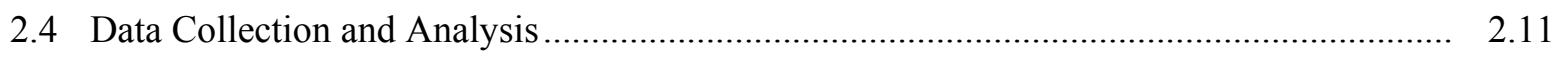

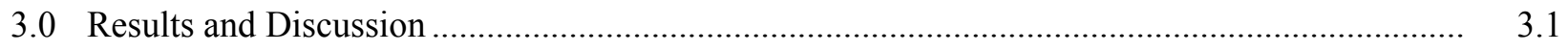

3.1 Actual and Estimated Energy Use Overview ..........................................................

3.2 Actual and Estimated Differences .............................................................................. 3.5

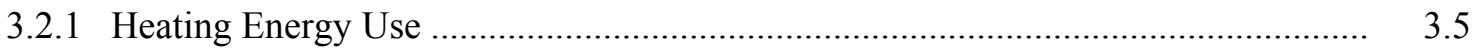

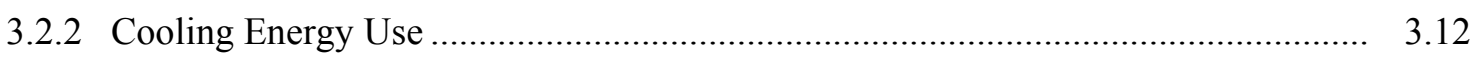

3.2.3 Actual Meteorological Year Corrections .......................................................... 3.15

3.2.4 Domestic Hot Water Energy Use ................................................................... 3.20

3.2.5 Clothes Dryer Energy Use ......................................................................... 3.22

3.2.6 Miscellaneous Unmonitored Energy Uses ......................................................... 3.25

3.2.7 Pre-Retrofit Modeled and Monitored Energy Use .............................................. 3.26

3.3 End-Use Energy Distribution ............................................................................ 3.27

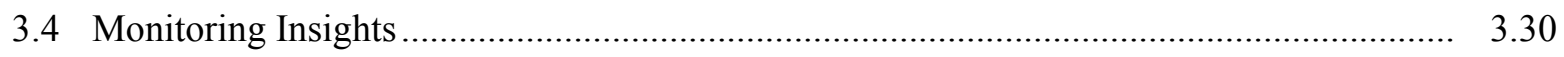

3.5 Indoor Air Quality Assessment ......................................................................... 3.31

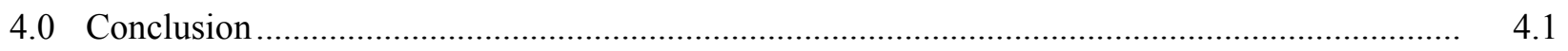

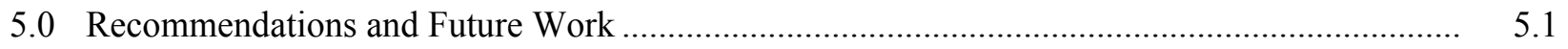

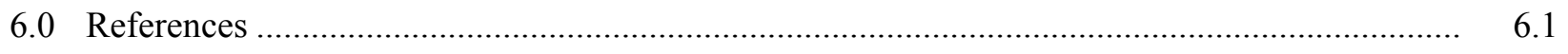

Appendix A - Metering Installation Details ........................................................................... A.1

Appendix B - Pre-Retrofit Truing Details .............................................................................. B. 1

Appendix C - Detailed Metering Results .......................................................................... C.1 


\section{Figures}

2.1 Schematic and photograph of an eGauge energy metering system, consisting of a main power meter unit, current transformers, voltage taps connected to a dual-pole breaker, HomePlug communication adapter, and an internet router

2.2 Screenshot of the eGauge energy meter online dashboard

2.3 Undersized CT example located at PNW-1 home for circuits 3 and 4, where the circuit capacity is 90 amps but the CT size is 50 amps

2.4 PNW-6 furnace energy use correction using the whole-house gas meter when the DHW heater is not operating

2.5 PNW-1 monthly and annual pre-retrofit utility bill and EnergyGauge ${ }^{\circledR}$ model diesel use true-up comparison

2.6 PNW-1 monthly and annual pre-retrofit utility bill and EnergyGauge ${ }^{\circledR}$ model electricity use true-up comparison

3.1 Annual and monthly recommended, estimated and actual energy savings percentages for six of the monitored homes

3.2 Monthly average estimated and actual savings percentages observed for six of the monitored homes

3.3 Monthly actual and estimated energy savings percentage comparison for six of the monitored homes

3.4 Actual and estimated energy use comparison for disaggregated end-uses summed over the monitoring period for six of the monitored homes, including a higher resolution inlayed figure

3.5 Comparison of post-retrofit modeled, AMY corrected, and metered monthly heating energy use for PNW-1, PNW-2, PNW-3, PNW-4, PNW-5, and PNW-6 homes..

3.6 Hourly heating energy use profile comparison for the PNW-2 home.

3.7 Hourly heating energy use profile comparison for the PNW-3 home.

3.8 Monitored strip heat and AHU energy use and dry bulb temperature comparison for PNW-2, PNW-3, and PNW-4 homes.

3.9 Modeled heating load and heating energy use for PNW-1, PNW-2, PNW-3, and PNW-4 homes

3.10 Post-retrofit modeled and metered miscellaneous energy use comparison for the PNW-1 home

3.11 Post-retrofit modeled and metered miscellaneous energy use comparison for the PNW-3 home.

3.12 Comparison of post-retrofit modeled, AMY corrected, and metered monthly cooling energy use comparison for PNW-1, PNW-2, PNW-3, PNW-4, PNW-5, and PNW-6 homes

3.13 Hourly cooling energy use profile comparison for the PNW-3 home

3.14 Hourly cooling energy use profile comparison for the PNW-1 home

3.15 Monthly heating energy and heating degree day comparisons for PNW-1, PNW-2, PNW-3, and PNW-4 homes

3.16 Monthly cooling energy and cooling degree day comparisons for PNW-1, PNW-2, PNW-3, PNW-4, PNW-5, and PNW-6 homes 
3.17 Comparison of direct normal irradiance, global horizontal irradiance, and cooling degree day percent change for AMY and post-retrofit models .

3.18 Comparison of post-retrofit modeled and metered DHW energy use for the PNW-3 home ...... 3.20

3.19 Comparison of post-retrofit modeled and metered DHW energy use for the PNW-2 home ...... 3.21

3.20 Comparison of the hourly DHW energy use profile for the PNW-3 home............................... 3.21

3.21 Comparison of the hourly DHW energy use profile for the PNW-2 home............................. 3.22

3.22 Comparison of post-retrofit modeled and metered dryer energy use for the PNW-5 home ....... 3.23

3.23 Comparison of post-retrofit modeled and metered dryer energy use for the PNW-1 home ....... 3.23

3.24 Comparison of the hourly dryer energy use profile for the PNW-5 home............................... 3.24

3.25 Comparison of the hourly dryer energy use profile for the PNW-1 home............................... 3.24

3.26 Comparison of post-retrofit modeled and metered miscellaneous energy use for the PNW-1 home

3.27 Comparison of the post-retrofit modeled and metered miscellaneous energy use for the PNW-5 home

3.28 Comparison of pre-retrofit modeled and metered disaggregated energy use for the PNW-7 home

3.29 Average of monthly end-use distribution for six of the monitored homes ............................. 3.28

3.30 Monthly end-use distribution for six of the monitored homes.............................................. 3.29

3.31 Comparison of daily electric use for the PNW-1 home ................................................ 3.30

3.32 Comparison of daily cooling energy use and dry bulb temperature for the PNW-4 home........ 3.31

3.33 Daily air handler unit (AHU) energy use for the PNW-4 home .......................................... 3.31

3.34 Average particulate matter concentrations indoors and outdoors for pre- and postretrofit in the PNW-3, PNW-4, and PNW-6 homes

3.35 Average $\mathrm{CO}_{2}$ concentrations indoors and outdoors for pre- and post-retrofit in the PNW-3, PNW-4, and PNW-6 homes.

3.36 Average relative humidity indoors and outdoors for pre- and post-retrofit in the PNW-3, PNW-4, and PNW-6 homes...

\section{Tables}

2.1 Key characteristics of the Pacific Northwest monitored homes

2.2 Summary of retrofits performed in Pacific Northwest monitored homes and monitoring approach.

2.3 Monitoring duration for Pacific Northwest homes .

2.4 AMY weather station locations for monitored homes

3.1 Average radon concentrations measured in the basement for pre- and post-retrofit in the PNW-3, PNW-4, and PNW-6 homes.

4.1 Summary of actual and estimated discrepancies, causes and proposed improvements 


\subsection{Introduction}

Energy use in residential homes has increased over the past several decades and now accounts for $22 \%$ of total energy use in the United States (EIA 2010). Because public desire to decrease overall energy demand is growing (Akerlof et al. 2010), attention is focused on making the residential sector more energy efficient. During the current downswing in new residential construction (U.S. Census Bureau 2011), retrofitting existing homes to save energy has become the focus of new energy-efficiency programs.

Historically, energy retrofits have occurred on a large scale through state-level weatherization programs and various other programs sponsored by electric and gas utilities. These programs have reduced the average annual natural-gas consumption by 20 to $25 \%$ and whole-house electrical energy by $10 \%$ (Schweitzer 2005; Blasnik 2006, 2007). To advance the state of the art, the U.S. Department of Energy (DOE) Building America (BA) Program has established a goal of achieving additional savings through more aggressive "deep energy retrofits" that reduce energy consumption by 30 to $50 \%$ or more on a whole-house basis. With more than 115 million existing households in the United States (BEDB 2012), residential energy retrofitting presents a large potential for energy savings. This large potential has led to the formation of numerous incentive programs and rebates by federal, state, and local governments and utilities.

However, previous research has shown that realized savings from retrofit measures may not be consistent with energy savings estimates produced by modeling software (Lancaster et al. 2012; Parker et al. 2012; Polly et al. 2011). In previous studies, research has generally shown models to over-predict energy savings and energy use, especially in older, less efficient homes (Polly et al. 2011). Modeling occupant behavior has proved to be especially important for improved model accuracy, especially decreasing the tendency of models to over-predict energy savings (Parker et al. 2012). In fact, Parker et al. (2012) has observed three-fold differences in energy use across otherwise identical homes, due to differences in occupancy and behavioral effects (Parker et al. 2012). These studies have found that detailed audit inputs, including operational behavior, can increase the accuracy of models to within $\pm 25 \%$ on a whole-house basis (Parker et al. 2012). However, previous research has focused on the accuracy of whole-house energy use and predicted energy savings.

Truing models based whole-house energy consumption and utility bills can make model results appear to represent actual whole-house energy consumption quite well. However, offsetting errors can give the illusion of accuracy when in fact individual end-uses are substantially different than the model predicts. However, this can make determining the fundamental accuracy of the model (e.g., how well the model predicts energy use at the component level) and identifying the root cause of inaccuracies difficult because sources of error can act simultaneously and confound one another (Polly et al. 2011). Submetered energy usage data are required for robust calibration of individualized models of a single home and homeowner (Parker et al. 2012). In this research project, seven homes in the Pacific Northwest that have undergone extensive energy retrofits were sub-metered and their post-retrofit energy usage were compared to energy models that have been trued based on pre-retrofit utility bills. With the sub-metered data, the accuracy of the overall whole-house model as well as the accuracy of specific equipment profiles can be examined. 
Continued success and growth of the retrofit industry will rely on consistent positive experiences from homeowners and program organizers. Thus, to improve the retrofit process and achieve increased savings by identifying the most impactful measures and approaches, there is a need to understand the variability and the factors that influence actual versus estimated energy savings in residential retrofits.

\subsection{Purpose and Scope}

Previously, a team of researchers from Pacific Northwest National Laboratory (PNNL) provided technical assistance on approximately 51 selected pilot residences in a variety of climate zones in the Pacific Northwest, Florida, and Texas. The research team, funded by DOE's BA Program, applied integrated building science and systems engineering principles to determine "what it takes" to achieve energy savings of 30 to $50 \%$ or more and simultaneously increase the comfort, combustion safety, durability, and indoor air quality (IAQ) of a home (Chandra et al. 2012).

Of the 51 homes, 23 homes completed retrofits during the study period. Seven of the 23 completed homes are located in the Pacific Northwest. For 14 home owners, detailed audit reports were provided to help facilitate the recommended deep energy retrofits. For other homes, retrofits were already determined or underway. The audit reports contained estimated energy savings for a package of retrofits, determined using EnergyGauge USA, an energy modeling software.

Many of the homeowners decided to proceed with the retrofits; some implementing all recommendations and others only a few. From this subset of homes that underwent retrofitting, seven of the homes were selected for extensive monitoring because they were estimated to have energy savings that were greater than $30 \%$. The owners of these homes also chose to pursue these extensive retrofits with substantial capital investments made with no financial incentives beyond achieving energy savings and addressing comfort issues. Comfort issues were a strong driver for some of the homeowners to pursue retrofits. Because the homeowners were willing to make the investments in their homes, it is presumed that they may be non-typical and are likely to have energy use patterns that differ from average homeowners, who may be less conscious of their energy use. The influence of these homeowners' behaviors was not factored into the analysis.

This report presents the monitoring and analysis of the seven homes in the Pacific Northwest. The analysis focuses on the differences between estimated (i.e., modeled) and actual energy savings, climate impacts, and occupant influences associated with retrofit energy savings. Limited data collected on the differences in indoor air quality between pre- and post-retrofit also are presented. 


\subsection{Research Methodology}

To determine the relationship between actual and estimated savings, seven homes that underwent deep energy retrofits in 2011-2012 were analyzed. Extensive audit information and modeling data are available for these homes. In addition, each home was independently metered, with some sub-metering of key equipment loads, to determine actual energy use post-retrofit. These metered data were compared to predict energy savings generated using EnergyGauge ${ }^{\circledR}$ energy modeling software. The seven homes used in this analysis, the metering and modeling approaches, and analysis performed are presented in the subsequent sections.

\subsection{Monitored Homes Background}

Seven homes, located in the Pacific Northwest, were selected to study the realized energy savings associated with energy retrofits expected to save more than $30 \%$ on a whole-house basis. The key characteristics of the selected homes are summarized in Table 2.1.

Table 2.1. Key characteristics of the Pacific Northwest monitored homes.

\begin{tabular}{ccccccc}
\hline Home & Location & $\begin{array}{c}\text { Floor Area } \\
\left(\mathrm{ft}^{2}\right)\end{array}$ & $\begin{array}{c}\text { HERS }^{(\mathrm{a})} \\
\text { Pre-retrofit }\end{array}$ & $\begin{array}{c}\text { HERS } \\
\text { Post-retrofit }\end{array}$ & $\begin{array}{c}\text { Estimated Energy } \\
\text { Savings } \\
(\mathrm{kBtu} / \mathrm{yr})^{(\mathrm{b})}\end{array}$ & $\begin{array}{c}\text { Estimated Energy } \\
\text { Savings (\%) }\end{array}$ \\
\hline PNW-1 & Dayton, WA & 2,638 & 125 & 90 & 97,584 & 63 \\
PNW-2 & Richland, WA & 3,100 & 137 & 71 & 31,787 & 37 \\
PNW-3 & Richland, WA & 1,692 & 177 & 112 & 21,806 & 24 \\
PNW-4 & Seattle, WA & 2,141 & 168 & 148 & 66,976 & 59 \\
PNW-5 & Portland, OR & 1,100 & $\mathrm{NA}^{(\mathrm{c})}$ & 68 & 101,846 & 63 \\
PNW-6 & Portland, OR & 2,999 & 87 & 69 & 30,768 & 27 \\
PNW-7 & Portland, OR & 2,020 & 166 & $\mathrm{NA}$ & $\mathrm{NA}$ & $\mathrm{NA}^{(\mathrm{c})}$ \\
\hline
\end{tabular}

(a) HERS = Home energy rating system.

(b) Difference between pre-retrofit and post-retrofit modeled annual energy use.

(c) $\mathrm{NA}=$ Not available.

The retrofits undertaken in each home are summarized in Table 2.2. The pre- and post-retrofit condition and characteristics of each home were determined using a detailed energy audit, including blower door and duct blaster testing. The detailed audit results, audit equipment, and recommended energy efficiency packages to achieve at least 30\% energy savings for each home are described in detail in a previously published report by Chandra et al. (2012). 
Table 2.2. Summary of retrofits performed in Pacific Northwest monitored homes and monitoring approach.

\begin{tabular}{|c|c|c|}
\hline Home & Retrofits Implemented & Metering Approach \\
\hline PNW-1 & $\begin{array}{l}\text { - Minimal air-sealing } \\
\circ \quad 10 \% \text { reduction in air leakage } \\
\text { - New SEER }{ }^{(\mathrm{a})} 16 / \mathrm{HSPF}^{(\mathrm{b})} 9.4 \text { ductless } \mathrm{HP}^{(\mathrm{c})} \text {, left old diesel } \\
\text { hydronic system in as backup }\end{array}$ & Electrical, diesel, T\&RH \\
\hline PNW-2 & - new SEER 15/HSPF $10 \mathrm{HP}$ & Electrical, T\&RH \\
\hline PNW-3 & $\begin{array}{l}\text { - New } 2.5 \text { ton SEER } 16 \mathrm{HP} \\
\text { - Duct sealing and redesign } \\
\text { Pre-Retrofit duct leakage }=400 \mathrm{cfm} 25^{(\mathrm{d})} \text {; post-retrofit }= \\
276 \mathrm{cfm} 25 . \text { Increased air flow through air handler from } \\
660 \mathrm{cfm} \text { to } 1,126 \mathrm{cfm} \text {. } \\
\text { - Insulated garage door }\end{array}$ & Electrical, T\&RH \\
\hline PNW-4 & $\begin{array}{l}\text { - New SEER } 18 / \mathrm{HSPF} 9 \mathrm{HP} \\
\text { - New duct system } \\
\text { - Insulation and air sealing in basement } \\
\text { Pre-Retrofit envelope leakage }=3,526 \mathrm{cfm} 50^{(\mathrm{e})} \text {; post- } \\
\text { retrofit }=2,450 \text { cfm50 }\end{array}$ & Electrical, T\&RH \\
\hline PNW-5 & 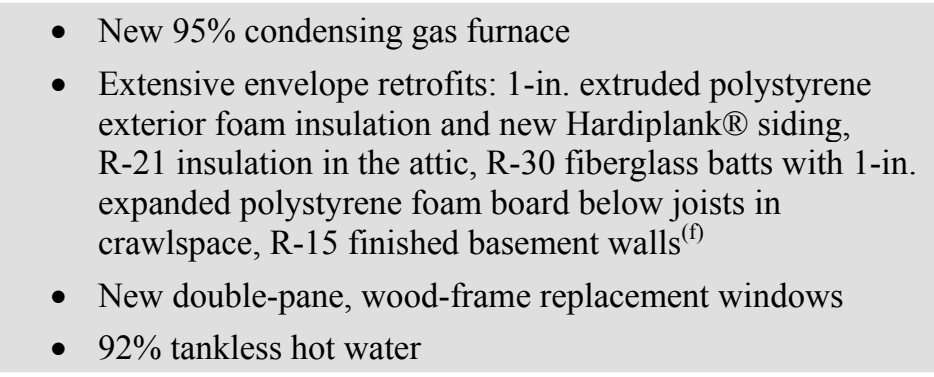 & Electrical, gas, T\&RH \\
\hline PNW-6 & $\begin{array}{l}\text { - } \mathrm{R}-30 \text { sprayfoam insulation on the roof deck } \\
\circ \quad \text { Pre-Retrofit envelope leakage }=4,816 \mathrm{cfm} 50 \text {; post- } \\
\text { retrofit }=3,623 \text { cfm } 50 \\
\text { - } 95 \% \text { condensing gas tankless hot water heater } \\
\text { - } 3.24 \mathrm{~kW} \text { solar photovoltaic panels }\end{array}$ & Electrical, solar, T\&RH \\
\hline PNW-7 & $\begin{array}{l}\text { - 2-in. polyiso roof insulation and dense-pack cellulose wall } \\
\text { insulation } \\
\text { - 3-head SEER } 16 \text { ductless HP with HRV }{ }^{(\mathrm{h})}\end{array}$ & Electrical, solar, T\&RH \\
\hline
\end{tabular}

(a) SEER = seasonal energy efficiency ratio.

(b) $\mathrm{HSPF}=$ heating seasonal performance factor.

(c) $\mathrm{HP}=$ heat pump.

(d) $\operatorname{cfm} 25=$ cubic feet per minute at 25 Pascals depressurization with respect to the body of the home, as measured by a duct blaster.

(e) $\operatorname{cfm} 50=$ cubic feet per minute at 50 Pascals depressurization with respect to the outside, as measured by a blower door.

(f) No pre-retrofit audit information.

(g) Completed September 2012. Test out has not been performed.

(h) Heat recovery ventilator. 


\subsection{Monitoring Description}

The disaggregated energy consumption for each home was monitored after the retrofits were completed. ${ }^{1}$ Monitoring consisted of electrical, fuel, temperature, relative humidity, and other miscellaneous metering, as presented in subsequent sections. The duration of monitoring is summarized in Table 2.3. Additional monitoring details for each home can be found in Appendix A.

Table 2.3. Monitoring duration for Pacific Northwest homes.

\begin{tabular}{clccc}
\hline Home & \multicolumn{1}{c}{ Location } & $\begin{array}{c}\text { Monitoring } \\
\text { Start Date }\end{array}$ & $\begin{array}{c}\text { Monitoring } \\
\text { End Date }^{(a)}\end{array}$ & $\begin{array}{c}\text { Days } \\
\text { Monitored }\end{array}$ \\
\hline PNW-1 & Dayton, WA & $12 / 23 / 2011$ & $8 / 31 / 2012$ & 252 \\
PNW-2 & Richland, WA & $12 / 22 / 2011$ & $8 / 31 / 2012$ & 253 \\
PNW-3 & Richland, WA & $1 / 20 / 2012$ & $8 / 31 / 2012$ & 224 \\
PNW-4 & Seattle, WA & $2 / 21 / 2012$ & $8 / 31 / 2012$ & 192 \\
PNW-5 & Portland, OR & $4 / 17 / 2012$ & $8 / 31 / 2012$ & 136 \\
PNW-6 & Portland, OR & $5 / 5 / 2012$ & $8 / 31 / 2012$ & 118 \\
PNW-7 & Portland, OR & $4 / 19 / 2012$ & $6 / 23 / 2012^{(\text {b) }}$ & 65 \\
\hline
\end{tabular}

(a) Actual monitoring is ongoing but data have only been analyzed through the dates shown.

(b) Monitoring suspended due to retrofits beginning. Retrofits completed September 2012.

\subsubsection{Electricity Metering}

In each home, the electrical energy was metered using an eGauge energy meter (eGauge Systems LLC, Boulder, Colorado). The eGauge device must be connected to main voltage leads inside the breaker panel so installation was performed by licensed electricians.

The eGauge metering system consists of a main power meter unit, current transformers (CTs), a HomePlug communication adapter and an Internet router, as shown schematically and photographically in Figure 2.1. The main metering unit allows for three-phase voltage connections, but only two phases are necessary for residential applications. Up to $12 \mathrm{CTs}$ can be connected to the main power unit, allowing 12 separate 120 VAC or 240 VAC appliances to be monitored. However, care should be used when monitoring 240 VAC appliances that contain substantial 120 VAC loads and may not be phase balanced. The main unit communicates via Power Line Carrier technology to the HomePlug adapter, which is connected directly to an Internet router. The eGauge meter data then is accessible via the Internet, obviating the need for local downloading of data.

\footnotetext{
${ }^{1}$ The PNW-7 home is not included in the pre- and post-retrofit comparison because retrofits were too late to be included in the analysis.
} 

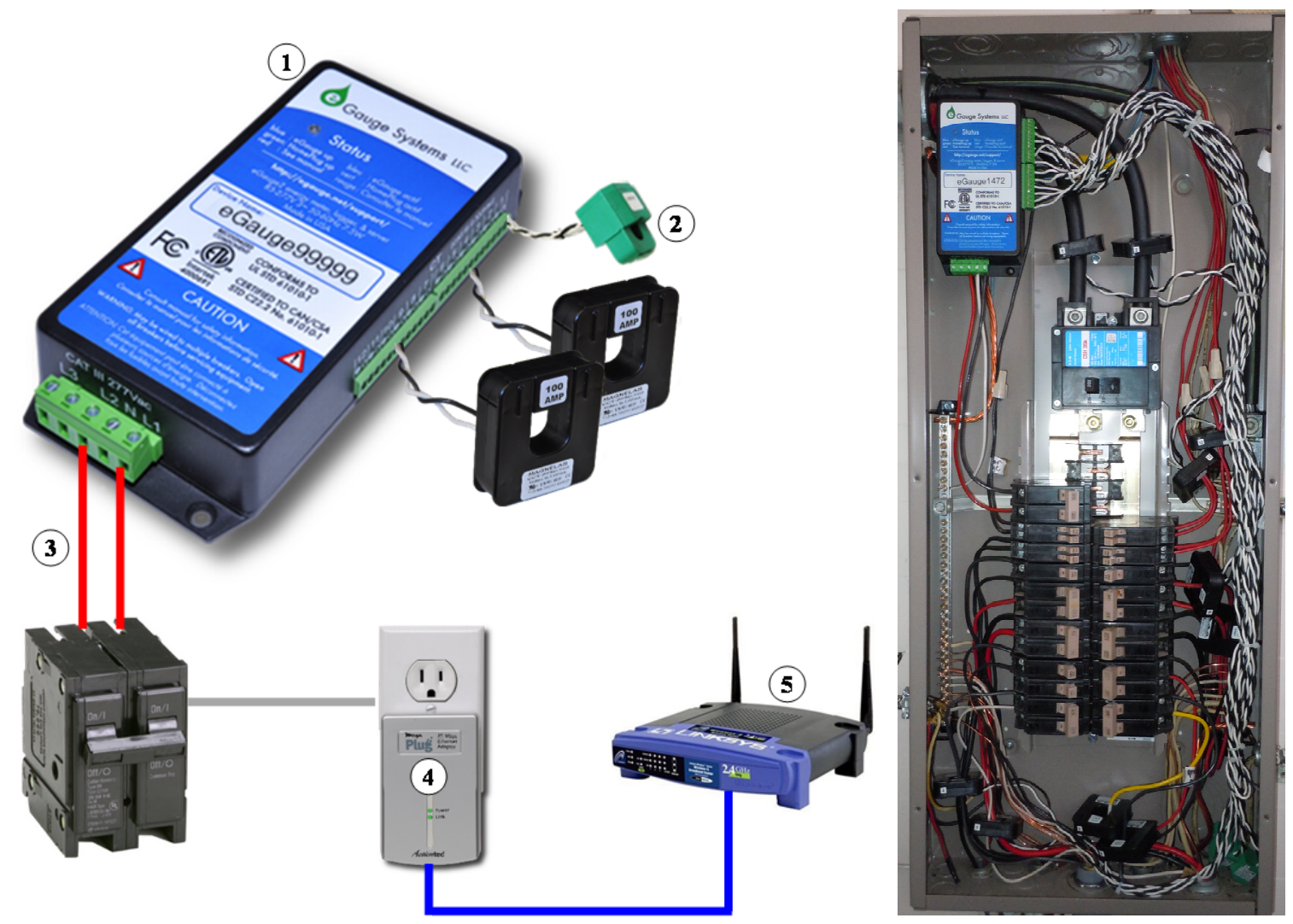

Figure 2.1. Schematic and photograph of an eGauge energy metering system, consisting of a 1) main power meter unit, 2) current transformers, 3) voltage taps connected to a dual-pole breaker, 4) HomePlug communication adapter, and 5) an internet router. Note that the HomePlug and Internet router are not shown in breaker panel photograph.

The CT size was selected to match the capacity of the circuit being monitored. Typically, the CT was sized to match the breaker; however, experience frequently dictated that a smaller CT could be used, which is desired to minimize measurement error.

The HomePlug adapter should be placed as close to the eGauge main unit (i.e., the breaker panel) as possible to ensure consistent communication. In addition, the main unit should be powered via its own separate breaker, to provide for the potential need to re-boot the unit. Throughout this project, of the seven eGauge systems deployed, only twice did an eGauge need to be re-booted-once after a power outage and once after a change in the Internet service provider.

For each home, data from the eGauge devices were downloaded via the Internet at 1-minute and 1-hour intervals. The eGauge interface allows the user to select power or energy, interval and duration of data to save and creates a comma-separated value file. The Internet interface also provides a convenient dashboard for viewing energy use and other trended information (see Figure 2.2). Many homeowners found the dashboard very revealing and informative.

In addition to the eGauge device, an additional energy meter was required at the PNW-5 home to monitor the air conditioning $(\mathrm{A} / \mathrm{C})$ unit because the circuit was located in a second breaker panel. For this one circuit, a WattNode ${ }^{\circledR}$ energy meter (Continental Control Systems, Boulder, Colorado) was paired with a Madgetech Pulse 101A data logger (Madgetech Inc., Warner, New Hampshire). The pulse logger 
was set to record data at 5-minute intervals, and because of the integrating nature of pulse loggers, this device did not require frequent downloading.

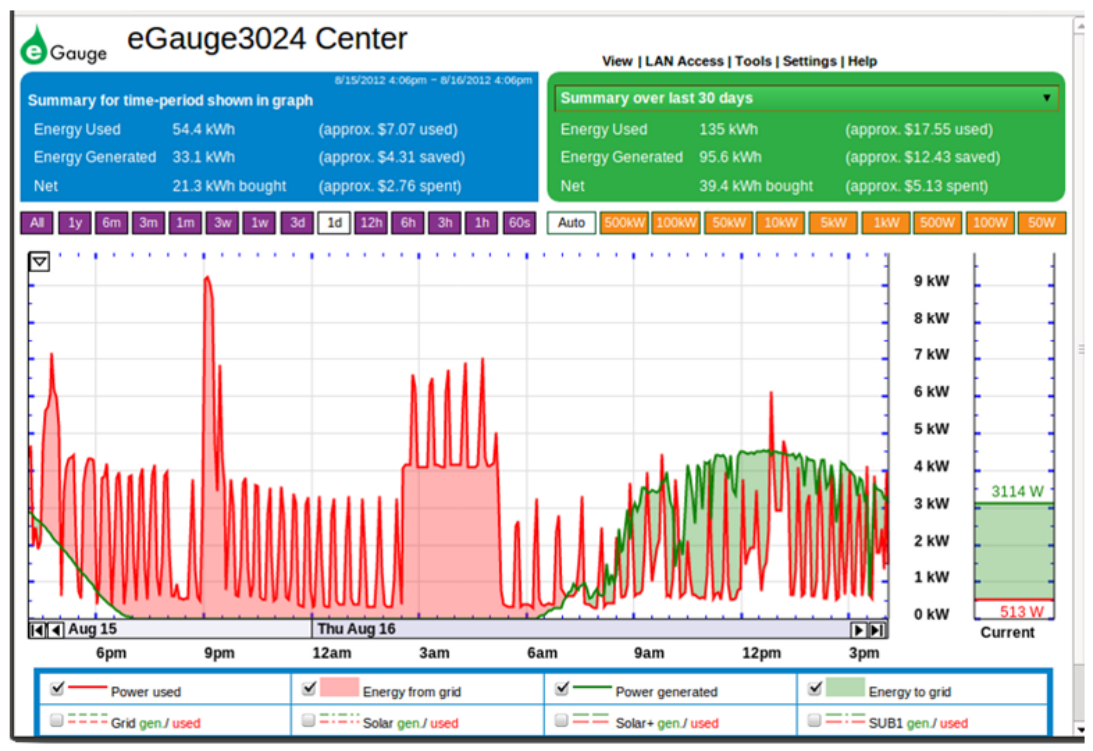

Figure 2.2. Screenshot of the eGauge energy meter online dashboard.

\subsubsection{Undersized Current Transformers}

Often the CTs installed were undersized for the circuit they were monitoring (see Appendix A for monitoring details) to reduce measurement error. Using 1-minute data, the current for each phase of the circuit was calculated and compared to the size of the CT, as shown in Figure 2.3, where the circuit capacity is 90 amps but the CT size is 50 amps. There were no incidents where the measured current was within $110 \%$ of the CT rating and was often many factors less, as shown below.

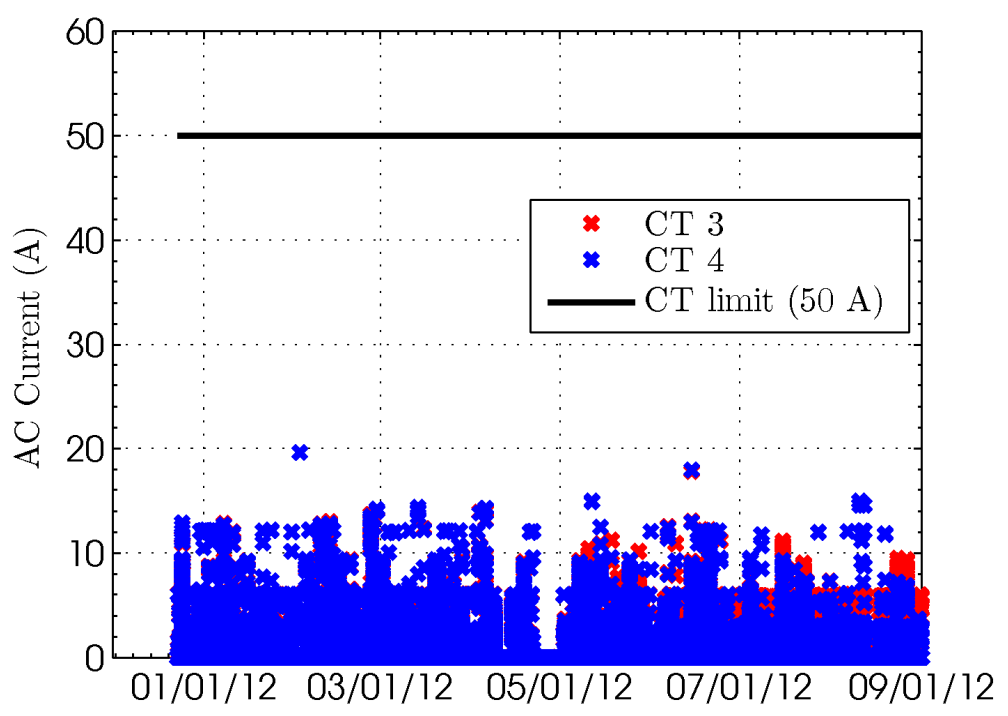

Figure 2.3. Undersized CT example located at PNW-1 home for circuits 3 and 4, where the circuit capacity is 90 amps but the CT size is 50 amps. 


\subsubsection{Fuel Metering}

The three homes located in Portland, Oregon (PNW-5, 6, and 7) use fossil fuels for heating and/or domestic hot water (DHW) use so these loads need to be metered separately. Many of the other homes used fossil fuels for heating and various appliances (e.g., kitchen range or DHW heater) prior to retrofitting to an electric heat pump or ductless split system; however, any remaining fuel appliances were not metered (i.e., range). In addition to the Portland homes, a choice was made to leave the existing diesel boiler in place in PNW-1 after retrofitting to a four-head ductless split system; this was done primarily to provide backup heat during extreme winter periods and secondly, because of asbestos abatement costs.

Therefore, these four homes contained fuel metering approaches specific to each home to capture heating and/or DHW energy use. For two of the homes (PNW-5 and PNW-6), an Elster AC-250 (Elster American Meter, Nebraska City, Nebraska) whole-house diaphragm gas meter was installed because the furnaces and DHW heaters in these homes were fueled by natural gas.

The Elster gas meter was equipped with a pulse output device, which sends a pulse (i.e., frequency) signal proportional to the volume of gas flowing through the gas meter. These pulse signals were recorded using a Madgetech Pulse 101A pulse data logger. Data collected by this instrument did require downloading by a local subcontractor.

The furnaces in each home also were monitored using a Veris H600 (or similar) current switch (Veris Industries, Portland, Oregon), connected to a Madgetech State 101A state logger. A Hobo U9-001 state logger was used at one home. The current switch was positioned over either the blower fan or gas proportional valve wire, depending on the specific furnace. This metering approach provides a statechange sequence for the furnace, from which the run-time can be calculated. When the blower fan was monitored, the pre- and post-purge blower sequence timing was determined during the monitoring installation and subsequently subtracted from the calculated run-time for each cycle to ensure only the run-time associated with fuel use was calculated.

Two of the Portland homes, PNW-5 and PNW-6, contain tankless DHW heaters, a non-condensing unit and a condensing unit, respectively. Each of the tankless DHW units was metered extensively (see Appendix A, Sections A.5 and A.6 for details), including water flow rate, entering and exiting water temperature, and gas flow. ${ }^{1}$ This metering approach allows for independent quantification of load and energy consumption, enabling the calculation of real-time efficiencies.

The furnace energy consumption for PNW-6 was then calculated using the known input capacity and the metered run-time. However, because of many factors, including gas manifold pressure, equipment age, etc., the actual gas usage will vary from the input rating. Therefore, the data from the whole-house gas meter were used to calibrate the run-time data for time periods when the DHW heater was off (as determined from the hot water flow). Calibration of the furnace run-time data is shown in Figure 2.4, where the raw energy use data calculated from the run-time and known input capacity was over-estimated by $29 \%$. Once corrected using gas meter data, the corrected furnace energy use agreed well with gas meter readings, as indicated in Figure 2.4, where a $45^{\circ}$ line indicates perfect agreement.

\footnotetext{
${ }^{1}$ Gas and water flow rate meters measure signals from internal sensors in the DHW heater.
} 


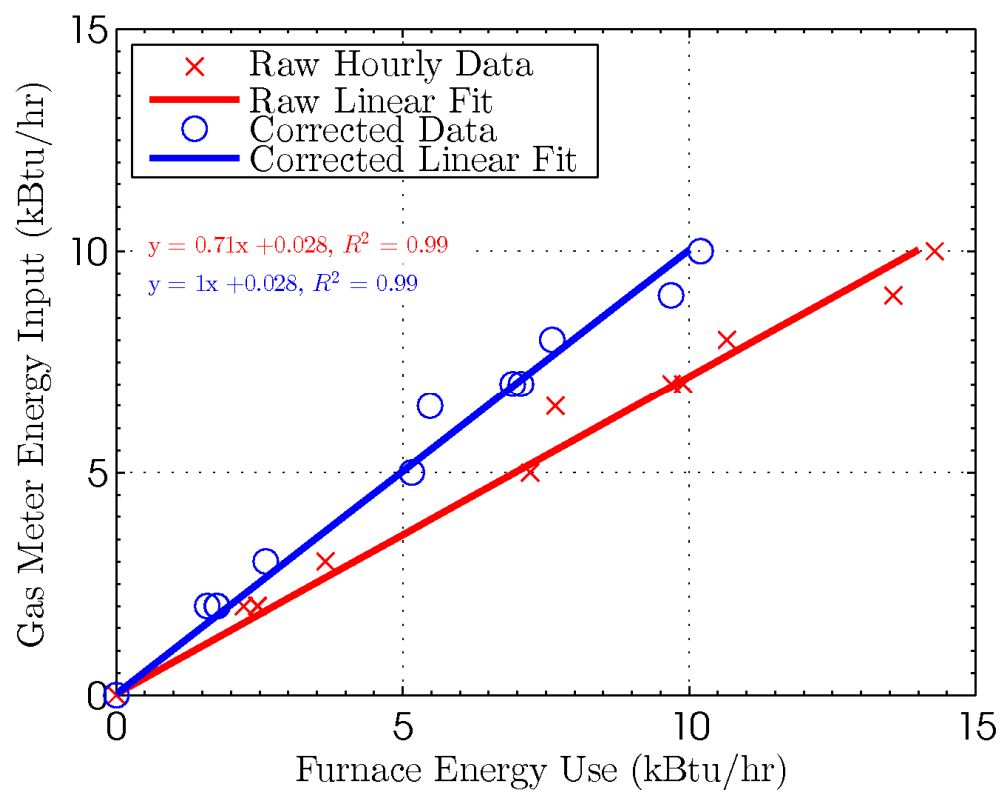

Figure 2.4. PNW-6 furnace energy use correction using the whole-house gas meter when the DHW heater is not operating.

\subsubsection{Environmental and Indoor Air Quality Measurements}

In addition to electricity and fuel metering, each home was equipped with multiple temperature and relative humidity $(\mathrm{RH})$ meters to record space comfort data and to provide supporting data regarding thermostat set points, moisture concerns, etc. Most homes used Madgetech RHTemp101A data loggers; some Hobo U10-033 temperature/RH loggers were used as well. The Madgetech data loggers typically can store 500,000 samples, compared to 64,000 samples with a Hobo data logger. This equates to a difference of 347 and 44 days, respectively, for data recorded at 1-minute intervals.

To provide more robust assessment of indoor air contaminants that can affect occupant health and safety, a number of key indoor air pollutants were measured for a period of 1 to 7 days following the testin (pre-retrofit) and test-out (post-retrofit) audits in several homes in the Pacific Northwest. In each home, individual samples of particulate matter $(\mathrm{PM})$, nitrogen oxides $\left(\mathrm{NO}_{\mathrm{x}}\right)$, carbon monoxide $(\mathrm{CO})$, carbon dioxide $\left(\mathrm{CO}_{2}\right)$, total volatile organic compounds (TVOCs), formaldehyde $\left(\mathrm{CH}_{2} \mathrm{O}\right)$, and radon were collected. The particulates, TVOCs, $\mathrm{CO}_{2}$, temperature, and $\mathrm{RH}$ were sampled using the EVM 7 environmental monitor to collect real-time samples for anywhere from 1 to 7 days. The PM sampling train includes an impactor, an optical engine, a gravimetric filter cassette, a pump, and an orificecontrolled flow sensor. The TVOC sensor is a photo-ionization detector with parts-per-million (ppm) sensitivity, and the $\mathrm{CO}_{2}$ sensor is a non-dispersive infrared sensor. Both sensors operate with a small fan to pull air across the sensors and exhaust it. To test for $\mathrm{NO}_{\mathrm{x}}$ and $\mathrm{CH}_{2} \mathrm{O}$, samples were collected with a chemical-specific sample collection tube and a hand-operated pump. For CO sampling, a real-time handheld $\mathrm{CO}$ detector was used to determine ambient $\mathrm{CO}$ concentrations. The research team determined radon concentrations in existing homes using the RadStar R300 radon meter. The standard operating protocol for indoor air-quality testing, including a description of the equipment, is described in more detail by Chandra et al. (2012) in a previously published report. 


\subsection{Modeling Description}

During the initial home energy audits, appliance specifications, occupant behavior information, building and duct leakage test data, and other details were collected using a consistent audit template (Chandra et al. 2012). These data then were entered into a residential energy modeling program to model the existing building (i.e., pre-retrofit) energy consumption. Each home was modeled in EnergyGauge ${ }^{\circ}$, BeOpt, and/or REM/Rate ${ }^{\mathrm{TM}}$ (FSEC 2011; NREL 2010; AEC 2010). However this report focuses on results computed using EnergyGauge ${ }^{\circledR}$.

Results from each pre-retrofit model then were trued using monthly utility bills from the homeowner. This is done using a utility bill analysis spreadsheet that compares the homeowner's actual monthly utility bills to the generated model output. The base load, heating load, and cooling load are then simultaneously optimized to create a model that accurately reflects the homeowner's usage patterns (see Chandra et al. 2012 for more details).

Figure 2.5 shows a comparison of the usage data from the model and the actual usage utility bill (in terms of gallons of diesel fuel used) for the PNW-1 home. Similarly, Figure 2.6 provides a comparison of electricity use. For some homes, difficulty was encountered in truing the pre-modeling results to the utility bill data because realistic adjustments could not be made within EnergyGauge ${ }^{\circledR}$.

Specifically, the PNW-3 home had electric utility bills for January and February that were relatively low but November and December bills showed usage that was much higher than predicted in the modeling estimates. This differential probably is the result of differences between actual encountered weather and the assumed weather input into the model. The PNW-4 home had uncharacteristically high electricity use from October through December that is likely not due to weather because heating loads were served with a pre-retrofit oil boiler, which shows excellent agreement. Further, the PNW-5 had poor agreement with natural gas use because the home was not occupied pre-retrofit and only estimates provided by the homeowner were available to benchmark pre-retrofit natural gas use. Finally, the modeled pre-retrofit electricity use for PNW-6 could not be reasonably adjusted to meet both the cooling load and base load simultaneously, so post-retrofit modeling estimates may over-predict cooling energy use. Moreover, the heating energy use could not be matched for both January through March and November through December heating periods, resulting in an over-prediction in heating during January through March. These influences are discussed further in Chapter 4.0. The remaining pre-retrofit model and utility bill true-up figures for each home are provided in Appendix B.

The trued pre-retrofit model was then used to evaluate various retrofit measures and compare energy and cost savings. These results were then presented to the homeowners in the audit reports as the recommended retrofit package. However, for many of the homes, a recommended retrofit package was not determined by PNNL for a number of reasons, including home participation timing, home performance contractor participation, etc.

Subsequently, after the retrofit packages were completed, a final post-retrofit model was generated using the actual retrofits implemented and test-out data. The test-out involves the same tests, conducted in the same manner, as the test-in audit; home energy assessment; combustion safety testing (as applicable); and IAQ testing. The goal of the test-out audit is to quantify post-retrofit changes in home energy performance and IAQ. 


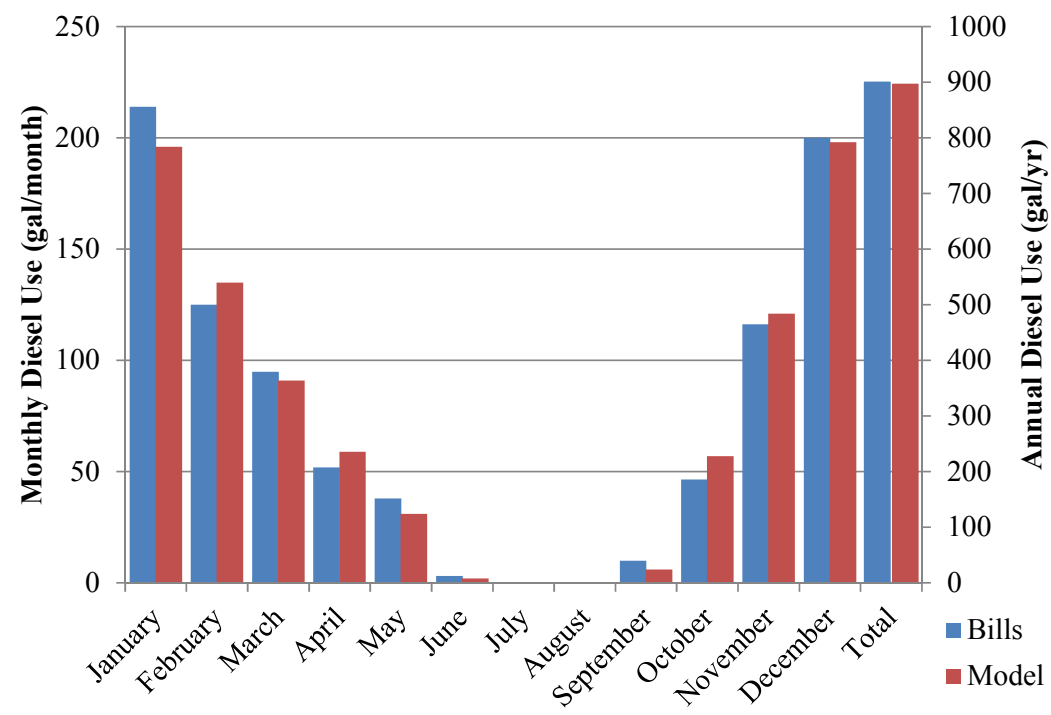

Figure 2.5. PNW-1 monthly and annual pre-retrofit utility bill and EnergyGauge ${ }^{\circledR}$ model diesel use trueup comparison.

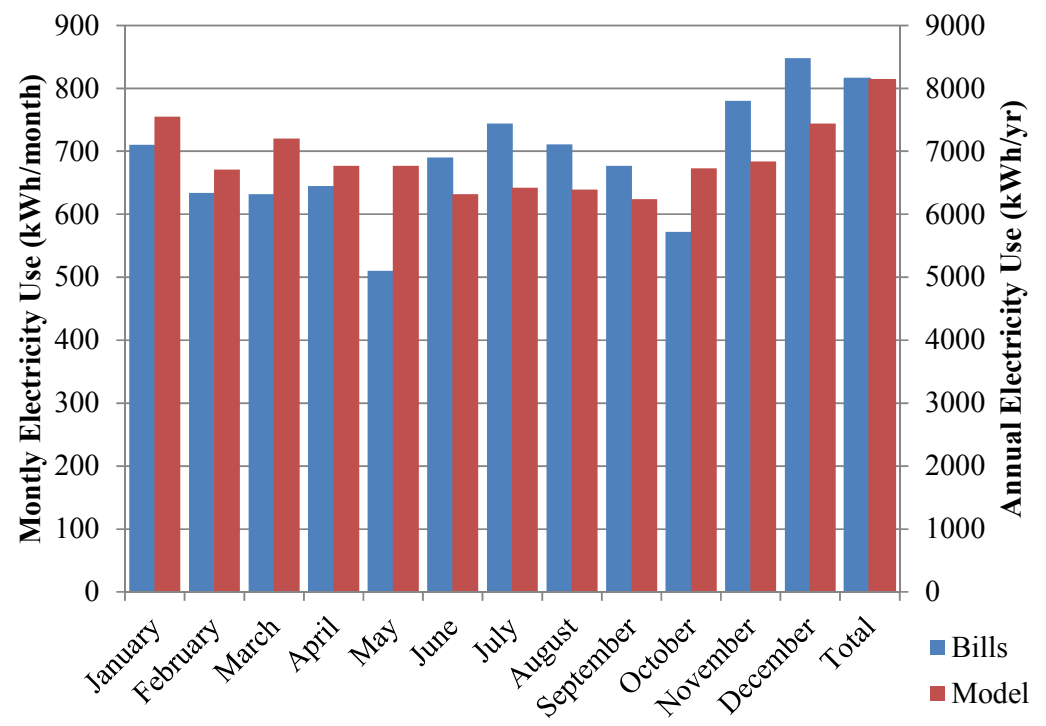

Figure 2.6. PNW-1 monthly and annual pre-retrofit utility bill and EnergyGauge ${ }^{\circledR}$ model electricity use true-up comparison.

However, all of the results generated for this analysis have relied on computer models and therefore, each of the seven homes presented in this report also was extensively monitored (as discussed in Section 2.2) to allow for actual and estimated energy savings comparisons. The pre-retrofit, recommended-retrofit and post-retrofit models, coupled with post-monitored data, allow comparison of the following:

- recommendations and actual retrofits implemented

- estimated energy savings from pre-retrofit to post-retrofit condition 
- actual energy use from post-retrofit condition

- actual and estimated energy savings.

\subsubsection{Typical and Actual Meteorological Year Approach}

One potential drawback regarding the pre- and post-retrofit models is the use of typical meteorological year (TMY) weather data. The models use TMY $3^{1}$ weather data to estimate heating, cooling, and other weather-dependent loads, but were trued against usage data from utility bills for a specific year (Wilcox and Marion 2008). The year in which the utility bills were taken likely do not exhibit typical weather as specified in TMY3 files.

Given the potential impact of weather in heating and cooling energy use, PNNL researchers sought to correct for weather influence using Actual Meteorological Year (AMY) data for each of the seven homes. Weather data were purchased from Weather Analytics (Weather Analytics Inc., Winchester, Massachusetts) for the date ranges covering the monitoring period (see Table 2.3) from selected weather stations, which are identified in Table 2.4.

Table 2.4. AMY weather station locations for monitored homes.

\begin{tabular}{ccc}
\hline Home & Location & AMY Weather Station Location \\
\hline PNW-1 & Dayton, WA & KALW, Walla Walla, WA \\
PNW-2 & Richland, WA & KPSC, Pasco, WA \\
PNW-3 & Richland, WA & KPSC, Pasco, WA \\
PNW-4 & Seattle, WA & KBFI, Seattle, WA \\
PNW-5 & Portland, OR & KPDX, Portland, OR \\
PNW-6 & Portland, OR & KPDX, Portland, OR \\
\hline
\end{tabular}

Two forms of weather data were provided by Weather Analytics: 1) hourly historical commaseparated value (CSV) data files and 2) DOE-2 packed binary (BIN) weather files. The hourly historical CSV files contain various weather data in a continuous time-series format. However, the AMY BIN weather files contain only 1 year (i.e., 8,760 hr) of data. The format of the AMY BIN files is identical format to that of the TMY3 binary files used by EnergyGauge ${ }^{\circledR}$.

Using Fortran scripts, ${ }^{2}$ PNNL researchers converted the TMY3 binary files used by EnergyGauge ${ }^{\circledR}$ for each of the weather locations specified in Table 2.4 into ASCII files, which can be viewed and edited using a spreadsheet. The AMY BIN files also were converted into ASCII files. Subsequently, AMY data from the converted BIN files were pasted into the converted TMY3 binary files for the date ranges provided in Table 2.3. Because the monitoring period was less than a year, all other data remained as TMY3, to prevent skewing of the comparisons for periods during which monitoring data were not available. It should be noted that the cloud-cover data remained as TMY3 data, because the data provided in the AMY BIN file were consistently zero. Similar Fortran scripts were used to convert the AMY/TMY

\footnotetext{
${ }^{1}$ TMY3 refers to a third update of TMY data for 1020 locations based on data from 1991 to 2005.

${ }^{2}$ Fortran scripts were provided by ZT Taylor of PNNL, and are not publicly available.
} 
combination ASCII files back to binary format for use as input files for EnergyGauge ${ }^{\circledR}$. Subsequently, all the post-retrofit models were re-run using AMY input files.

Steps were taken to ensure that the conversion process using the Fortran scripts did not inappropriately influence the simulations. A TMY3 file was converted to an ASCII file, viewed (but not edited) and then converted back to a BIN file. The TMY3 and BIN files were used as inputs for EnergyGauge ${ }^{\circledR}$ and the results were compared. Perfect agreement was observed. In addition, the AMY BIN file contents were compared to the hourly historical CSV file content and perfect agreement was found.

\subsection{Data Collection and Analysis}

For each of the models (pre-, recommended, post-retrofit, and post-retrofit AMY) generated, hourly simulation results were saved for heating, cooling, and end-use energy use, dry bulb temperature, and heating and cooling loads. Similarly, all monitored data were saved in at most 1-hour intervals. Some of the metered data were collected at shorter intervals and required summing to hourly data.

All of the raw data (i.e., hourly modeling data and metered data) were then processed using Matlab ${ }^{\circledR}$ R2012a (The MathWorks, Inc., Natick, Massachusetts) to generate daily and monthly data for comparison. Monthly results also were exported to a spreadsheet for further analysis. 


\subsection{Results and Discussion}

The data collected and analyzed from end-use energy meters were compared to the modeled energy savings based on the retrofit measures pursued in each home to determine if homeowners achieved the level of savings predicted by the EnergyGauge ${ }^{\circledR}$ model. These data were also compared to the savings based on the retrofit package recommended to each homeowner. The discrepancies observed between modeled energy consumption and actual metered energy consumption were further investigated to determine the cause or source of any variability, if possible. Results, discussion, and lessons learned from modeling and monitoring of residential home energy use are presented in the ensuing sections of this chapter. Also, preliminary data examining the relationship between retrofit measures and the concentration of indoor air contaminants are presented in Section 3.5.

\subsection{Actual and Estimated Energy Use Overview}

The recommended retrofit and post-retrofit modeled energy use was compared relative to the preretrofit modeled energy use to determine the recommended and estimated energy savings, respectively. The recommended energy savings percentage can be found from

$$
\text { Recommended energy savings } \%=\left(1-\frac{\text { modeled recommended energy use }}{\text { modeled pre-retrofit energy use }}\right) \times 100 \text {, }
$$

and the estimated energy savings percentage can be calculated using

$$
\text { Estimated energy savings } \%=\left(1-\frac{\text { modeled post-retrofit energy use }}{\text { modeled pre-retrofit energy use }}\right) \times 100 \text {. }
$$

Similarly, the post-retrofit monitored energy use was compared to the pre-retrofit modeled energy use to determine the actual energy savings, calculated using

$$
\text { Actual energy savings } \%=\left(1-\frac{\text { monitored post-retrofit energy use }}{\text { modeled pre-retrofit energy use }}\right) \times 100 \text {. }
$$

The modeled pre-retrofit energy use was used in all three comparisons to provide a consistent baseline. The recommended, estimated, and actual energy savings are presented in Figure 3.1 for each monitored home. It should be noted that negative energy savings indicates more energy use when compared to the pre-retrofit condition. This often occurred in homes that did not have A/C installed preretrofit but were retrofitted to a heat pump with cooling capability. In addition, annual energy savings are provided, where actual savings were projected for the PNW-1 through PNW-4 homes. For the remaining homes, the annual savings were assumed to be an average of the monitored savings. The projected savings were determined by comparing estimated savings for months in which monitored data were not available to similar months in which monitored data were available (i.e., predict December energy use from January monitored data). This approach provides estimates that differ from actual monitored data. 


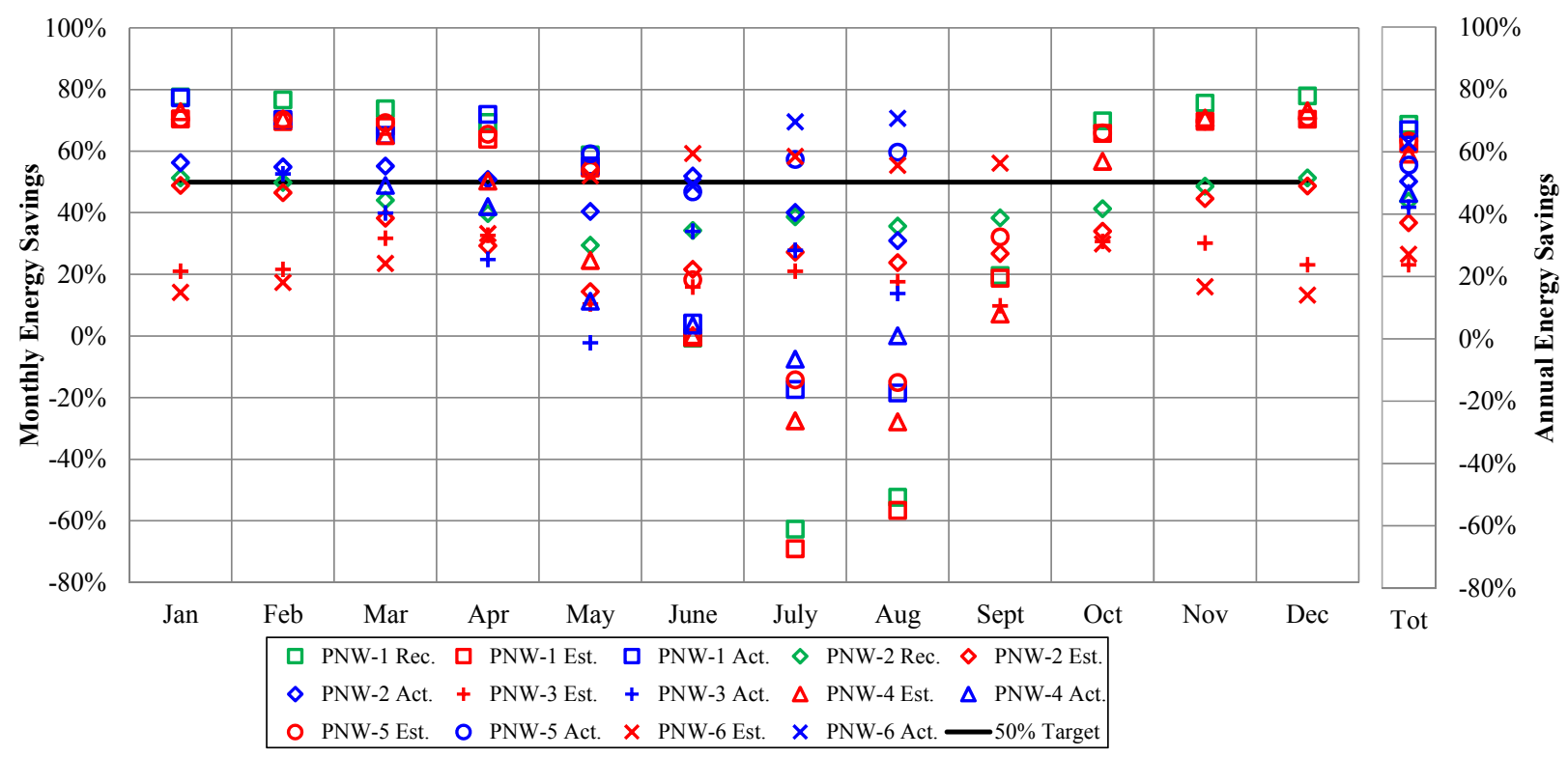

Figure 3.1. Annual and monthly recommended, estimated and actual energy savings percentages for six of the monitored homes. Annual energy savings are based on projections or average monitored savings.

As shown in Figure 3.1, the recommendations made by PNNL researchers are fairly consistent with the actual implemented retrofits. The PNW-1 home was recommended to save $69 \%$ annually, while the estimated savings is expected to be $63 \%$, a difference of only $6 \%$. Similarly, the PNW-2 home was recommended to save $44 \%$ and is expected to save $37 \%$ annually. The monthly recommended and estimated savings comparisons for these two homes differ by at most $15 \%$, a difference that occurred in May for the PNW-2 home.

Annually, the actual savings range from $42 \%$ to $67 \%$ while the estimated savings range from $24 \%$ to $63 \%$. However, the comparison between estimated and actual savings by month is quite different. An average of the estimated and actual energy savings is shown in Figure 3.2 to illustrate the general distribution of estimated and actual savings. Homes were only included in this average if monitored data were available for each month (e.g., only PNW-1 and PNW-2 are included for January). In general, the actual savings were greater in heating months and less during cooling months. 


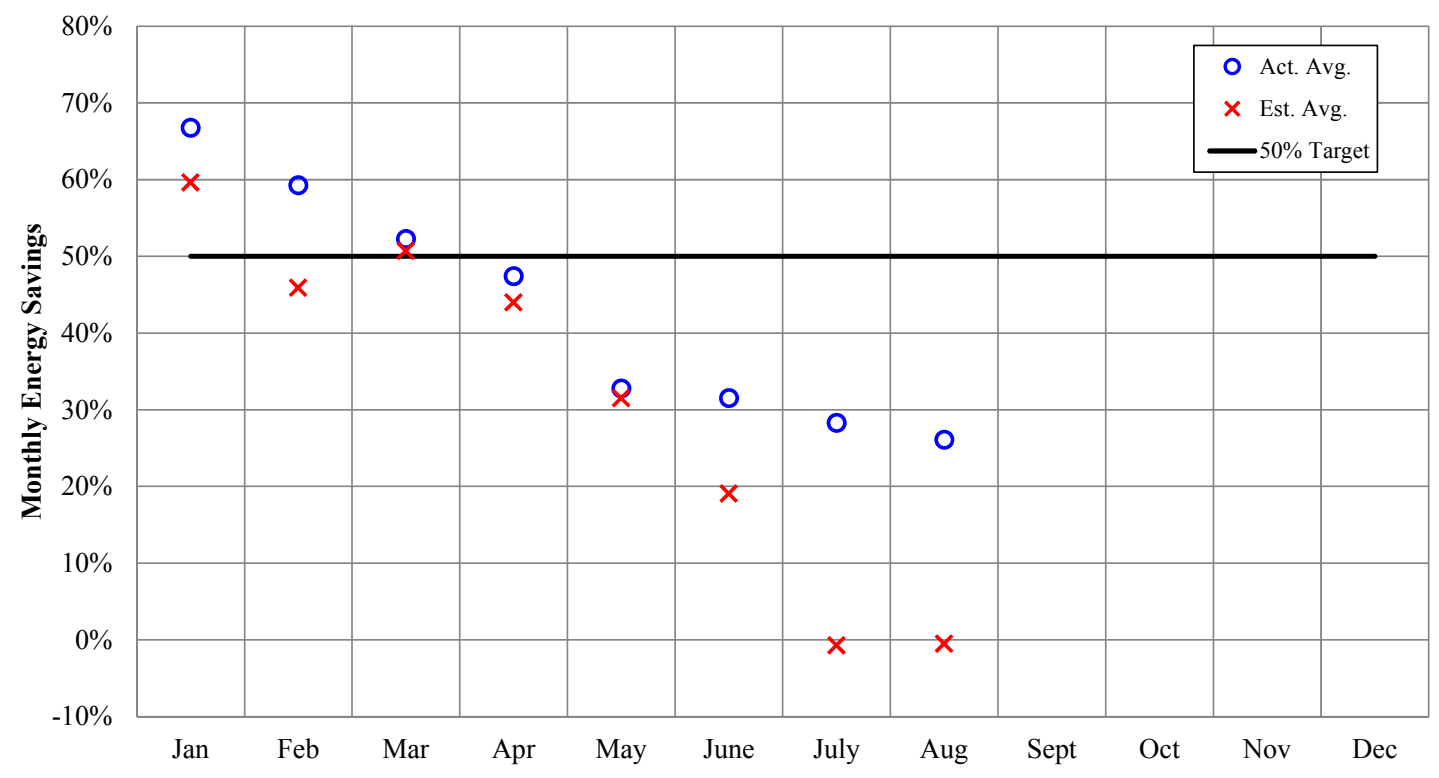

Figure 3.2. Monthly average estimated and actual savings percentages observed for six of the monitored homes.

To better illustrate the comparison between modeled estimated and monitored actual energy savings, the difference of the savings percentage for each home is presented in Figure 3.3, where positive values indicate that homes saved more energy than predicted and vice versa. On average, most of the homes saved more energy that predicted, which is consistent with findings from previous studies (Polly et al. 2011; Parker et al. 2012). Increased savings may seem beneficial, except that had better savings estimates been provided, homeowners might have chosen to pursue additional retrofits to achieve better paybacks. Two of the homes, PNW-4 and PNW-5, are predicted to save less energy than estimated, but this assumes that September through December energy savings are consistent with current monitored data. This is unlikely considering that savings are likely to depend on heating, cooling, and base load time periods.

In addition to monthly whole-house energy use comparisons, Figure 3.4 provides the difference between actual and estimated post-retrofit energy use by disaggregated end-use, calculated using

$$
\text { post-retrofit energy use comparison }=\left(1-\frac{\text { monitored post-retrofit energy use }}{\text { modeled post-retrofit energy use }}\right) \times 100 \text {. }
$$

This calculation compares the total sum of estimated and actual energy use for months during which monitoring data were available, which for some end-uses is only a few months. The most significant variance between estimated and actual energy use is for heating, ventilation, and air conditioning (HVAC), which ranges between $131 \%$ more and $72 \%$ less actual energy used compared to modeled estimates for the PNW-4 and PNW-6 homes, respectively.

The second end-use indicating the most variance is miscellaneous end-uses. This report defines miscellaneous end-uses as all electric end-uses not disaggregated by the metering equipment, which is different for each home. Section 3.3 provides a breakdown of end-uses for each home. 


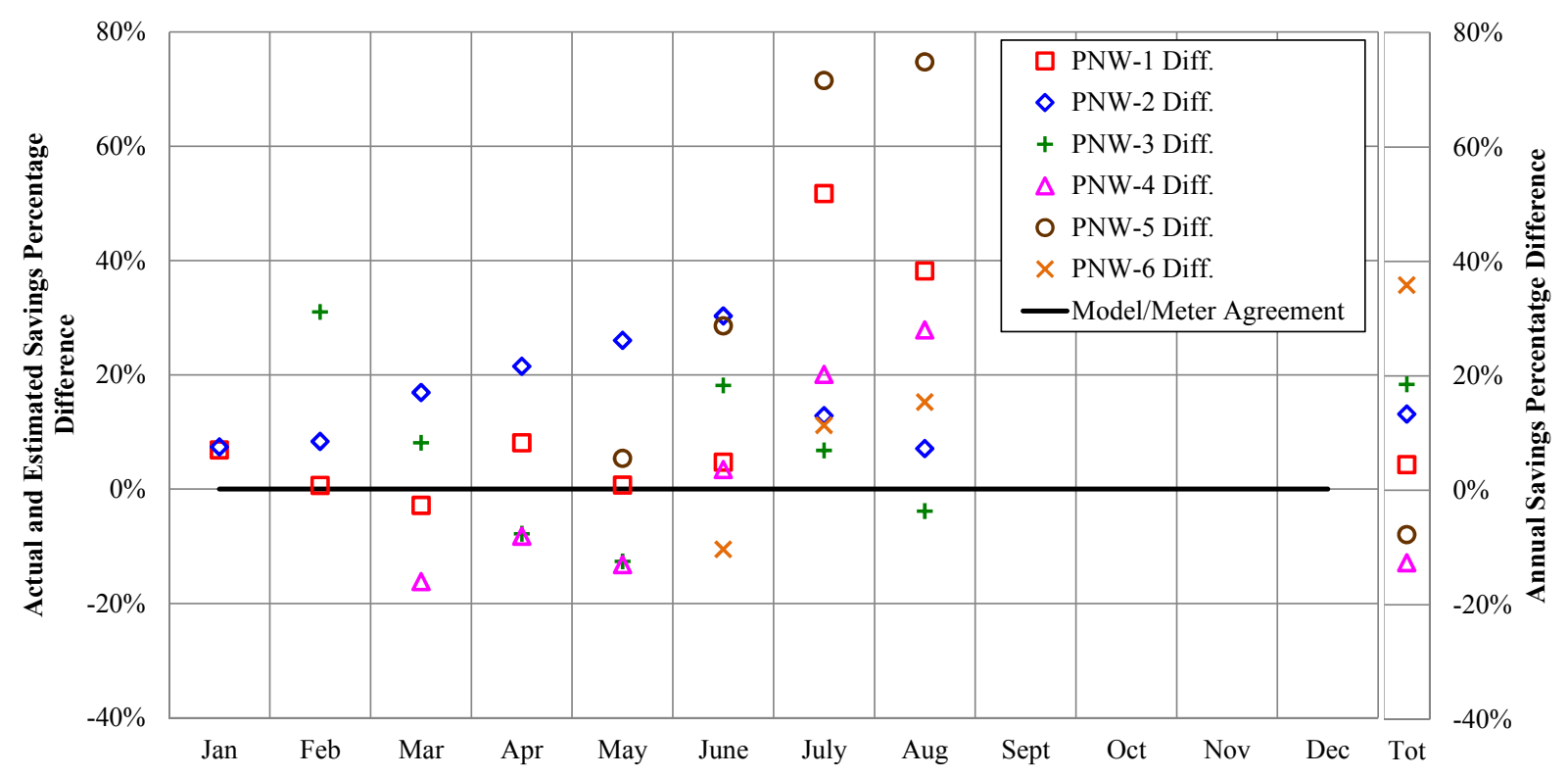

Figure 3.3. Monthly actual and estimated energy savings percentage comparison for six of the monitored homes. Annual energy savings comparisons are based on projections or average monitored savings. Note that positive values indicate that actual energy use is less than estimated.

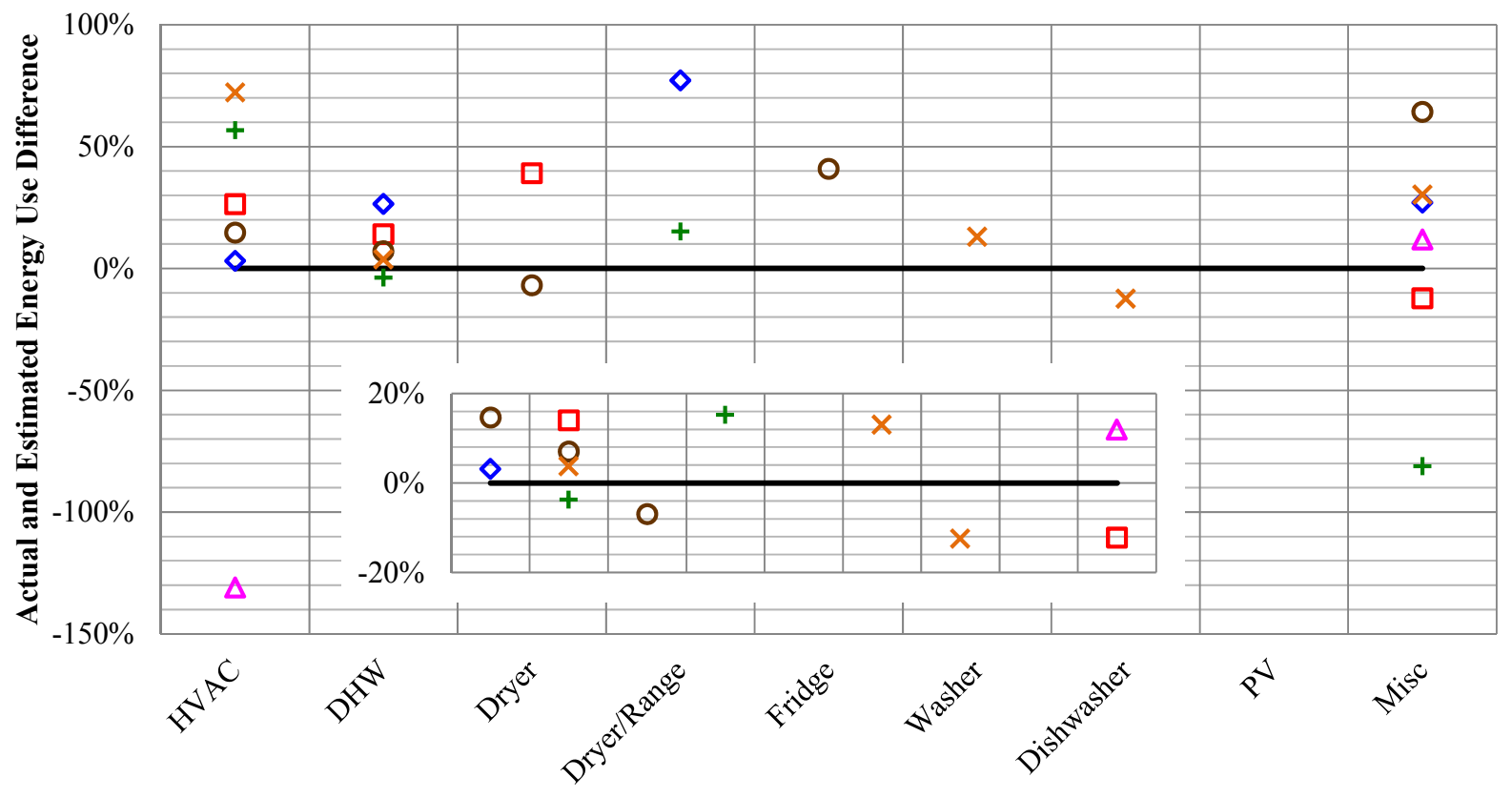

$\square$ PNW-1 $\diamond$ PNW-2 + PNW-3 $\triangle$ PNW-4 0 PNW-5 $\times$ PNW-6 —-Model/Meter Agreement

Figure 3.4. Actual and estimated energy use comparison for disaggregated end-uses summed over the monitoring period for six of the monitored homes, including a higher resolution inlayed figure.

In addition to miscellaneous end-uses, many of the other disaggregated end-uses (e.g., refrigerator, dryer, washer, etc.) exhibited large variations in estimated and actual energy savings. An inlayed figure is 
provided to enhance the resolution for the end-uses that are near zero, which indicates perfect agreement between modeled and monitored data. The best end-use prediction, excluding HVAC, was for DHW heater energy use at the PNW-3 and PNW-6 homes, at 4\% greater and 4\% less than estimated, respectively. The majority of end-uses were greater than $\pm 10 \%$ and, on average, homes used less energy than was estimated.

As indicated above, the predicted energy use exhibited large variations both for home totals, as well as disaggregated end-uses. The following sections attempt to explain these differences, using detailed monitoring data.

\subsection{Actual and Estimated Differences}

The following sections address the differences between actual and estimated energy use for the major end-uses - heating, cooling, DHW, and miscellaneous. Clothes dryer energy use is compared because of its relative size compared to other single end-uses (see comparison at the end of this chapter in Figure 3.30). In addition, the pre-retrofit data from the PNW-7 home are compared, illustrating the importance of collecting pre- and post-retrofit monitored data for further work.

\subsubsection{Heating Energy Use}

The actual heating energy use for each home has been disaggregated, where available, and compared to post-retrofit modeled ${ }^{1}$ and post-retrofit AMY modeled, as shown in Figure 3.5.

For many of the homes, the estimated heating energy use is quite different than the monitored data, with the exception of the PNW-2 home, where the heating energy use matches quite nicely. In addition, for a few of the homes, heating energy was used during months during which modeled energy use was zero because the models assumed no heating typically occurs during these months (e.g., May for the PNW-3 home). This clearly is a poor modeling assumption and requires better information from the homeowner. However, for some months, the heating use was quite a bit higher than the modeling estimates (e.g., April and May for the PNW-4 home). For these months, other explanations are necessary and are typically occupant driven.

Another important observation is that, in general, the AMY modeled energy use matches more closely with actual energy use, which is discussed further in Section 3.2.3.1. This indicates that the weather experienced during the month of monitoring was different than during a typical month, so energy use, as expected, would be different. However, in many cases, the AMY modeled energy use increase or decrease was not enough to match the monitored data reasonably. During the month of February, for example, the PNW-3 home was predicted to use less energy when AMY weather data were used; however, the monitored data are still significantly below that of the AMY modeled data. This can be attributed to three separate factors: 1) over-estimation of heating energy use, 2) hidden electric resistance heating, or 3) occupant behavior. The influences of these factors are discussed in subsequent sections.

\footnotetext{
${ }^{1}$ Unless specified otherwise, we assumed in this report that "post-retrofit modeled" refers to models developed using TMY weather data.
} 

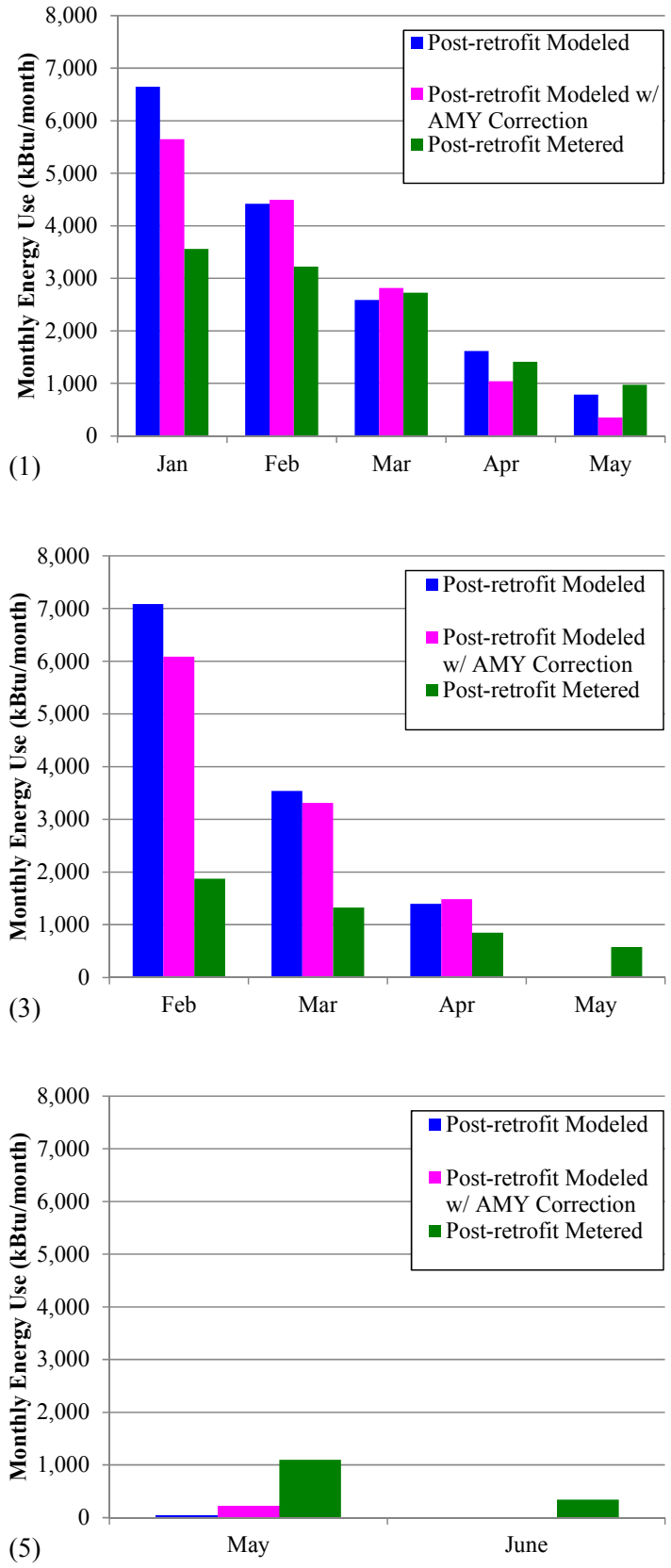
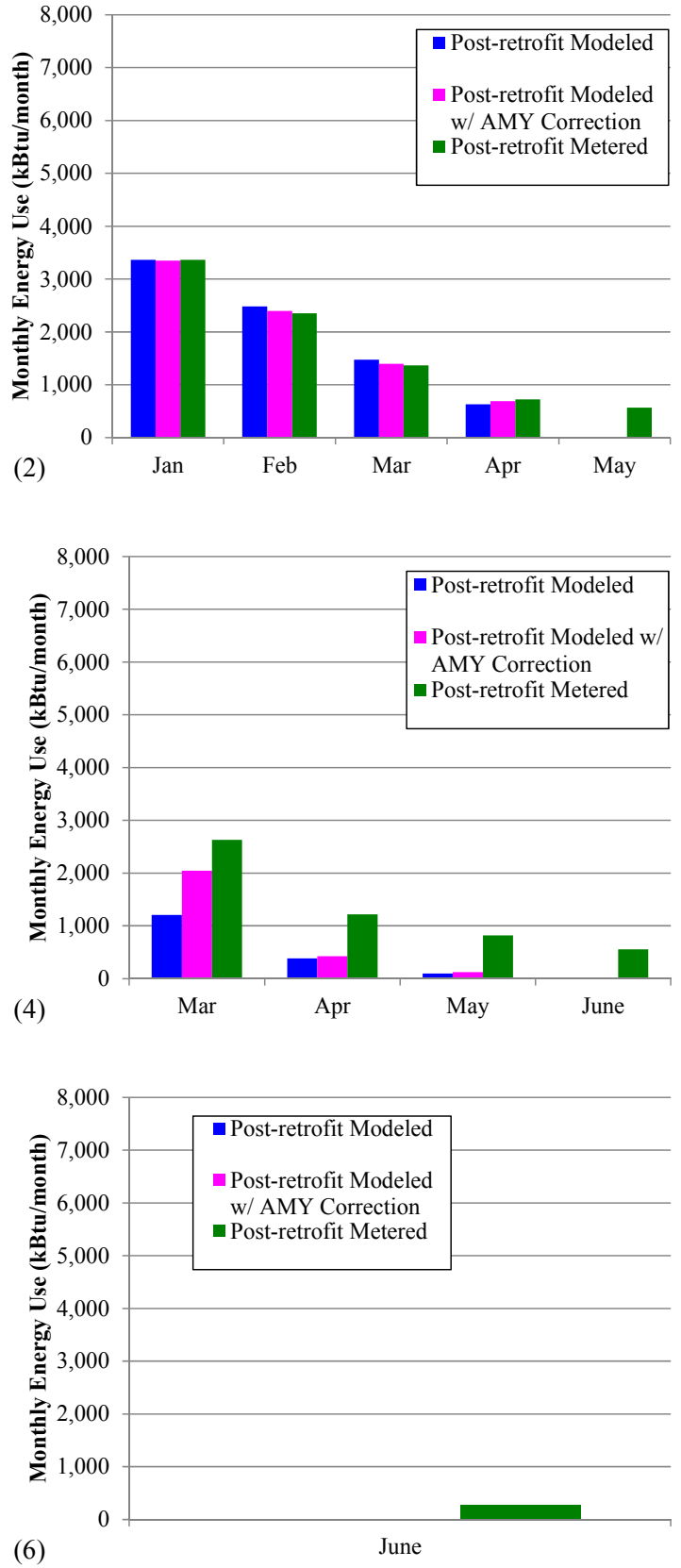

Figure 3.5. Comparison of post-retrofit modeled, AMY corrected, and metered monthly heating energy use for 1) PNW-1, 2) PNW-2, 3) PNW-3, 4) PNW-4, 5) PNW-5, and 6) PNW-6 homes.

To further understand the differences between estimated and actual heating energy use, Figure 3.6 and Figure 3.7, present the hourly heating energy use profiles ${ }^{1}$ for the PNW-2 and PNW-3 homes, respectively. These two homes represent the best and worst heating energy-use predictions observed,

\footnotetext{
${ }^{1}$ The error bars in all hourly profiles presented in this report represent the maximum and minimum values observed during the given hour and not the standard deviation. This presentation provides insight into the maximum load observed for the equipment monitored.
} 
respectively. The hourly heating energy use profiles provide insight into the reasons the estimated energy use was predicted well or poorly (see Appendix $\mathrm{C}$ for heating profiles for other homes ${ }^{1}$ ). The monitored heating energy use for the PNW-2 home matches fairly well with the modeled profiles. Differences clearly exist because models assume an average heating distribution, while actual homeowners control their homes quite differently. The PNW-3 home heating profile reveals that the model is predicting the behavior of the homeowner fairly well (i.e., more heating at night, close to no heating during the afternoon); however, the magnitude of the heating used is not consistent. This could be because of a number of factors, including incorrect temperature set-points used in the model, poor characterization of the home, hidden resistance heating, etc.

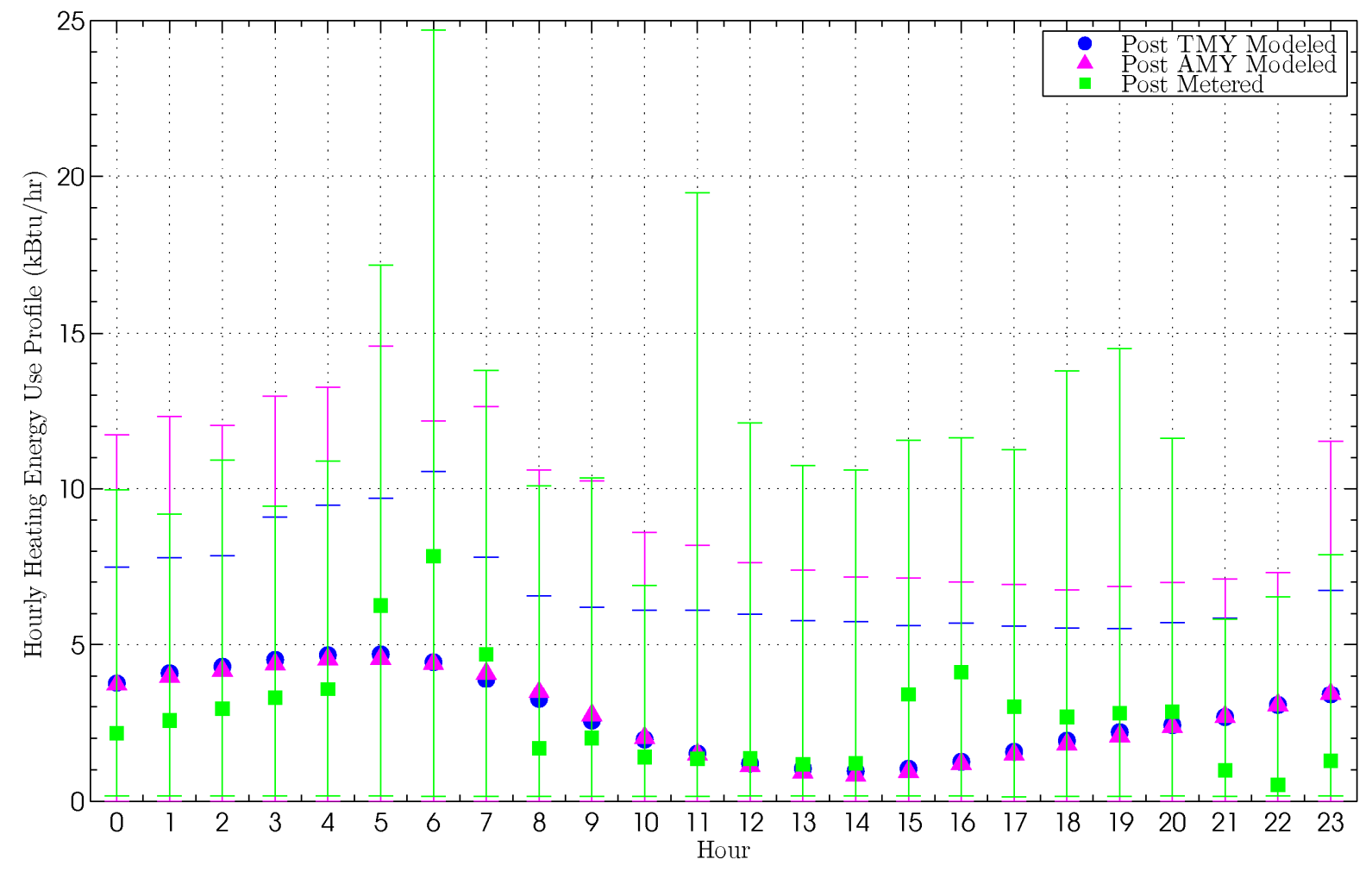

Figure 3.6. Hourly heating energy use profile comparison for the PNW-2 home.

\footnotetext{
${ }^{1}$ Full-page figures can be found at http://deepenergyretrofits.pnnl.gov/resources/.
} 


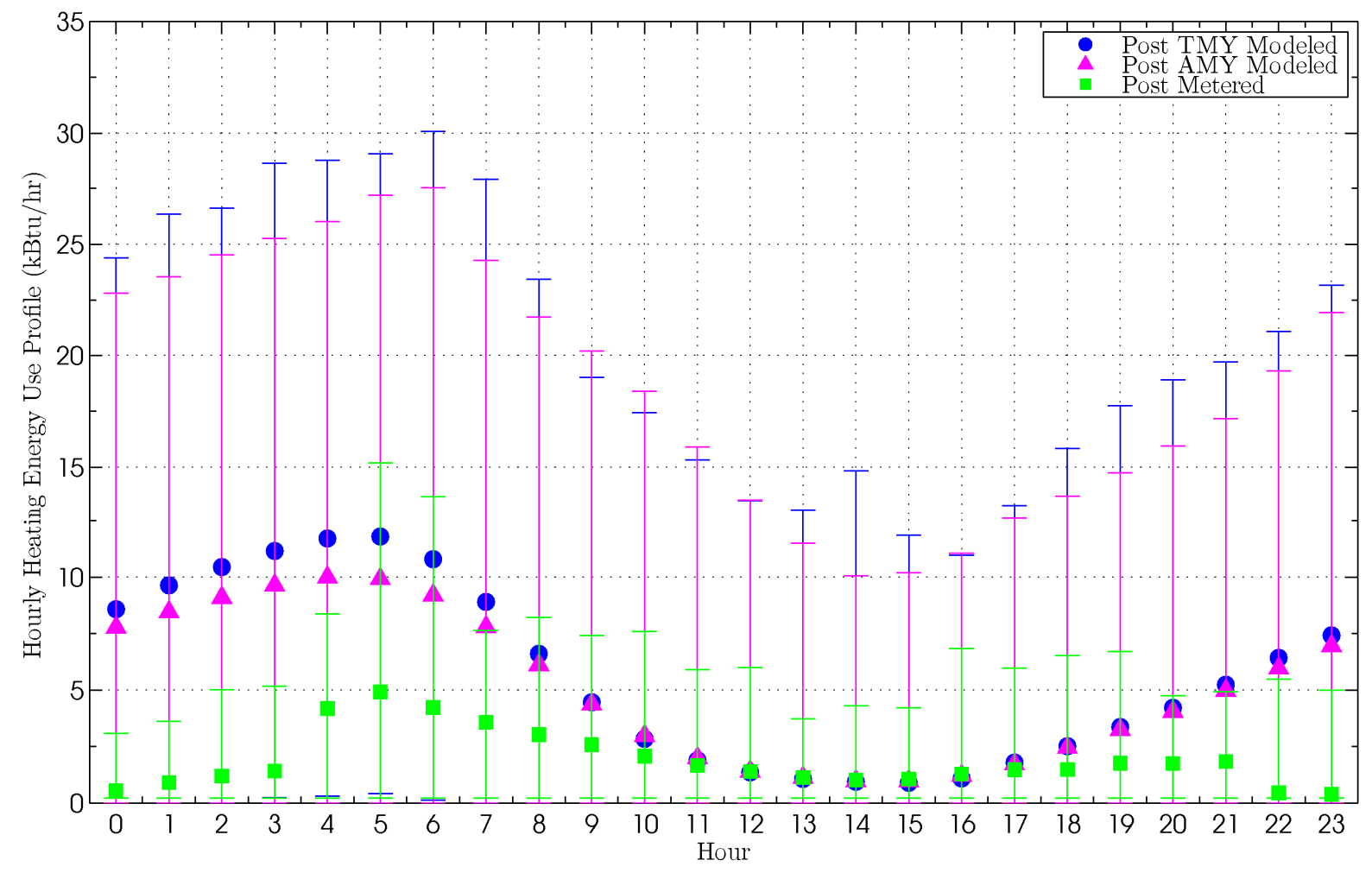

Figure 3.7. Hourly heating energy use profile comparison for the PNW-3 home.

\subsubsection{Heat Pump Strip Heat Impacts}

One of the factors discovered that influences heating energy use was strip, or backup, heat energy use. Strip heating is electric resistance heating used in heat pump systems during periods when the outside dry bulb temperature is too low to allow refrigerant evaporation. Figure 3.8 highlights the monitored strip heat and fan, or air handling unit (AHU), energy use for three of the Pacific Northwest homes. The physical nature of the AHU and strip heat did not allow them to be disaggregated, but they can be distinguished given their relative capacities. The AHU is represented by the cloud of data that is constantly less than $2 \mathrm{kBtu} / \mathrm{hr}$. At temperatures less than $45^{\circ} \mathrm{F}$, as indicated by the linear regression, the strip heat/AHU energy use increases because strip heat is being used to complement the heat pump. The specific dry bulb temperature at which strip heat is activated depends on the specific heat pump and a number of other factors so $45^{\circ} \mathrm{F}$ is used only as a visual reference. 

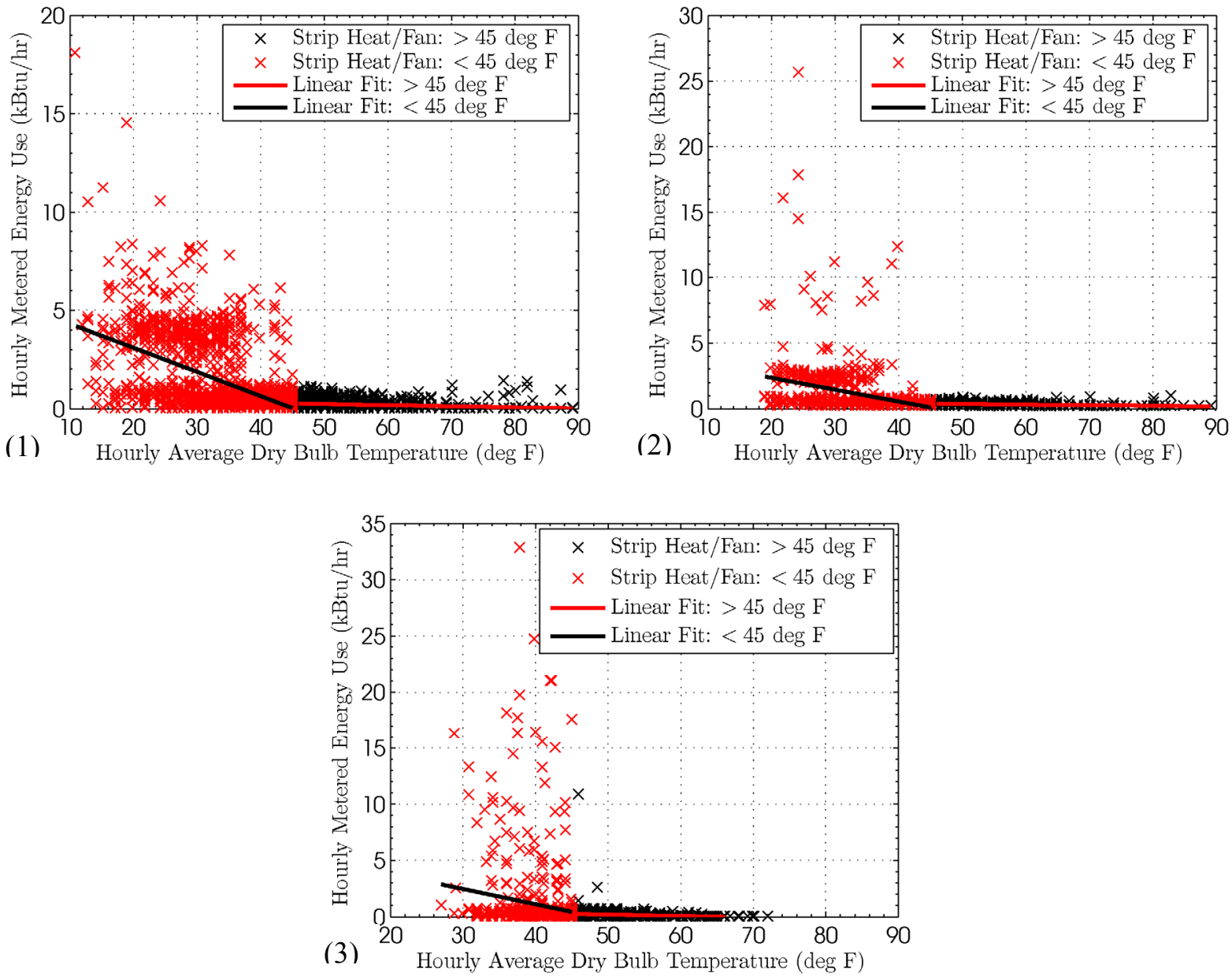

Figure 3.8. Monitored strip heat and AHU energy use and dry bulb temperature comparison for 1) PNW-2, 2) PNW-3, and 3) PNW-4 homes.

In contrast, Figure 3.9 presents the modeled load and heating energy for the homes that have heat pumps post-retrofit. The load on the home represents the heating demanded by the home to maintain the desired indoor temperatures. The homes with pre-retrofit data extending above the diagonal black line represent homes that had a fuel heating system pre-retrofit, where the slope of this data is related to the efficiency of the heating equipment. The PNW-2 and 3 homes had electric resistance heating pre-retrofit, as indicated by the data with a slope equal to one (or 100\% efficiency). Data extending below the diagonal line indicate heat pumps, which have efficiencies greater than one. The impacts of strip heat can be seen when the slope of the post-retrofit TMY (and AMY) curve changes, which occurs at around $20 \mathrm{kBtu} / \mathrm{hr}$.

The first key observation to note is that the PNW-1 home does not have strip heat. The homeowners chose not to purchase strip heat with their ductless mini-split system to save costs and because they have a diesel-fueled boiler for backup heating. However, the energy model does not provide an option in which strip heat is excluded. Clearly, the model assumes that the PNW-1 home is using strip heat significantly as indicated by the substantial cloud of data. During periods when the strip heat is in use, the efficiency of the modeled heating system is much lower than the actual heating system, which does not have strip heat. 
Furthermore, it is evident that the use of strip heat influenced the poor heating estimates for the PNW3 home, as discussed previously. For this home, the heating is dominated by strip heat, as shown by the large cloud of post-retrofit modeled data with a slope of around one, ranging from a load around 20 to $40 \mathrm{kBtu} / \mathrm{hr}$. This clearly indicates that the home was poorly characterized, because the heating equipment is sized to meet the heating load using the heat pump for a majority of the time. This is evident in Figure 3.7 where the capacity of the monitored heat pump never exceeds $15 \mathrm{kBtu} / \mathrm{hr}$, which is well below the $30 \mathrm{kBtu} / \mathrm{hr}$ shown below. However, the magnitude of the strip heat increase in energy use was not quantified directly because the important modeling improvement would be to better characterize the home.
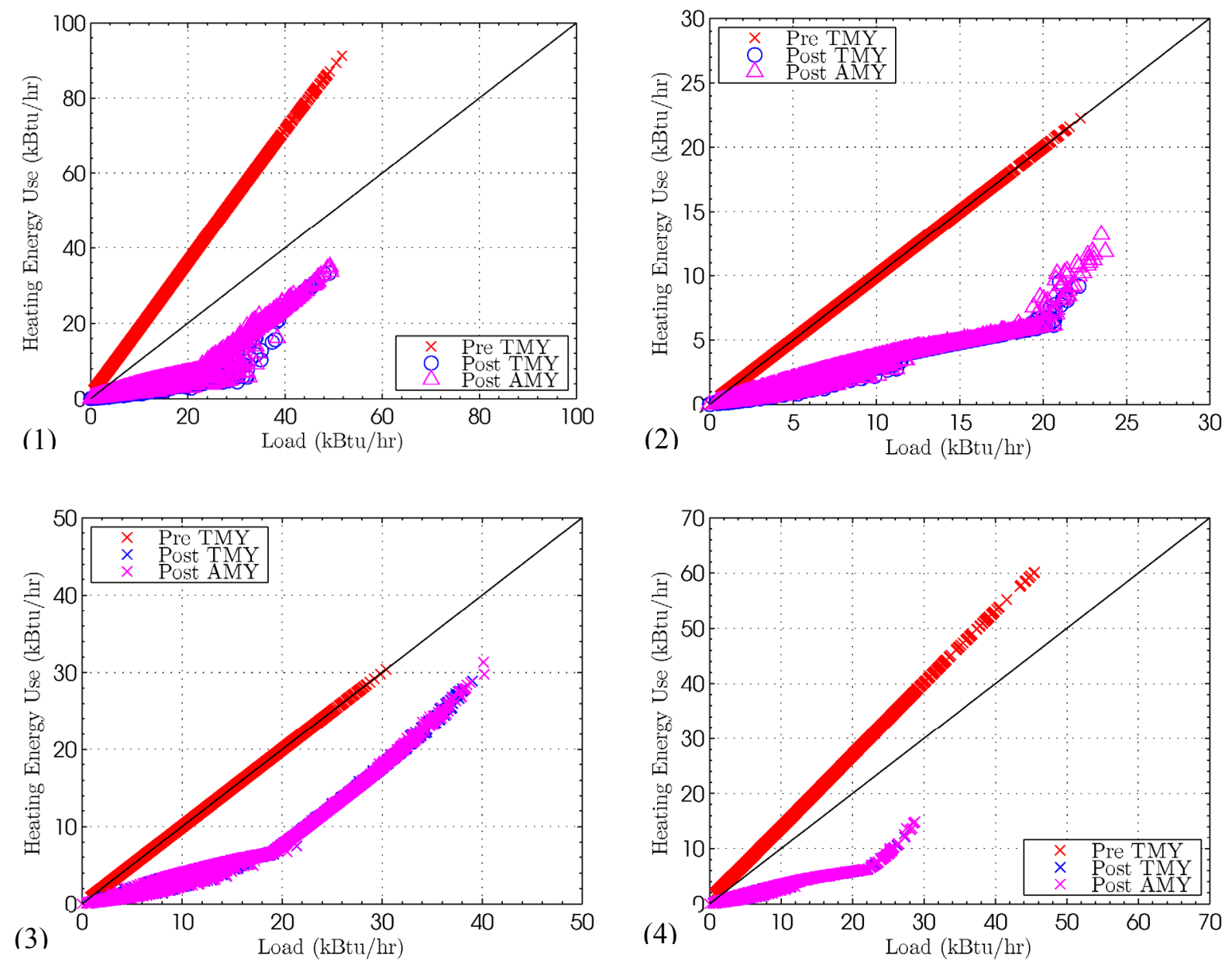

Figure 3.9. Modeled heating load and heating energy use for 1) PNW-1, 2) PNW-2, 3) PNW-3, and 4) PNW-4 homes.

\subsubsection{Electric Resistance Heating Impacts}

Another observed impact was the influence of electric resistance heating present throughout the monitored homes. While PNNL researchers were aware of resistance heating in some homes, specifically PNW-1, this heating was not disaggregated directly but was included in the monitoring of the total electricity use. 
The miscellaneous energy use for the PNW-1 and PNW-3 homes shown in Figure 3.10 and Figure 3.11 represents all electricity use that was not disaggregated by single end-use. This combination of energy use would include multiple lighting and receptacle circuits and appliances that were not separately monitored. As shown in Figure 3.10 and Figure 3.11, the significant amount of energy used occurs during the heating months exceeds the relatively flat base line energy use during the cooling months. This increase during the heating months could indicate the use of electric resistance heating. Coincidentally, the two homes highlighted in Figure 3.10 and Figure 3.11 represent the only homes with significant miscellaneous loads during the heating months and are homes that were over-predicted when comparing the model and monitored data, as shown in Figure 3.5 (1) and (3). Accounting for the resistance heating would create a better comparison between actual and estimated heating energy use. However, the small increases observed below (i.e., around 1,000 kBtu/month) would not completely bridge the gap between the modeled and metered data presented in Figure 3.5. In addition, zonal heating (i.e., heating only a few rooms, rather than the entire home) and/or inconsistent temperature distributions could also account for the differences in heating energy use.

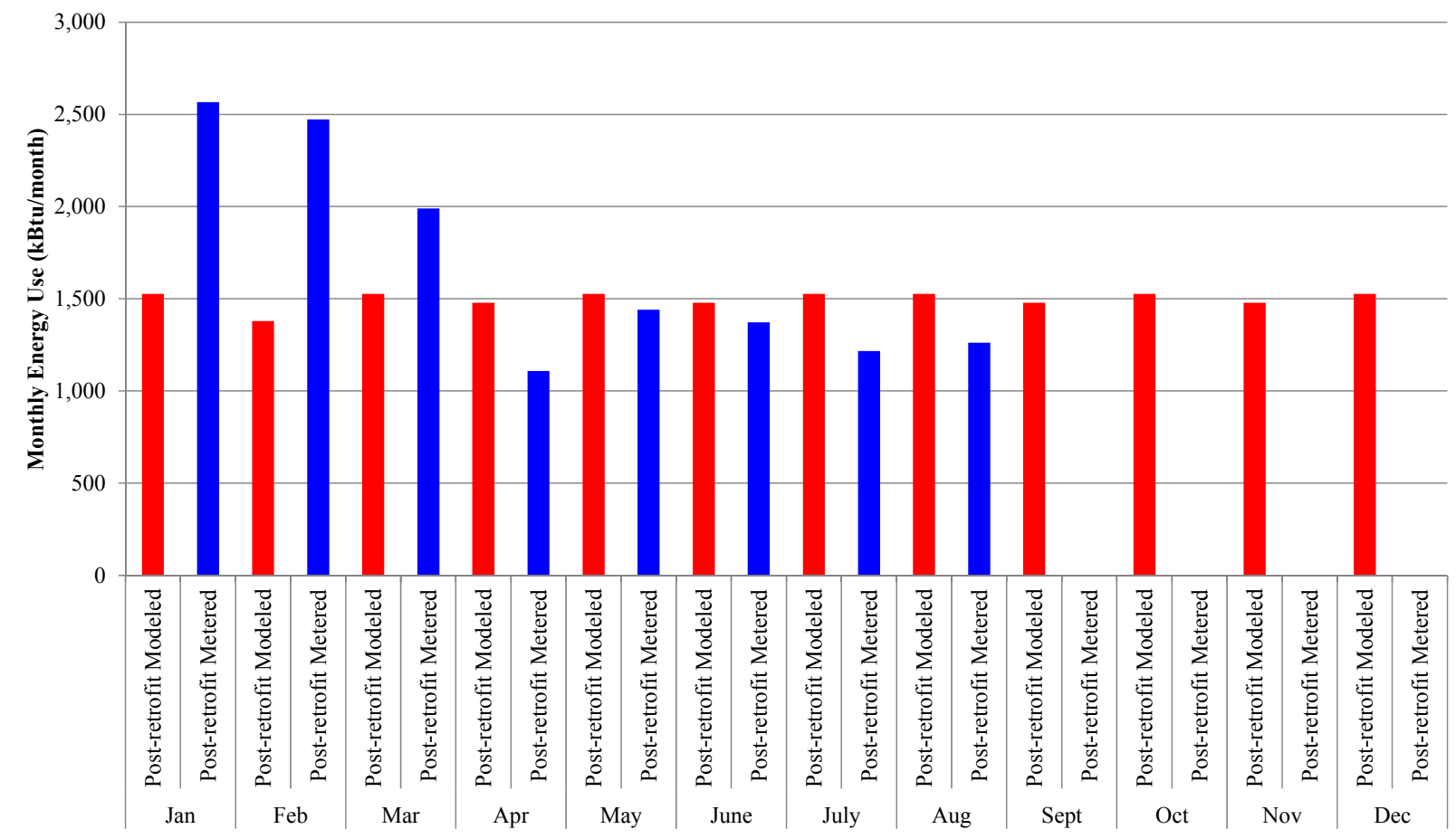

Figure 3.10. Post-retrofit modeled and metered miscellaneous energy use comparison for the PNW-1 home. 


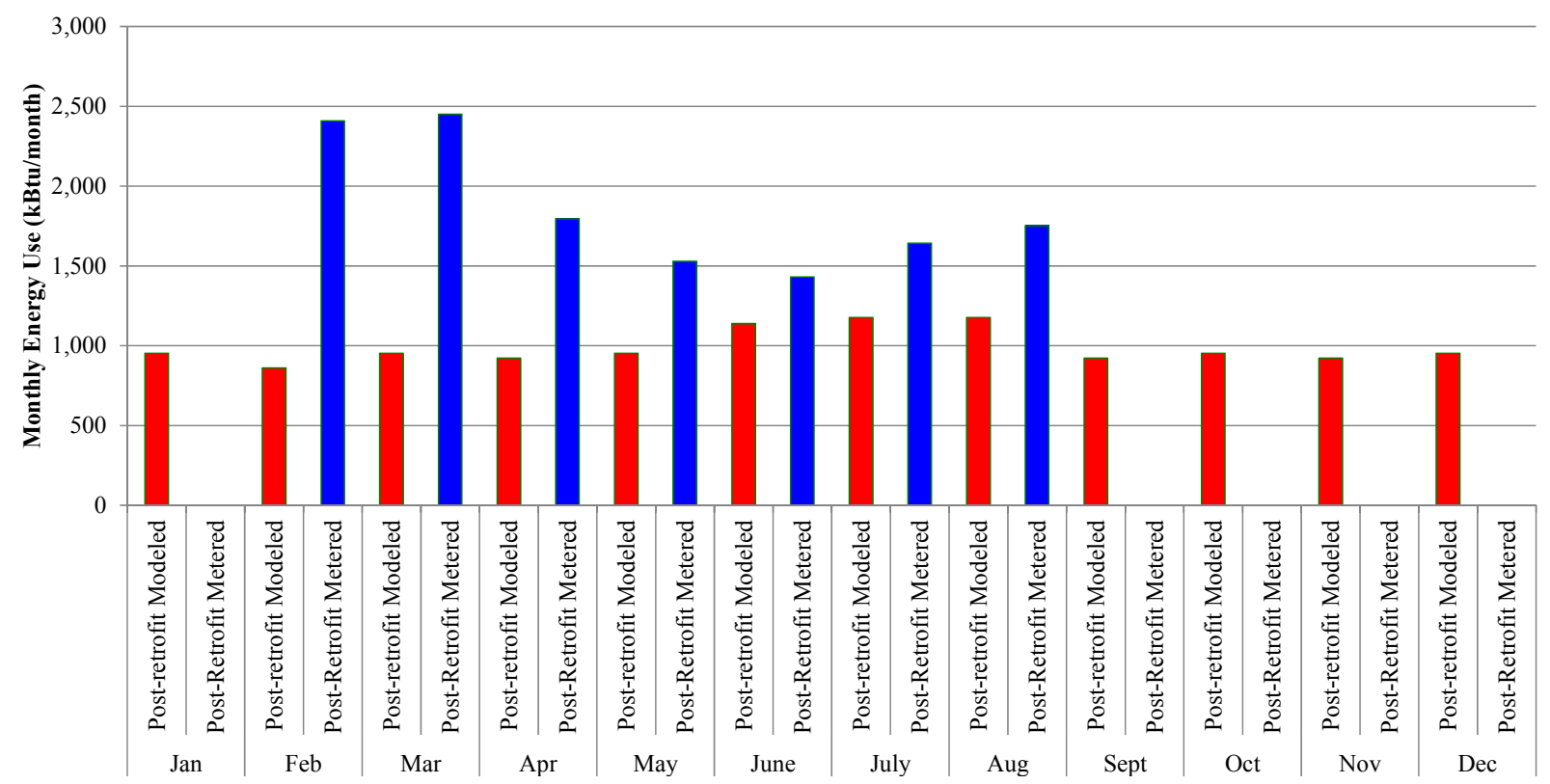

Figure 3.11. Post-retrofit modeled and metered miscellaneous energy use comparison for the PNW-3 home.

\subsubsection{Cooling Energy Use}

Similar to the heating energy use comparison, cooling energy use differences also were evaluated and are highlighted in Figure 3.12. Contrary to heating energy use estimates, the cooling monitoring data showed the existence of months when no cooling energy was used; however, the models assumed the contrary. Again, this indicates that either additional homeowner input is required to refine the assumptions used in the model, weather dictated that cooling was not necessary, or homeowners were being aggressively conservative in their energy use.

Again, contrary to heating energy use comparisons, the AMY estimates, in general, exceed the monitored cooling energy use and for some months is a factor of two or more greater than the monitored energy use. The AMY cooling corrections are discussed further in Section 3.2.3.2.

Cooling energy use profiles are provided in Figure 3.13 and Figure 3.14 to further explain differences in estimated cooling energy use for the best and worst predictions. The remaining cooling profiles can be found in Appendix C. ${ }^{1}$ As seen in Figure 3.13, the modeled profiles characterize the home and homeowner fairly well, because the modeled and monitored profiles match in shape. However, the magnitude of the modeled profiles exceeds the monitored profiles, which indicates that the temperature set-points are likely too low or the homeowner just turned off the $\mathrm{A} / \mathrm{C}$ unit, despite it being hot enough outside for the model to justify cooling. However, Figure 3.14 shows an example of the model misrepresenting the home and/or homeowner, where the monitored data indicate significant cooling during the night and less cooling during the day, whereas the model predicts the contrary. This is clearly

\footnotetext{
${ }^{1}$ Full-page figures can be found at http://deepenergyretrofits.pnnl.gov/resources/.
} 
an occupant-driven inconsistency because this occupant preferred to use the $\mathrm{A} / \mathrm{C}$ unit at night when it might be cool enough outside to provide free-cooling.
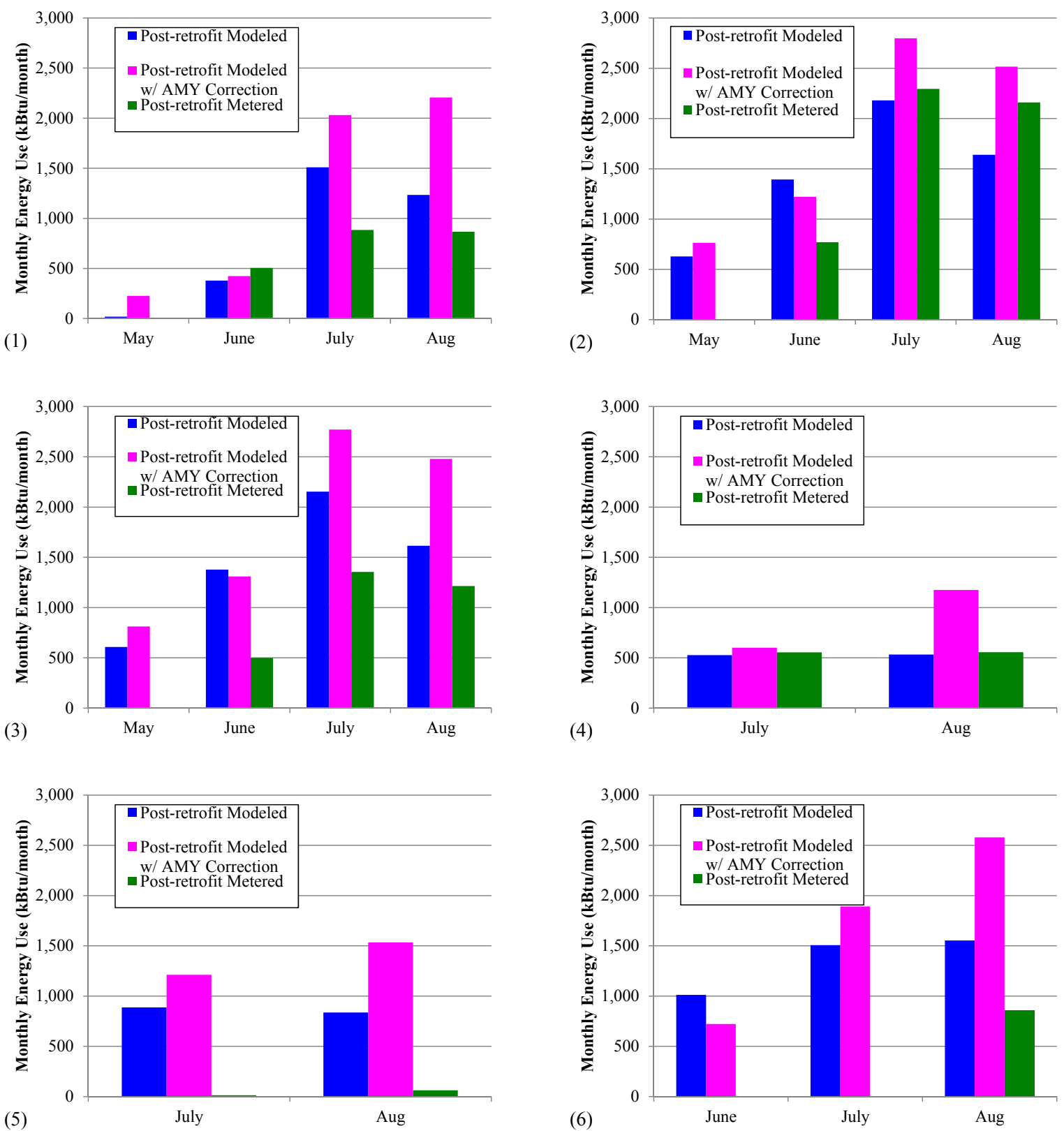

Figure 3.12. Comparison of post-retrofit modeled, AMY corrected, and metered monthly cooling energy use comparison for 1) PNW-1, 2) PNW-2, 3) PNW-3, 4) PNW-4, 5) PNW-5, and 6) PNW-6 homes. 


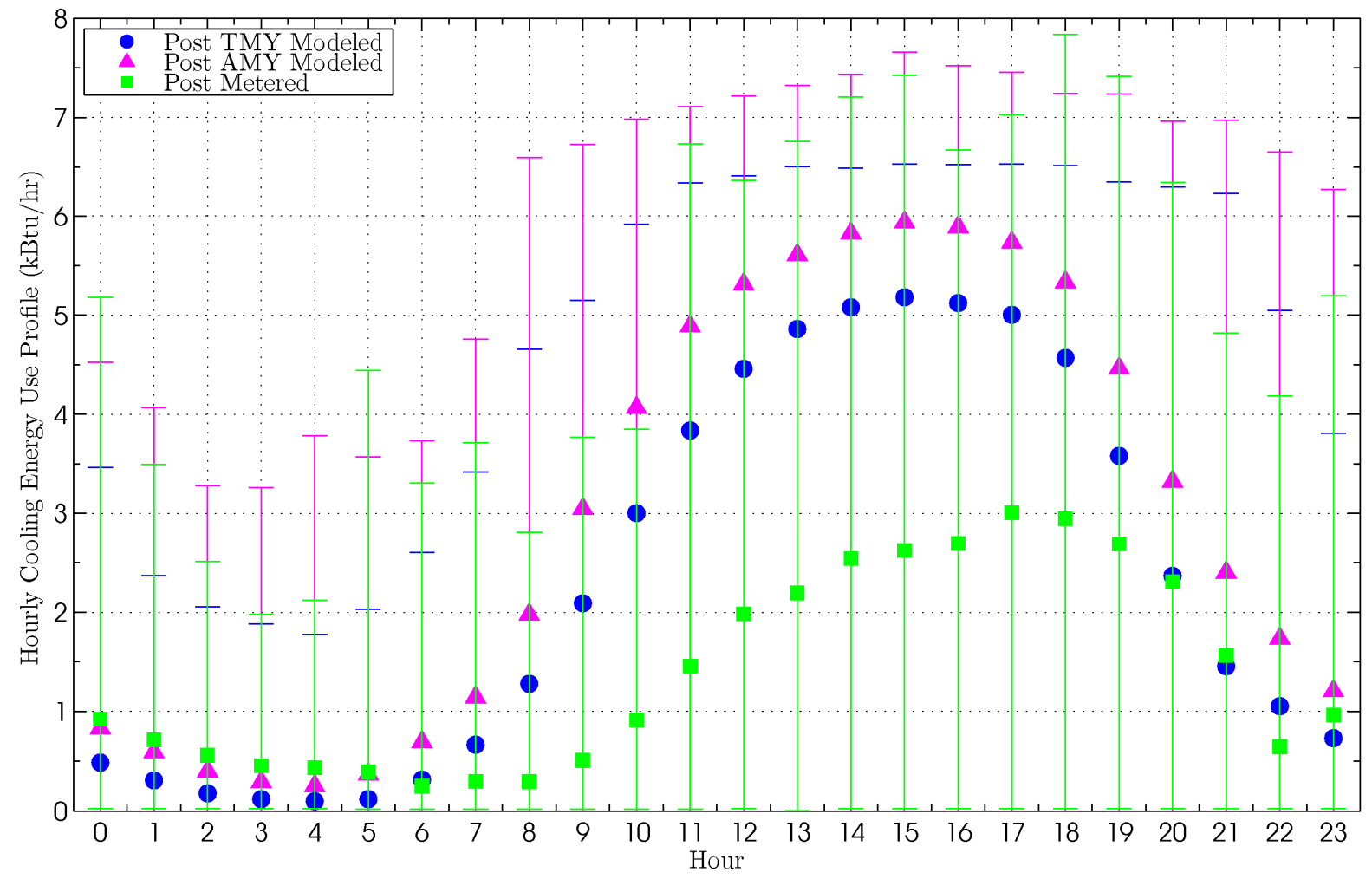

Figure 3.13. Hourly cooling energy use profile comparison for the PNW-3 home.

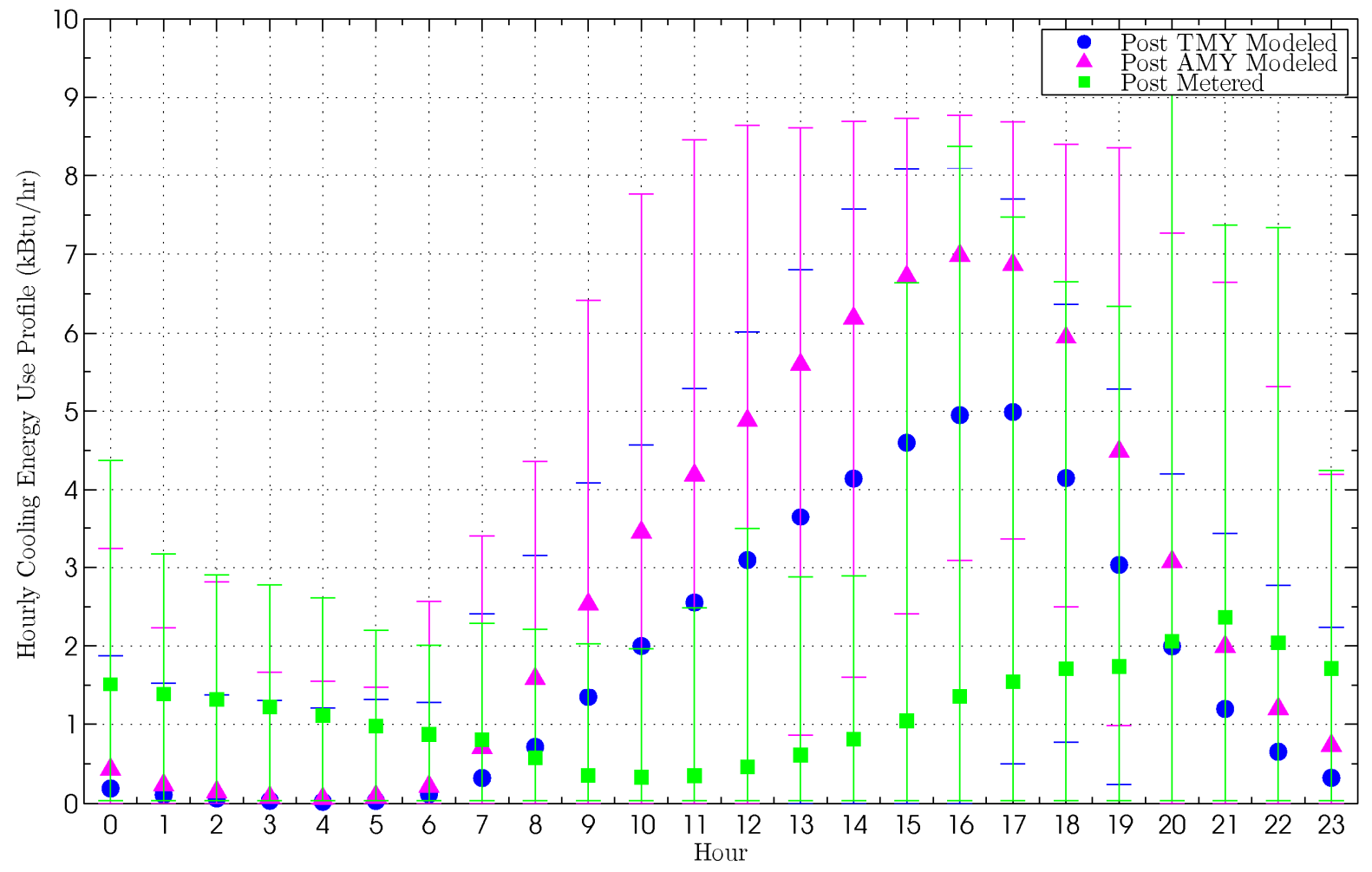

Figure 3.14. Hourly cooling energy use profile comparison for the PNW-1 home. 


\subsubsection{Actual Meteorological Year Corrections}

\subsubsection{Heating Corrections}

The influence of AMY corrections was evaluated by comparing the monthly heating energy use and heating degree days (HDDs). The HDD are defined as

$$
H D D=\frac{\sum_{1}^{24}\left(T_{B}-T_{D B}\right)}{24}
$$

where $\mathrm{T}_{\mathrm{B}}$ is the base temperature, assumed to be $65^{\circ} \mathrm{F} ; \mathrm{T}_{\mathrm{DB}}$ is the hourly outside dry bulb temperature, and the difference between the base and dry bulb temperature is summed for 24 hours and divided by 24 . The HDD for each day is related to the daily heating load on the building assuming an interior temperature of $70^{\circ} \mathrm{F}$ (the remaining $5^{\circ} \mathrm{F}$ is assumed to be met by internal loads; people, appliances, etc.). A summary of the monthly heating energy use and HDD are provided in Figure 3.15. The first observation is the agreement between the TMY and AMY modeled data, because these figures are independent of weather (i.e., at a given HDD value, the heating energy should be constant for TMY and AMY data), which show excellent agreement. The importance of AMY data lies in the fact that the TMY curve may not capture the full variability of the actual weather. This is observed in Figure 3.15 (4) where the AMY HDD approached 700 but the TMY HDD did not exceed 550. In other words, the AMY weather data represents a much colder year than the TMY data.

In addition, Figure 3.15 (2) indicates excellent agreement between the TMY, AMY modeled data and monitored data, where the model has captured the heating energy profile of this home well. Conversely, in Figure 3.15 (1) and (3) the monitored data would indicate that the home uses less energy at higher HDD values than models predict, indicating that the model does not represent the home or homeowner well. However, as previously discussed, the monitored data may be misleading because energy use from resistant heating is not included. Nonetheless, the missing resistance heating energy should have a minimal impact on the shape of the monitoring data curve because of its relative magnitude. Similar figures, using daily dry bulb temperature, rather than HDD, are provided in Appendix C. ${ }^{1}$ When using daily data, the daily average dry bulb temperature is equivalent to the HDD; however, monthly data are best presented using HDD, rather than monthly average dry bulb temperature.

\footnotetext{
${ }^{1}$ Full-page figures can be found at http://deepenergyretrofits.pnnl.gov/resources/.
} 

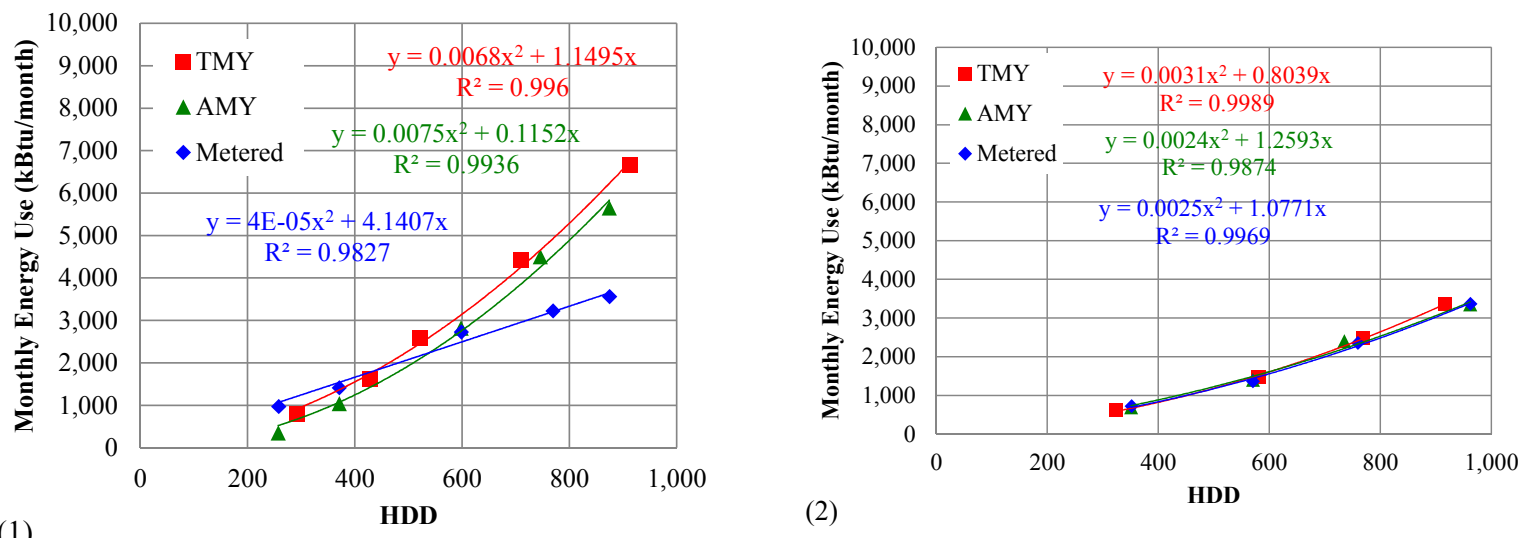

(1)
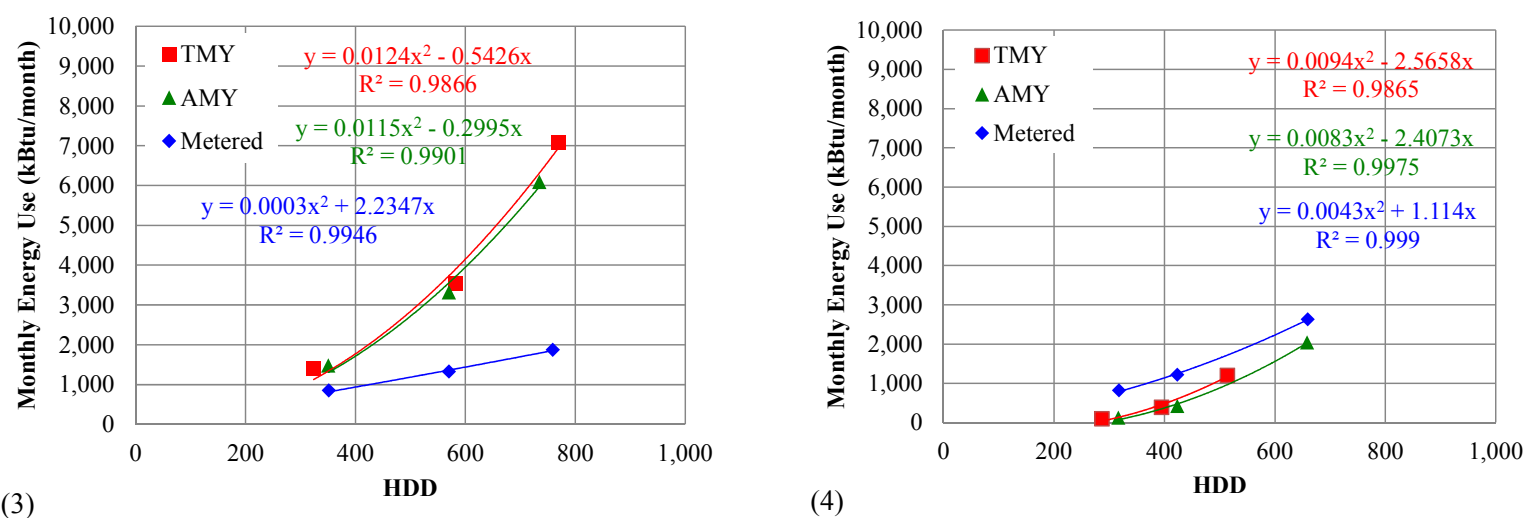

Figure 3.15. Monthly heating energy and heating degree day comparisons for 1) PNW-1, 2) PNW-2, 3) PNW-3, and 4) PNW-4 homes.

\subsubsection{Cooling Corrections}

Similar to heating, the AMY cooling corrections were evaluated using cooling degree days (CDDs), which are equivalent to HDDs, except the base temperature and the dry bulb temperature are reversed in the subtraction. The monthly cooling energy and CDD for each home are presented in Figure 3.16.

Unlike the heating corrections, the cooling corrections are far more inaccurate and complicated. Most of the homes exhibited large differences between the TMY post-retrofit modeled and monitored data because of a number of factors, namely the homeowners did not use their $\mathrm{A} / \mathrm{C}$ as often as expected. Some homeowners did not turn on their A/C systems for entire months, as shown in Figure 3.16 (5) and (6). For these homes, homeowner conservation is the leading cause for actual and estimated discrepancies. However, for the PNW-2 home, there is excellent agreement between the TMY modeled and monitored curves, indicating that the model characterizes the home and homeowner well. However, the AMY modeled results are quite different.

In general, the AMY modeled data result in a linear offset from the TMY data (i.e., TMY and AMY linear regressions have the same slope), which would indicate that the increase in cooling energy use for a given CDD is not associated with an increase in dry bulb temperature but rather another influence. 

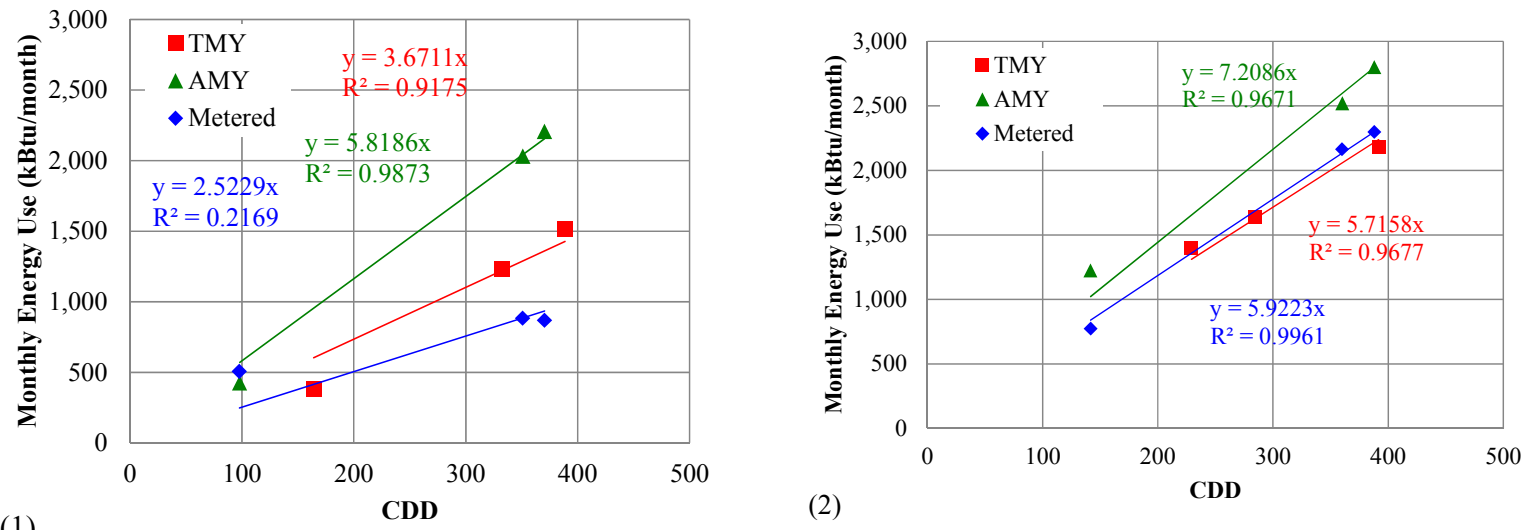

(1)
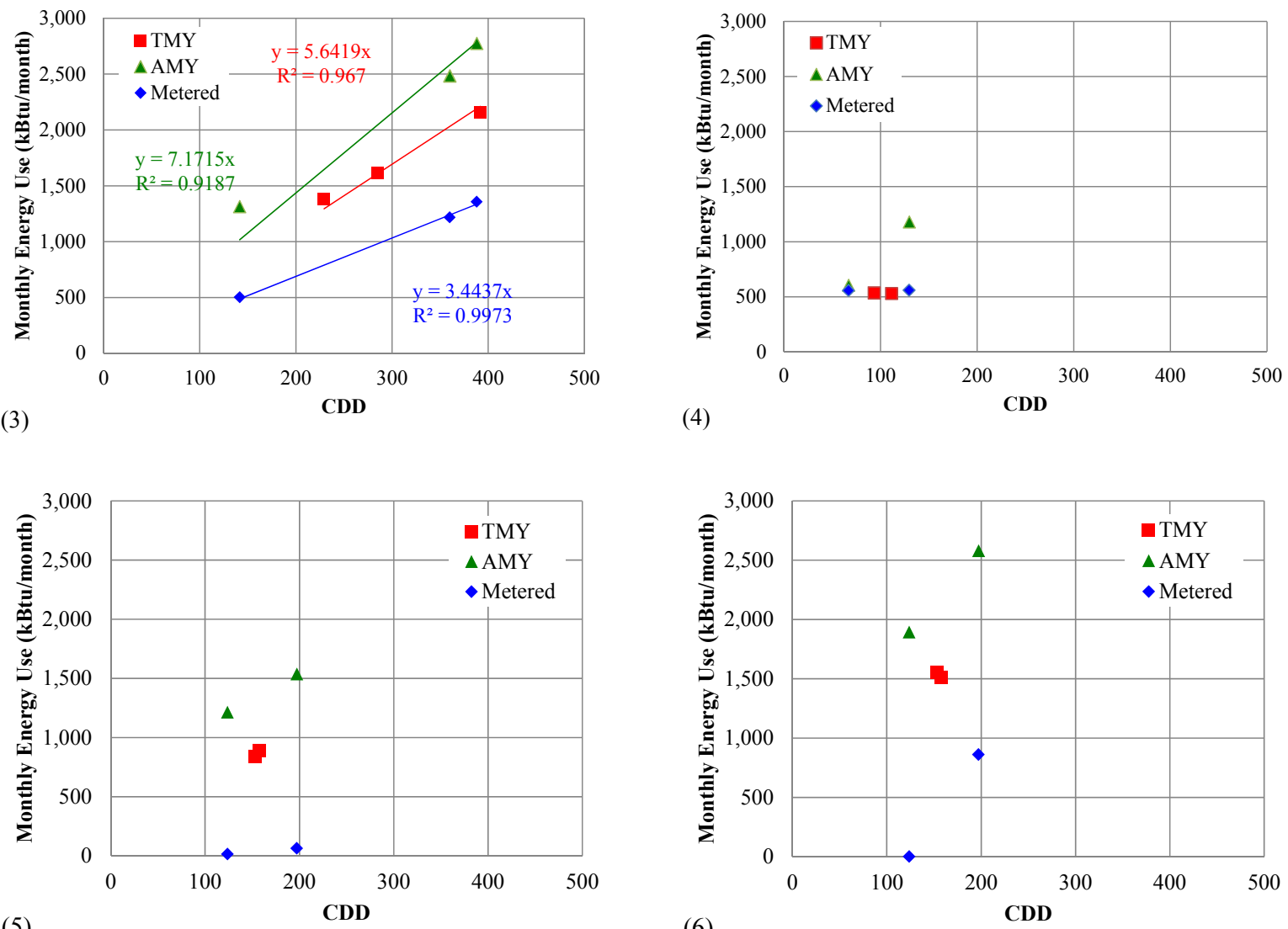

(5)

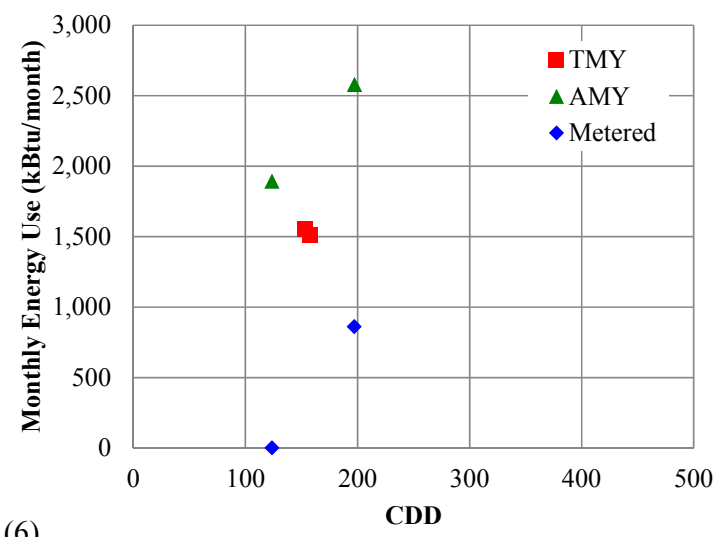

Figure 3.16. Monthly cooling energy and cooling degree day comparisons for 1) PNW-1, 2) PNW-2, 3) PNW-3, 4) PNW-4, 5) PNW-5, and 6) PNW-6 homes.

Solar insolation, which is a variable in the TMY and AMY weather files, was assumed to be the cause for the linear offset associated with the AMY results because increases in solar insolation will increase cooling energy use due to solar heat gain. The direct normal irradiance (DNI) and global horizontal irradiance (GHZ) input data were extracted from the TMY and AMY data files and compared to the change in cooling energy. To determine the relationship of solar insolation and increased cooling energy use, the percent change in DNI was compared to the percent change in cooling energy use for a given 
period. The DNI percent change represents the percent change in DNI from the TMY and AMY data, during the same time period of TMY and AMY cooling energy change. In addition, the change in CDD also was compared and is presented in Figure 3.17. The grayed-out regions of these figures represent an unrealistic correlation (i.e., CDD decreases but cooling energy increases). The CDD results clearly indicate that the increase in cooling energy is not associated with an increase in CDD alone, which confirms that the AMY cooling energy use variation is associated with another influence. The DNI and GHZ comparisons show much better correlation, with the GHZ comparison having only one data point within the unrealistic correlation region. This would indicate that the input AMY solar irradiance data are influencing the cooling energy in an uncharacteristic way, compared to the TMY solar irradiance data. However, the exact manifestation of the solar irradiation influence on the cooling energy increase was not investigated in this study. Further evaluation would allow researchers to better understand how AMY weather data affect the estimated cooling energy. 

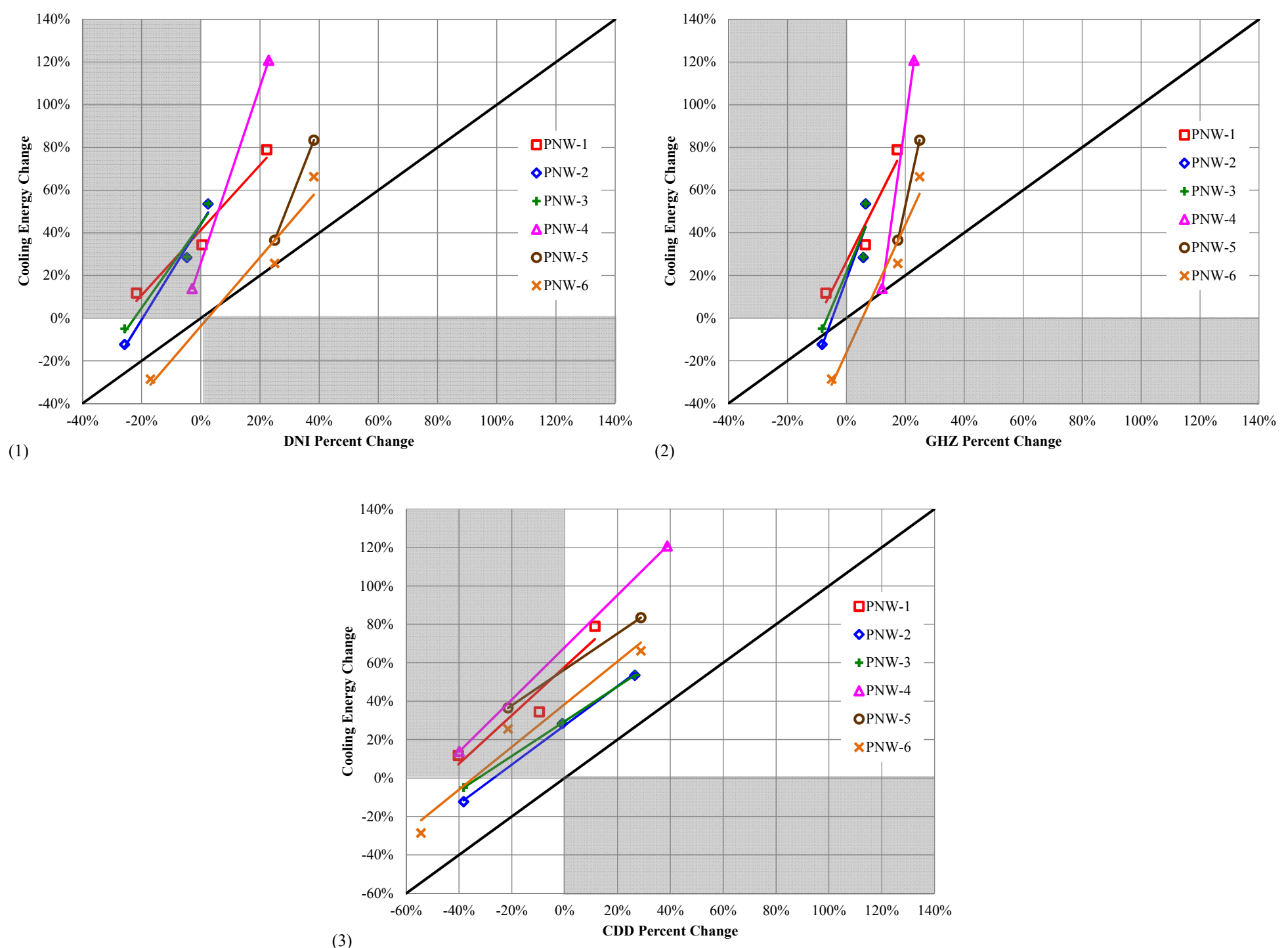

Figure 3.17. Comparison of 1) direct normal irradiance, 2) global horizontal irradiance, and 3) cooling degree day percent change for AMY and post-retrofit models. 


\subsubsection{Domestic Hot Water Energy Use}

The estimated and actual DHW energy use for the PNW-3 and PNW-2 homes is presented by month in Figure 3.18 and Figure 3.19, which represent the best and worst prediction of DHW energy use. The hourly DHW energy use profiles for the PNW-3 and PNW-2 homes also are provided in Figure 3.20 and Figure 3.21, respectively. On average, the monthly DHW energy use for the PNW-3 home matches fairly well, but the hourly profile indicates the model does not match well on an hourly basis, where sharp morning energy use is offset by limited night-time energy use. However, the monthly DHW energy use for the PNW-2 home is consistently lower than the modeled estimates, which is consistent with the hourly profile shown in Figure 3.21. The monitored data presented in Figure 3.21 also indicate an erratic DHW usage pattern, unlike the smooth profile the model anticipates.

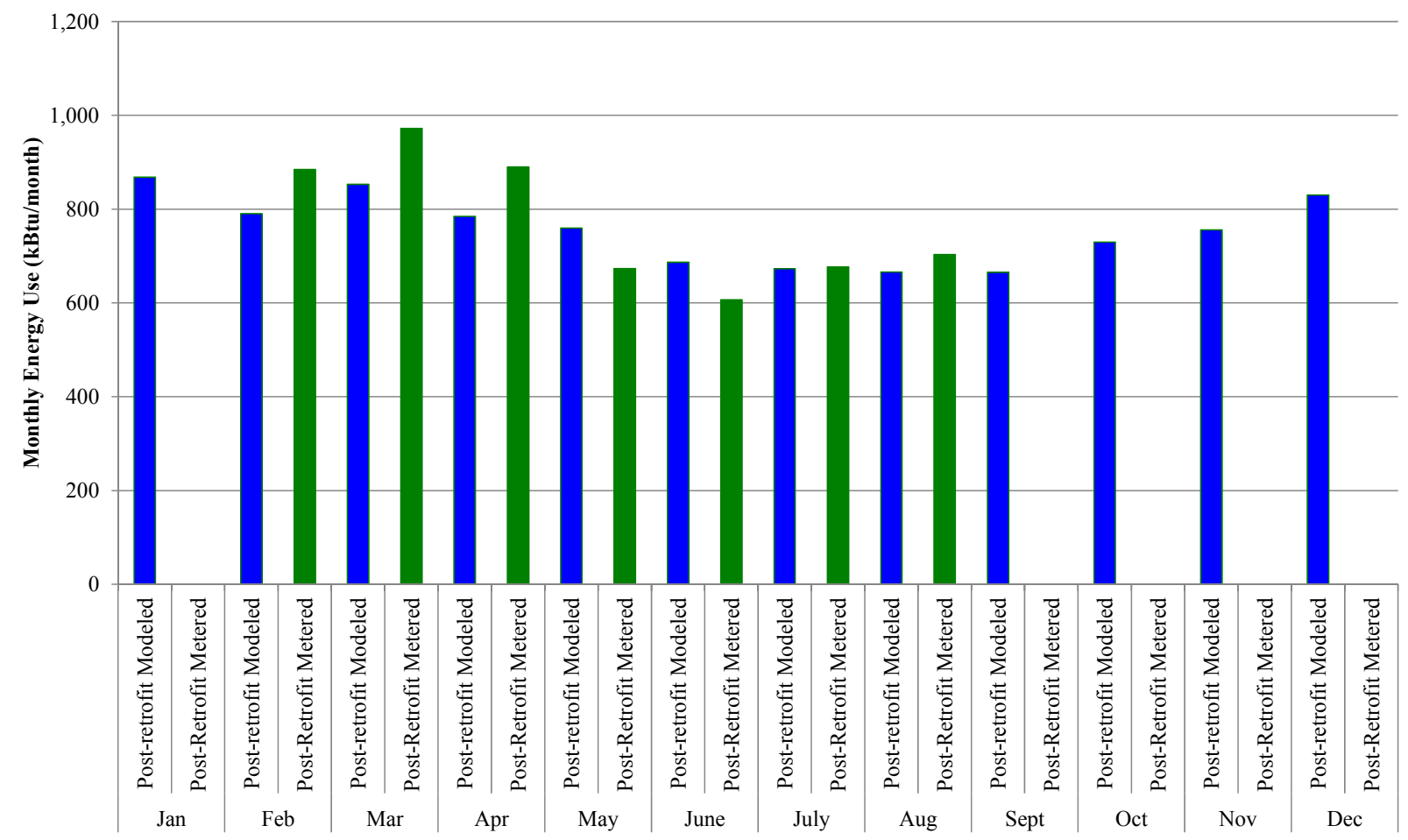

Figure 3.18. Comparison of post-retrofit modeled and metered DHW energy use for the PNW-3 home. 


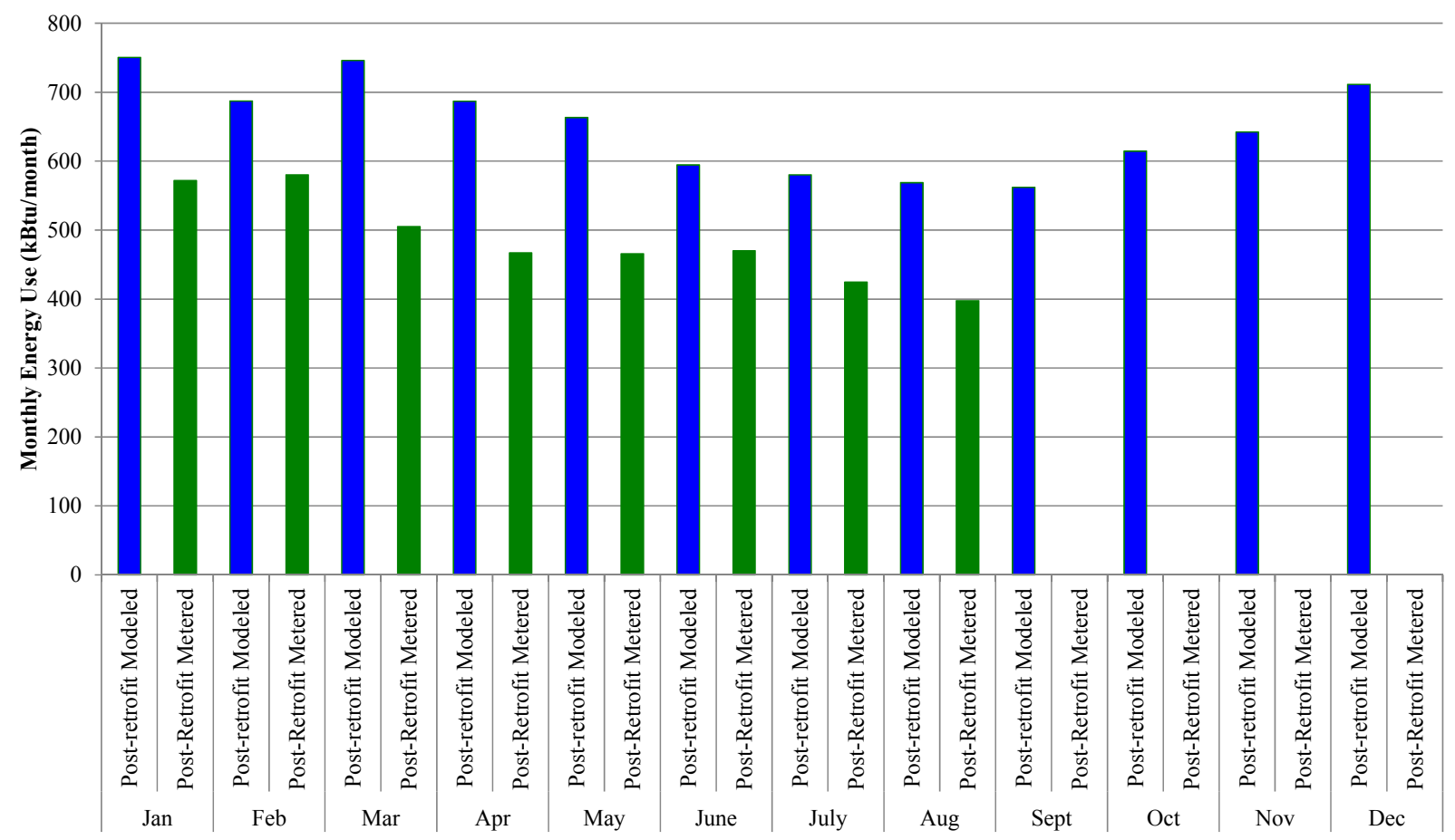

Figure 3.19. Comparison of post-retrofit modeled and metered DHW energy use for the PNW-2 home.

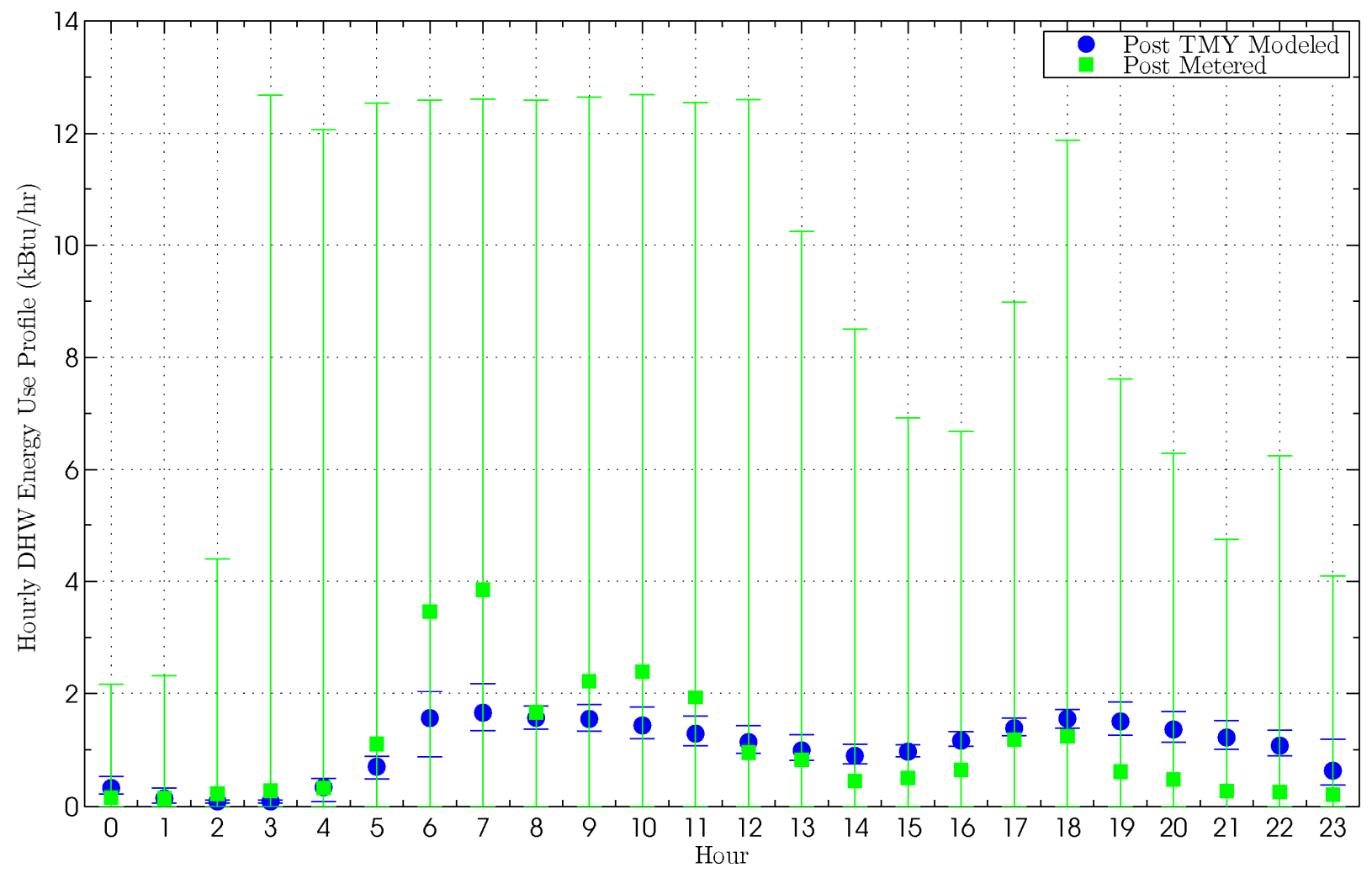

Figure 3.20. Comparison of the hourly DHW energy use profile for the PNW-3 home. 


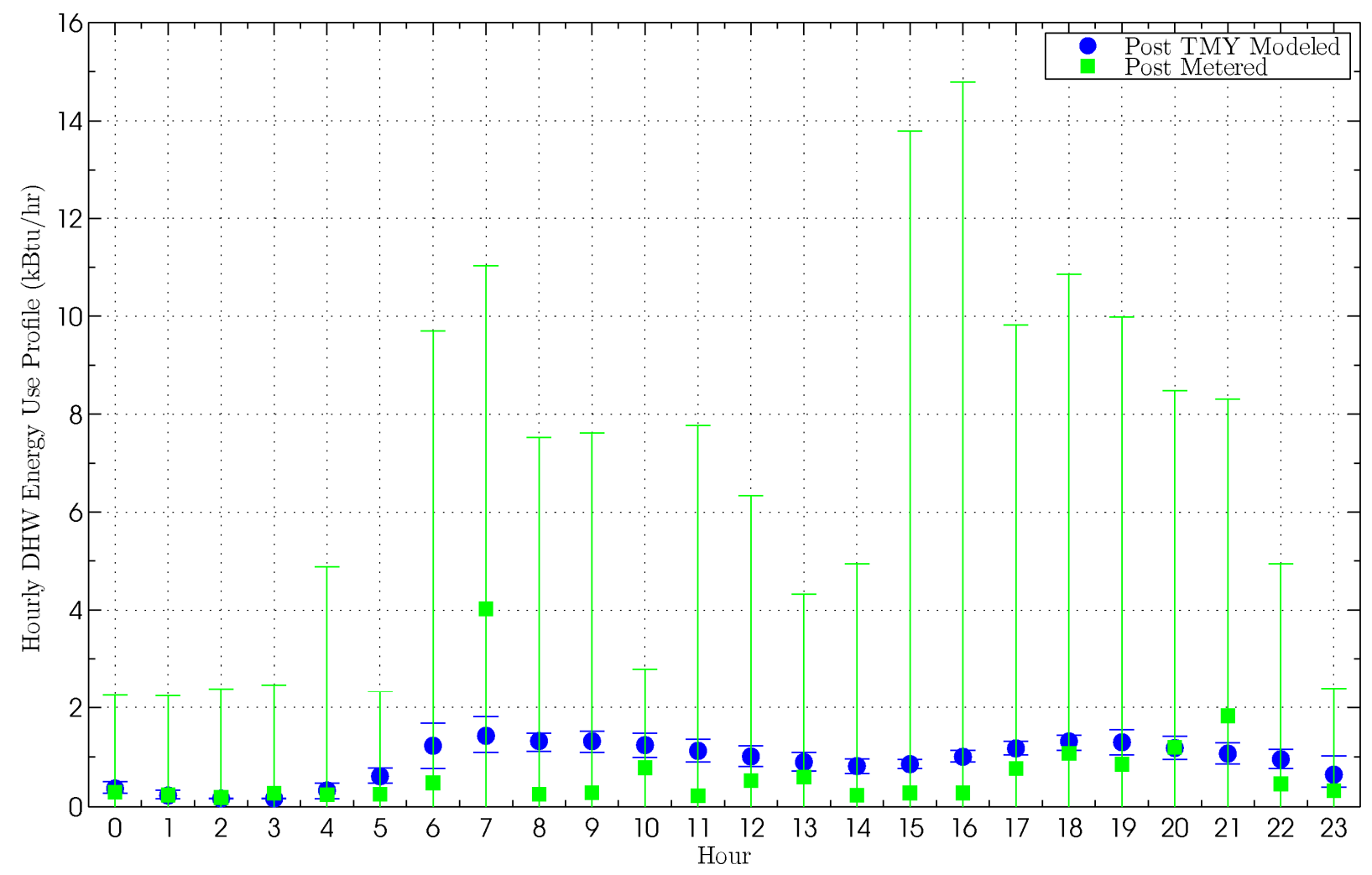

Figure 3.21. Comparison of the hourly DHW energy use profile for the PNW-2 home.

\subsubsection{Clothes Dryer Energy Use}

As an example of the energy use predictions for single end-use appliances, comparisons between actual and estimated clothes dryer energy use for the PNW-5 and PNW-1 homes are presented in Figure 3.22 and Figure 3.23, respectively. The hourly dryer energy use profiles for these homes also are provided in Figure 3.24 and Figure 3.25, respectively. Dryer energy use for the PNW-5 home, on average, agrees well with the model predictions, despite significant monthly variations. However, the PNW-1 home consistently uses much less dryer energy than predicted. The hourly profiles for each home show limited similarities between the modeled and monitored data, which indicates that the model is accurate only for predicting average energy use and that the distribution of energy use does not correlate with the sporadic use of most homeowners. 


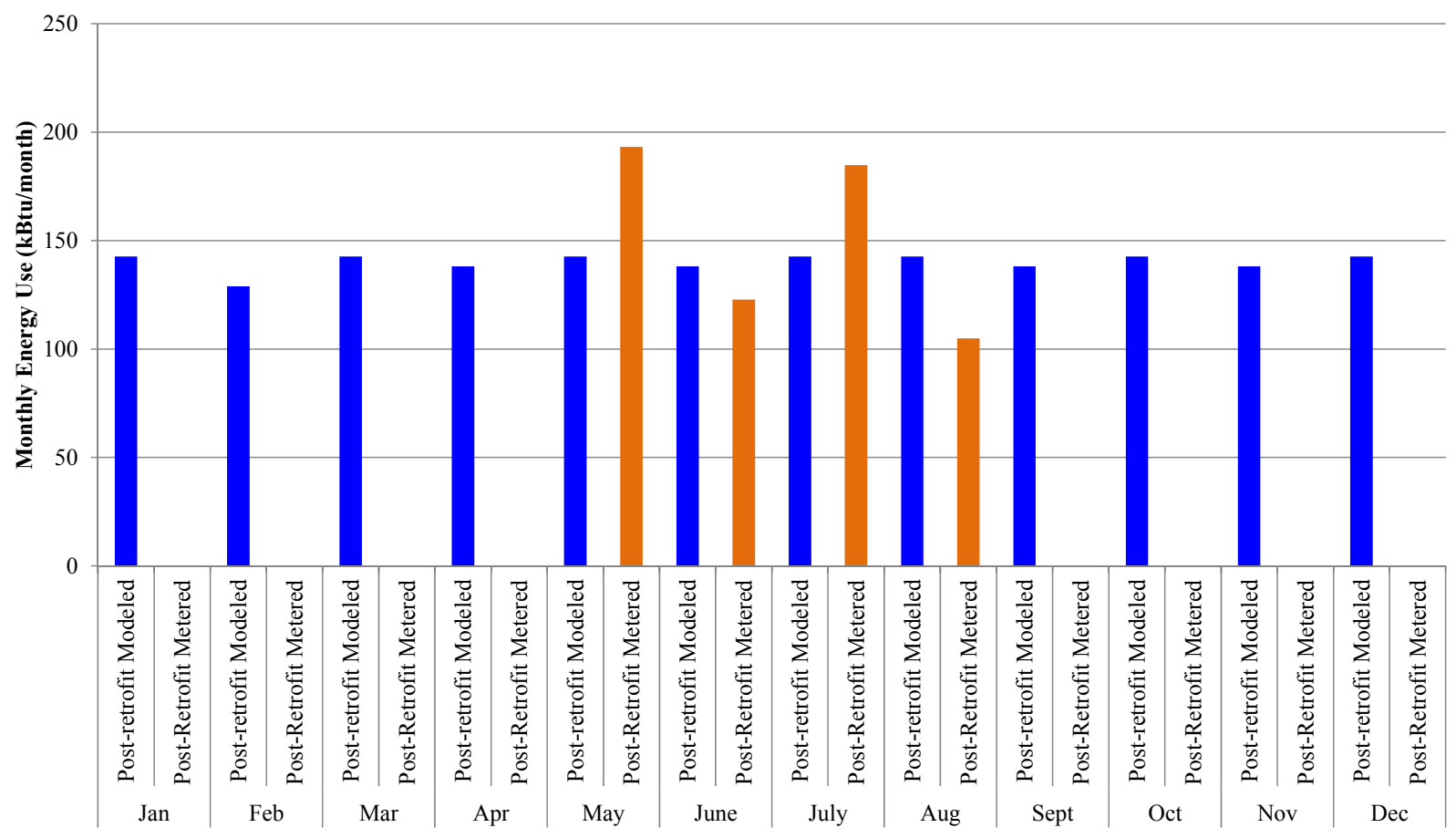

Figure 3.22. Comparison of post-retrofit modeled and metered dryer energy use for the PNW-5 home.

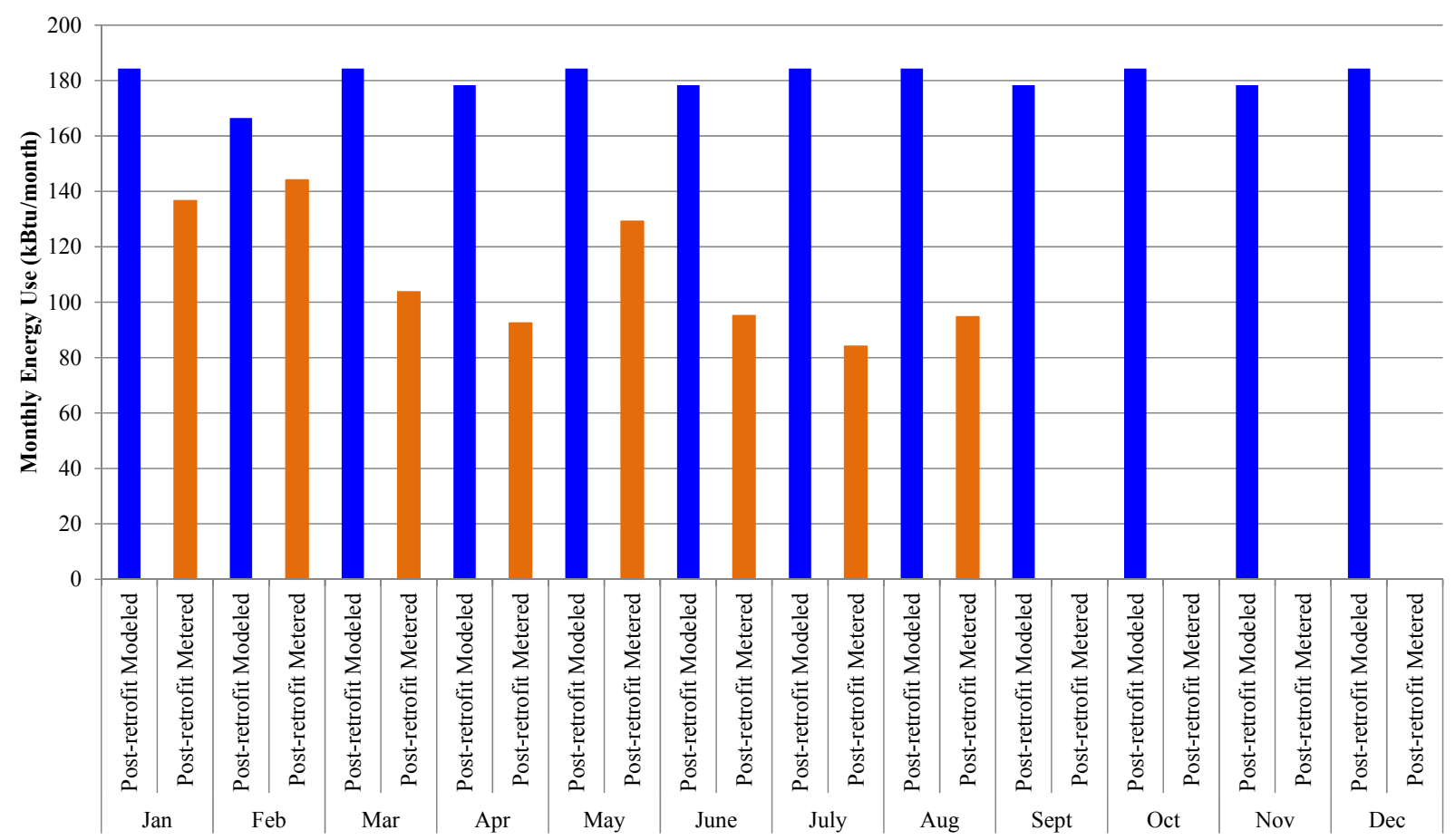

Figure 3.23. Comparison of post-retrofit modeled and metered dryer energy use for the PNW-1 home. 


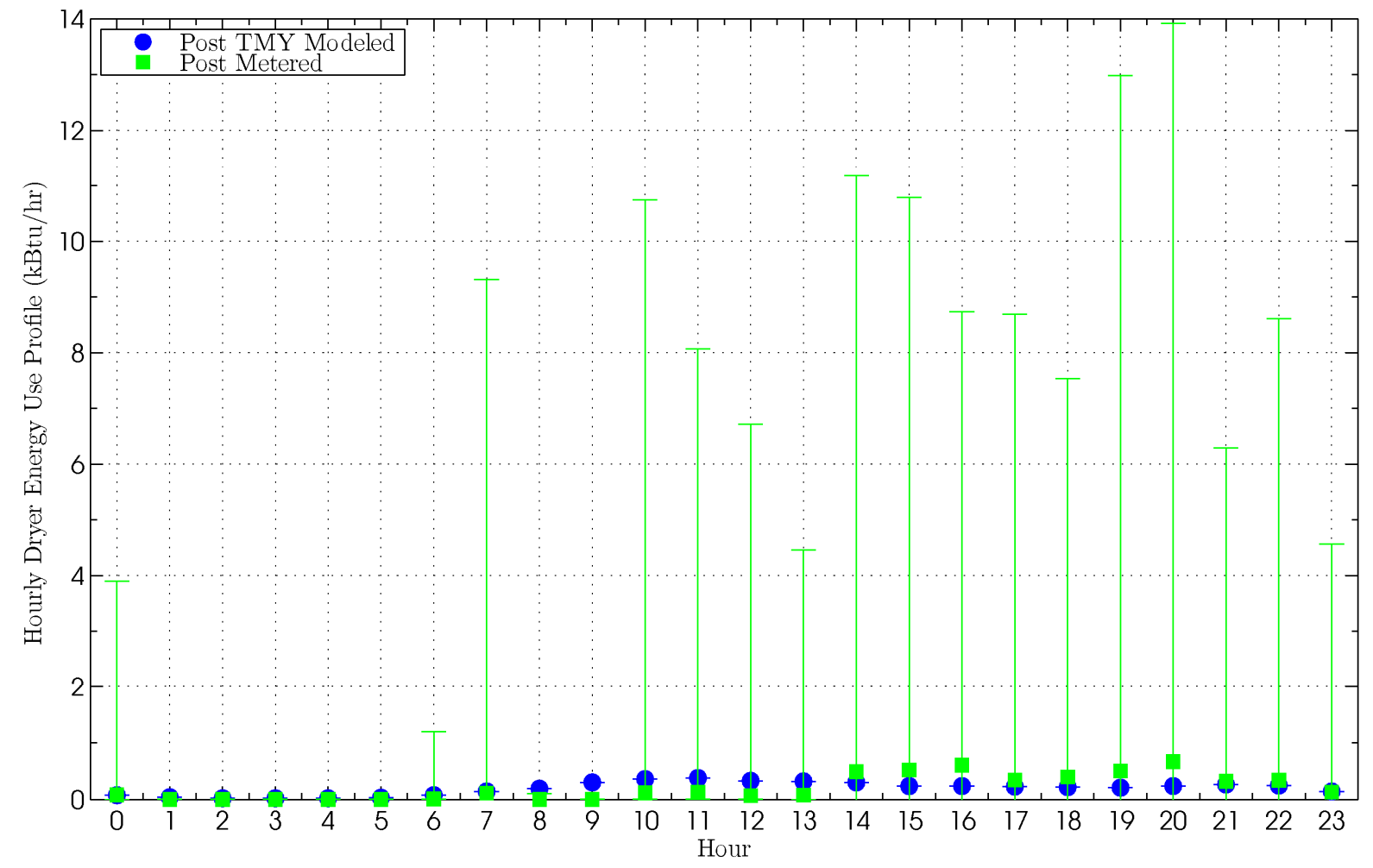

Figure 3.24. Comparison of the hourly dryer energy use profile for the PNW-5 home.

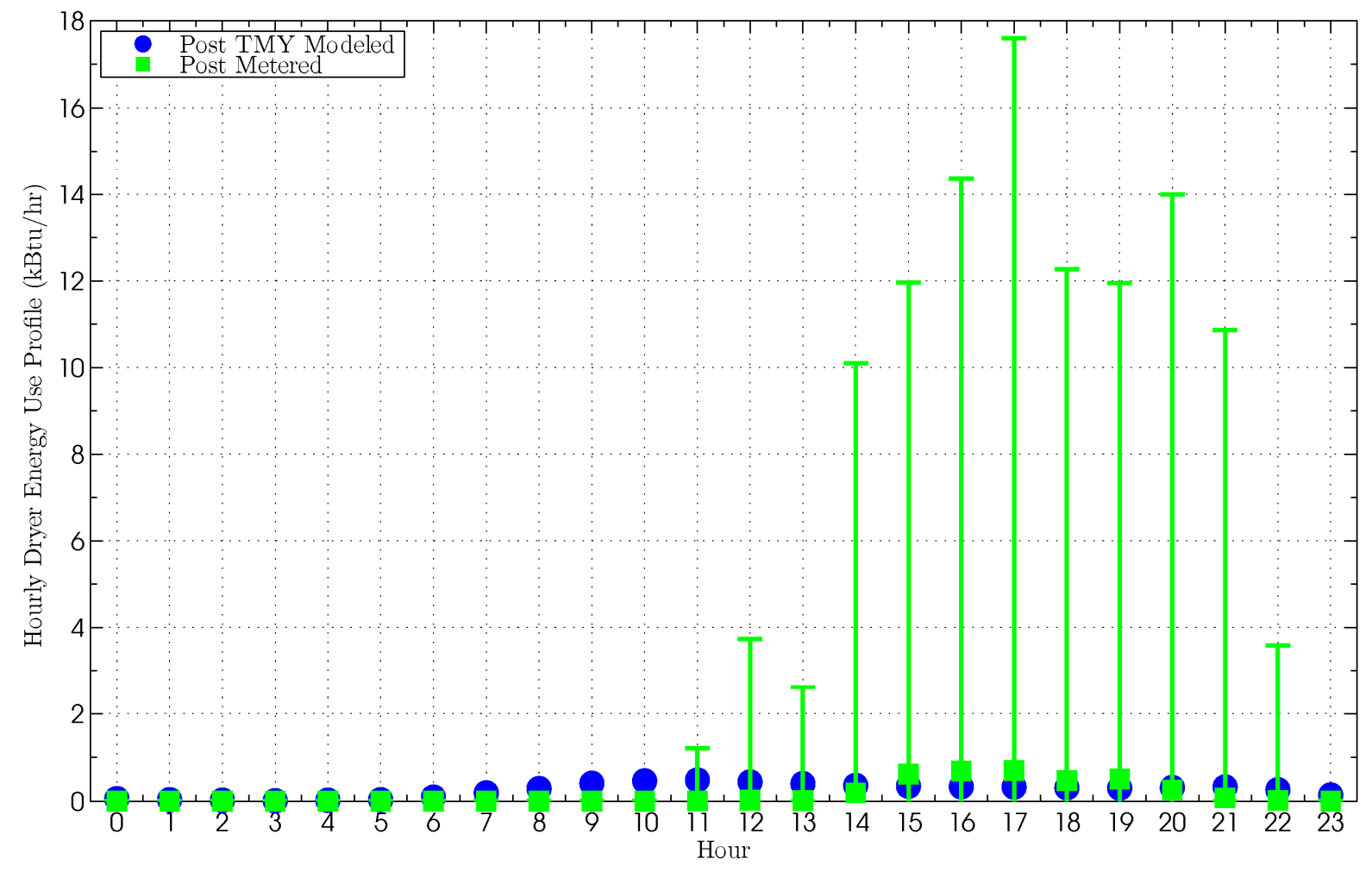

Figure 3.25. Comparison of the hourly dryer energy use profile for the PNW-1 home. 


\subsubsection{Miscellaneous Unmonitored Energy Uses}

Miscellaneous energy use is defined as a combination of all end-uses that were not monitored as a single end-use and constitutes approximately 25 to 61\% (not including DHW energy use) of the energy use in the Pacific Northwest monitored homes (see Figure 3.30). These miscellaneous energy uses consist of lighting, various appliances, and electrical equipment (i.e., televisions, stereos, etc.). The miscellaneous energy use for the PNW-4 home also included the DHW heater energy because it could not be monitored separately.

The actual and estimated miscellaneous energy use for the PNW-1 and PNW-5 homes are shown in Figure 3.26 and Figure 3.27, respectively, and represent the best and worst miscellaneous energy use model predictions. Despite the assumption of a significant resistance heating load, the miscellaneous energy use for the PNW-1 home has the best comparison to modeled estimations, which indicates that correlation is not causality. The PNW-5 home, however, has consistently lower miscellaneous energy use than assumed in the model; however, the lack of seasonal trends seems to be representative. This is indicative of a poor model and suggests that more refined modeling assumptions are required.

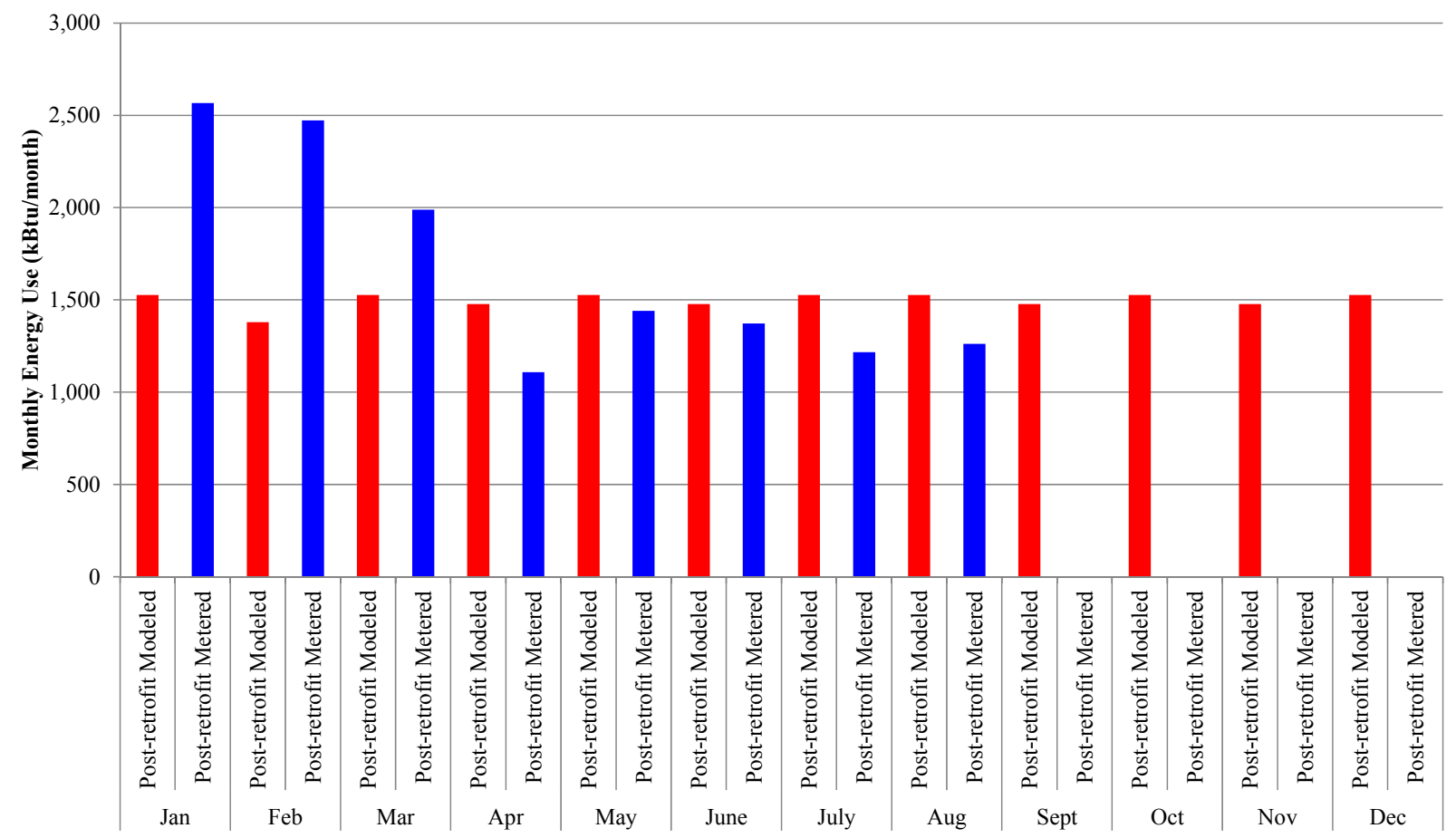

Figure 3.26. Comparison of post-retrofit modeled and metered miscellaneous energy use for the PNW-1 home. 


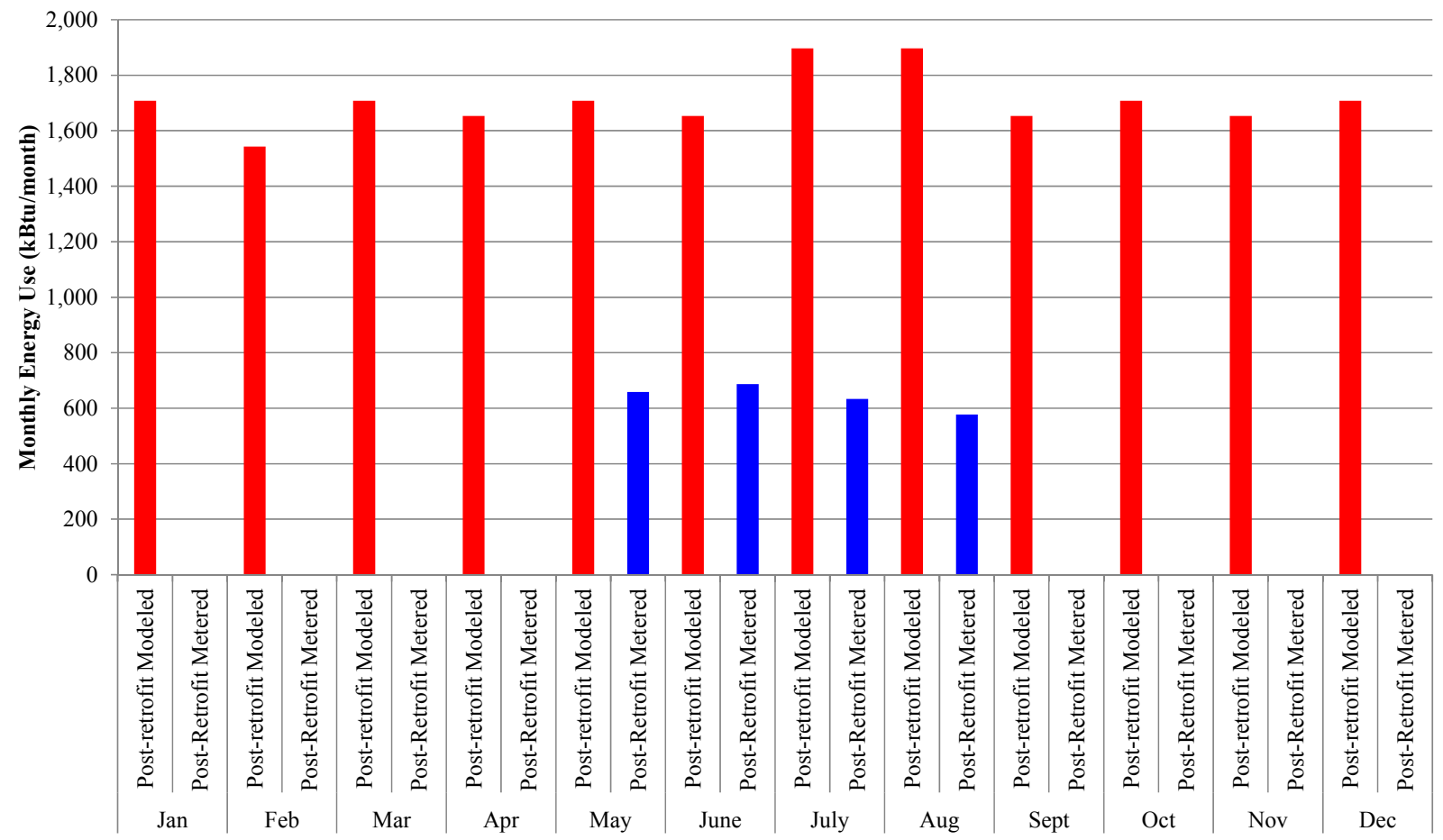

Figure 3.27. Comparison of the post-retrofit modeled and metered miscellaneous energy use for the PNW-5 home.

\subsubsection{Pre-Retrofit Modeled and Monitored Energy Use}

The pre-retrofit modeled and monitored energy use for the PNW-7 home is presented in Figure 3.28, where the model was developed and trued against past utility bills prior to collecting monitoring data. Unfortunately, only one complete month of monitored data is available for comparison and no HVAC monitored data are available. However, as seen, the DHW, dryer, and miscellaneous energy uses are over-estimated in the pre-retrofit model. Although these data are not significant enough for use in truing a model, this result highlights the importance of collecting pre-retrofit data to characterize a home for further work if detailed energy use information is desired. 


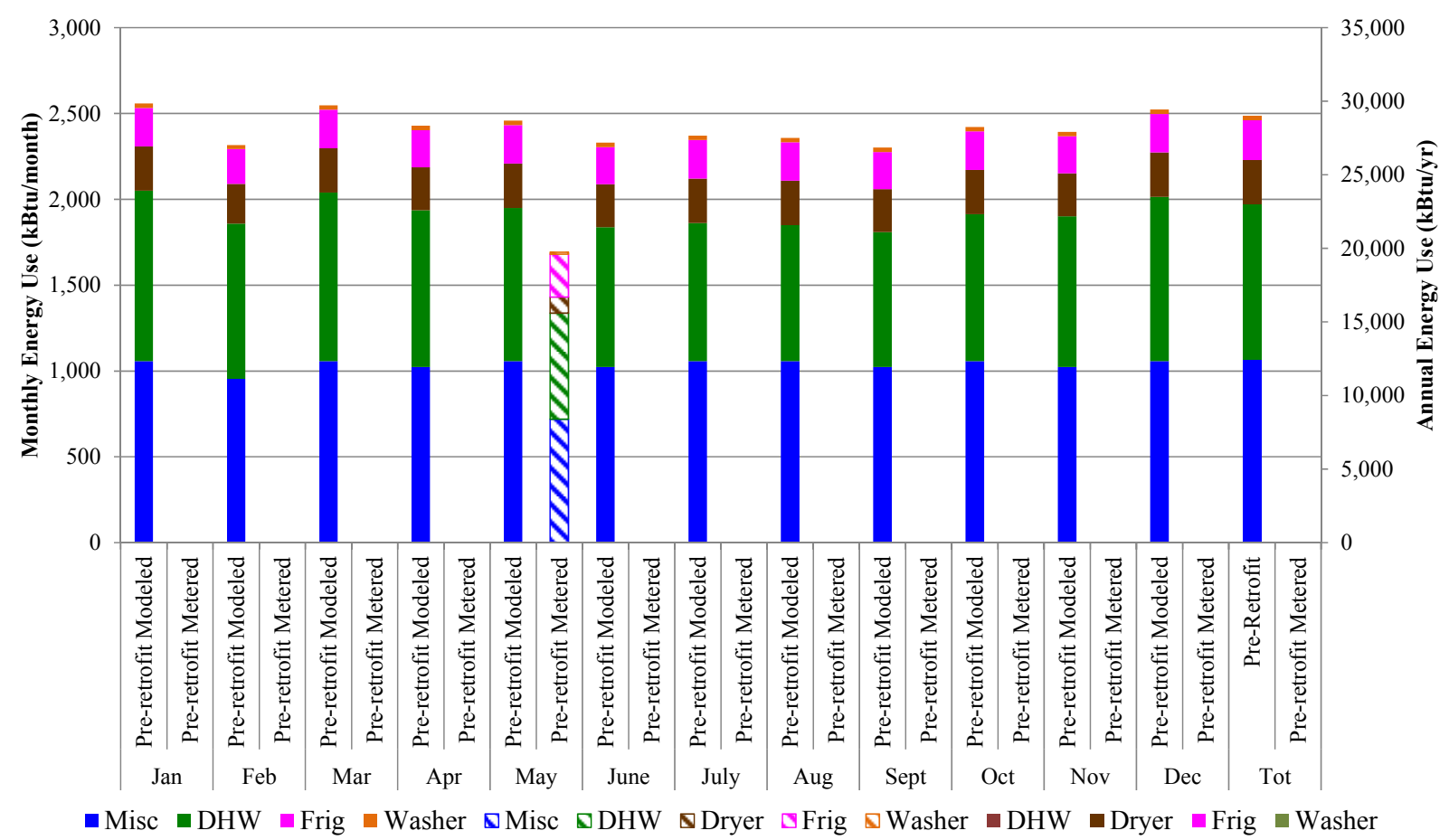

Figure 3.28. Comparison of pre-retrofit modeled and metered disaggregated energy use for the PNW-7 home.

\subsection{End-Use Energy Distribution}

The average end-use energy distribution for the six post-retrofit monitored homes is presented in Figure 3.29 and provides a visual breakdown of how energy is used in each home, on average. The monthly distribution of energy use for each home is presented in Figure 3.30. The miscellaneous energy use cannot be compared directly between homes because it is defined differently for each home depending on how many end-uses were disaggregated. However, the combination of all end-uses except HVAC and DHW can be compared directly.

This distribution of end-uses indicates that HVAC use, as expected, dominates the percentage of energy use in the heating months but dramatically decreases for some homes in the cooling months. The variation of the observed energy use distribution also is important to note, although it is somewhat obvious. For a given month, the distribution of end-uses from home to home can vary dramatically. This is partly the reason for the difficulty associated with predicting energy-use for a dynamic residential home. 


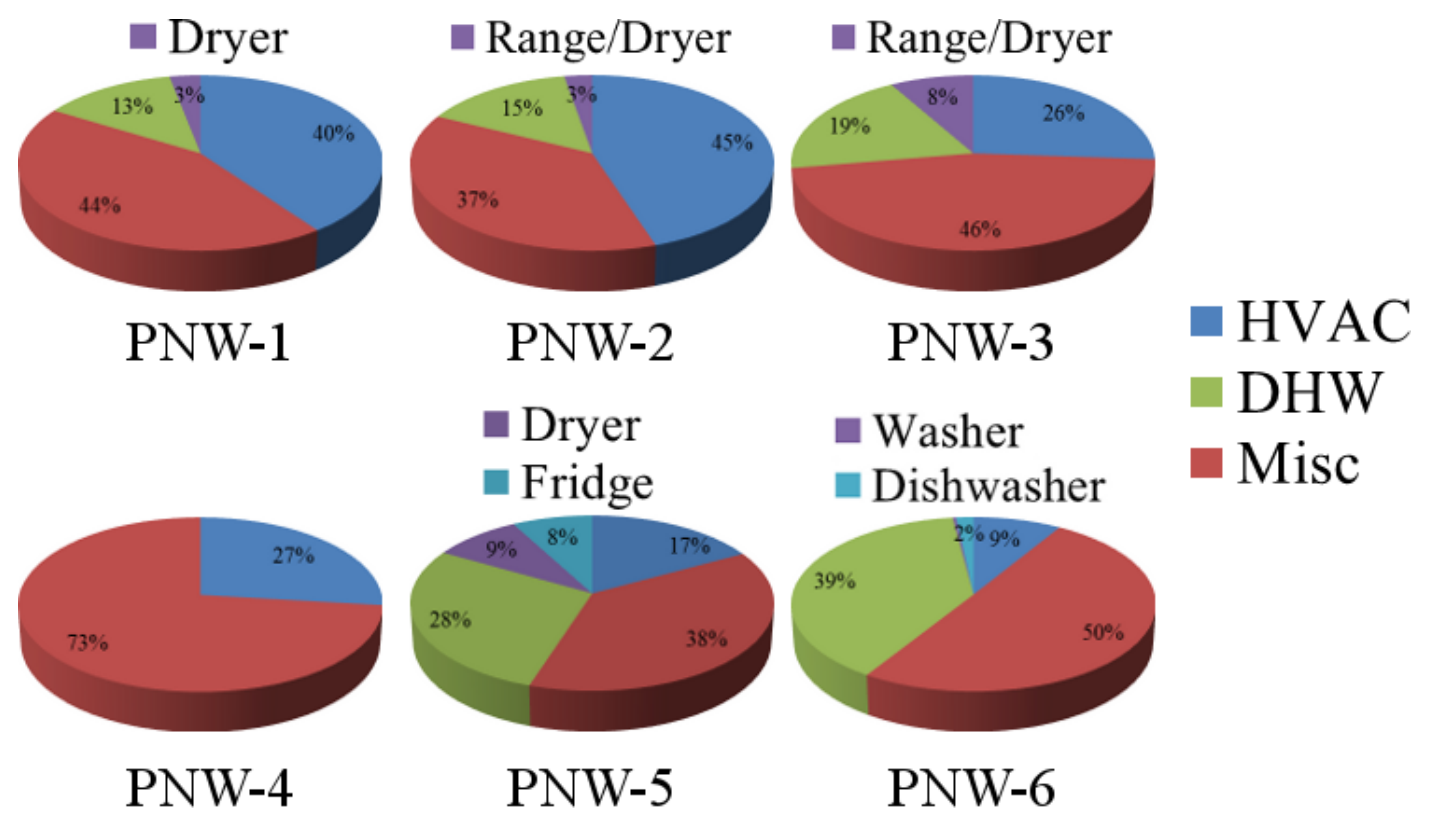

Figure 3.29. Average of monthly end-use distribution for six of the monitored homes. 


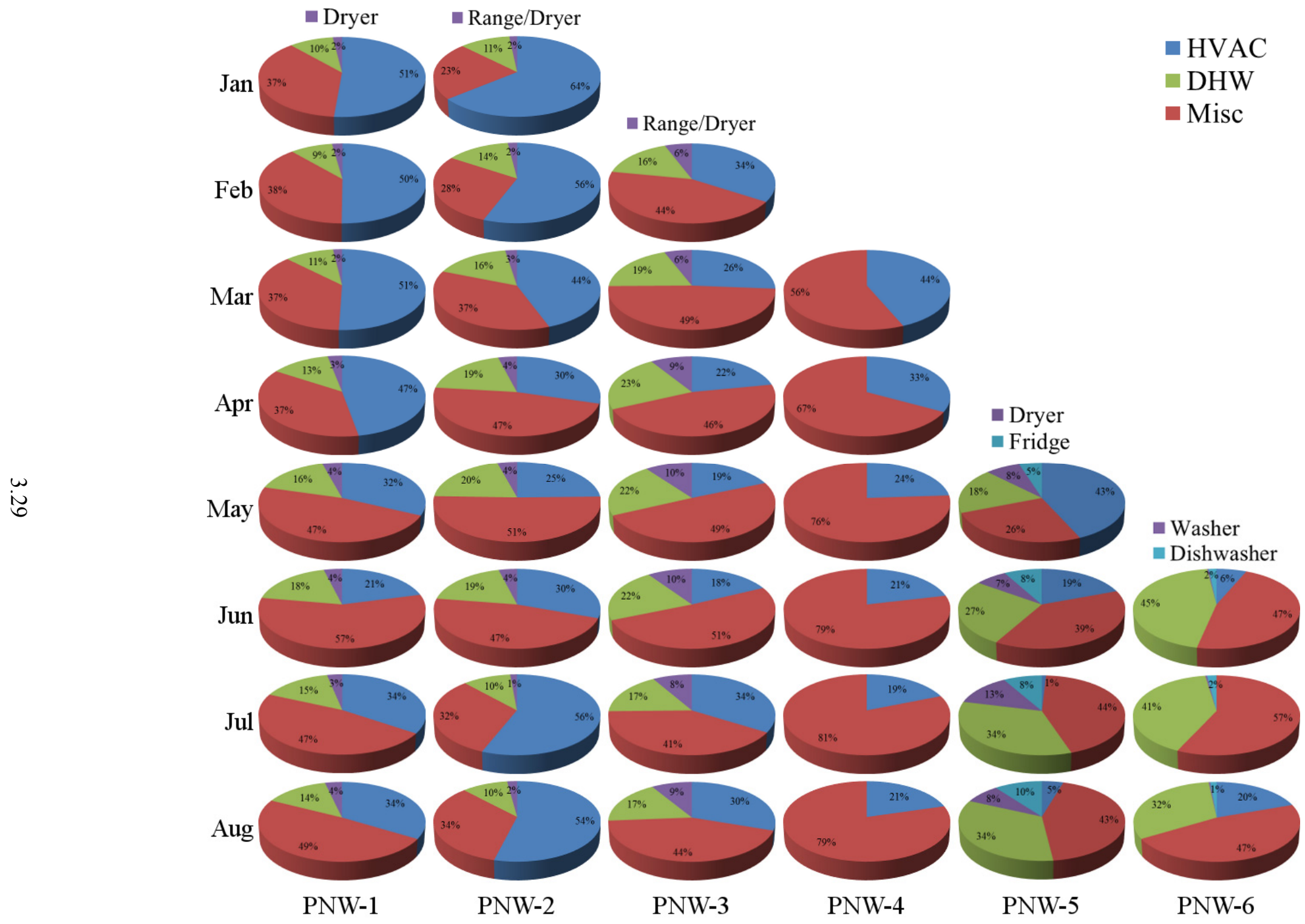

Figure 3.30. Monthly end-use distribution for six of the monitored homes. 


\subsection{Monitoring Insights}

One of the benefits of monitoring disaggregated energy use, rather than relying on utility bills, is that it provides the ability to understand and account for the impact of occupant behavior on home energy use. One such example is shown in Figure 3.31, which presents the daily electricity use for the PNW-1 home. It is evident in mid-April that the homeowners used far less energy than typical; around $20 \mathrm{kBtu} / \mathrm{d}$ compared to the $125 \mathrm{kBtu} / \mathrm{d}$ normally used. It was confirmed with the homeowners that this irregularity occurred when homeowners were on vacation, during which time they turned off the majority of energy consuming equipment in their home. This level of monitoring detail can provide better estimates of typical energy use, where vacation periods can be ignored as outliers and trends of energy use per day can be established. In addition, with this information, homeowners can begin to understand the largest energy users in their home and the best ways to decrease their energy use based on feedback from day-to-day, month-to-month, or annual energy comparisons.

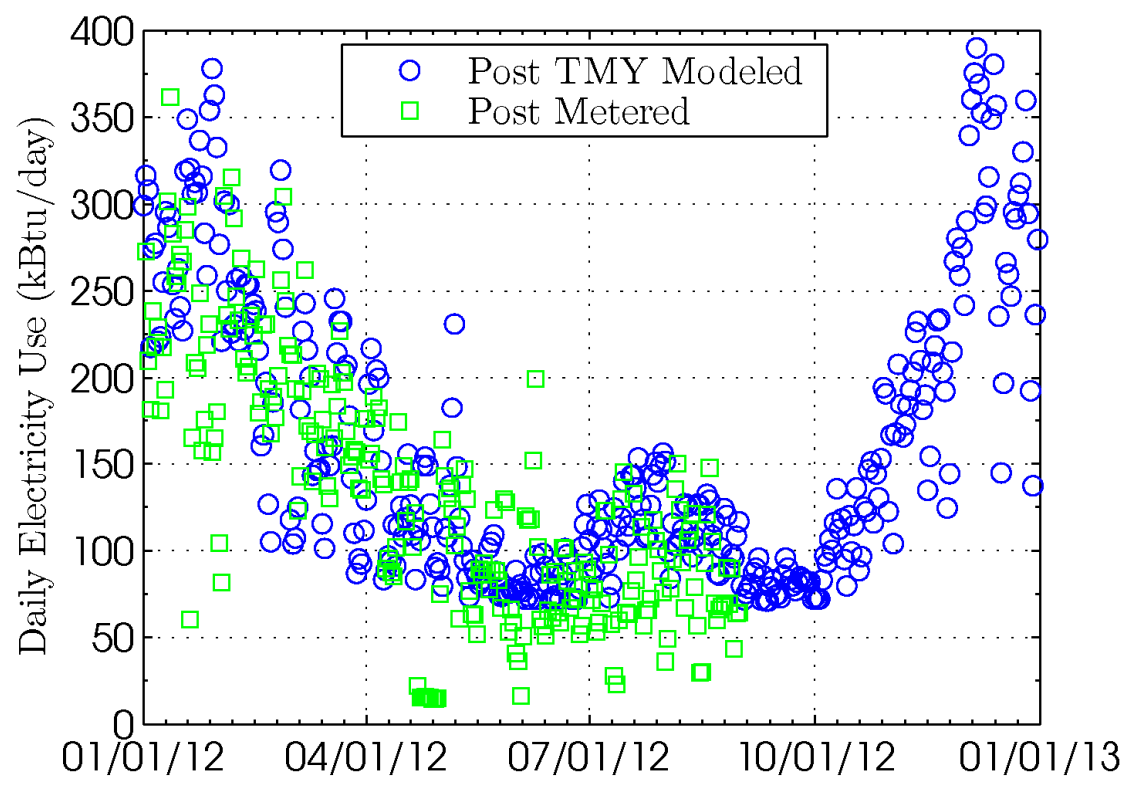

Figure 3.31. Comparison of daily electric use for the PNW-1 home.

Figure 3.32 shows the daily cooling energy and dry bulb temperature for the PNW-4 home where it is clear that some heating is taking place during what would appear (based on input from the homeowner) to be a cooling period. Had utility bills been used to estimate the cooling energy used, this information would have been lost and estimates would be flawed by the gross information provided by utility bills.

Disaggregated energy use information also can be used to diagnose improperly functioning equipment. For example, Figure 3.33 presents the daily AHU energy use for the PNW-4 home, where it was discovered by chance that the homeowner had unknowingly left his AHU on for 26 days straight. During this time, approximately $35,620 \mathrm{Btu}(10.4 \mathrm{kWh})$ were needlessly used, which is around 3.5 times the average AHU energy use in this home. PNNL researchers contacted the homeowner, who corrected the mistake immediately. Having this monitoring information enables homeowners to receive feedback regarding potential inefficiencies and improvements that can be made to their homes, which provides additional opportunities for energy savings. 


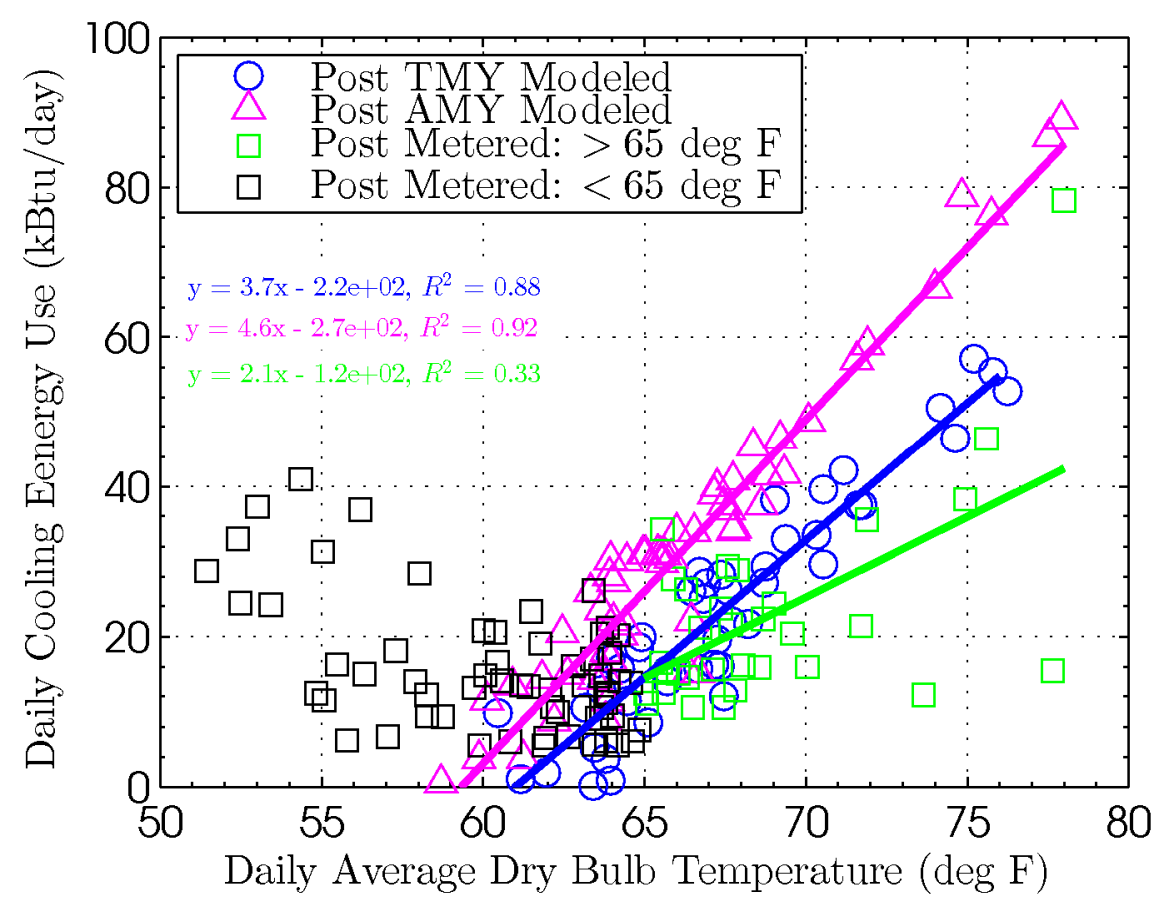

Figure 3.32. Comparison of daily cooling energy use and dry bulb temperature for the PNW-4 home.

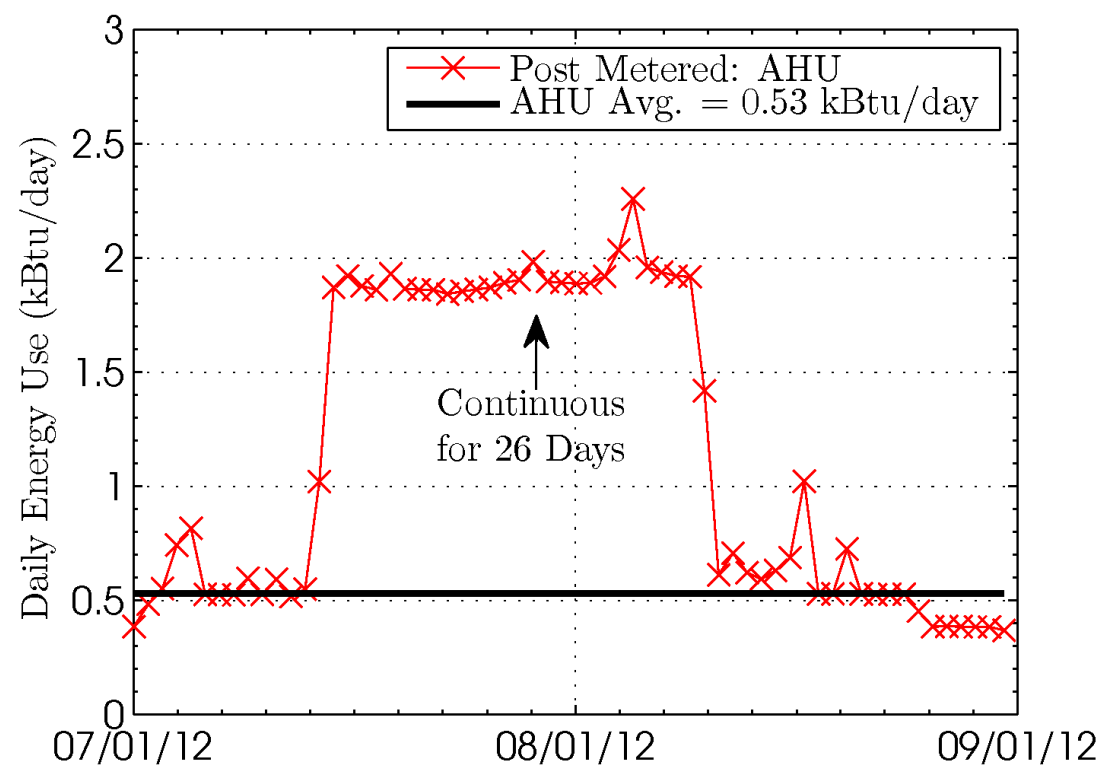

Figure 3.33. Daily air handler unit (AHU) energy use for the PNW-4 home.

\subsection{Indoor Air Quality Assessment}

The purpose of the evaluation is to explore the relationship between IAQ in homes and home tightness or the installation of energy-related retrofit measures in homes. Of concern is the fact that airsealing, installing additional insulation, and other home improvement measures can increase the concentration of hazardous air contaminants in homes, thereby increasing exposure rates for occupants 
and causing unhealthy living situations (Widder and Baechler 2011). Concentrations of PM, TVOCs, $\mathrm{NO}_{\mathrm{x}}, \mathrm{CO}, \mathrm{CO}_{2}, \mathrm{CH}_{2} \mathrm{O}$, and radon were measured for nine homes in the Pacific Northwest. Unfortunately, only three homes had complete data sets from pre- and post-retrofit energy audits and IAQ data at the conclusion of the study period. Some homes did proceed with retrofits while other homes did not complete the retrofits in time for post-retrofit data to be collected and analyzed. Because of the small sample size, it is not possible to make generalized or statistically significant conclusions from the available data. However, these anecdotal results can be helpful in analyzing the effect of retrofits and tighter building envelopes on IAQ in these specific homes.

For all three homes, most concentrations of TVOCs, $\mathrm{CO}, \mathrm{NO}_{\mathrm{x}}$, and $\mathrm{CH}_{2} \mathrm{O}$ were below the detection limit of the measuring device, which indicates they are also below published standard limits. Thus, it is not possible to determine the change in concentrations resulting from retrofits. These results are consistent with previous studies undertaken at Lawrence Berkeley National Laboratory (LBNL) and the New York State Energy Research and Development Authority, which found measured pollutant concentrations in existing homes were well below established standard limits and showed a stronger correlation between pollutant source strength and IAQ than the air-tightness of the house (Nitschke et al. 1985; Berk et al. 1981; Sherman and Dickerhoff 1998; Offermann et al. 1982).

In future experiments, more precise equipment could be used to increase the accuracy, precision, and resolution of these measurements. However, if the concentrations are considerably below minimum exposure limits, it would be important to first consider whether the additional expense to determine accurate concentrations at these low levels was worthwhile. Research suggests there could still be irritant effects and negative health consequences resulting of combinations of chronic exposure to low-level VOCs with additive irritant effects (ACGIH 2005; Wang et al. 2007; Wolkoff et al. 1997; Weschler 2004). Thus, the additional resources and expense associated with more accurate determination of pollutant concentrations in retrofit homes may be justified.

For measured PM concentrations, the difference between pre- and post-retrofit concentrations depended on the retrofit that occurred. Indoor and outdoor PM concentrations for both pre- and postretrofit in all three homes for which complete IAQ data were available are presented in Figure 3.34. In one home, PNW-3, the old, dusty duct system was cleaned, sealed, and replaced. This appeared to improving the PM concentrations, because prior to the retrofit the PM concentrations were higher indoors than outdoors, whereas after the retrofit the PM concentrations indoors and outdoors were the same. In the PNW-4 home, measured PM concentrations indoors were lower than outdoors regardless of the retrofits. This is probably due to the high-efficiency particulate air filter installed in the home (the homeowner has multiple chemical sensitivities). In the PNW-6 home, ventilation was added, which, similar to the PNW-3 home, resulted in concentrations of PM measured indoors that were the same as those measured outdoors. However, in this home the pre-retrofit PM concentration was lower than that measured outdoors, probably because the building shell provided some filtration. 


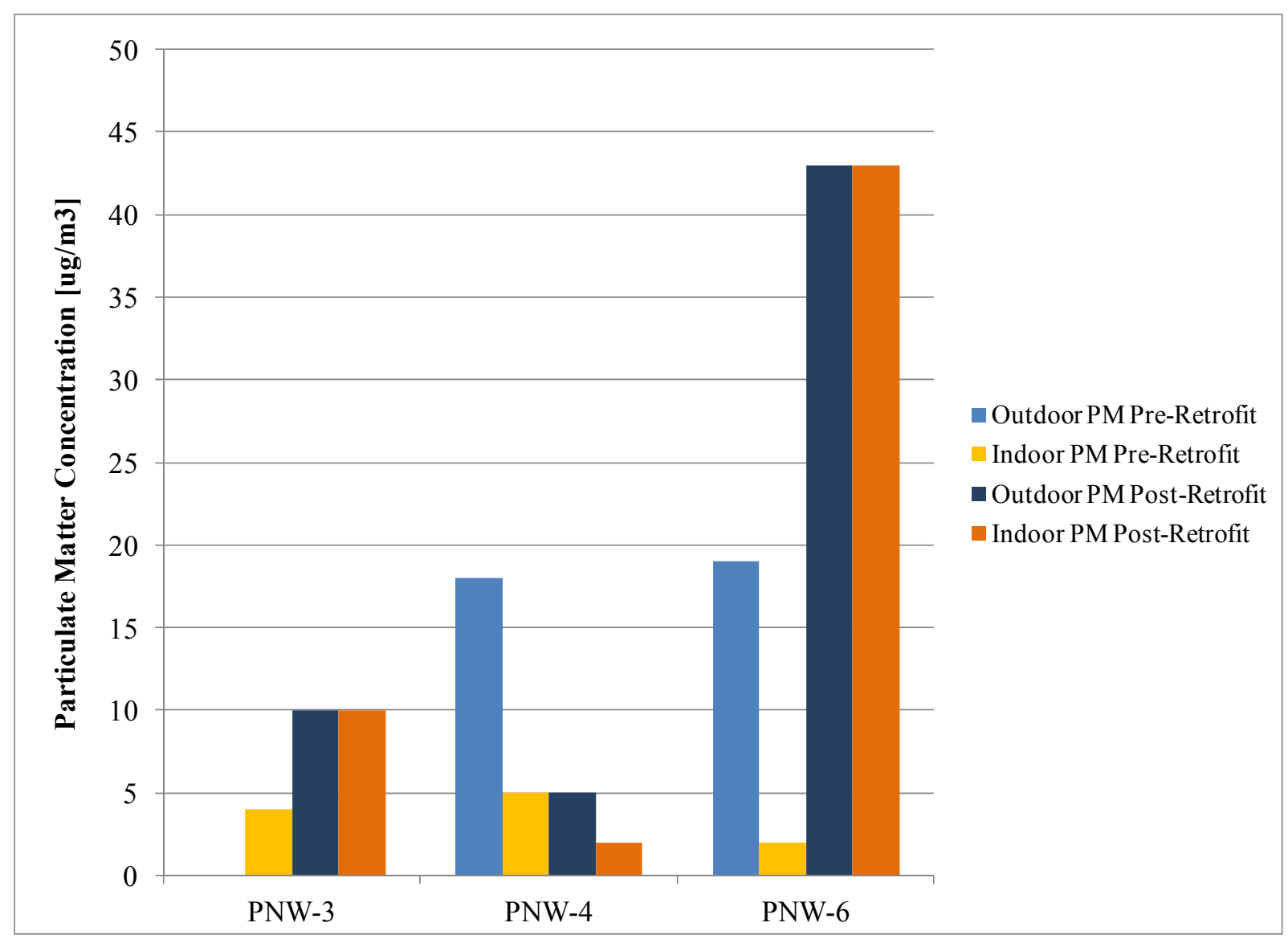

Figure 3.34. Average particulate matter concentrations indoors and outdoors for pre- and post-retrofit in the PNW-3, PNW-4, and PNW-6 homes.

Although the amount and method of providing ventilation air changed in some homes, there were no significant changes in average $\mathrm{CO}_{2}$ concentrations pre- and post-retrofit when the ratios of indoor versus outdoor concentrations were compared. In the PNW-3 and PNW-4 homes, both pre- and post-retrofit measured $\mathrm{CO}_{2}$ concentrations were significantly above outdoor ambient concentrations, as shown in Figure 3.35. This relationship did not change post-retrofit. It is worthwhile noting that the PNW-4 home received significant air sealing and duct sealing, while the PNW-3 home received only duct sealing and no envelope improvements. In the PNW-6 home, where mechanical ventilation was added in the form of a heat recovery ventilator ( $\mathrm{HRV}$ ), average $\mathrm{CO}_{2}$ concentrations appeared to decrease and were equivalent to outdoor concentrations. 


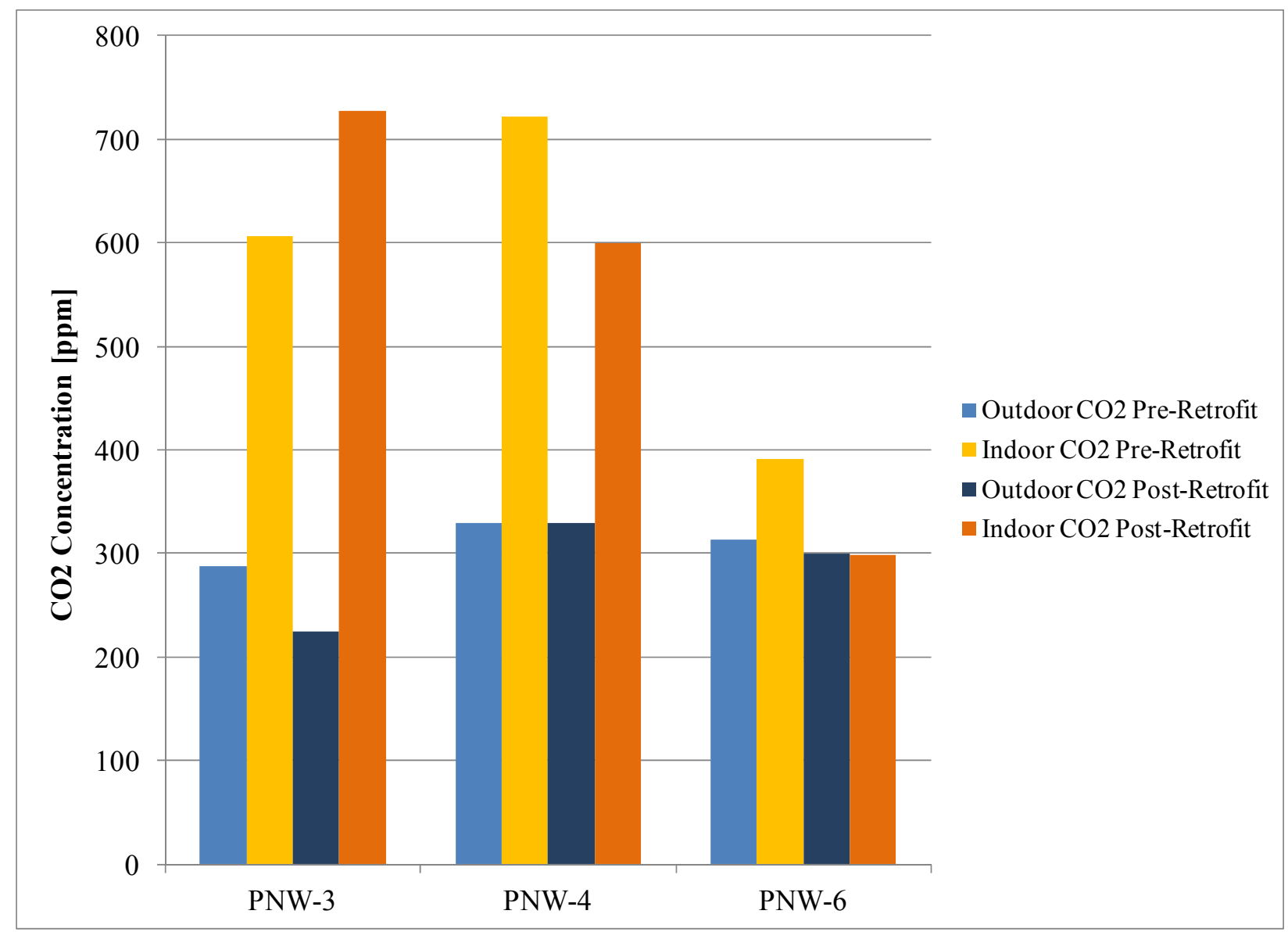

Figure 3.35. Average $\mathrm{CO}_{2}$ concentrations indoors and outdoors for pre- and post-retrofit in the PNW-3, PNW-4, and PNW-6 homes.

Relative humidity increased slightly (relative to outside) in two homes, PNW-3 and PNW-4, as shown in Figure 3.36. Relative humidity in the PNW-6 home was very similar to the outdoor relative humidity both pre- and post-retrofit. This home had significant RH issues associated with an incomplete air barrier on the roof deck. This was causing excessive humidity, condensation, and staining on the eaves. As a primary part of the retrofit, the existing batt insulation was removed from the roof deck in the side attics and spray foam was added to serve as a complete thermal and air barrier, thus reducing the condensation potential on the roof deck and limiting the stack effect. The measured RH in the living area of the home was the same as that measured outside both pre-retrofit and post-retrofit. Because of an equipment malfunction, the RH in the attic was not available at the time of reporting. Analysis of attic $\mathrm{RH}$ levels could yield interesting results related to the effectiveness of the attic retrofit at mitigating the condensation problem. Anecdotal information provided by the homeowner indicated that the second floor of the home is much more comfortable, the relative humidity levels in the attic and side attics seem to be reduced, and no additional staining has been observed. 


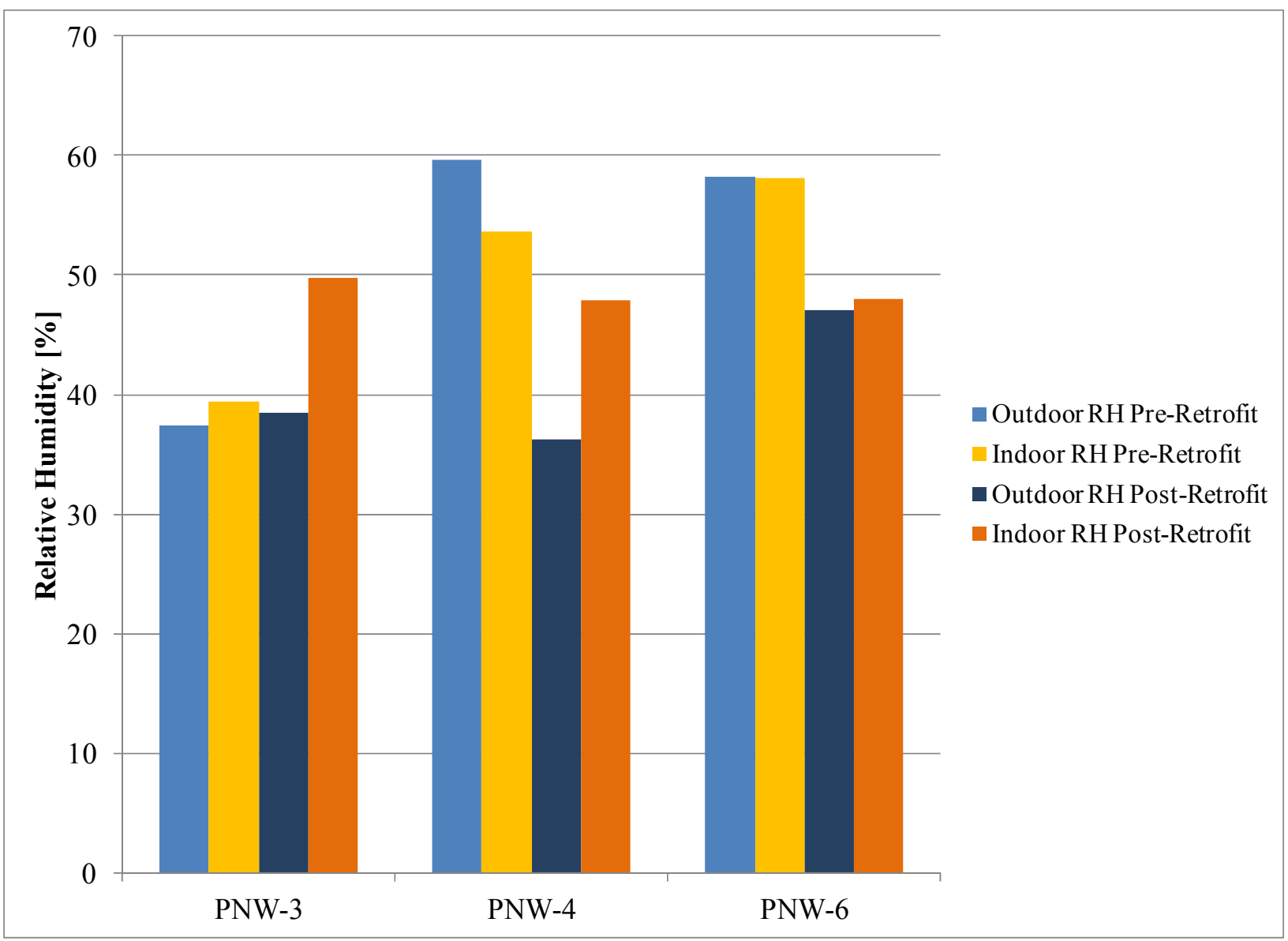

Figure 3.36. Average relative humidity indoors and outdoors for pre- and post-retrofit in the PNW-3, PNW-4, and PNW-6 homes.

Pre- and post-retrofit radon concentrations also were assessed for these three homes to determine if concentrations were below the U.S. Environmental Protection Agency (EPA) action limit of $4 \mathrm{pCi} / \mathrm{L}$ and if there was an observable increase in concentration as a result of retrofit activity (EPA 2009). Average radon concentrations (assessed in the basement of each home) were compared pre- and post-retrofit and are presented in Table 3.1. Outdoor concentrations were not determined. Radon concentrations in the basement of PNW-3 increased slightly, from 0.1 to $0.3 \mathrm{pCi} / \mathrm{L}$. The significance of this concentration increase, or its cause, is not known based on the available data, because this home did not undergo any air sealing measures. In the PNW-4 and PNW-6 homes, which were tightened significantly, 25\% and 31\% respectively, radon concentrations also were seen to increase. Radon concentrations increased approximately 42 and $68 \%$ from pre-retrofit conditions, respectively. For both homes, decreasing the envelope air leakage by $1 \%$ relative to the pre-retrofit condition appeared to increase radon concentrations by $2 \%$. While these two data points are not sufficient to draw strong conclusions, this finding illustrates the concern associated with increasing radon concentrations when homes are tightened as part of a retrofit to achieve more energy efficiency. However, in both these cases, measured pre- and post-retrofit radon concentrations were below the EPA action limit of $4 \mathrm{pCi} / \mathrm{L}$. 
Table 3.1. Average radon concentrations measured in the basement for pre- and post-retrofit in the PNW-3, PNW-4, and PNW-6 homes.

\begin{tabular}{llcccc}
\hline & & Pre-Retrofit & Post-Retrofit & Change & Percent Change \\
\hline \multirow{2}{*}{ PNW-3 } & Air Leakage [cfm50] & 1,763 & 1,763 & 0 & NA \\
& Radon Concentration [pCi/L] & 0.1 & 0.3 & 0.2 & $200 \%$ \\
\multirow{2}{*}{ PNW-4 } & Air Leakage [cfm50] & 3,526 & 2,450 & 1,076 & $31 \%$ \\
& Radon Concentration [pCi/L] & 0.4 & 0.67 & 0.27 & $68 \%$ \\
\multirow{2}{*}{ PNW-6 } & Air Leakage [cfm50] & 4,816 & 3,623 & 1,193 & $25 \%$ \\
& Radon Concentration [pCi/L] & 1.9 & 2.7 & 0.8 & $42 \%$ \\
\hline
\end{tabular}




\subsection{Conclusion}

Seven homes from the Pacific Northwest were selected to evaluate the differences between estimated and actual energy savings achieved from deep energy retrofits. The energy savings resulting from these retrofits were estimated, using energy modeling software, to save at least $30 \%$ on a whole-house basis. After the retrofits were completed, each of the homes was extensively monitored, with the exception of one home that was monitored pre-retrofit. The modeled pre-retrofit energy use was trued against monthly utility bills prior to making retrofit recommendations and modeling post-retrofit energy use.

The pre-retrofit modeled energy use truing process proved to be quite difficult, often requiring unrealistic parameters to be tuned to get modeled results to match data from utility bills. Unfortunately, any discrepancies created during the pre-retrofit modeling propagate into the post-retrofit results, skewing estimated savings. It was especially difficult to match pre-retrofit utility bills and modeled results for the PNW-3, -5 and -6 homes. For example, electricity energy use comparison for the PNW-6 home could not match the base load while simultaneously meeting the cooling load using realistic temperature set-points and assuming base load based on minimum utility bills during shoulder seasons. This broad-based method of using utility bills to estimate heating, cooling, DHW, and miscellaneous loads can produce inaccurate results because of differences in occupant behavior that are not captured by the "typical" occupancy parameters used in the model. Specifically, the miscellaneous loads, which can be quite substantial, are difficult to accurately estimate from monthly utility bills, pointing to a need for better preretrofit energy use analysis methods and cost-effective simple monitoring solutions.

The post-retrofit modeled estimates and the monitored actual energy use were compared and differences were analyzed. Many reasons were found to explain the differences between actual and estimated energy savings. Specific discrepancies and causes for the discrepancies are highlighted, for each home, in Table 4.1. In addition, the homeowners that participated in this study are likely to be more energy conscience and conservative than would be expected of average homeowners given that the retrofits were paid for exclusively by the homeowners. The major causes for discrepancies are listed below:

- Occupant behavior influences energy use, dramatically in some cases.

- Differences between actual and modeled "typical” weather can be significant.

- Modeling inputs can be limited and inflexible, making it difficult to adapt the model for various homeowners.

- Complex homes are difficult to model accurately.

Occupants involved in this study are more likely to conserve energy because they volunteered for this study and paid for the retrofits without non-energy related financial incentives. In general, the models were found to represent average energy use patterns quite well for those homeowners that do not aggressively save or use energy, have an average number of occupants, and do not manipulate their heating and cooling set-points and equipment operation. However, most homes do not fall into this average category, resulting in modeling inaccuracies that are dominated by inaccuracies in the miscellaneous electrical load usage. Unfortunately, attempting to true pre-retrofit energy use models to pre-retrofit utility bills without adequately accounting for non-typical occupancy behavior resulted in 
turning the wrong "knobs" in the model and propagated the error into the post-retrofit energy use model and calculated energy savings.

Table 4.1. Summary of actual and estimated discrepancies, causes and proposed improvements.

\begin{tabular}{|c|c|c|}
\hline $\begin{array}{l}\text { Actual and Estimated } \\
\text { Discrepancies }\end{array}$ & $\begin{array}{l}\text { Cause of } \\
\text { Discrepancy }\end{array}$ & $\begin{array}{l}\text { Proposed } \\
\text { Method for Improvement }\end{array}$ \\
\hline \multicolumn{3}{|c|}{ PNW-1 Home } \\
\hline - Heating under-estimated & $\begin{array}{l}\text { - Occupant behavior and } \\
\text { resistance heating }\end{array}$ & $\begin{array}{l}\text { - Improved occupant model } \\
\text { - Model resistance heating }\end{array}$ \\
\hline - Cooling over-estimated & - Occupant behavior & - Improved occupant model \\
\hline - End-uses under-estimated & - Number and age of occupants & - Improved end-use modeling adjustments \\
\hline - Strip heat over-estimated & - HP does not have strip heat & - Improved model inputs \\
\hline \multicolumn{3}{|c|}{ PNW-2 Home } \\
\hline - Heating over-estimated & - Weather influence & - Use AMY weather model input \\
\hline - Cooling differences & $\begin{array}{l}\text { - Occupant behavior (e.g., } \\
\text { cooling at night) }\end{array}$ & - Improved occupant model \\
\hline - DHW over-estimated & - Occupant number and behavior & - Improved occupant model \\
\hline $\begin{array}{l}\text { - Miscellaneous loads under- } \\
\text { estimated }\end{array}$ & - Occupant number and behavior & $\begin{array}{l}\text { - Better understand miscellaneous loads } \\
\text { - Improved occupant model }\end{array}$ \\
\hline \multicolumn{3}{|c|}{ PNW-3 Home } \\
\hline - Heating over-estimated & - Difficult home to model & - Improved modeling approach \\
\hline - Cooling over-estimated & - Difficult home to model & - Improved modeling approach \\
\hline $\begin{array}{l}\text { - Miscellaneous loads under- } \\
\text { estimated }\end{array}$ & $\begin{array}{l}\text { - Occupant behavior } \\
\text { - Resistance heating }\end{array}$ & $\begin{array}{l}\text { - Improved occupant model } \\
\text { - Model resistance heating }\end{array}$ \\
\hline $\begin{array}{l}\text { - Heating dominated by strip } \\
\text { heat }\end{array}$ & - Difficult home to model & - Model warnings for unrealistic situations \\
\hline \multicolumn{3}{|c|}{ PNW-4 Home } \\
\hline - Heating under-estimated & $\begin{array}{l}\text { - Weather influence } \\
\text { - Added equipment }\end{array}$ & $\begin{array}{l}\text { - Use AMY weather model input } \\
\text { - Improved modeling approach }\end{array}$ \\
\hline - Cooling misrepresented & $\begin{array}{l}\text { - Poor modeling inputs } \\
\text { - Occupant behavior }\end{array}$ & $\begin{array}{l}\text { - Improved modeling approach } \\
\text { - Improved occupant model }\end{array}$ \\
\hline \multicolumn{3}{|c|}{ PNW-5 Home } \\
\hline - Heating under-estimated & $\begin{array}{l}\text { - Weather influence } \\
\text { - Occupant behavior }\end{array}$ & - Use AMY weather model input \\
\hline - Cooling over-estimated & - Occupant behavior & - Improved occupant model \\
\hline $\begin{array}{l}\text { - Miscellaneous loads over- } \\
\text { estimated }\end{array}$ & - Occupant behavior & $\begin{array}{l}\text { - Improved occupant model } \\
\text { - Understand miscellaneous loads }\end{array}$ \\
\hline - Appliances over-estimated & - Occupant number and behavior & - Improved occupant model \\
\hline \multicolumn{3}{|c|}{ PNW-6 Home } \\
\hline - Heating misrepresented & - Poor pre-retrofit model & - Improved modeling approach \\
\hline - Cooling over-estimated & - Occupant behavior & - Improved occupant model \\
\hline $\begin{array}{l}\text { - Miscellaneous loads over- } \\
\text { estimated }\end{array}$ & - Occupant behavior & - Improved occupant model \\
\hline
\end{tabular}


The difference between monthly whole-house actual and estimated energy savings ranged from $75 \%$ more energy saved than predicted by the model to $16 \%$ less energy saved for all the monitored homes. Similarly, the annual energy savings difference was between $36 \%$ and $-14 \%$, which was estimated based on existing monitored savings because an entire year's worth of data is not available. Further, the monthly post-retrofit energy use for specific end-uses (i.e., HVAC, DHW, dryer, etc.) ranged from 131\% under-predicted to $77 \%$ over-predicted.

On average, for all six monitored homes (see Figure 3.2) the actual energy use is consistently less than estimates, indicating that homeowners are saving more energy than estimated. The average actual savings for the 8 -month monitoring period was $43 \%$, compared to an estimated savings average of $31 \%$, an error of $26 \%$ between the actual and estimated savings values. Despite the variance observed, this work provides much better comparisons than other simulated energy results when effort is not taken to account for occupant behavior or specific home characteristics, where differences often are factors of two or more (Lancaster et al. 2012). This level of accuracy also agrees with previous studies which that have found agreement of simulated energy savings within $\pm 25 \%$ when homes and occupants are wellcharacterized.

Although it is advantageous that homeowners are saving more energy (and money) than anticipated, if more accurate estimates were provided, these homeowners might have chosen to perform additional retrofits to achieve additional savings and better cost paybacks. This discrepancy between actual and estimated energy use indicates a need for better modeling tools and assumptions. Despite the best efforts of researchers, the estimated energy savings are too inaccurate to determine reliable paybacks for retrofit projects. While the monitored data allows researchers to understand why these differences exist, it is not cost-effective to monitor each home with the level of detail presented here. Therefore, an appropriate balance between modeling and monitoring must be determined that is widely applicable for national retrofit programs and the home performance industry. 


\subsection{Recommendations and Future Work}

This work identified the differences between actual and estimated energy savings resulting from retrofits that were estimated to save $30 \%$ or more on a whole-house basis. A number of discrepancies were found between actual and estimated energy savings, including pre-retrofit energy use tuning difficulties, occupant behavior, and modeling limitations. As a result, the following recommendations are provided to address these deficiencies and provide better tools and approaches for estimating energy savings from retrofits.

Improve the tuning process. Standardized and consistent processes and approaches are needed to create more accurate estimates of pre-retrofit energy use and improved tuning of pre-retrofit models. The tuning process using monthly energy bills can be quite inaccurate for estimating disaggregated (i.e., HVAC, DHW, miscellaneous, etc.) loads that are needed to generate an accurate pre-retrofit energy use model. Considering that retrofits affect specific end-uses and the savings associated with those end-uses, estimating energy use from end-uses that are to be retrofit becomes especially important. For example, a process that requires multiple years of utility bills, which can be averaged, to provide a more accurate estimate could be considered. In addition, a streamlined process for developing a correlation between $\mathrm{HDD} / \mathrm{CDD}$ and utility bills may provide better heating and cooling estimates.

Develop simple occupant-based energy models. Often energy models are quite accurate at predicting the heat load and energy use of weather-affected HVAC equipment and the building shell under normal occupancy patterns; however, when occupant behavior dominates energy use, the model accuracy decreases substantially. The inaccuracy introduced by occupancy can also affect the accuracy of the building-related energy use, if models are inappropriately trued to match utility bills. Occupants have a significant impact on energy use, and simple models are needed to accurately estimate energy use for different occupant types. Also, model inputs that are easy to understand and represent occupant habits, such as number of dishwasher loads per week or hours of TV watched per week, could help improve behavior-based miscellaneous electrical load use, which is a substantial source of model inaccuracy. In particular, many of the homeowners observed in this study were far more energy conscience and conservative that would be expected from average homeowners. While this may play a large role in the discrepancies observed, it further indicates models are needed to account for conservative, average and liberal energy users alike.

Incorporate actual weather inputs. HVAC energy use can vary substantially from year to year based on weather changes. Currently, it is difficult to correct for actual weather with energy models because they use typical (or average) weather inputs. The modeling results can be post-processed to account for weather variations but this is a time-consuming process. Simple models that can incorporate actual weather data easily are needed to provide more accurate estimates of HVAC energy use. This capability also would improve the tuning process where modeling results can be compared to utility bills using the actual weather that occurred during the billing period.

In addition, this work found significant increases in cooling energy use when modeling using AMY weather data. The reasons for this unrealistic increase in energy use were assumed to be a result of solar insolation inputs but could not be investigated completely in this study. It is recommended that further investigation regarding the influence of AMY weather data on cooling energy be considered. 
Develop simple, cost-effective monitoring solutions for improved tuning. While it is not possible to monitor every home in great detail, simple and cost-effective monitoring solutions should be developed that provide data for improved tuning of pre-retrofit models. Specifically, simple solutions that can provide insight into homeowners' miscellaneous energy use would be especially useful as a modeling input. 


\subsection{References}

American Conference of Governmental Industrial Hygienists (ACGIH). 2005. Threshold Limit Values for Chemical Substances and Physical Agents and Biological Exposure Indices. Cincinnati, Ohio.

AEC (Architectural Energy Corporation). 2010. REM/Rate. Software Version 12.96, Boulder, Colorado. Accessed September 2012 at: http://www.archenergy.com/products/remrate.

Akerlof K, R Debono, P Berry, A Leiserowitz, C Roser-Renouf, KL Clarke, A Rogaeva, MC Nisbet, MR Weathers, and EW Maibach. 2010. "Public Perceptions of Climate Change as a Human Health Risk: Surveys of the United States, Canada, and Malta." International Journal of Environmental Research and Public Health 7:2559-606.

BEDB (Buildings Energy Data Book). 2012. The Buildings Energy Data Book. Table 2.2.1. Accessed September 2012 at: http://buildingsdatabook.eren.doe.gov/TableView.aspx?table=2.2.1.

Berk JV, RA Young, SR Brown, and CD Hollowell. 1981. Impact of Energy-Conserving Retrofits on Indoor Air Quality in Residential Housing. LBL-12189, Lawrence Berkeley National Laboratory, Berkeley, California.

Blasnik M. 2006. Ohio Electric Partnership Program Impact Evaluation. Prepared for the Ohio Office of Energy Efficiency, Michael Blasnik and Associates, Boston, Massachusetts

Blasnik M. 2007. New Hampshire Weatherization Program Impact Evaluation Report. Prepared for the New Hampshire Office of Energy and Planning, Michael Blasnik and Associates, Boston, Massachusetts.

Chandra S, S Widder, G Parker, S Sande, J Blanchard, D Stroer, J McIlvaine, D Chasar, D Beal, and K Sutherland. 2012. Pilot Residential Deep Energy Retrofits and the PNNL Lab Homes. PNNL-21116, Pacific Northwest National Laboratory, Richland, Washington.

EIA (Energy Information Administration). 2010. July 2010 Monthly Energy Review: Energy Consumption by Sector. DOE/EIA-0035, EIA, U.S. Department of Energy, Washington, D.C. Accessed September 2012 at: http://www.eia.gov/FTPROOT/multifuel/mer/00351007.pdf.

EPA (U.S. Environmental Protection Agency). 2009. “A Citizen's Guide to Radon.” IE Division (ed.), Washington D.C. Available at: http://www.epa.gov/radon/pubs/citguide.html.

FSEC (Florida Solar Energy Center). 2011. EnergyGauge USA. Software Version 2.8.05, Cocoa, Florida. Accessed September 2012 at: http://energygauge.com/usares/default.htm.

Lancaster R, L Lutzenhiser, M Moezzi, S Widder, and S Chandra. 2012. Post-Retrofit Residential Assessments. PNNL-21362. Pacific Northwest National Laboratory, Richland, Washington.

Nitschke IA, GW Traynor, JB Wadach, ME Clarkin, and WA Clarke. 1985. Indoor Air Quality, Infiltration and Ventilation in Residential Buildings. New York Energy Research and Development Authority, Niagra Mohawk Power Corporation, Syracuse, New York. 
NREL (National Renewable Energy Laboratory). 2010. BeOpt. Software Version 1.1, Golden, Colorado. Accessed September 2012 at https://beopt.nrel.gov/home.

Parker D, E Mills, L Rainer, N Bourassa, and G Homan. 2012. Accuracy of the Home Energy Saver Energy Calculation Methodology. Proceedings of the ACEEE Summer Study on Buildings. American Council for an Energy-Efficient Economy, Pacific Grove, California.

Polly B, N Kruis, and D Roberts. 2011. Assessing and Improving the Accuracy of Energy Analysis for Residential Buildings. U.S. Department of Energy, Building America Program, Washington D.C.

Offermann FJ, CD Hollowell, WW Nazaroff, GD Roseme, and JR Rizzuto. 1982. "Low-Infiltration Housing in Rochester, New York: A Study of Air-Exchange Rates and Indoor Air Quality." Environment International 8:435-45.

Schweitzer M. 2005. Estimating the National Effects of the U.S. Department of Energy's Weatherization Assistance Program with State-Level Data: A Metaevaluation Using Studies from 1993 to 2005. ORNL/CON-493, Oak Ridge National Laboratory, Oak Ridge, Tennessee.

Sherman M and D. Dickerhoff. 1998. Air-Tightness of U.S. Dwellings. LBL-35700, Lawrence Berkeley National Laboratory, Berkeley, California.

U.S. Census Bureau. 2011. "New Residential Construction Chart.” Accessed September 2012 at: http://www.census.gov/briefrm/esbr/www/esbr020.html.

Wang S, HM Ang, and MO Tade. 2007. "Volatile organic compounds in indoor environment and photocatalytic oxidation: state of the art." Environment International 33:694-705.

Weschler CJ. 2004. "Chemical reactions among indoor pollutants: what we've learned in the new millennium." Indoor Air 14 Suppl 7:184-94.

Widder SH and MC Baechler. 2011. Potential Health and Safety Effects of Residential Energy Retrofits - An Overview of the Literature. PNNL-20231, Pacific Northwest National Laboratory; Richland, Washington.

Wilcox S and W Marion. 2008. User's Manual for TMY3 Data Sets. NREL/TP-581-43156, National Renewable Energy Laboratory, Golden, Colorado. Accessed September 2012 at: http://rredc.nrel.gov/ solar/old_data/nsrdb/1991-2005/tmy3/.

Wolkoff P, PA Clausen, B Jensen, GD Nielsen, and CK Wilkins. 1997. "Are we measuring the relevant indoor pollutants." Indoor Air 7:92-106. 


\section{Appendix A}

\section{Metering Installation Details}




\section{Appendix A}

\section{Metering Installation Details}

\section{A.1 PNW-1 Home}

Table A.1. PNW-1 eGauge energy meter channel configuration

\begin{tabular}{|c|c|c|c|c|c|}
\hline $\mathrm{CT}$ & $\begin{array}{c}\text { CT } \\
\text { Rating }\end{array}$ & $\begin{array}{l}\text { Circuit } \\
\text { Rating }\end{array}$ & $\begin{array}{c}\text { Circuit } \\
\text { Number }\end{array}$ & $\begin{array}{c}\text { Line } \\
\text { Number } \\
(1 \text { or } 2)\end{array}$ & Description \\
\hline 1 & 150 & 200 & NA & 2 & Whole house, B phase \\
\hline 2 & 150 & 200 & NA & 1 & Whole house, A phase \\
\hline 3 & 50 & 90 & $17,21,29$ & 1 & \multirow{2}{*}{ Bath Heater / range / 240V irrigation pump } \\
\hline 4 & 50 & 90 & $15,19,27$ & 2 & \\
\hline 5 & 30 & 30 & 30 & 1 & \multirow{2}{*}{ Heat Pump } \\
\hline 6 & 30 & 30 & 28 & 2 & \\
\hline 7 & 20 & 20 & 22 & 1 & \multirow{2}{*}{ DHW } \\
\hline 8 & 20 & 20 & 20 & 2 & \\
\hline 9 & 30 & 30 & 18 & 1 & \multirow{2}{*}{ Dryer } \\
\hline 10 & 30 & 30 & 16 & 2 & \\
\hline 11 & 30 & 40 & 10 & 1 & Basement stairwell lights and outlets / upstairs lights \\
\hline 12 & 30 & 40 & 12 & 2 & Main floor lights / studio outlets \\
\hline
\end{tabular}

Table A.2. PNW-1 other metering devices

\begin{tabular}{ccc}
\hline Device Type & Device Name & Location \\
\hline Hobo U10-003 T/RH & STUDIO & Studio \\
Hobo U10-003 T/RH & BASEMENT & Basement \\
Hobo U10-003 T/RH & KIT & Kitchen \\
Hobo U10-003 T/RH & ENTRY & Front door entry \\
Hobo U10-003 T/RH & MASTER.BR & Master BR \\
Hobo U9-001 State & FURN & Boiler $^{(a)}$ \\
\hline (a) & Boiler does not have a pre or post purge. No boiler \\
\multicolumn{3}{c}{ capacity rating available. } \\
\hline
\end{tabular}




\section{A.2 PNW-2 Home}

Table A.3. PNW-2 eGauge energy meter channel configuration.

\begin{tabular}{|c|c|c|c|c|c|}
\hline $\mathrm{CT}$ & $\begin{array}{r}\text { CT } \\
\text { Rating }\end{array}$ & $\begin{array}{l}\text { Circuit } \\
\text { Rating }\end{array}$ & $\begin{array}{c}\text { Circuit } \\
\text { Number }\end{array}$ & $\begin{array}{c}\text { Line } \\
\text { Number } \\
\text { (1 or } 2) \\
\end{array}$ & Description \\
\hline 1 & 150 & 200 & NA & 1 & \multirow{2}{*}{ Whole house } \\
\hline 2 & 150 & 200 & NA & 2 & \\
\hline 3 & 70 & 80 & 2,6 & 1 & \multirow{2}{*}{ AHU fan and strip heat (indoor AHU) } \\
\hline 4 & 70 & 80 & 4,8 & 2 & \\
\hline 5 & 50 & 40 & 14 & 1 & \multirow{2}{*}{ Heat pump compressor (outdoor unit) } \\
\hline 6 & 50 & 40 & 16 & 2 & \\
\hline 7 & 30 & 30 & 22 & 1 & \multirow{2}{*}{ DHW } \\
\hline 8 & 30 & 30 & 24 & 2 & \\
\hline 9 & 50 & 80 & 10,18 & 1 & \multirow{2}{*}{ Range / dryer } \\
\hline 10 & 50 & 80 & 12,20 & 2 & \\
\hline 11 & 20 & 30 & 11,15 & 2 & Living room and kit lights / bath lights and outlets \\
\hline 12 & 20 & 30 & 13,17 & 1 & Bedroom lights and outlets / family and living room outlets \\
\hline
\end{tabular}

Table A.4. PNW-2 other metering devices.

\begin{tabular}{ccc}
\hline Device Type & Device Name & Location \\
\hline Hobo U10-003 T/RH & MASTER.BR & Master Bedroom \\
Hobo U10-003 T/RH & BASEMENT & Basement \\
Hobo U10-003 T/RH & SUNROOM & Sun room \\
Hobo U10-003 T/RH & LR & Living room \\
\hline
\end{tabular}




\section{A.3 PNW-3 Home}

Table A.5. PNW-3 eGauge energy meter channel configuration.

\begin{tabular}{|c|c|c|c|c|c|}
\hline $\mathrm{CT}$ & $\begin{array}{c}\text { CT } \\
\text { Rating }\end{array}$ & $\begin{array}{l}\text { Circuit } \\
\text { Rating }\end{array}$ & $\begin{array}{l}\text { Circuit } \\
\text { Number }\end{array}$ & $\begin{array}{l}\text { Line } \\
\text { Number } \\
(1 \text { or } 2)\end{array}$ & Description \\
\hline 1 & 150 & 200 & NA & 1 & \multirow{2}{*}{ Whole house } \\
\hline 2 & 150 & 200 & NA & 2 & \\
\hline 3 & 50 & 40 & Sub 2 & 1 & \multirow{2}{*}{ HP compressor / outdoor fan / new panel } \\
\hline 4 & 50 & 40 & Sub 4 & 2 & \\
\hline 5 & 100 & 80 & $8,9,19$ & 1 & \multirow{2}{*}{ Strip heat / Fan AHU } \\
\hline 6 & 100 & 80 & $10,21,22$ & 2 & \\
\hline 7 & 100 & 80 & 1,3 & 1 & \multirow{2}{*}{ Range / dryer } \\
\hline 8 & 100 & 80 & 2,4 & 2 & \\
\hline 9 & 30 & 30 & 23,24 & 1 & \multirow{2}{*}{ DHW } \\
\hline 10 & 30 & 30 & 25,26 & 2 & \\
\hline 11 & 30 & 35 & 15,16 & 1 & $\begin{array}{c}\text { Basement bath lights / garage outlets / LR KIT DR lights outlets / } \\
\text { LR TV / Micro }\end{array}$ \\
\hline 12 & 30 & 35 & $14,17,18$ & 2 & Kitchen outlets / refrigerator / upstairs baths outlets \\
\hline
\end{tabular}

Table A.6. PNW-3 other metering devices.

\begin{tabular}{ccc}
\hline Device Type & Device Name & Location \\
\hline Hobo U10-003 T/RH & GAR & Garage \\
Hobo U10-003 T/RH & BASE & Basement \\
Hobo U10-003 T/RH & LR & Living room \\
Hobo U10-003 T/RH & MBR & Master \\
Hobo U10-003 T/RH & 2NDBR & 2nd bedroom \\
\hline
\end{tabular}




\section{A.4 PNW-4 Home}

Table A.7. PNW-4 eGauge energy meter channel configuration.

\begin{tabular}{|c|c|c|c|c|c|}
\hline CT & $\begin{array}{c}\text { CT } \\
\text { Rating }\end{array}$ & $\begin{array}{l}\text { Circuit } \\
\text { Rating }\end{array}$ & $\begin{array}{l}\text { Circuit } \\
\text { Number }\end{array}$ & $\begin{array}{l}\text { Line } \\
\text { Number } \\
(1 \text { or } 2)\end{array}$ & Description \\
\hline 1 & 150 & 200 & NA & 1 & \multirow{2}{*}{ Whole house } \\
\hline 2 & 150 & 200 & NA & 2 & \\
\hline 3 & 50 & 60 & 1 & 1 & \multirow{2}{*}{ Strip heat } \\
\hline 4 & 50 & 60 & 3 & 2 & \\
\hline 5 & 20 & 20 & 5 & 1 & \multirow{2}{*}{ Mini split } \\
\hline 6 & 20 & 20 & 7 & 2 & \\
\hline 7 & 100 & 90 & 2 & 1 & \multirow{2}{*}{$\begin{array}{l}\text { Sub-panel (feeds smaller panel in mud room, adjacent to } \\
\text { kitchen) }\end{array}$} \\
\hline 8 & 100 & 90 & 4 & 2 & \\
\hline 9 & 50 & 40 & 6 & 1 & \multirow{2}{*}{ HP outside unit } \\
\hline 10 & 50 & 40 & 8 & 2 & \\
\hline
\end{tabular}

Table A.8. PNW-4 other metering devices.

\begin{tabular}{cccc}
\hline Device Type & Device Name & Location & Notes \\
\hline $\begin{array}{c}\text { Madgetech } \\
\text { RHTemp101A }\end{array}$ & OFF & Office & SN N70848 \\
Madgetech & SR & Sun room & SN N70849 \\
RHTemp101A & & & \\
Madgetech & BASE & Basement & SN N70846 \\
RHTemp101A & MB & Master BR & SN N70847 \\
Madgetech & RHTemp101A & &
\end{tabular}




\section{A.5 PNW-5 Home}

Table A.9. PNW-5 eGauge energy meter channel configuration.

\begin{tabular}{cccccc}
\hline CT & $\begin{array}{c}\text { CT } \\
\text { Rating }\end{array}$ & $\begin{array}{c}\text { Circuit } \\
\text { Rating }\end{array}$ & $\begin{array}{c}\text { Circuit } \\
\text { Number }\end{array}$ & $\begin{array}{c}\text { Line } \\
\text { Number } \\
(1 \text { or } 2)\end{array}$ & Description \\
\hline 1 & 100 & 100 & NA & 2 & Whole house \\
2 & 100 & 100 & NA & 1 & Dryer \\
3 & 30 & 30 & 20 & 1 & Frig \\
4 & 30 & 30 & 18 & 2 & Washer \\
5 & 20 & 20 & 11 & 1 & Kitchen lights \\
6 & 20 & 20 & 5 & 2 & Dining room lights \\
7 & 20 & 15 & 12 & 1 & Living room lights \\
8 & 20 & 20 & 1 & 2 & Bedroom lights \\
9 & 20 & 15 & 6 & 2 & Unknown / unknown / attic lights \\
10 & 20 & 20 & 7 & 1 & Attic outlets / unknown \\
11 & 30 & 45 & $4 / 8 / 16$ & 1 & \\
\hline 12 & 30 & 30 & $2 / 10$ & 2 &
\end{tabular}

Table A.10. PNW-5 other metering devices.

\begin{tabular}{|c|c|c|c|}
\hline Device Type & Device Name & Location & Notes \\
\hline Madgetech RHTemp101A & BASE & Basement & On wall next to switch \\
\hline Madgetech RHTemp101A & DL & Dining room & Above built-in cabinet \\
\hline Madgetech RHTemp101A & MB & Maser BR & Homeowners' room, over door \\
\hline Madgetech RHTemp101A & $2 \mathrm{ND}$ & 2nd floor (attic) & On post \\
\hline Madgetech State101A & FURN & $\begin{array}{l}\text { 2nd floor closet, } \\
\text { next to furn. }\end{array}$ & $1 \mathrm{sec}$. interval \\
\hline Madgetech Pulse101A & $\mathrm{H} 2 \mathrm{O}$ & $\begin{array}{l}\text { DHW water flow } \\
\text { meter, inside unit }\end{array}$ & Pulse output flow meter, 6 sec. interval \\
\hline Madgetech TC101A & TRET & Make-up water line & Type T thermocouple (TC), 6 sec. interval \\
\hline Madgetech Volt101A & DHWG & $\begin{array}{l}\text { DHW gas flow, } \\
\text { inside unit }\end{array}$ & Proportional valve, $3 \mathrm{sec}$. interval \\
\hline Madgetech TC101A & TSUP & $\begin{array}{l}\text { Supply line, inside } \\
\text { unit }\end{array}$ & Type T TC, 6 sec interval \\
\hline Madgetech Pulse101A & $\mathrm{AC}$ & Basement panel & Multiplier: $0.001,5 \mathrm{~min}$. interval \\
\hline Madgetech Pulse101A & GASM & Gas meter, outside & Pulse output, 9 sec. interval \\
\hline
\end{tabular}




\section{A.6 PNW-6 Home}

Table A.11. PNW-6 eGauge energy meter channel configuration.

\begin{tabular}{cccccc}
\hline CT & $\begin{array}{c}\text { CT } \\
\text { Rating }\end{array}$ & $\begin{array}{c}\text { Circuit } \\
\text { Rating }\end{array}$ & Circuit Number & $\begin{array}{c}\text { Line } \\
\text { Number } \\
(1 \text { or } 2)\end{array}$ & Description \\
\hline 1 & 150 & 200 & NA & 1 & Whole house \\
2 & 150 & 200 & NA & 2 & A/C \\
3 & 30 & 30 & 5 & 1 & Many lights and outlets / dryer / range \\
4 & 30 & 30 & 7 & 2 & Disposal / dishwasher \\
5 & 70 & 105 & $13 \mathrm{a}, \mathrm{b}, 1 \mathrm{a}, 1 \mathrm{~b}$ & 1 & Washer \\
6 & 70 & 105 & $3 \mathrm{~b}, 3 \mathrm{a}, 11 \mathrm{a}, 15 \mathrm{~b}$ & 2 & Kitchen lights and under counter lighting / cooktop, \\
7 & 20 & 20 & $2 \mathrm{~b}$ & 1 & kitchen outlets and refrigerator \\
8 & 20 & 20 & $20 \mathrm{~b}$ & 2 & Master BR lights, upstairs bath, 2nd floor lights and \\
outlets / sunroom computer outlet
\end{tabular}

Table A.12. PNW-6 other metering devices.

\begin{tabular}{cccc}
\hline Device Type & Device Name & Location & Notes \\
\hline Madgetech RHTemp101A & BASE & Basement & Next to switch, foot of stairs \\
Madgetech RHTemp101A & MB & Master BR & Moved to attic on 8/13/12 \\
Madgetech RHTemp101A & 1ST & 1st floor & Dining room above shelves \\
Madgetech RHTemp101A & TV & TV room & Above door \\
Madgetech RHTemp101A & ATTIC & Attic & On post \\
Madgetech RHTemp101A & BR & Child's room & West side wall \\
Madgetech State101A & FURN & Furnace & 1 sec., SN: N75238 \\
Madgetech Pulse101A & GASM & Outside gas meter & 9 sec, SN: N74819 \\
Madgetech Pulse101A & H2O & DHW H2O Flow & 6 sec, SN: N74821 \\
Madgetech Volt101A & DHWG & DHW Gas Valve & 3 sec, SN: N74821 \\
Madgetech State101A & PUMP & DHW Pump State & 1 sec, SN: N75239 \\
Madgetech TC101A & TRET & DHW Ret. Temp. & 6 sec, SN: N76764 \\
Madgetech TC101A & TSUP & DHW. Sup. Temp. & 6 sec, SN: N76765 \\
\hline
\end{tabular}




\section{A.7 PNW-7 Home}

Table A.13. PNW-7 eGauge energy meter channel configuration.

\begin{tabular}{cccccc}
\hline CT & $\begin{array}{c}\text { CT } \\
\text { Rating }\end{array}$ & $\begin{array}{c}\text { Circuit } \\
\text { Rating }\end{array}$ & $\begin{array}{c}\text { Circuit } \\
\text { Number }\end{array}$ & $\begin{array}{c}\text { Line } \\
\text { Number } \\
(1 \text { or } 2)\end{array}$ & Description \\
\hline 1 & 150 & 200 & NA & 1 & Whole house \\
2 & 150 & 200 & NA & 2 & DHW \\
3 & 30 & 40 & 2 & 1 & Dryer \\
4 & 30 & 40 & 4 & 2 & Micro/kitchen outlets / main floor outlets \\
5 & 30 & 30 & 6 & 1 & Basement BR / lights / outlets w/ fridge \\
6 & 30 & 30 & 8 & 2 & 2nd floor lights \\
7 & 30 & 40 & 15,23 & 2 & Master BR lights and outlets \\
8 & 30 & 55 & $16,20,24$ & 2 & Fridge, disposal \\
9 & 20 & 20 & 10 & 1 & Washer \\
10 & 20 & 20 & 12 & 2 & 1 \\
11 & 20 & 20 & 14 & 1 & \\
12 & 20 & 20 & 13 & 1 & \\
\hline
\end{tabular}

Table A.14. PNW-7 other metering devices.

\begin{tabular}{cccc}
\hline Device Type & Device Name & Location & Notes \\
\hline $\begin{array}{c}\text { Madgetech } \\
\text { RHTemp101A }\end{array}$ & KIT & Kitchen & Under cabinet \\
$\begin{array}{c}\text { Madgetech } \\
\text { RHTemp101A }\end{array}$ & 2ND & 2nd floor & Hallway \\
$\begin{array}{c}\text { Madgetech } \\
\text { RHTemp101A }\end{array}$ & BASE & Basement & Central wall \\
$\begin{array}{c}\text { Madgetech } \\
\text { RHTemp101A }\end{array}$ & LR & Living room & South wall \\
Madgetech State101A & FURN & Furnace & $\begin{array}{c}\text { Inside unit, on blower fan } \\
\text { No pre or post fan purge }\end{array}$ \\
\hline
\end{tabular}


Appendix B

\section{Pre-Retrofit Truing Details}




\section{Appendix B}

\section{Pre-Retrofit Truing Details}

\section{B.1 PNW-1 Home}

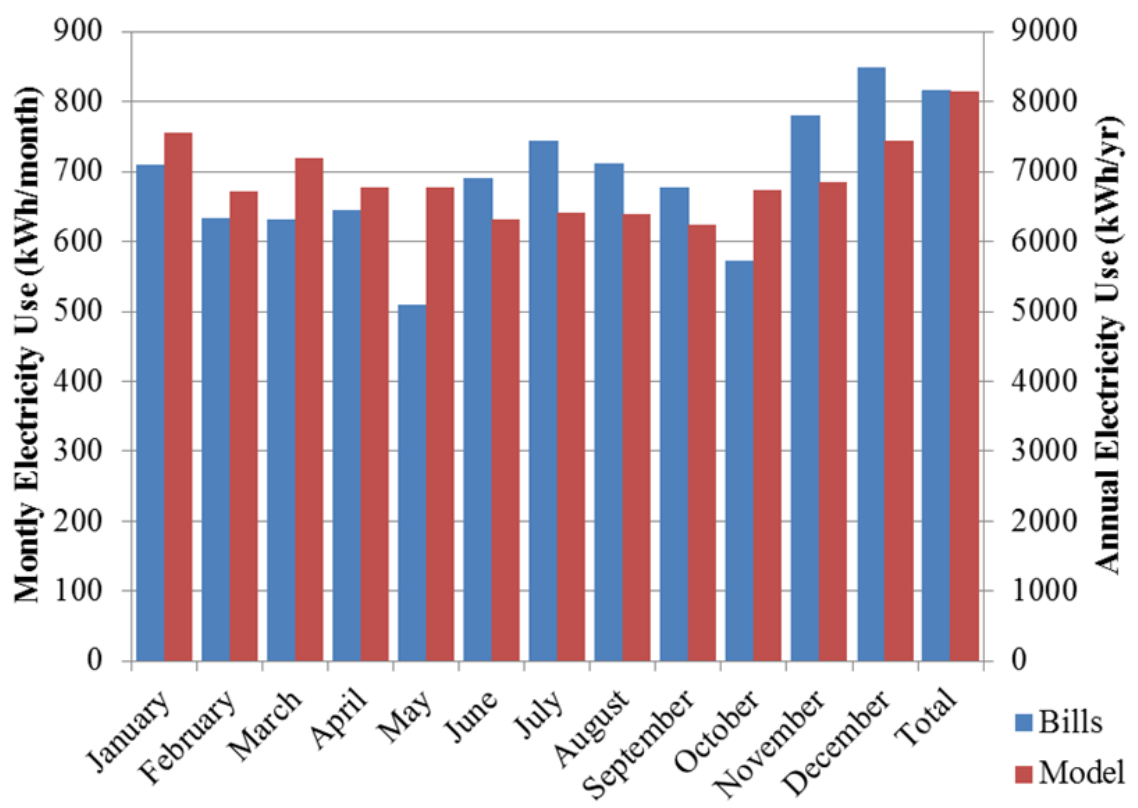

Figure B.1. PNW-1 pre-retrofit modeled and utility bill monthly and annual electricity use comparison.

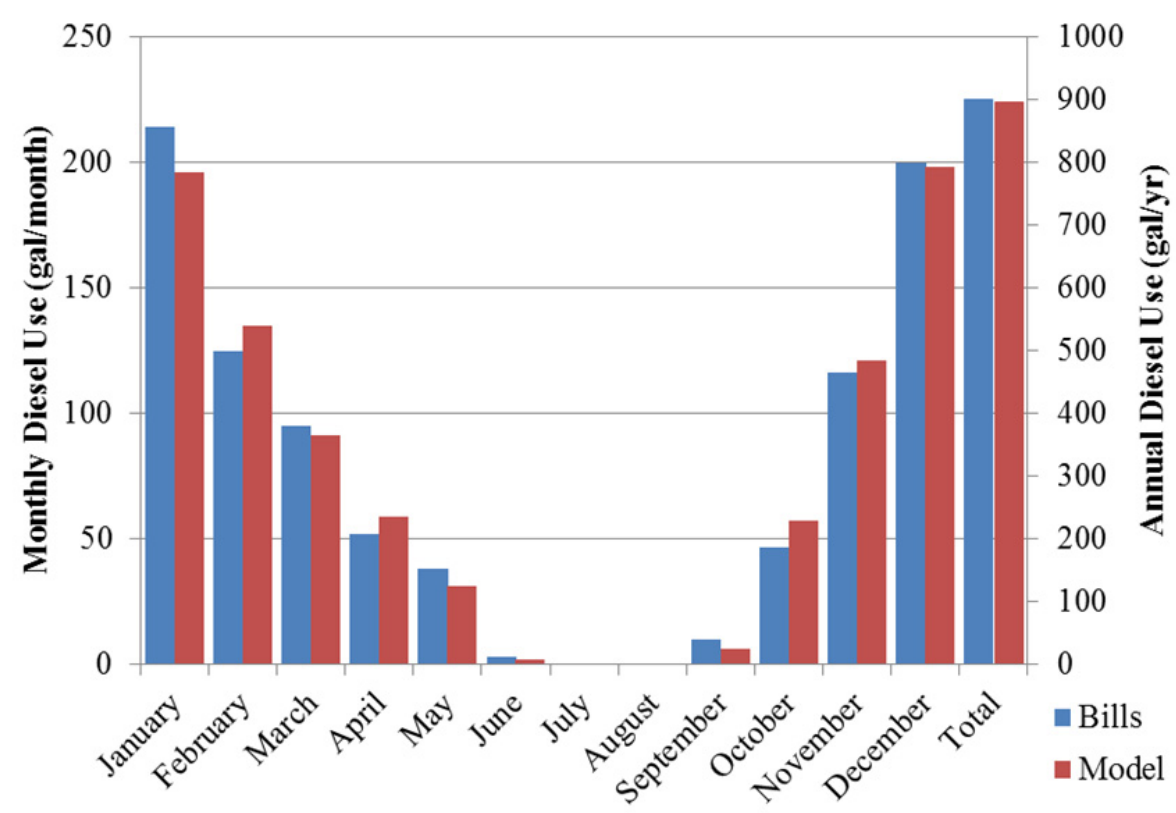

Figure B.2. PNW-1 pre-retrofit modeled and utility bill monthly and annual diesel use comparison. 


\section{B.2 PNW-2 Home}

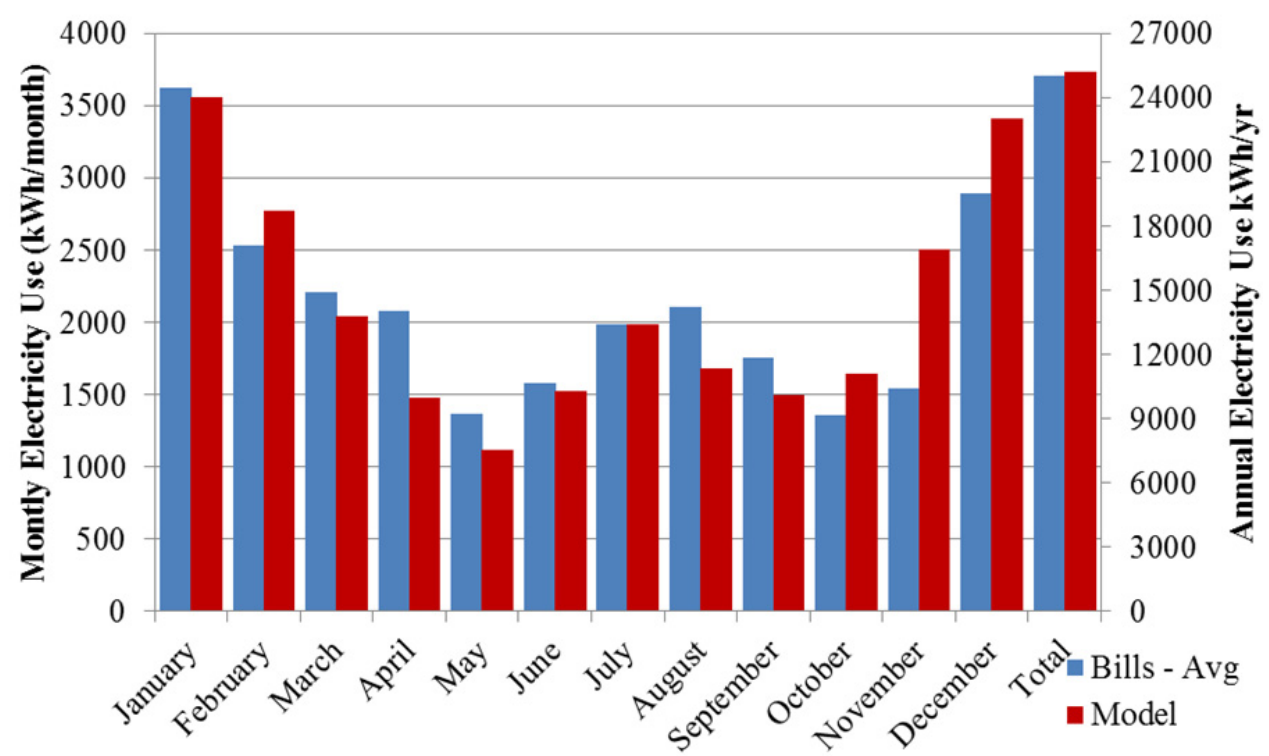

Figure B.3. PNW-2 pre-retrofit modeled and utility bill monthly and annual electricity use comparison.

\section{B.3 PNW-3 Home}

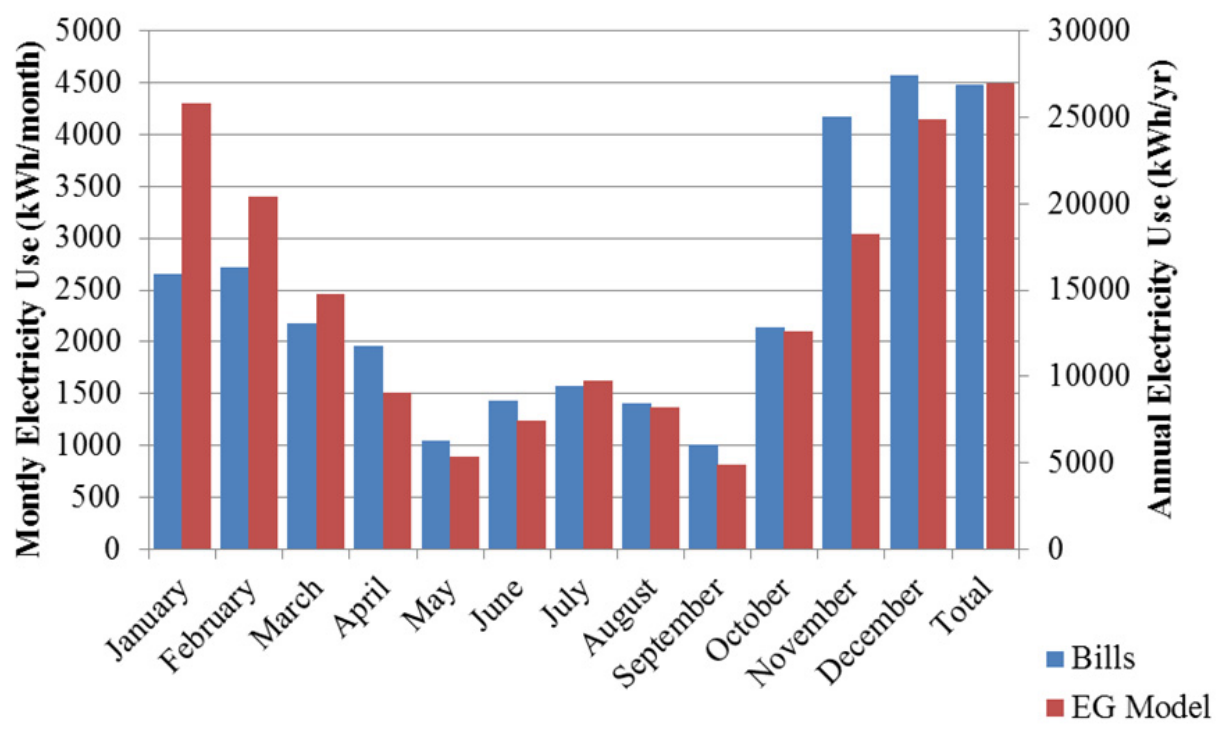

Figure B.4. PNW-3 pre-retrofit modeled and utility bill monthly and annual electricity use comparison. 


\section{B.4 PNW-4 Home}

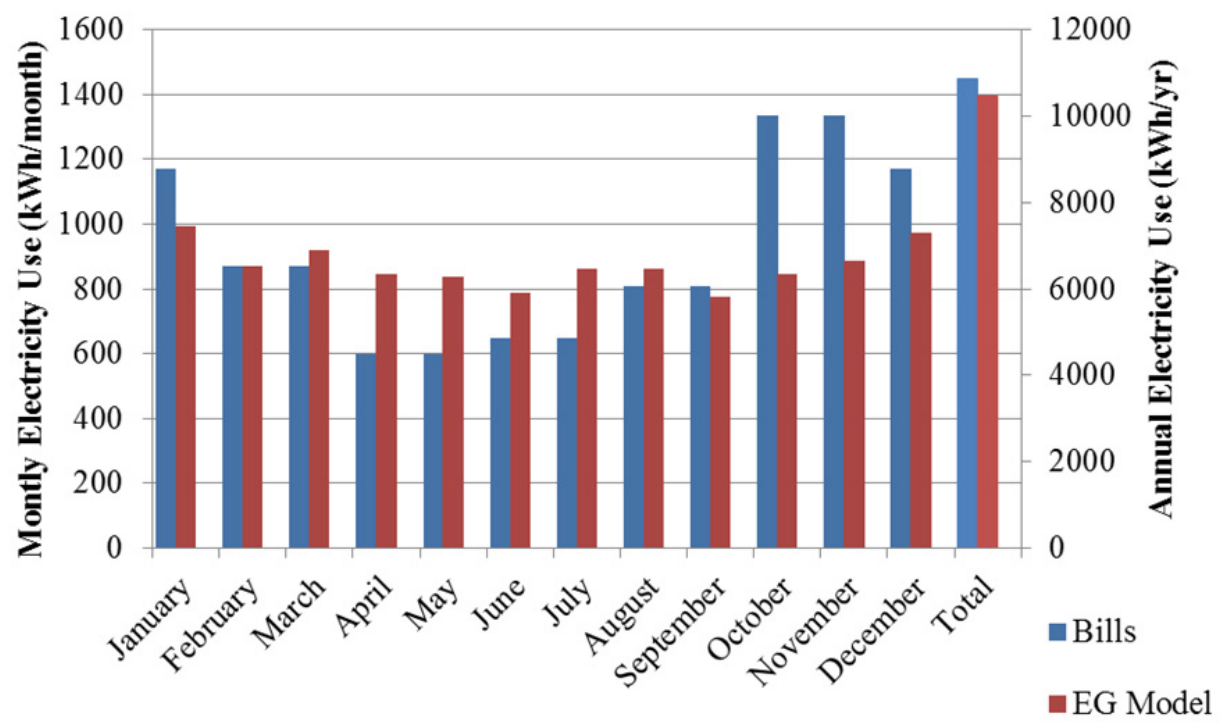

Figure B.5. PNW-4 pre-retrofit modeled and utility bill monthly and annual electricity use comparison.

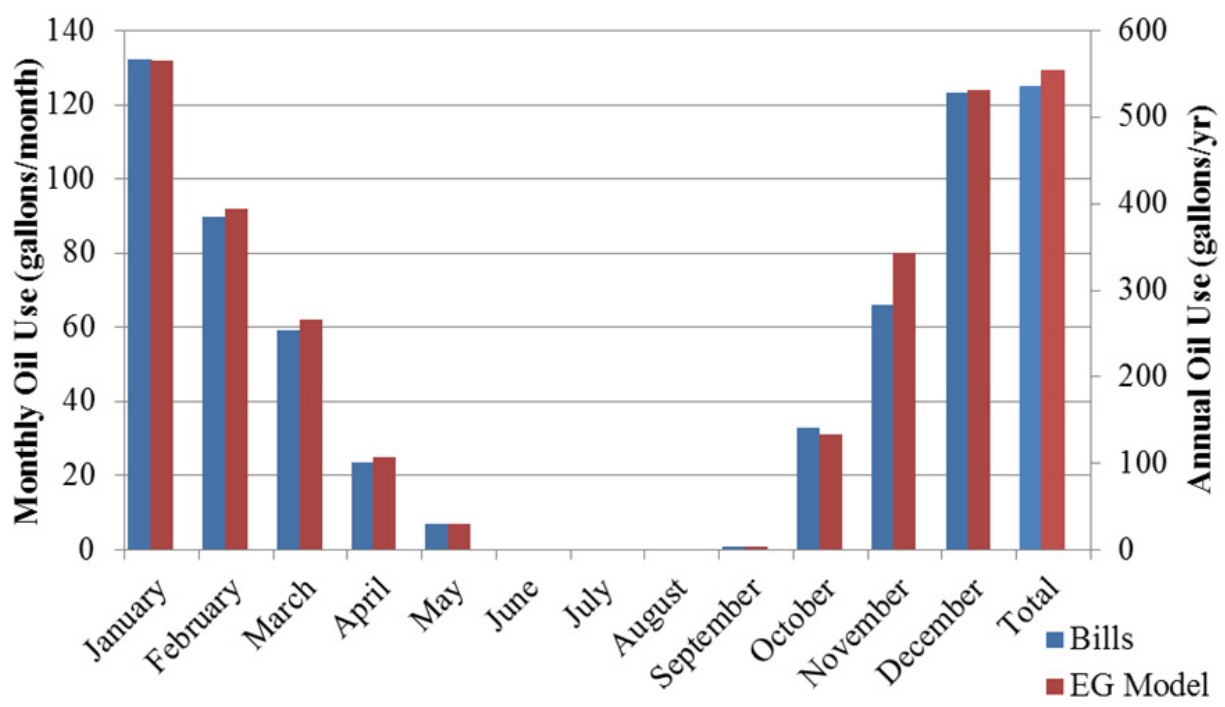

Figure B.6. PNW-4 pre-retrofit modeled and utility bill monthly and annual fuel oil use comparison. 


\section{B.5 PNW-5 Home}

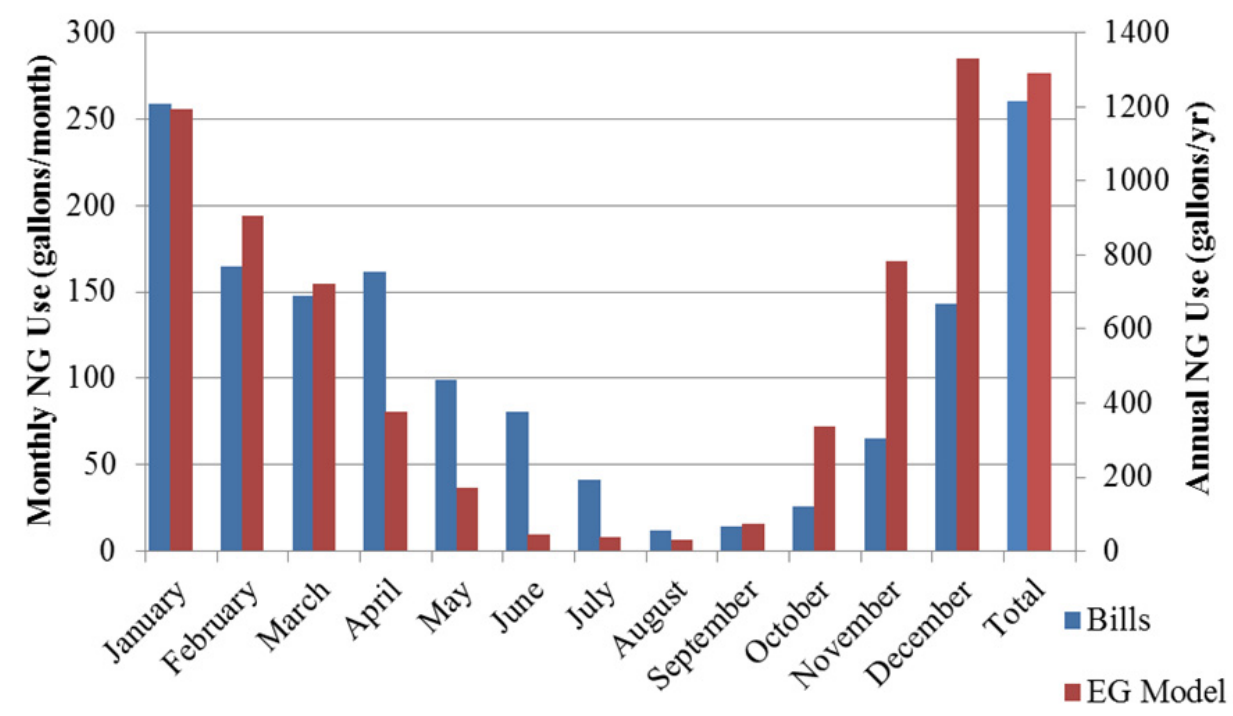

Figure B.7. PNW-5 pre-retrofit modeled and utility bill monthly and annual natural gas use comparison.

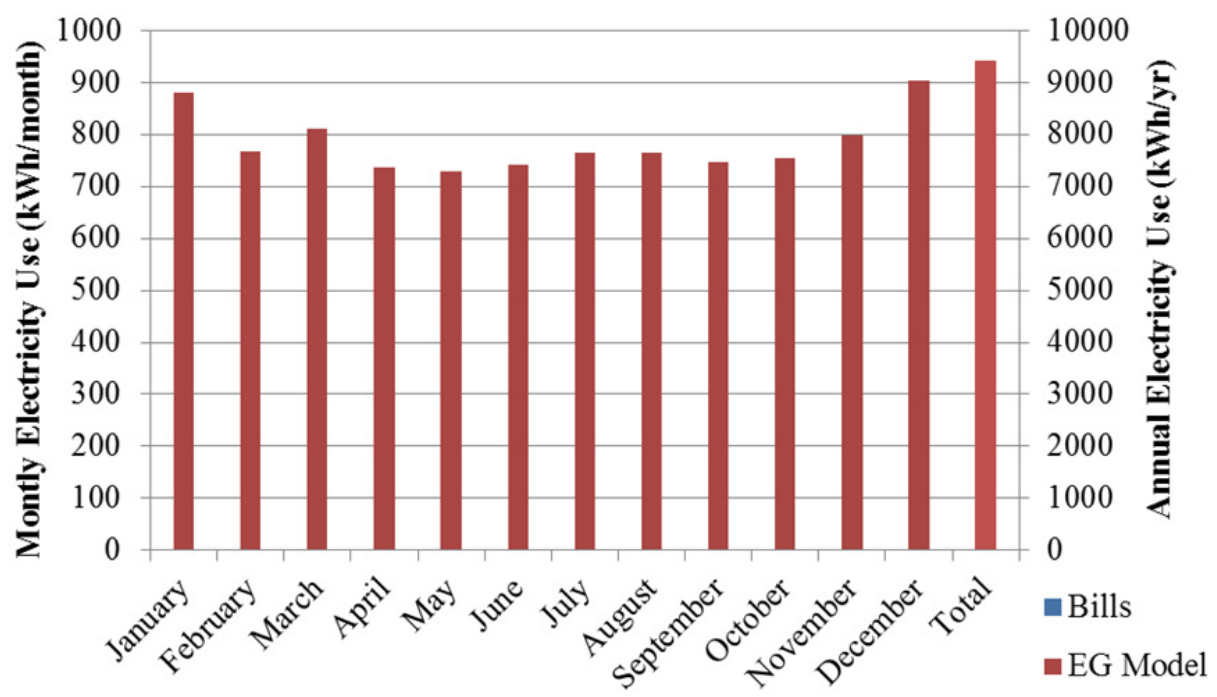

Figure B.8. PNW-5 monthly and annual electricity use comparison, where utility bills were not available because the home was not occupied prior to the retrofit. 


\section{B.6 PNW-6 Home}

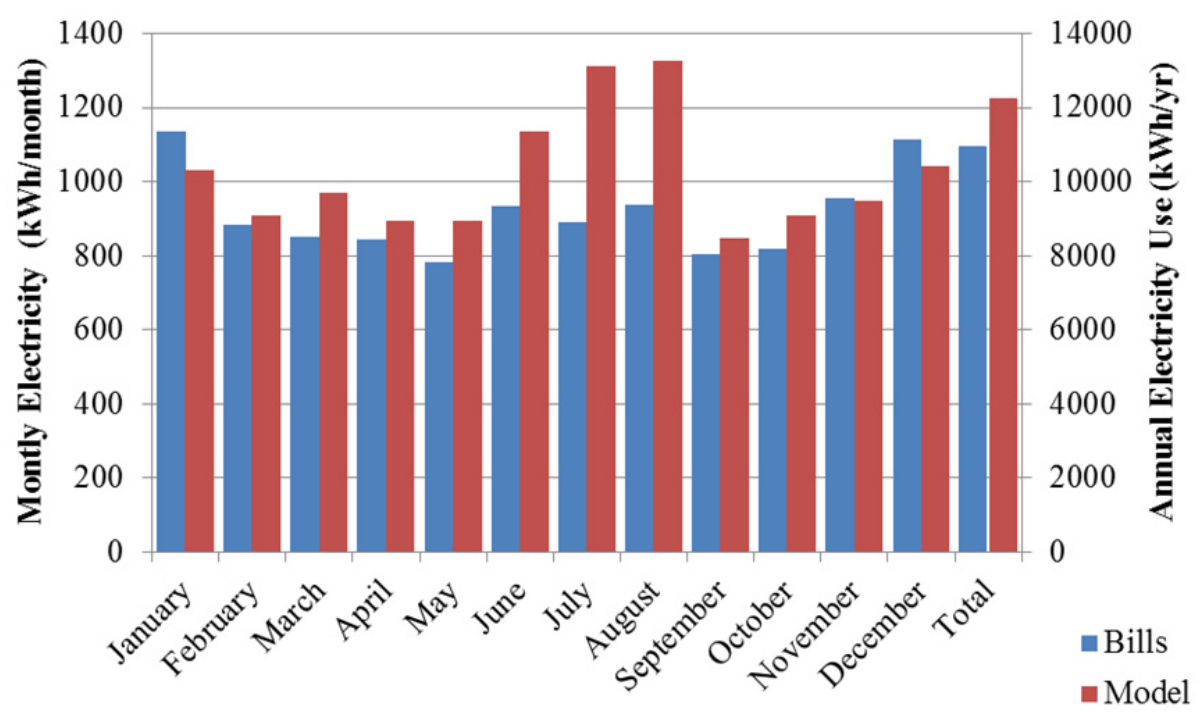

Figure B.9. PNW-6 pre-retrofit modeled and utility bill monthly and annual electricity use comparison.

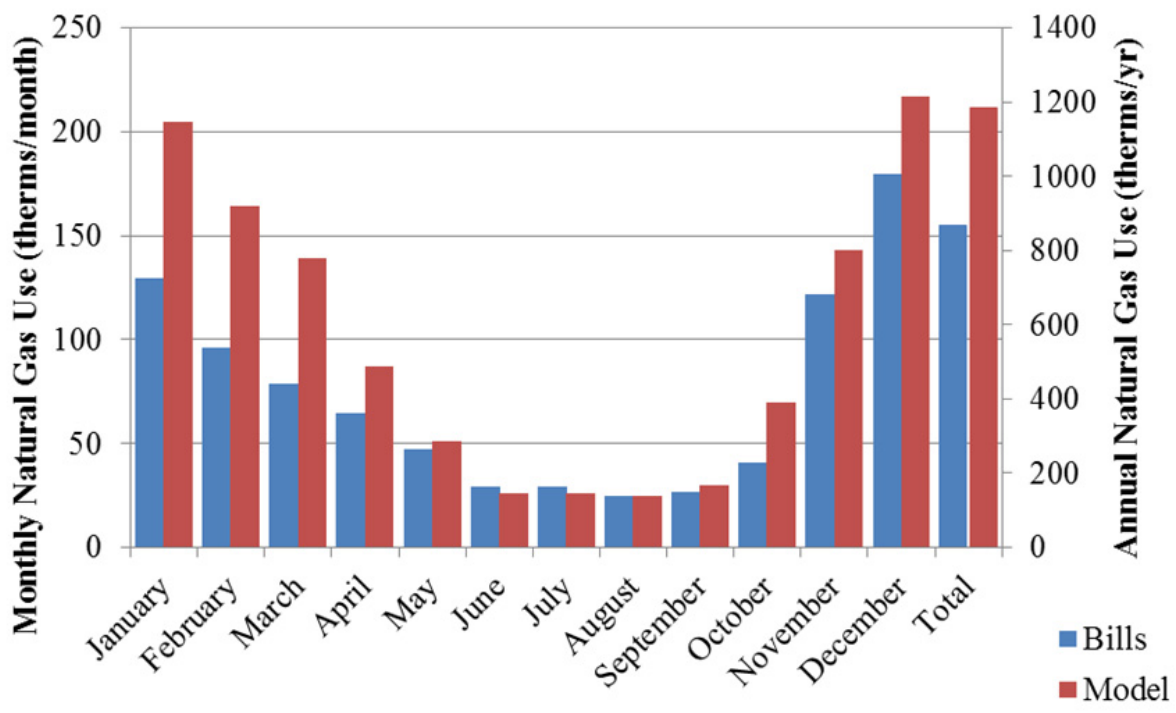

Figure B.10. PNW-6 pre-retrofit modeled and utility bill monthly and annual natural gas use comparison. 


\section{Appendix C}

\section{Detailed Metering Results}




\section{Appendix C}

\section{Detailed Metering Results}

\section{C.1 PNW-1 Home ${ }^{1}$}

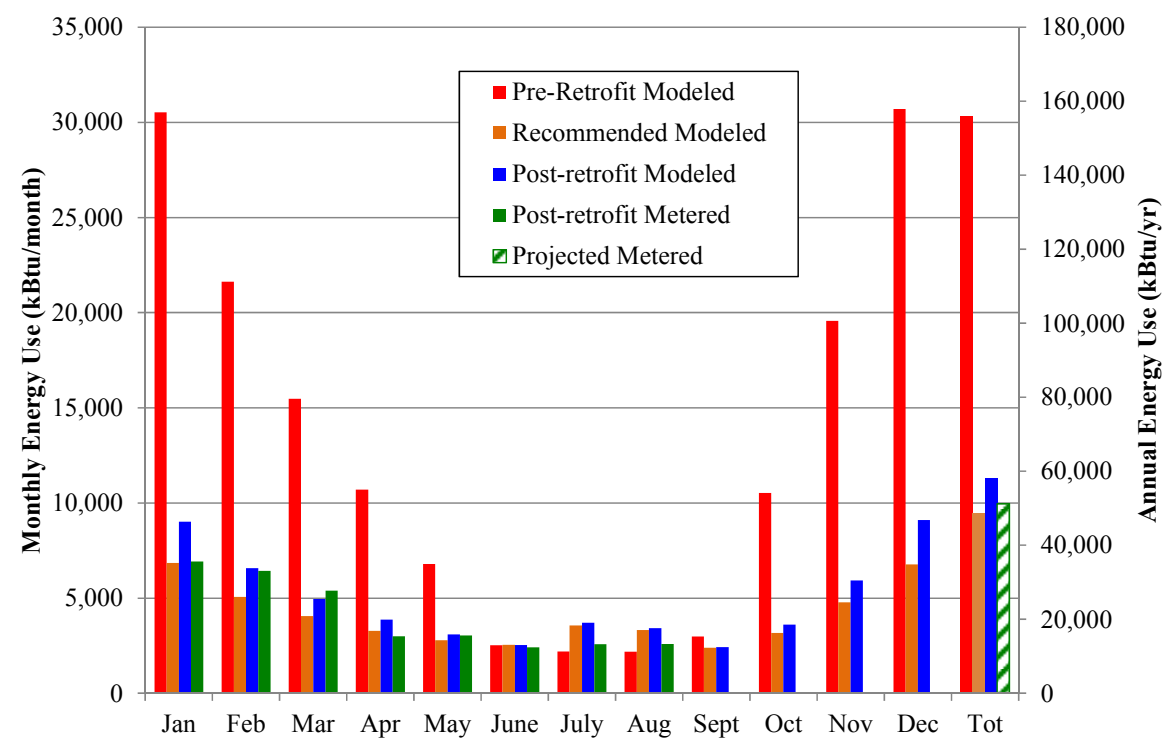

Figure C.1. PNW-1 monthly and annual pre-retrofit modeled, post-retrofit modeled, and metered results.

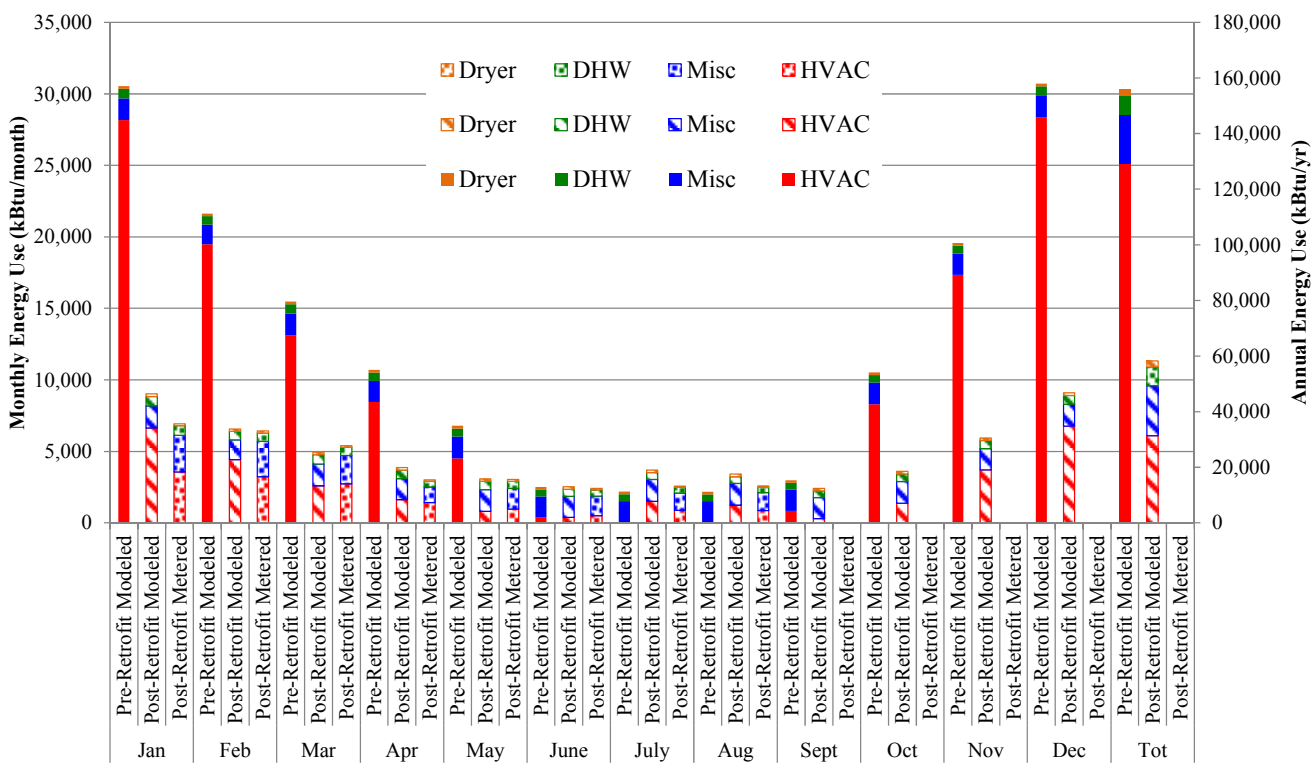

Figure C.2. PNW-1 monthly and annual pre-retrofit modeled, post-retrofit modeled and metered results disaggregated by end-use.

\footnotetext{
${ }^{1}$ Full-page figures can be found at http://deepenergyretrofits.pnnl.gov/resources/.
} 


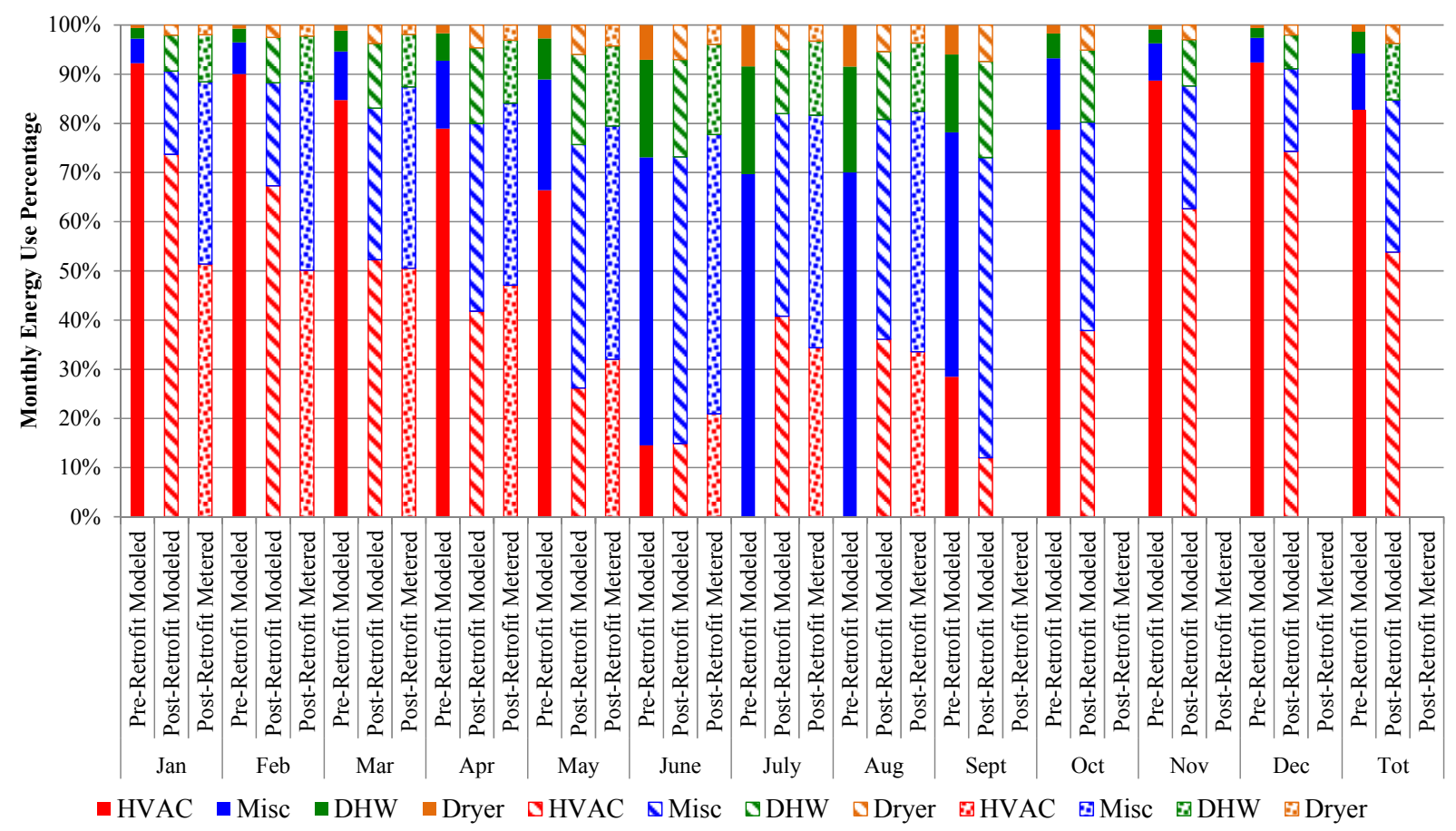

Figure C.3. PNW-1 monthly and annual pre-retrofit modeled, post-retrofit modeled, and metered results percentage by end-use.

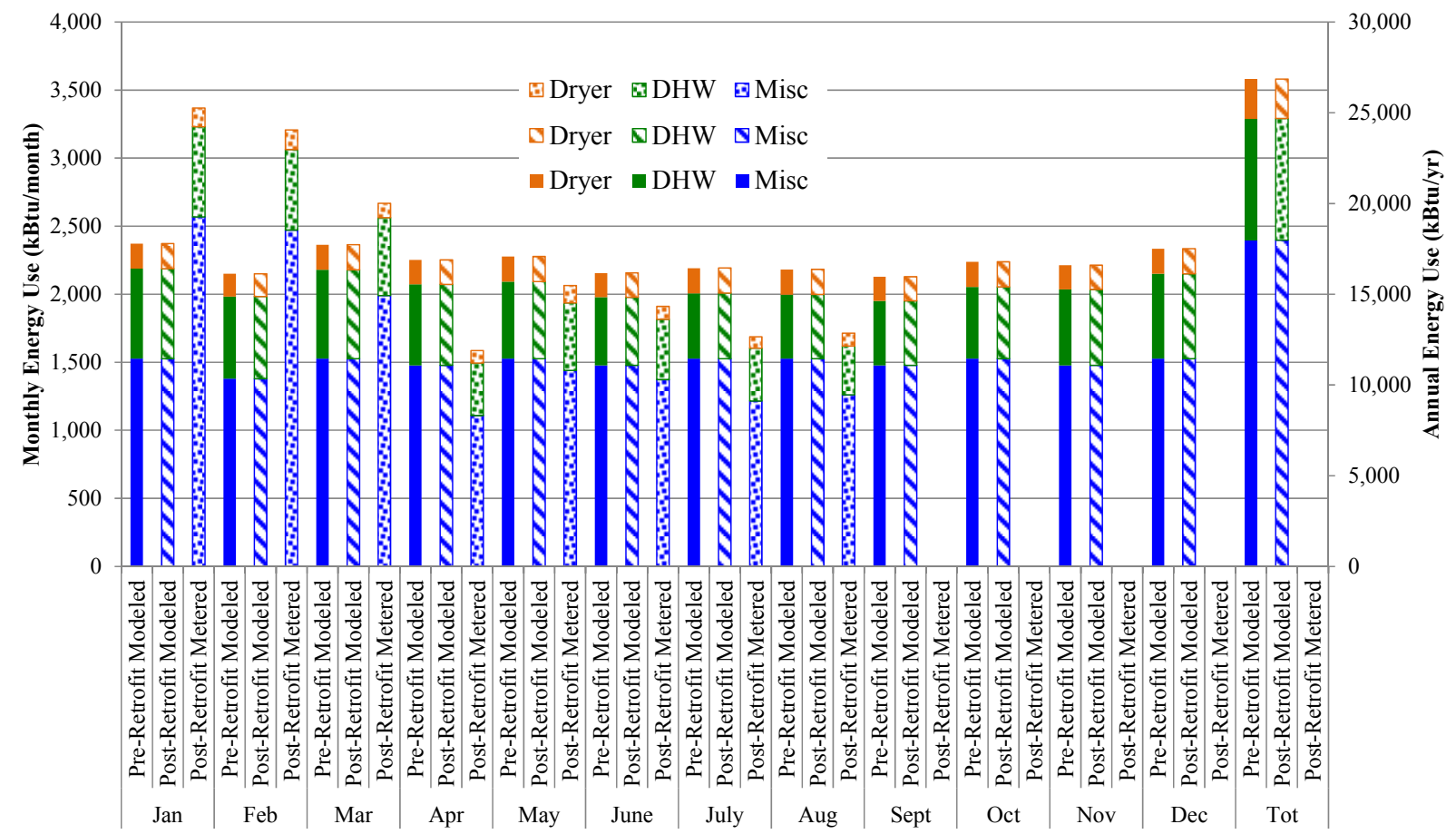

Figure C.4. PNW-1 monthly and annual pre-retrofit modeled, post-retrofit modeled, and metered results disaggregation by minor end-use. 


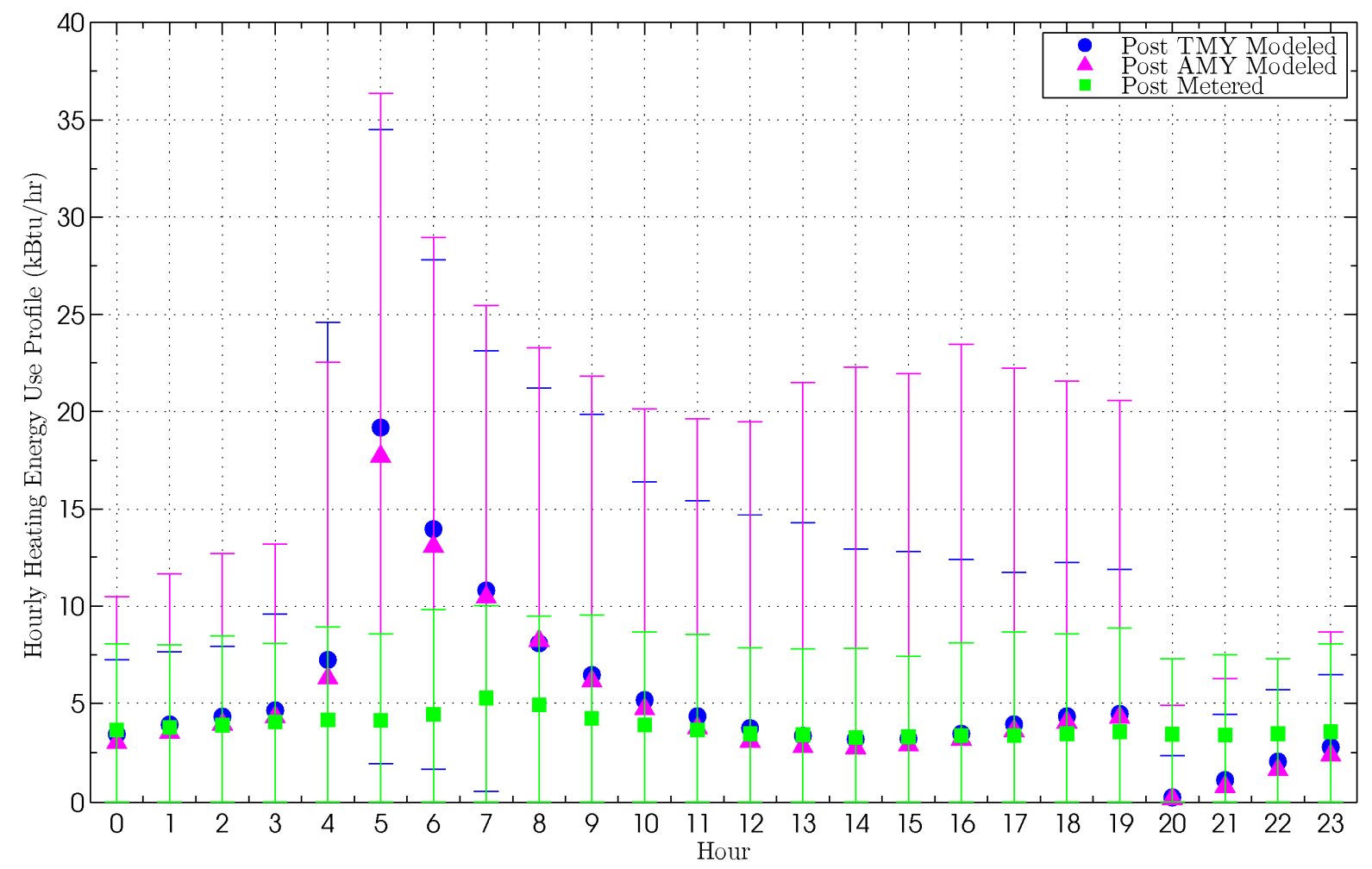

Figure C.5. PNW-1 hourly heating energy use profile comparison. ${ }^{1}$

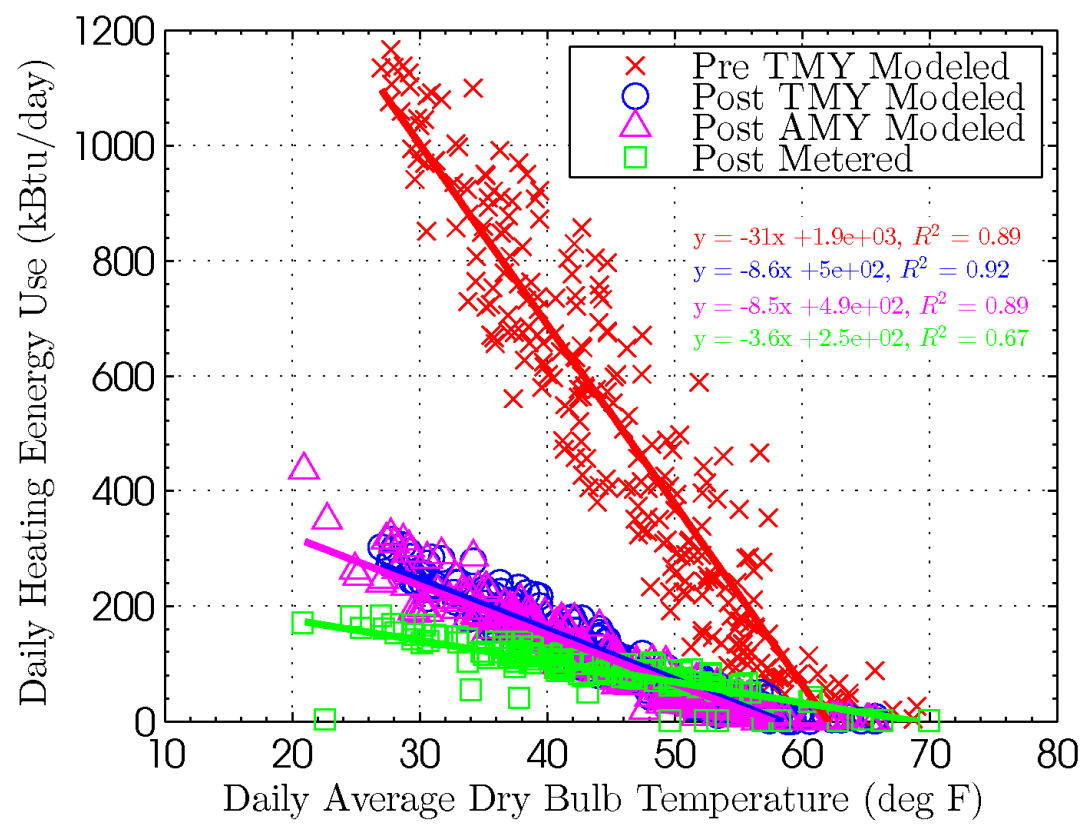

Figure C.6. PNW-1 daily heating energy use and dry bulb temperature comparison.

\footnotetext{
${ }^{1}$ The error bars in all hourly profiles presented in this report represent the maximum and minimum values observed during the given hour and not the standard deviation. This presentation provides insight into the maximum load observed for the equipment monitored.
} 


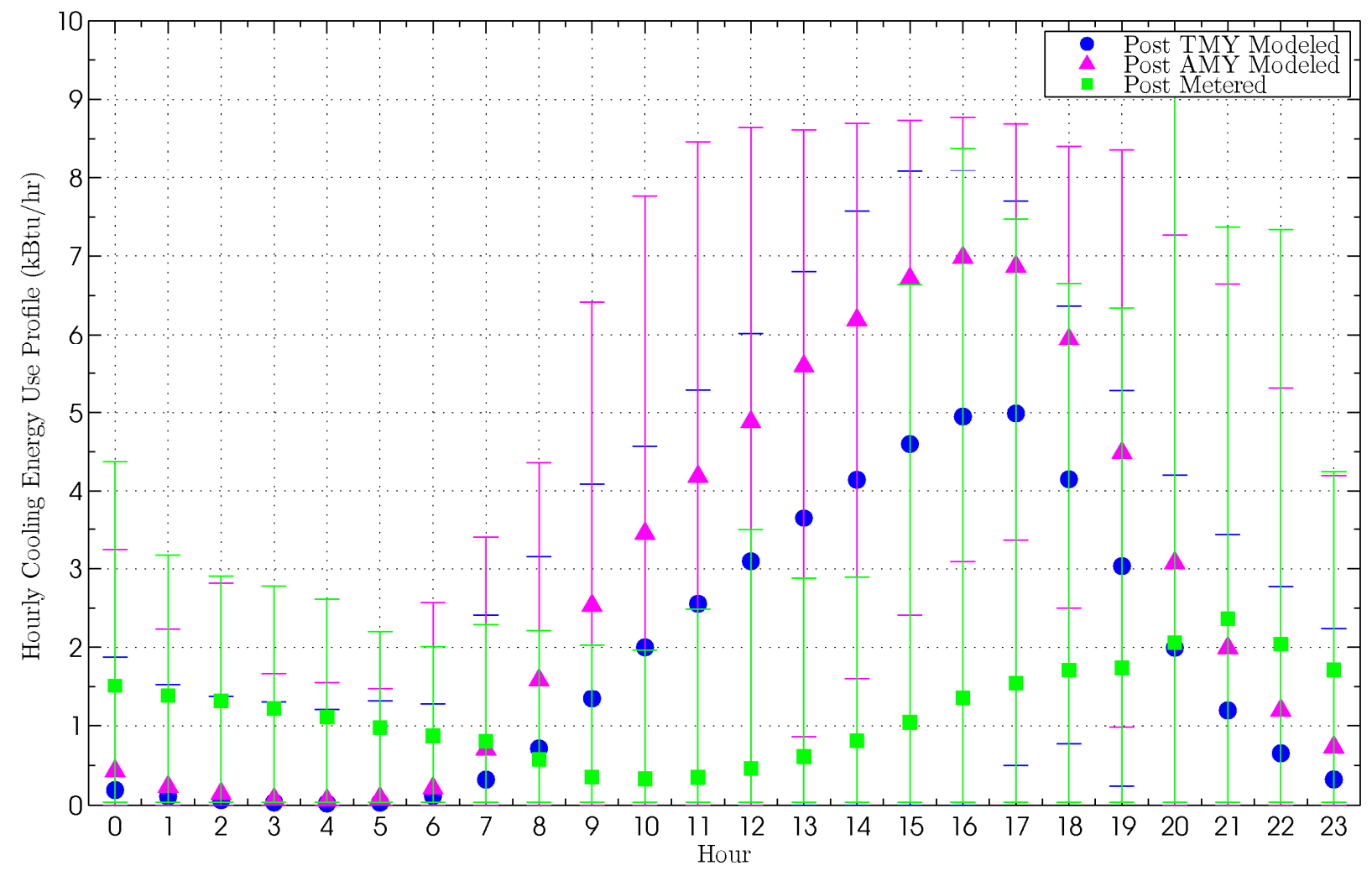

Figure C.7. PNW-1 hourly cooling energy use profile comparison.

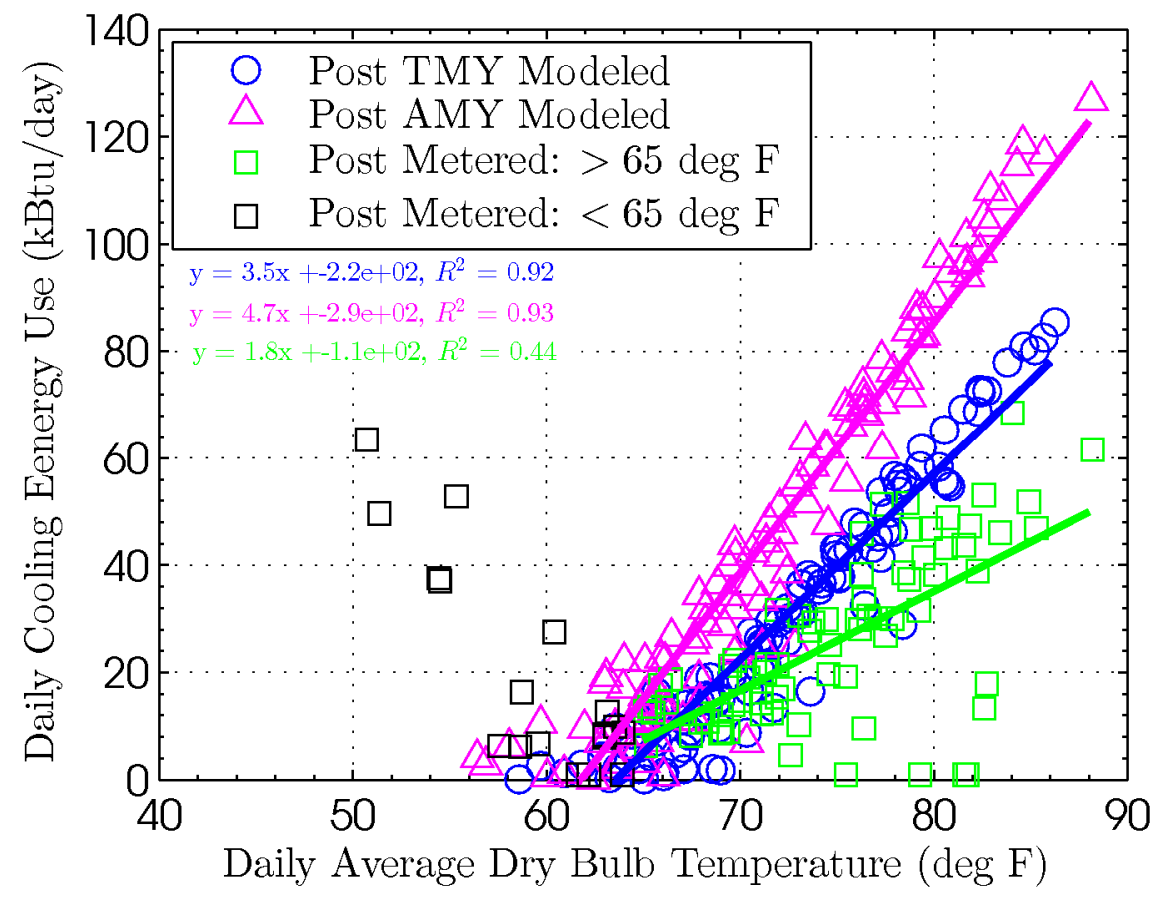

Figure C.8. PNW-1 daily cooling energy use and dry bulb temperature comparison. 


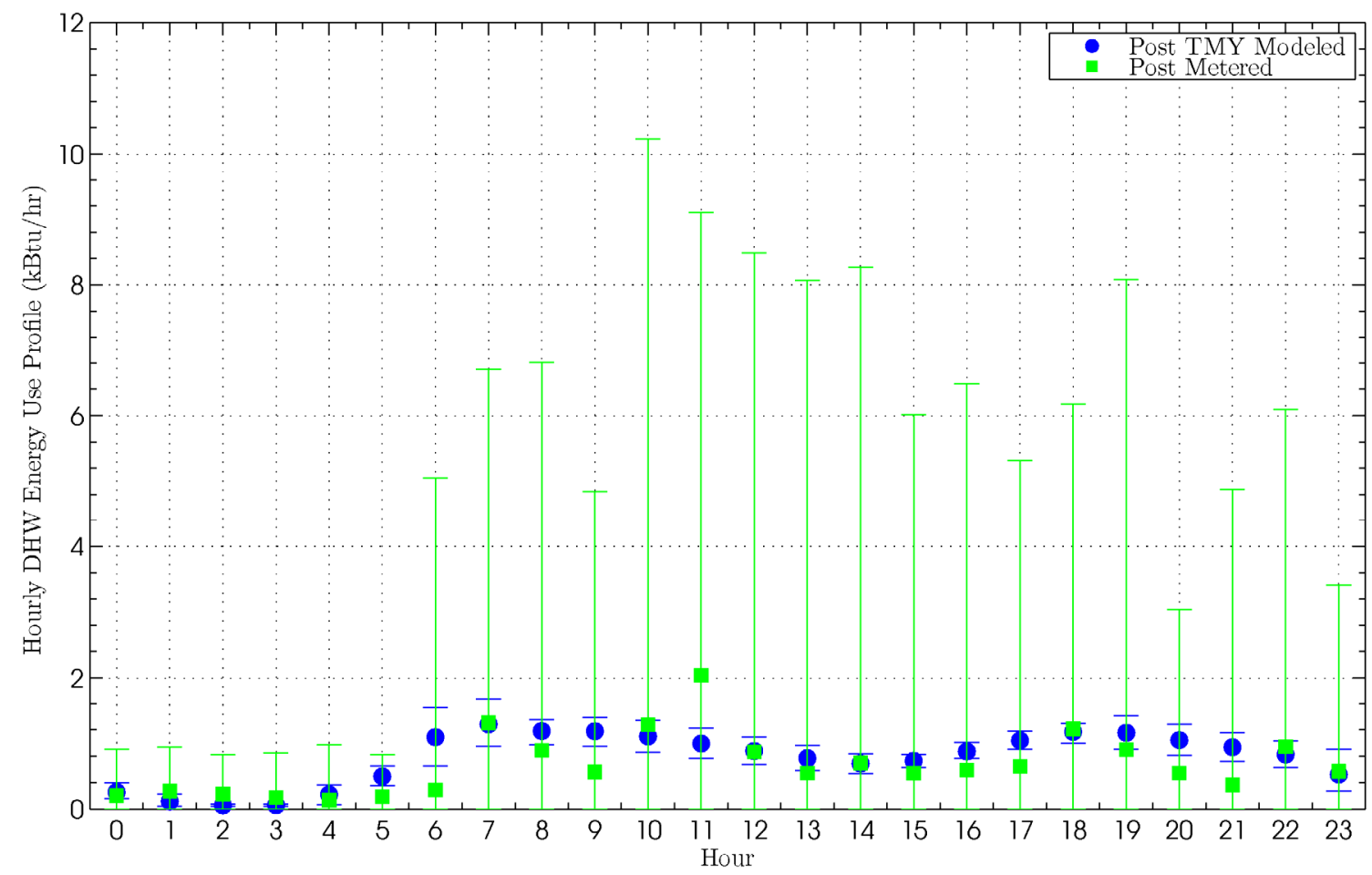

Figure C.9. PNW-1 hourly DHW energy use profile comparison.

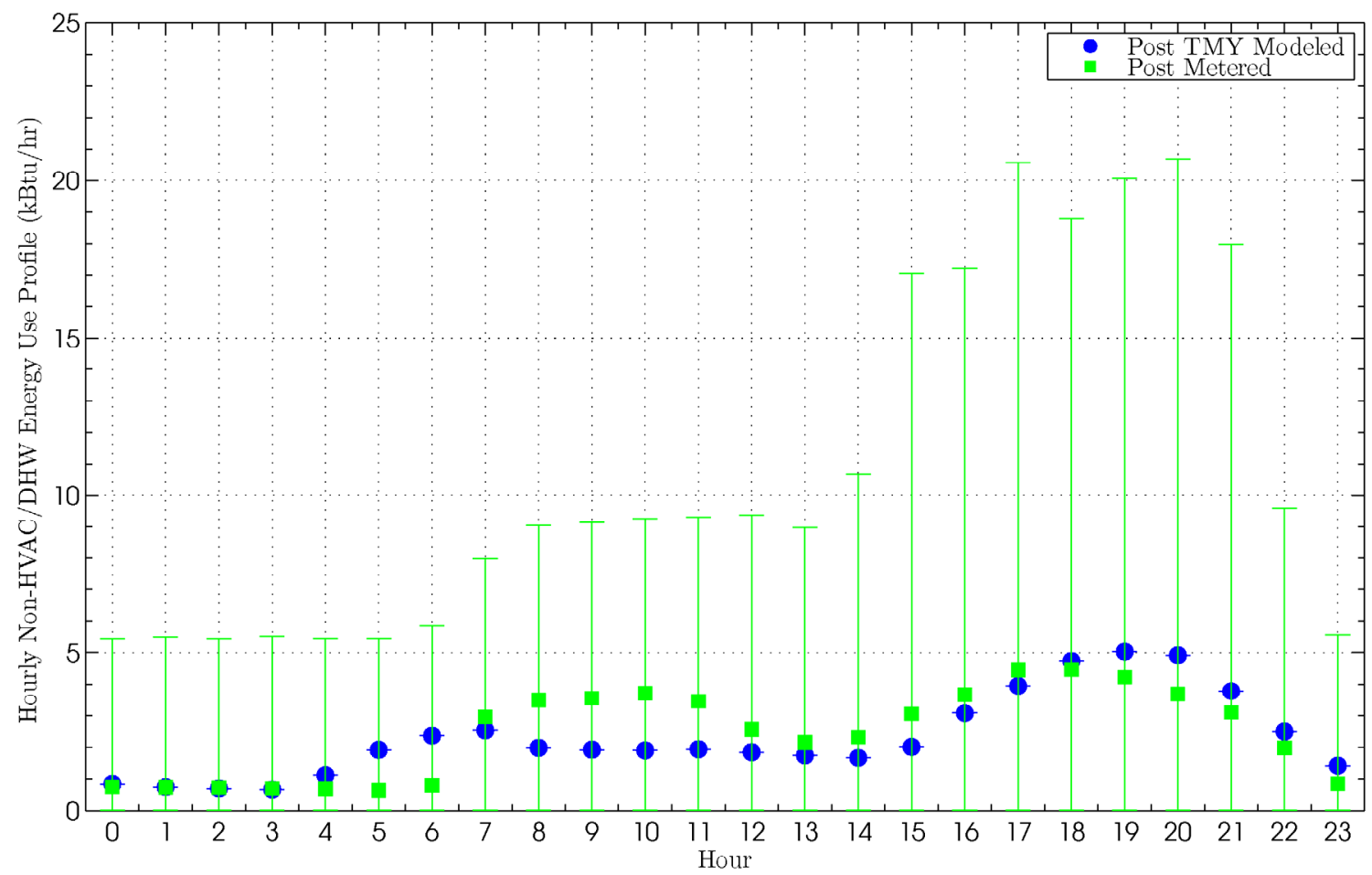

Figure C.10. PNW-1 hourly energy use, excluding HVAC and DHW, profile comparison. 


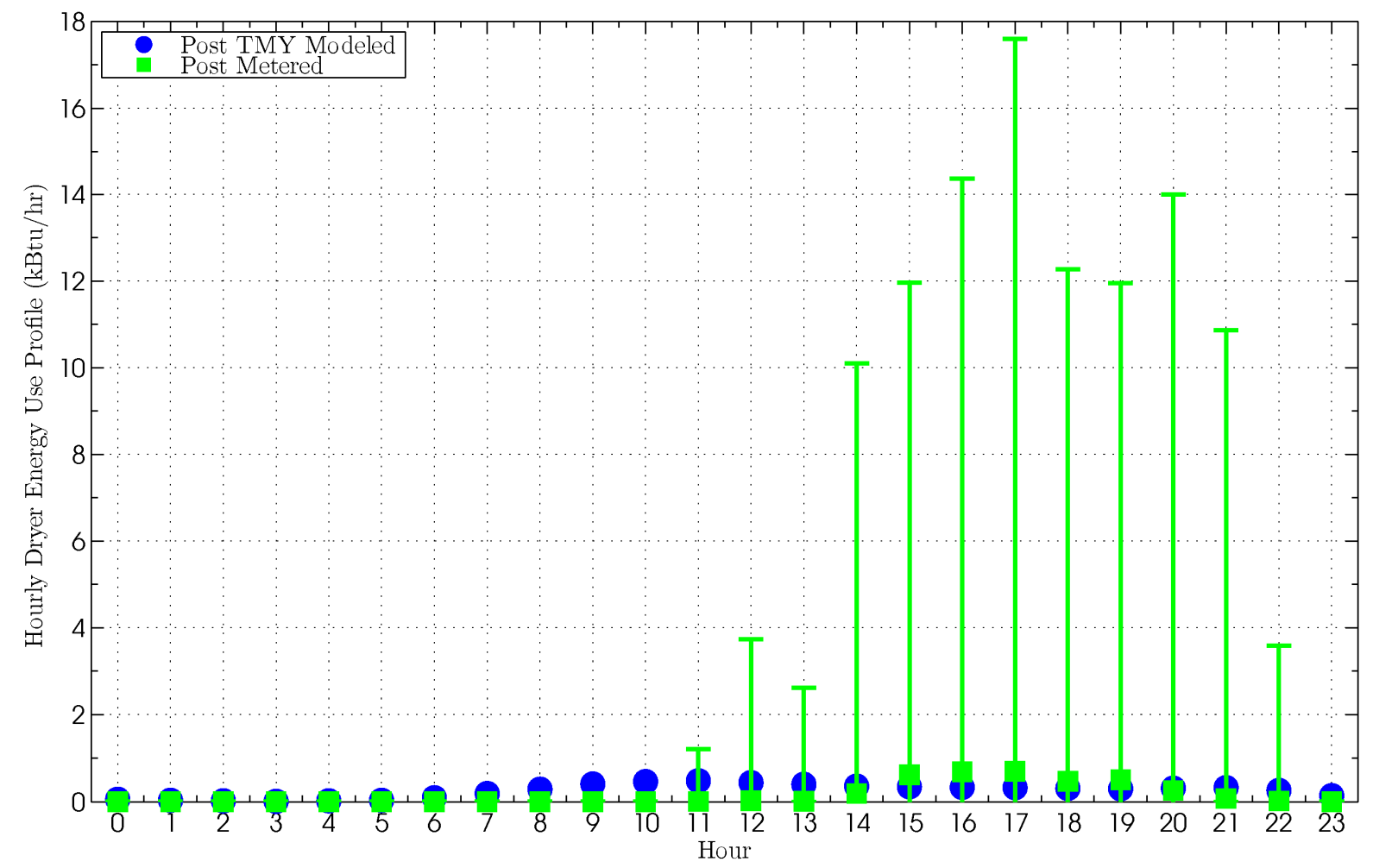

Figure C.11. PNW-1 hourly dryer energy use profile comparison.

\section{C.2 PNW-2 Home}

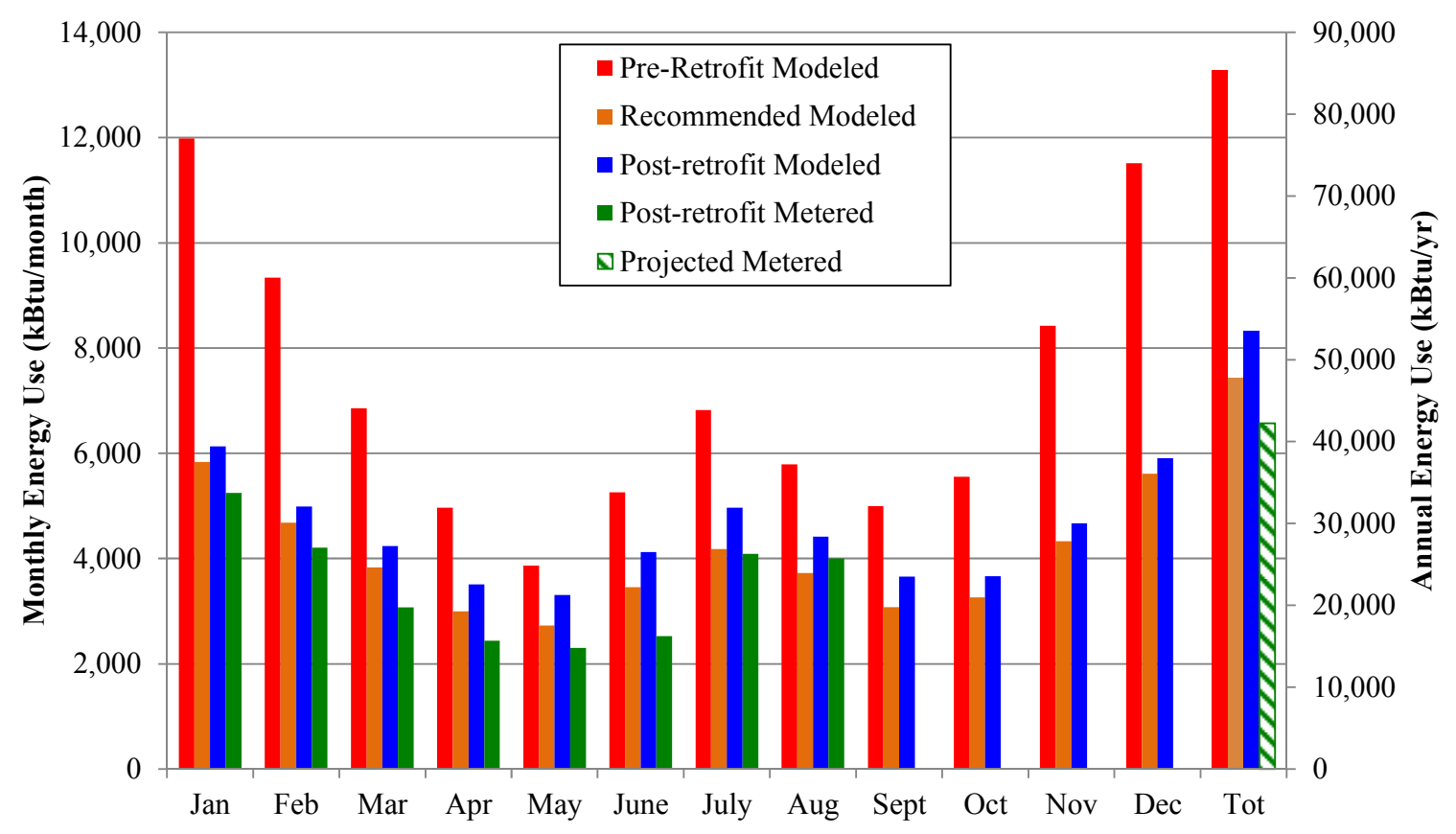

Figure C.12. PNW-2 monthly and annual pre-retrofit modeled, post-retrofit modeled, and metered results. 


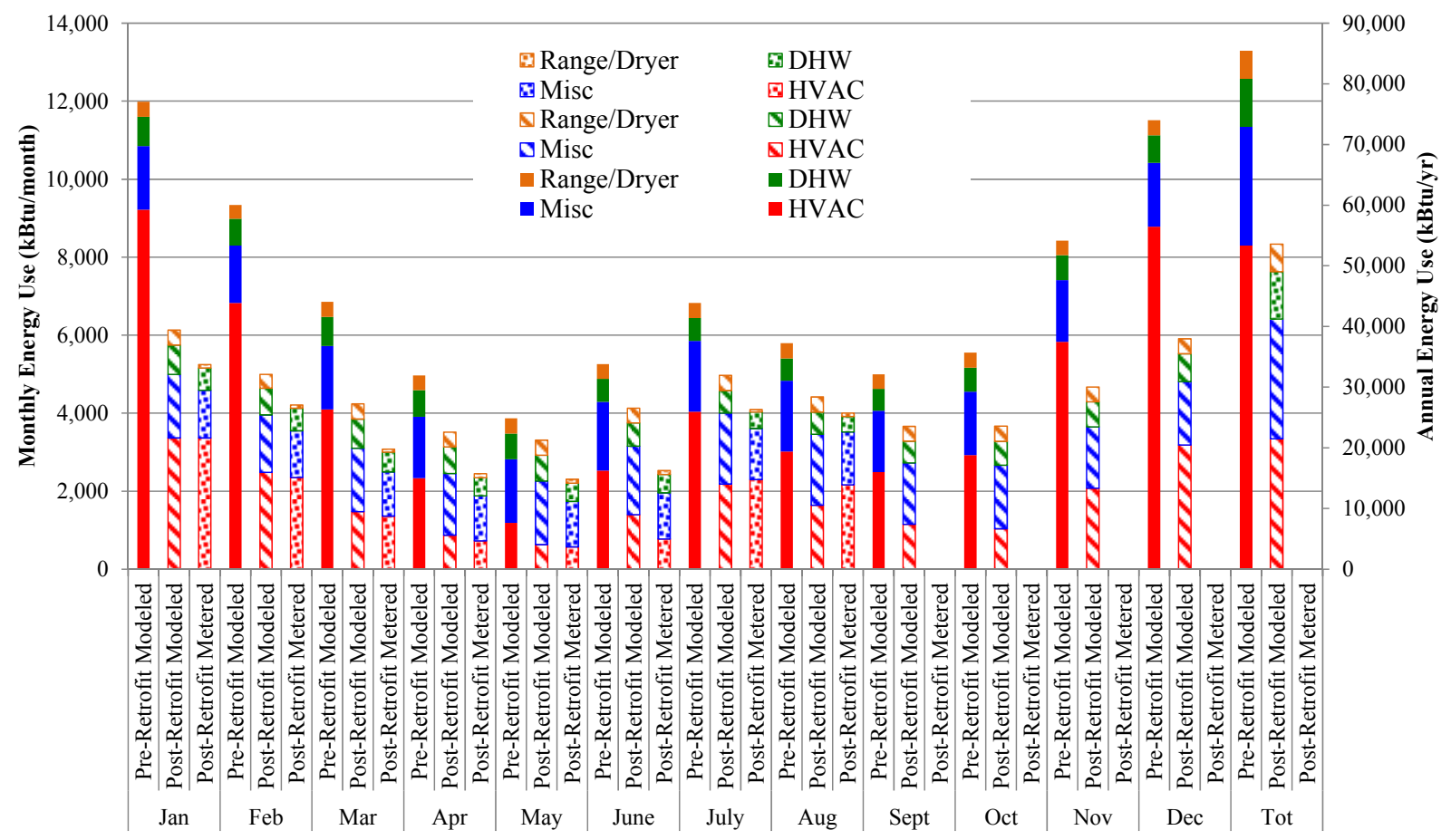

Figure C.13. PNW-2 monthly and annual pre-retrofit modeled, post-retrofit modeled, and metered results disaggregated by end-use.

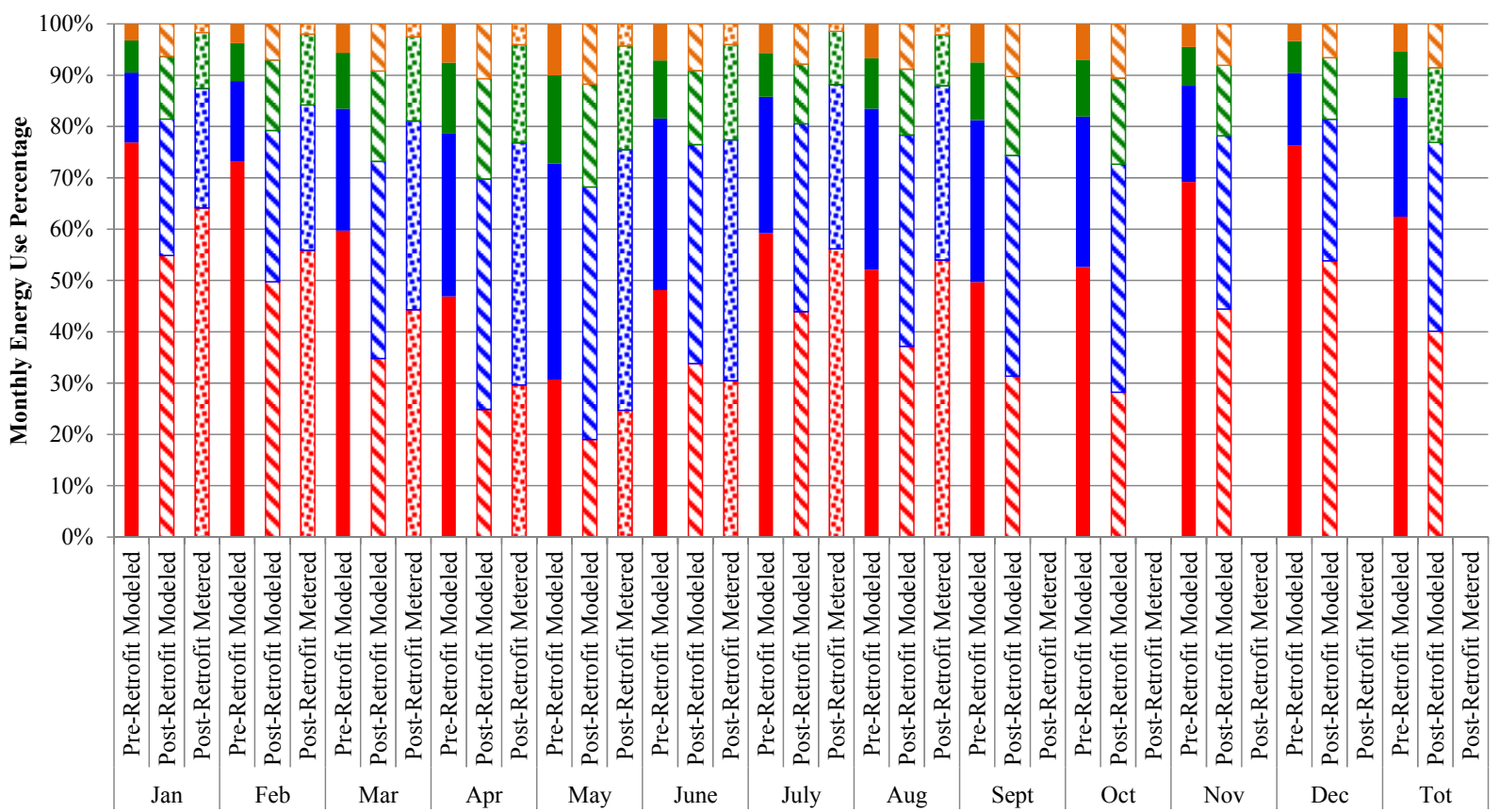

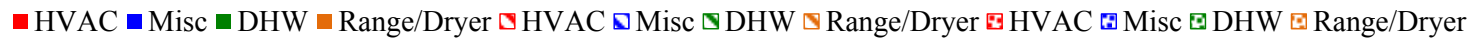

Figure C.14. PNW-2 monthly and annual pre-retrofit modeled, post-retrofit modeled, and metered results percentage by end-use. 


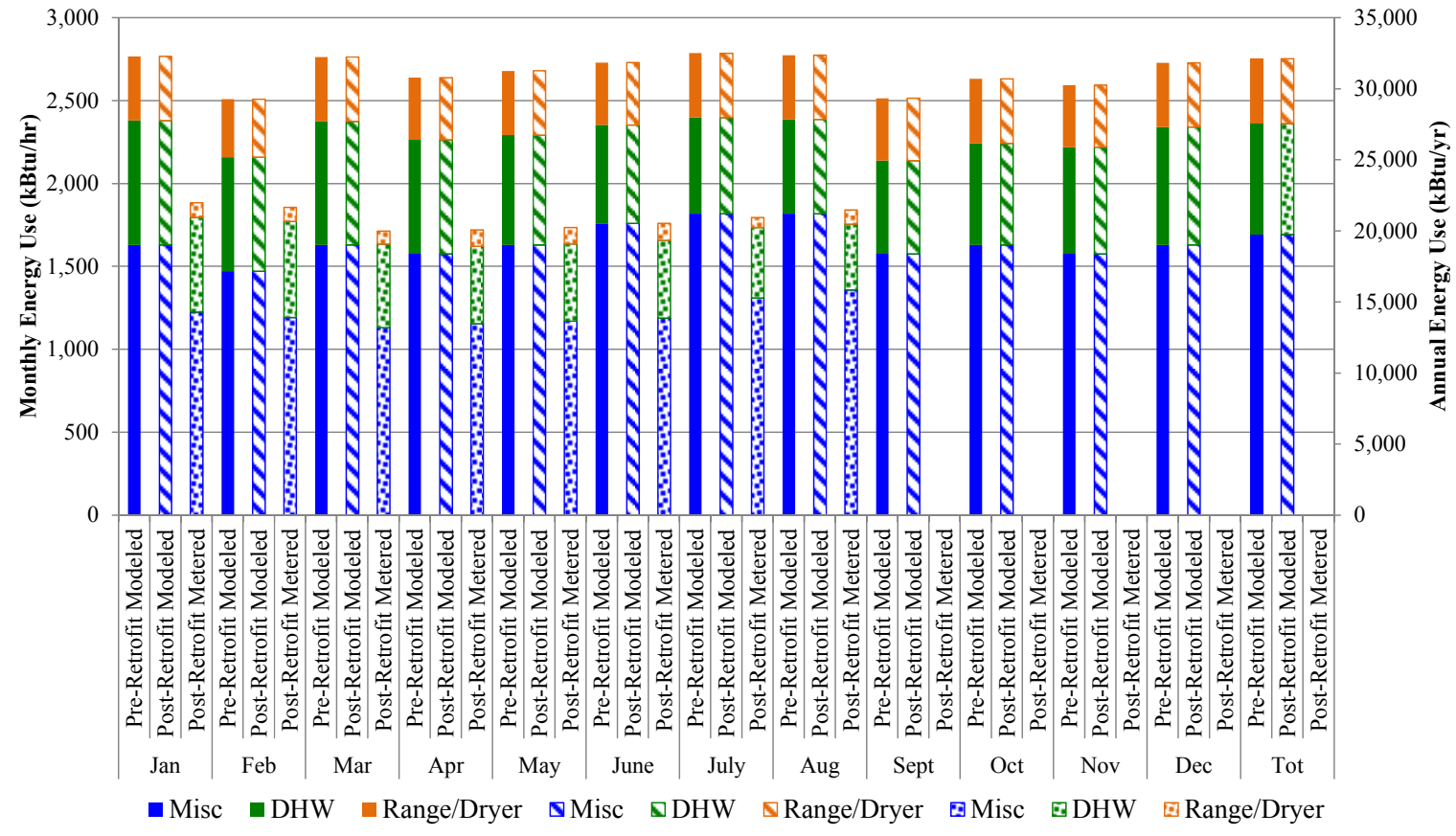

Figure C.15. PNW-2 monthly and annual pre-retrofit modeled, post-retrofit modeled, and metered results disaggregation by minor end-use.

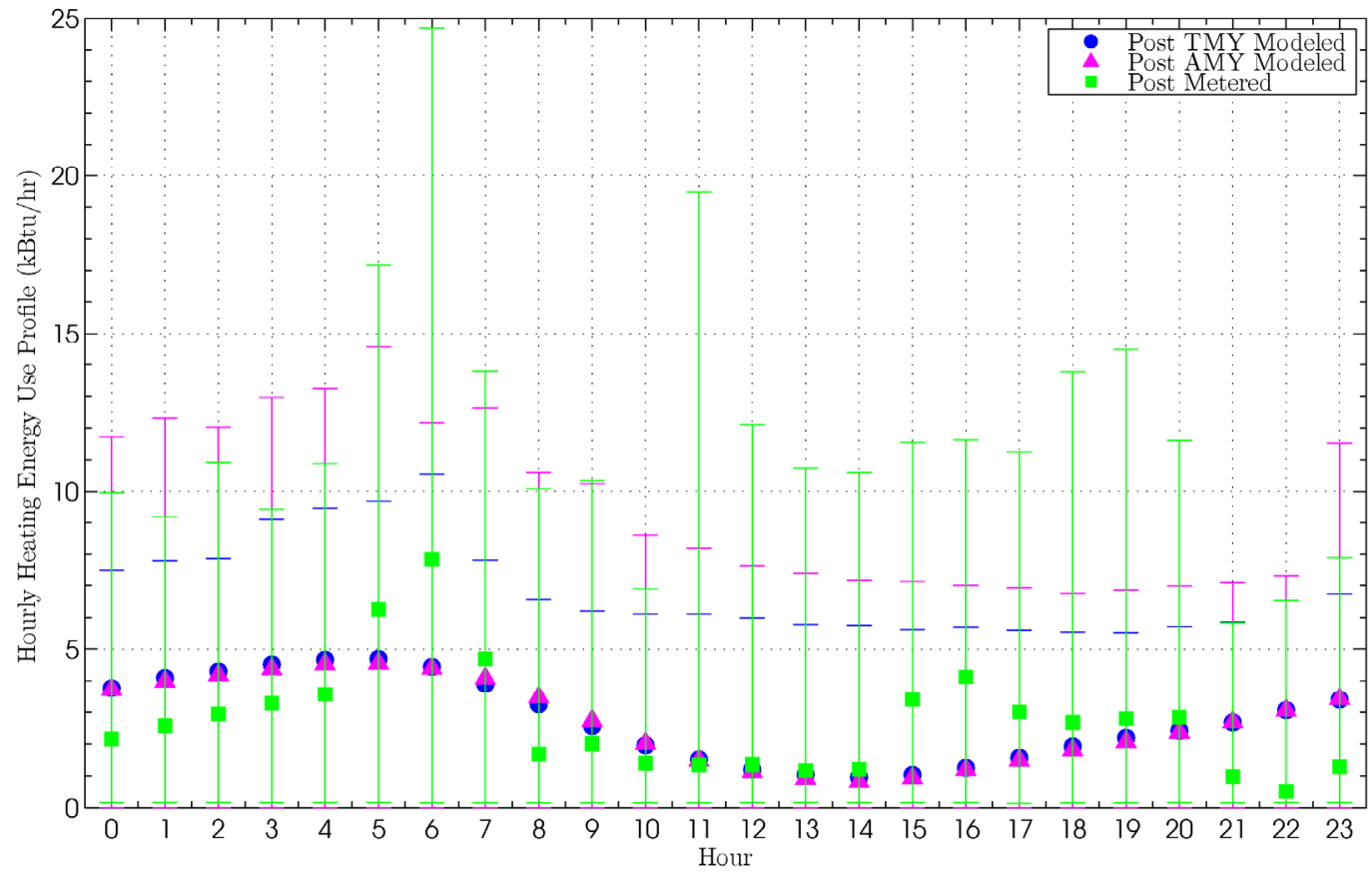

Figure C.16. PNW-2 hourly heating energy use profile comparison. ${ }^{1}$

\footnotetext{
${ }^{1}$ The error bars in all hourly profiles presented in this report represent the maximum and minimum values observed during the given hour and not the standard deviation. This presentation provides insight into the maximum load observed for the equipment monitored.
} 


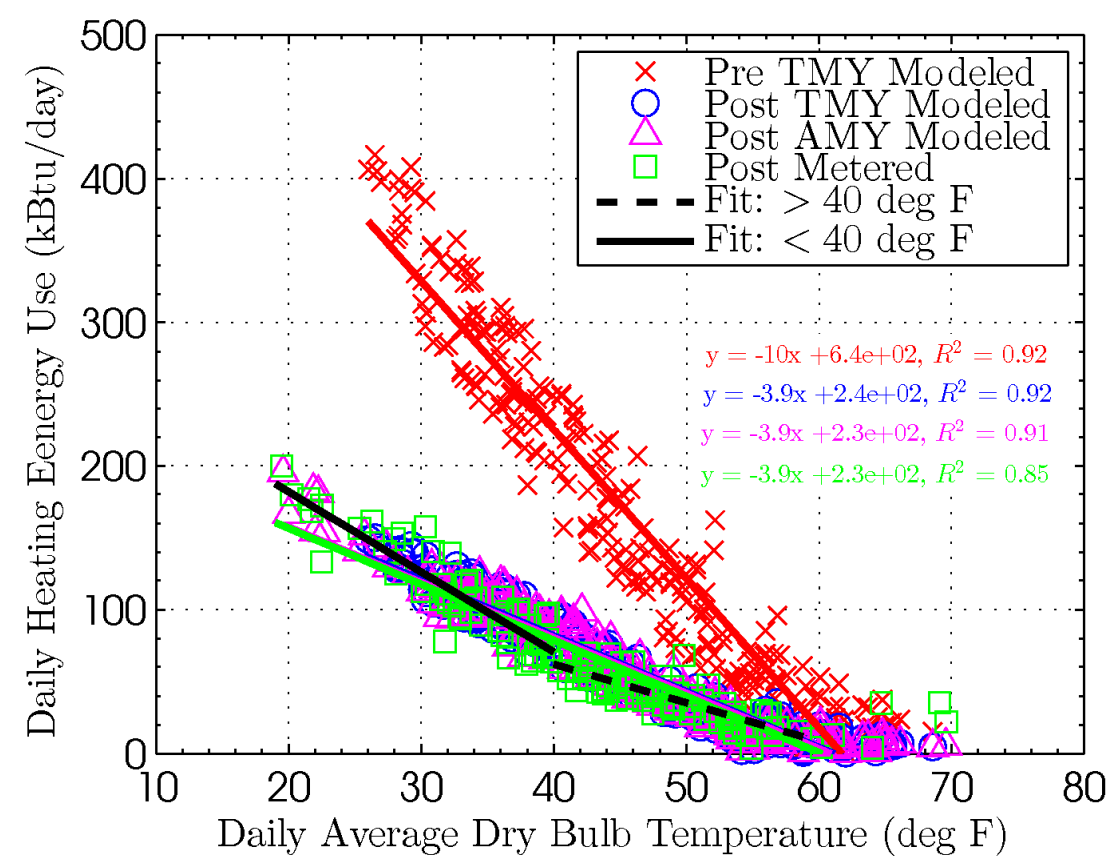

Figure C.17. PNW-2 daily heating energy use and dry bulb temperature comparison.

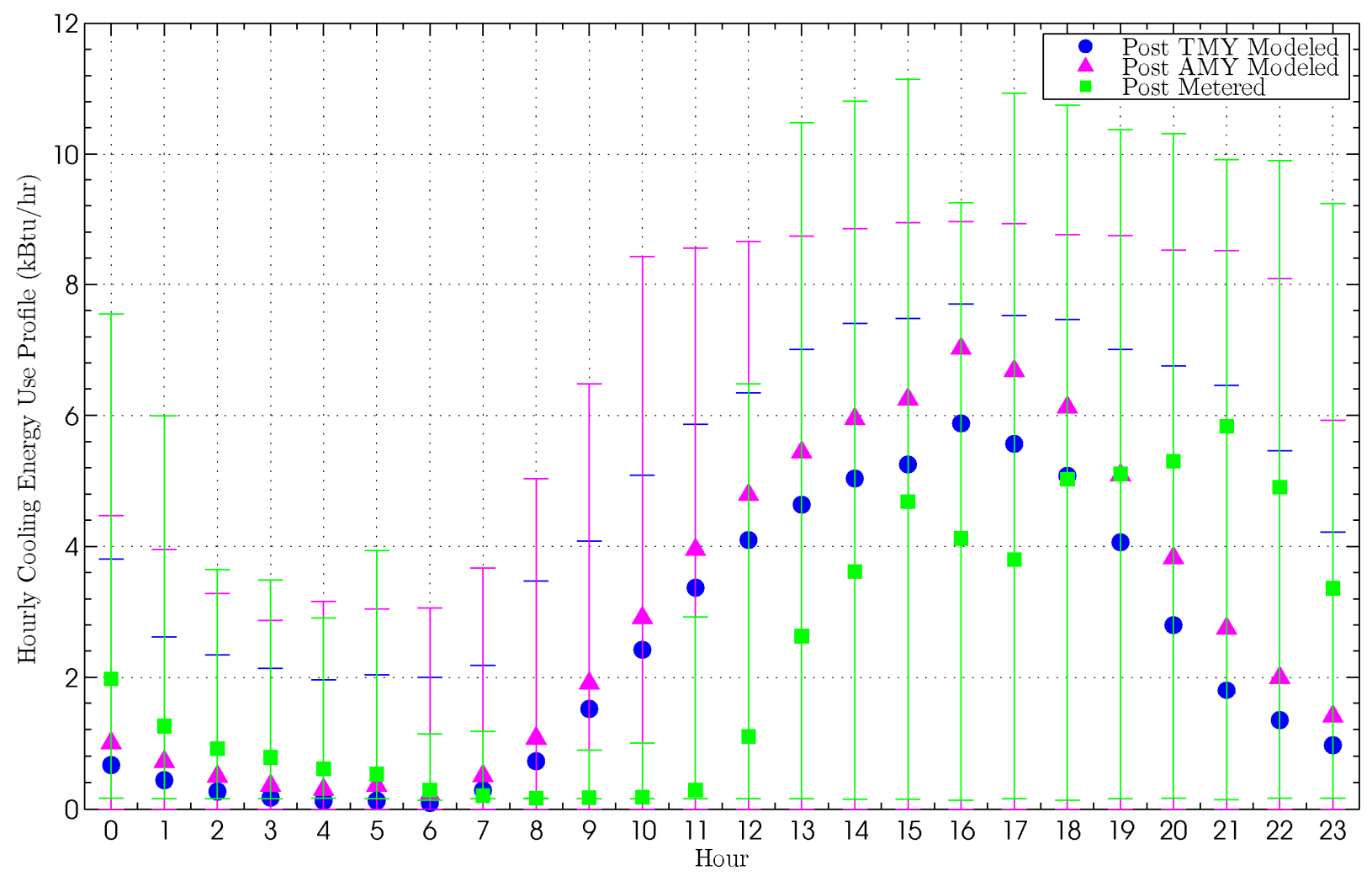

Figure C.18. PNW-2 hourly cooling energy use profile comparison. 


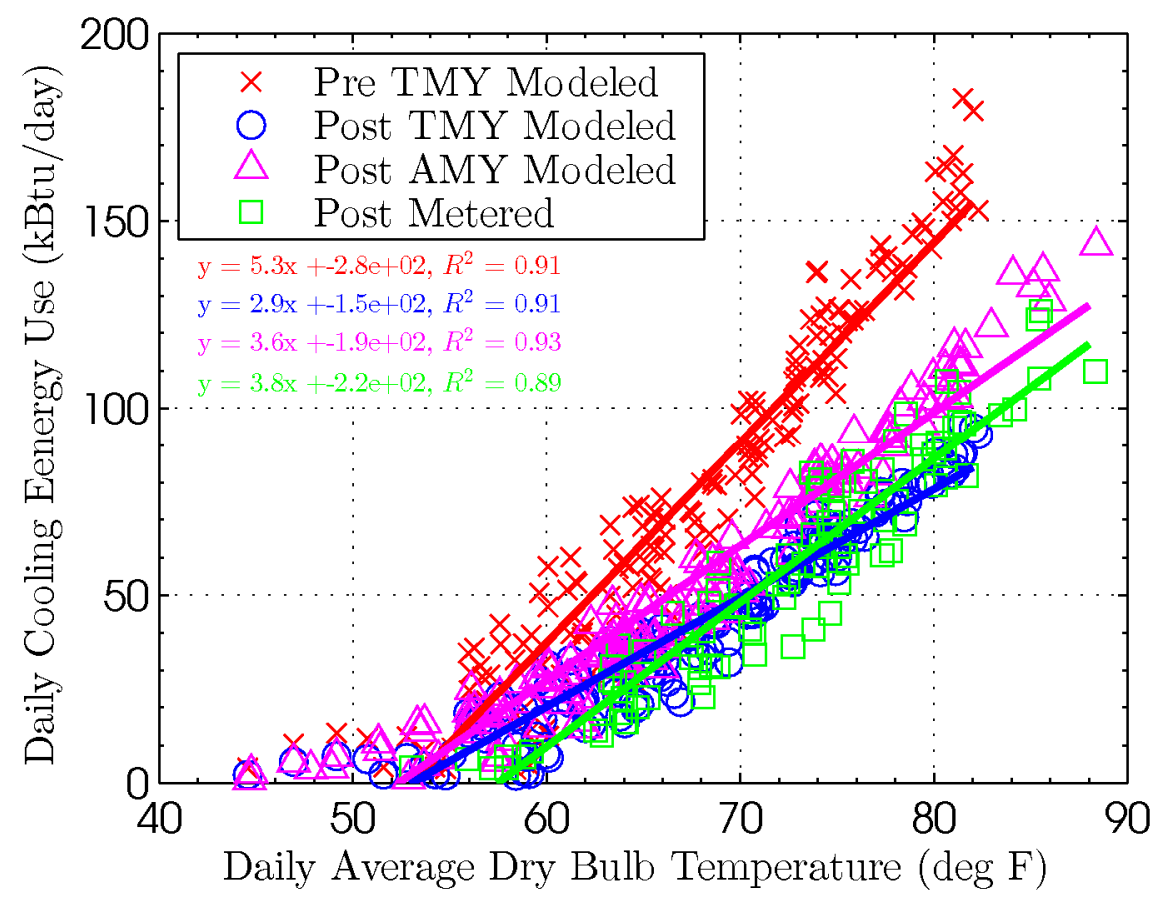

Figure C.19. PNW-2 daily cooling energy use and dry bulb temperature comparison.

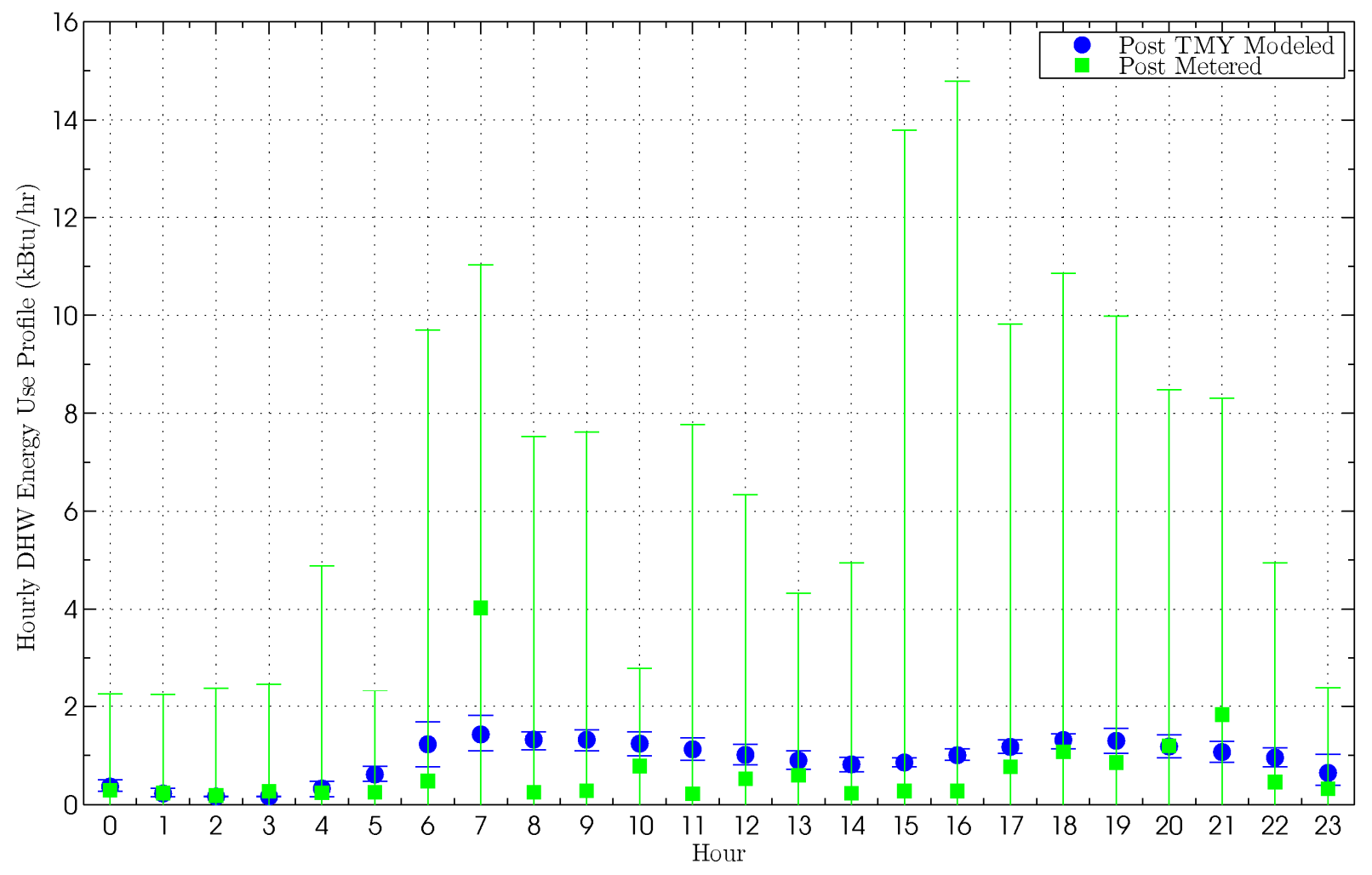

Figure C.20. PNW-2 hourly DHW energy use profile comparison. 


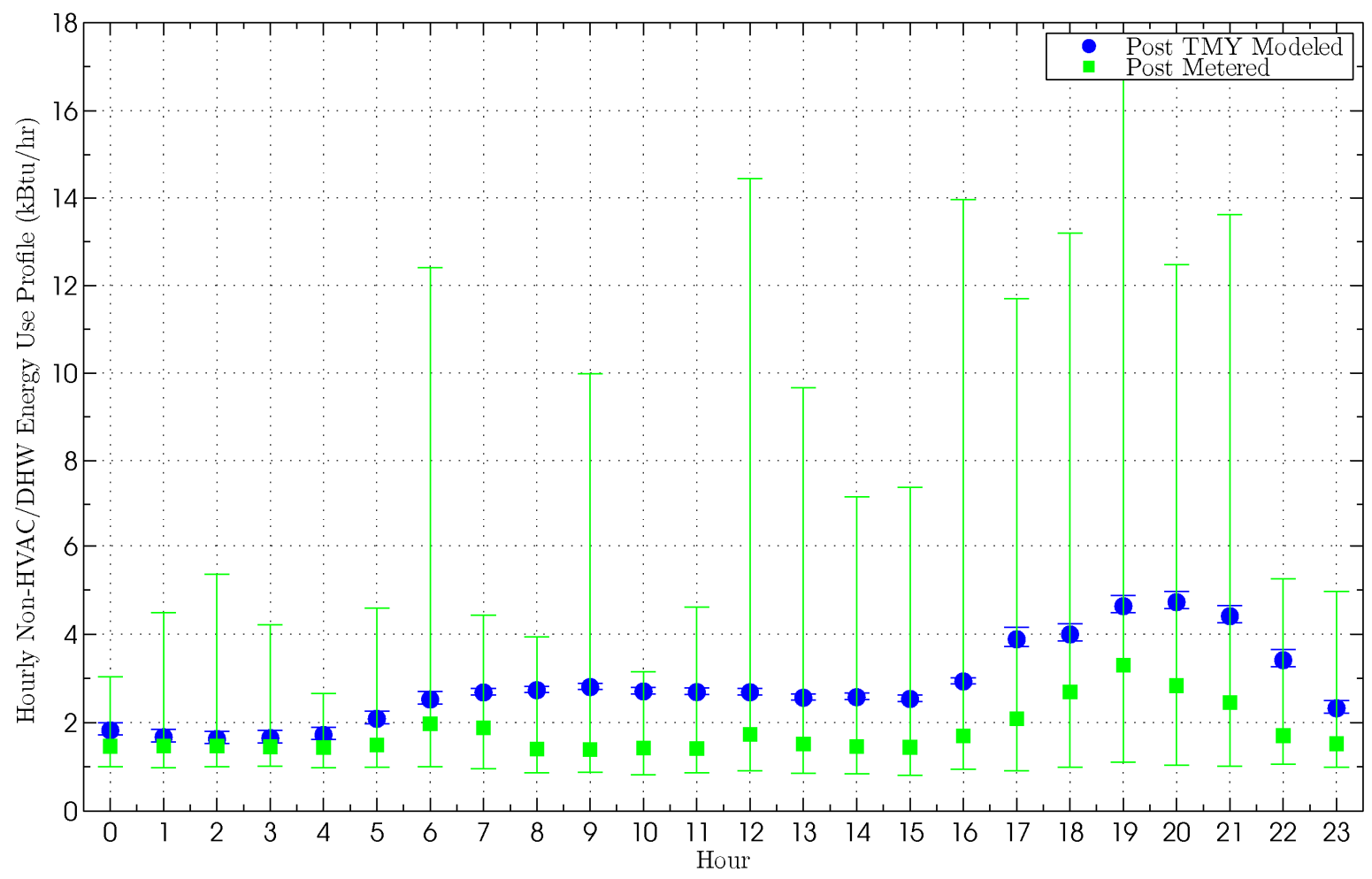

Figure C.21. PNW-2 hourly energy use, excluding HVAC and DHW, profile comparison.

\section{C.3 PNW-3 Home}

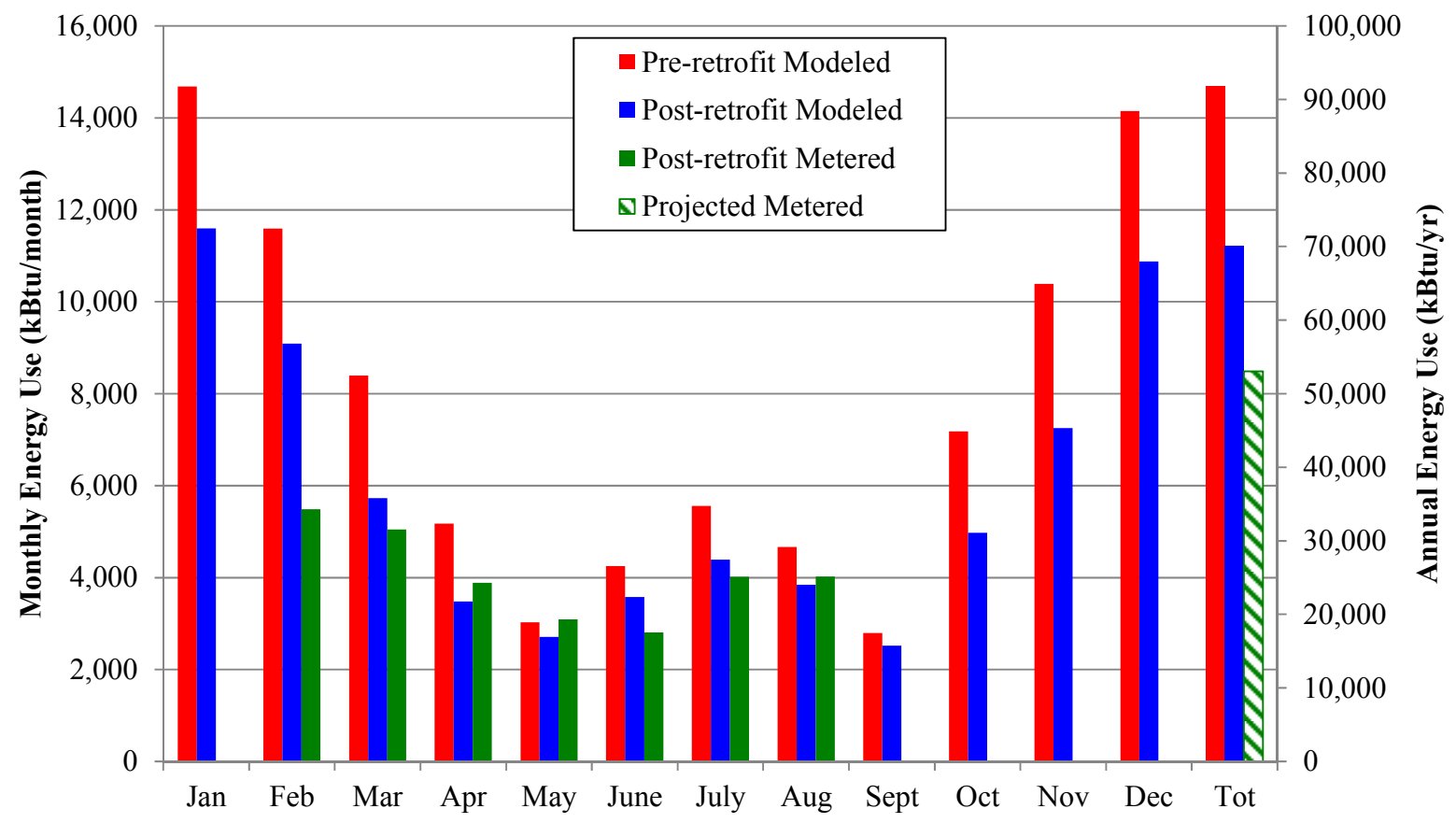

Figure C.22. PNW-3 monthly and annual pre-retrofit modeled, post-retrofit modeled, and metered results. 


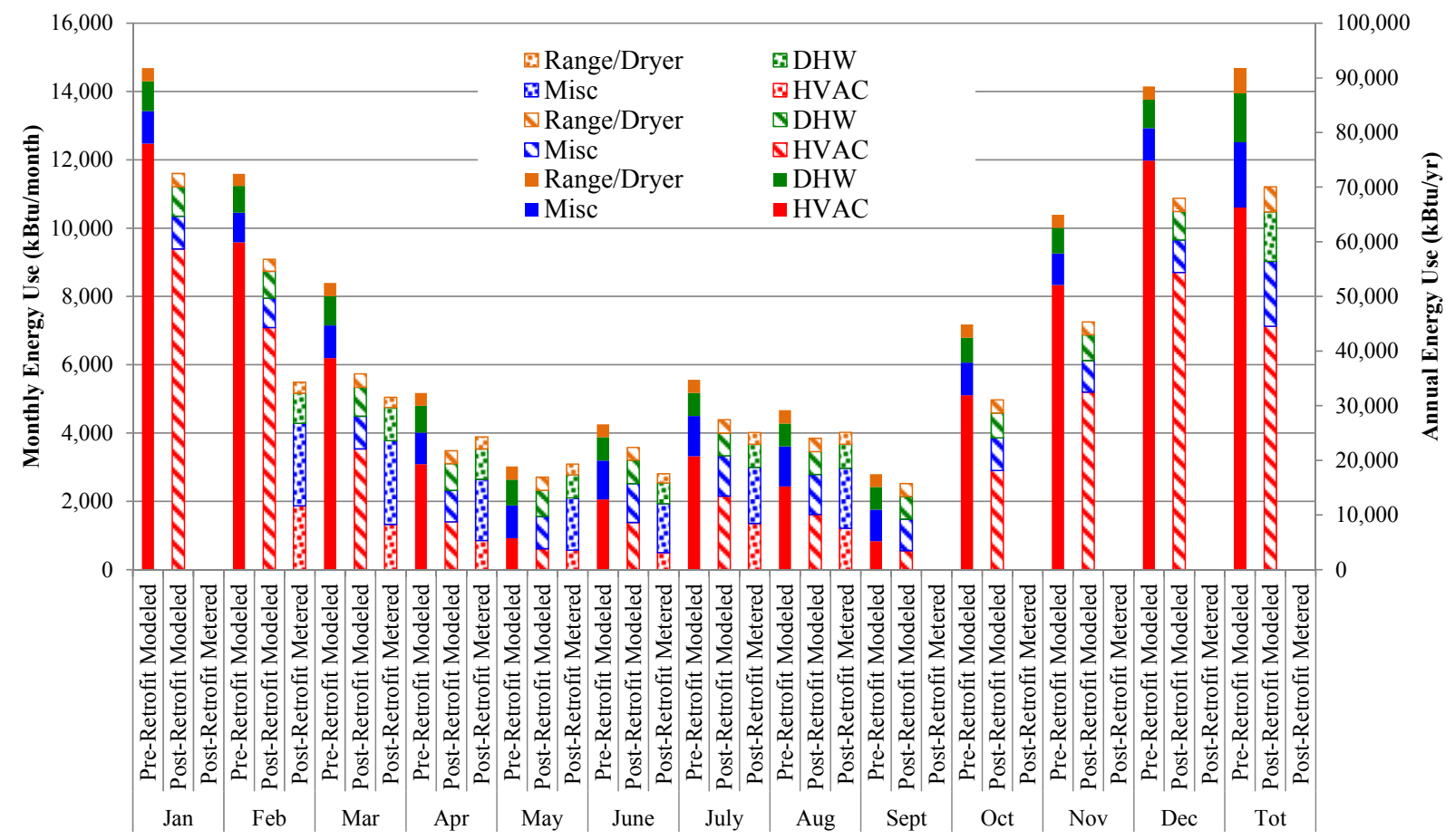

Figure C.23. PNW-3 monthly and annual pre-retrofit modeled, post-retrofit modeled, and metered results disaggregated by end-use.

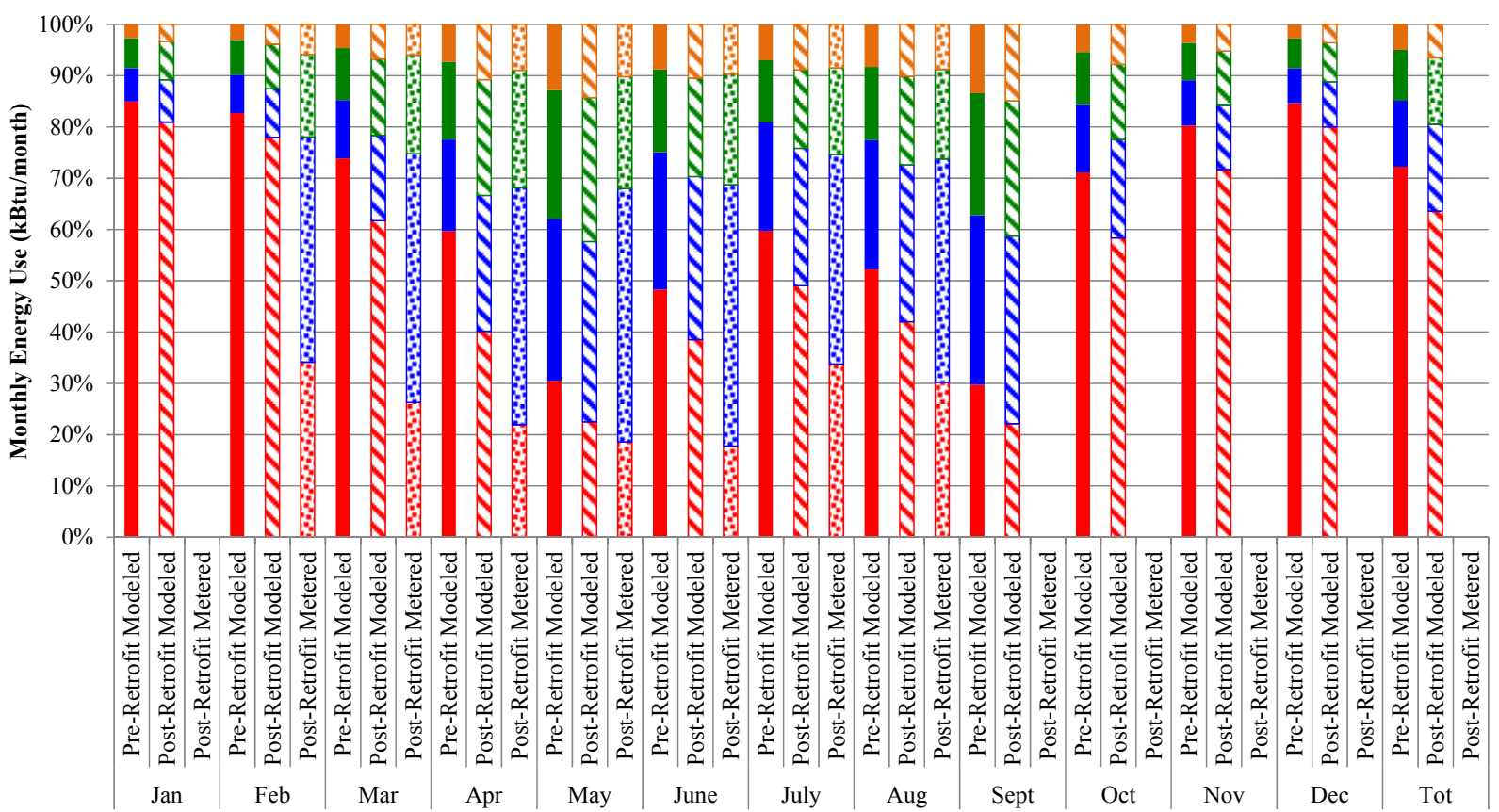

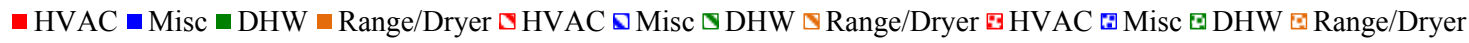

Figure C.24. PNW-3 monthly and annual pre-retrofit modeled, post-retrofit modeled, and metered results percentage by end-use. 


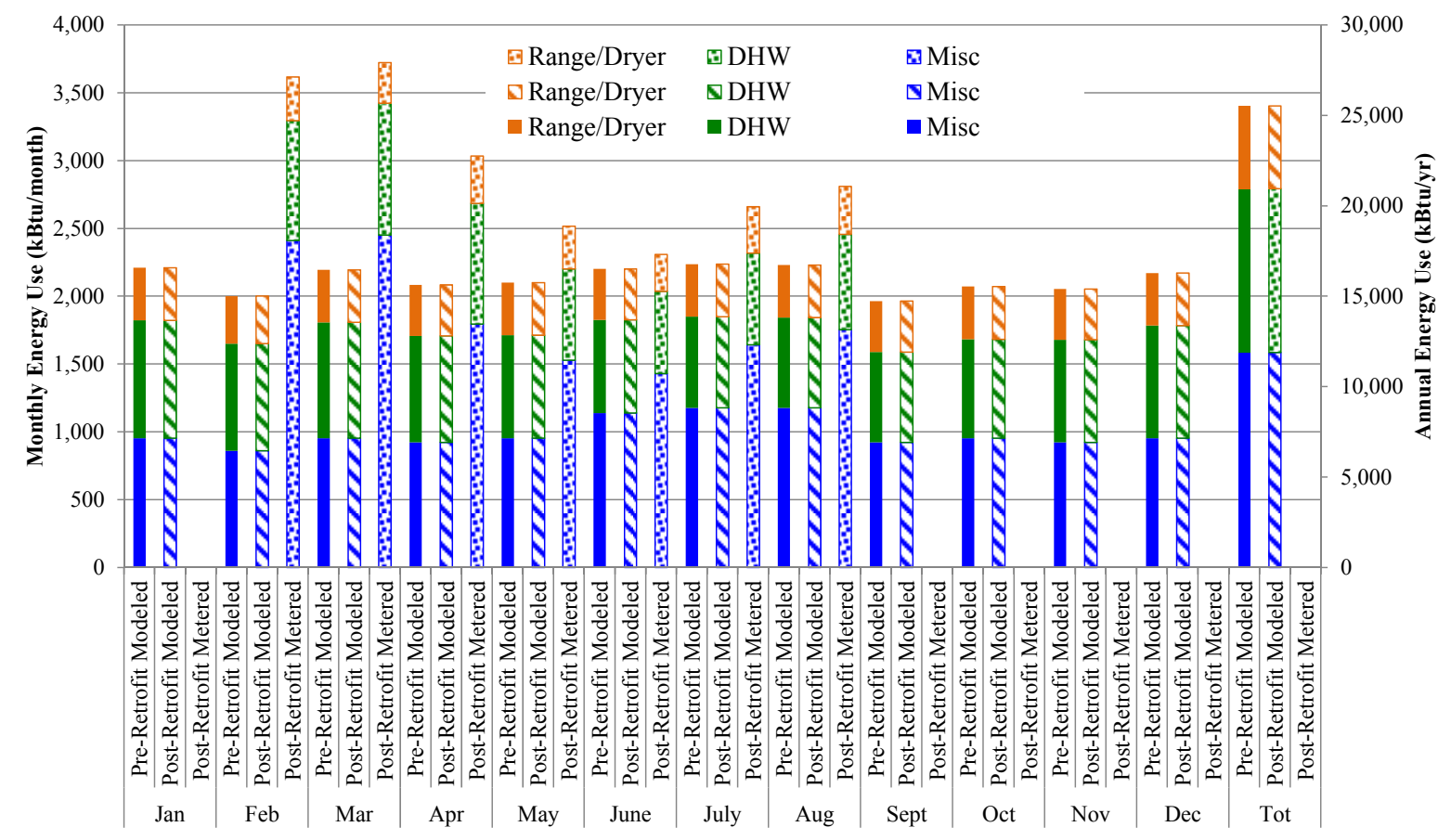

Figure C.25. PNW-3 monthly and annual pre-retrofit modeled, post-retrofit modeled, and metered results disaggregation by minor end-use.

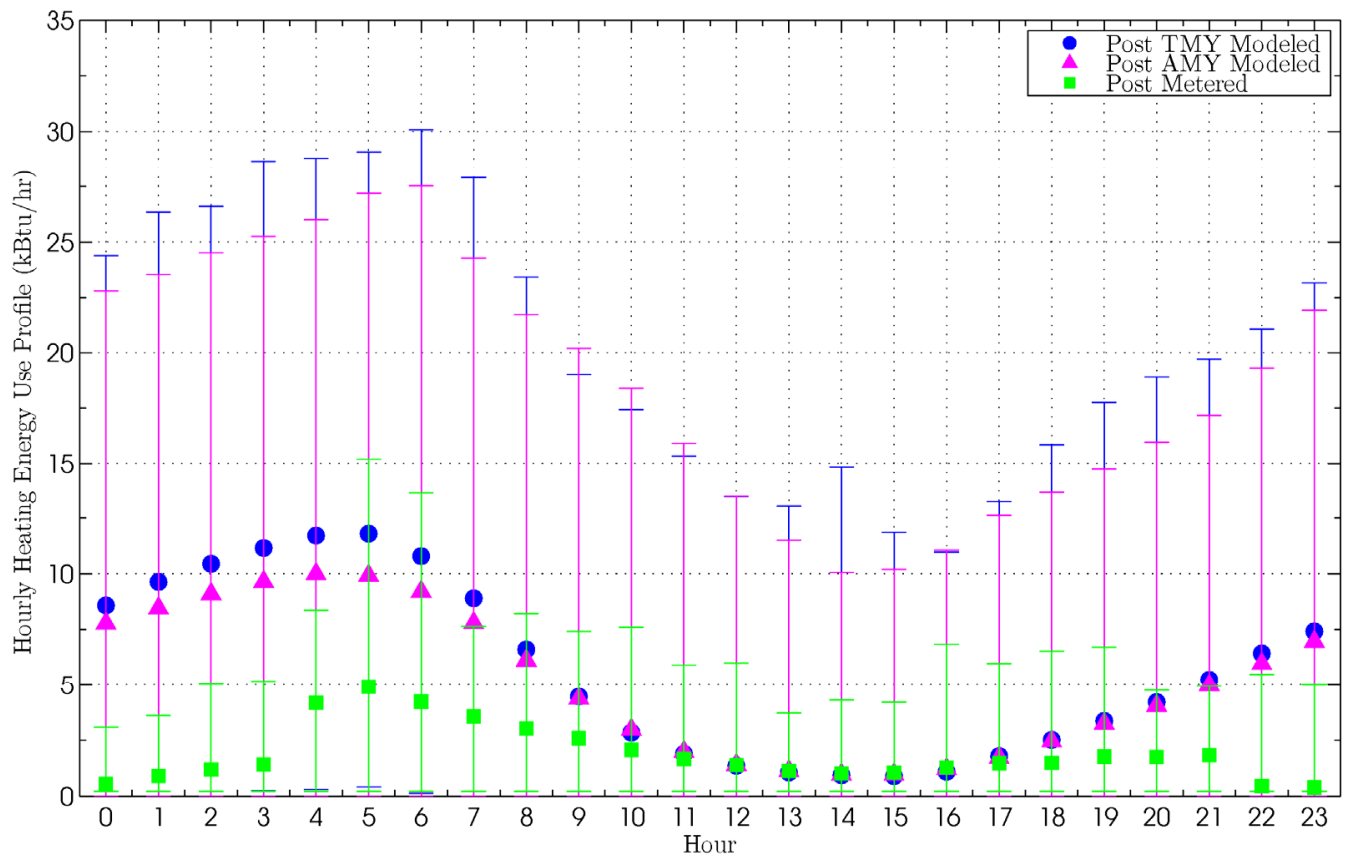

Figure C.26. PNW-3 hourly heating energy use profile comparison. ${ }^{1}$

\footnotetext{
${ }^{1}$ The error bars in all hourly profiles presented in this report represent the maximum and minimum values observed during the given hour and not the standard deviation. This presentation provides insight into the maximum load observed for the equipment monitored.
} 


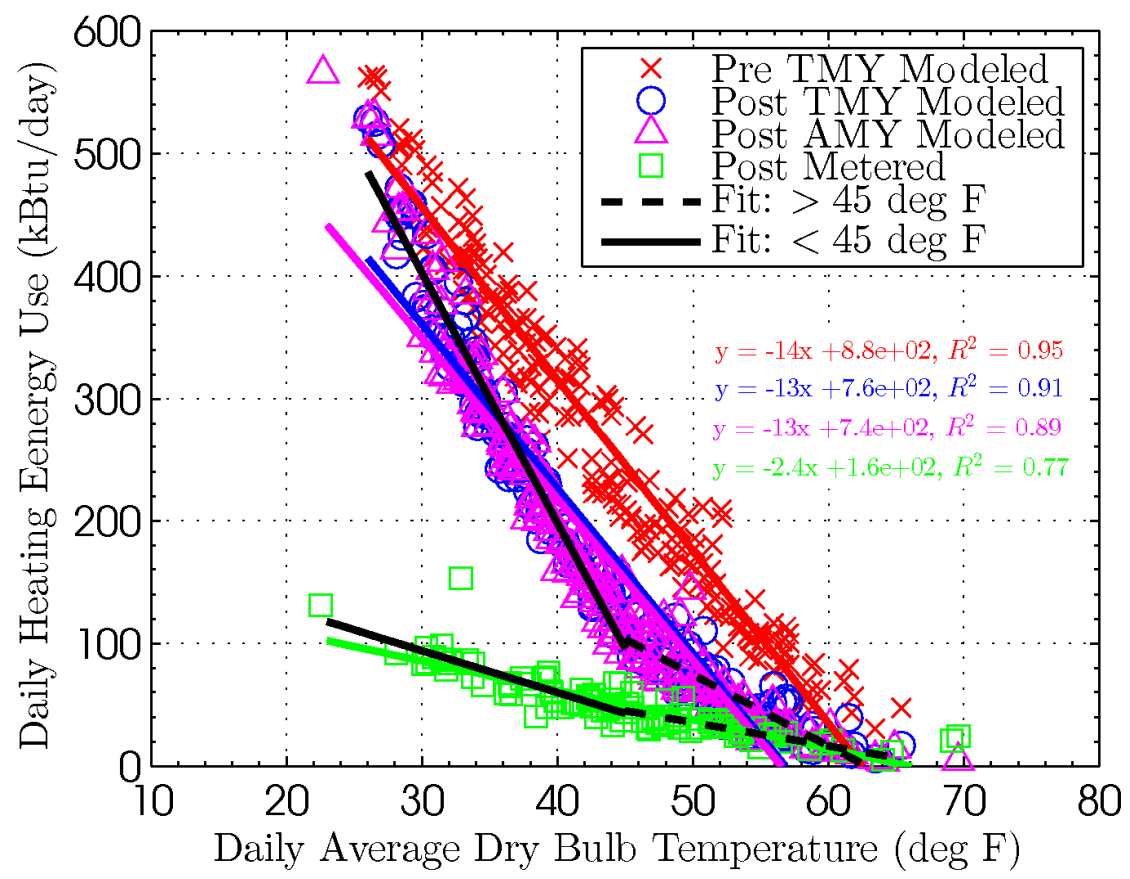

Figure C.27. PNW-3 daily heating energy use and dry bulb temperature comparison.

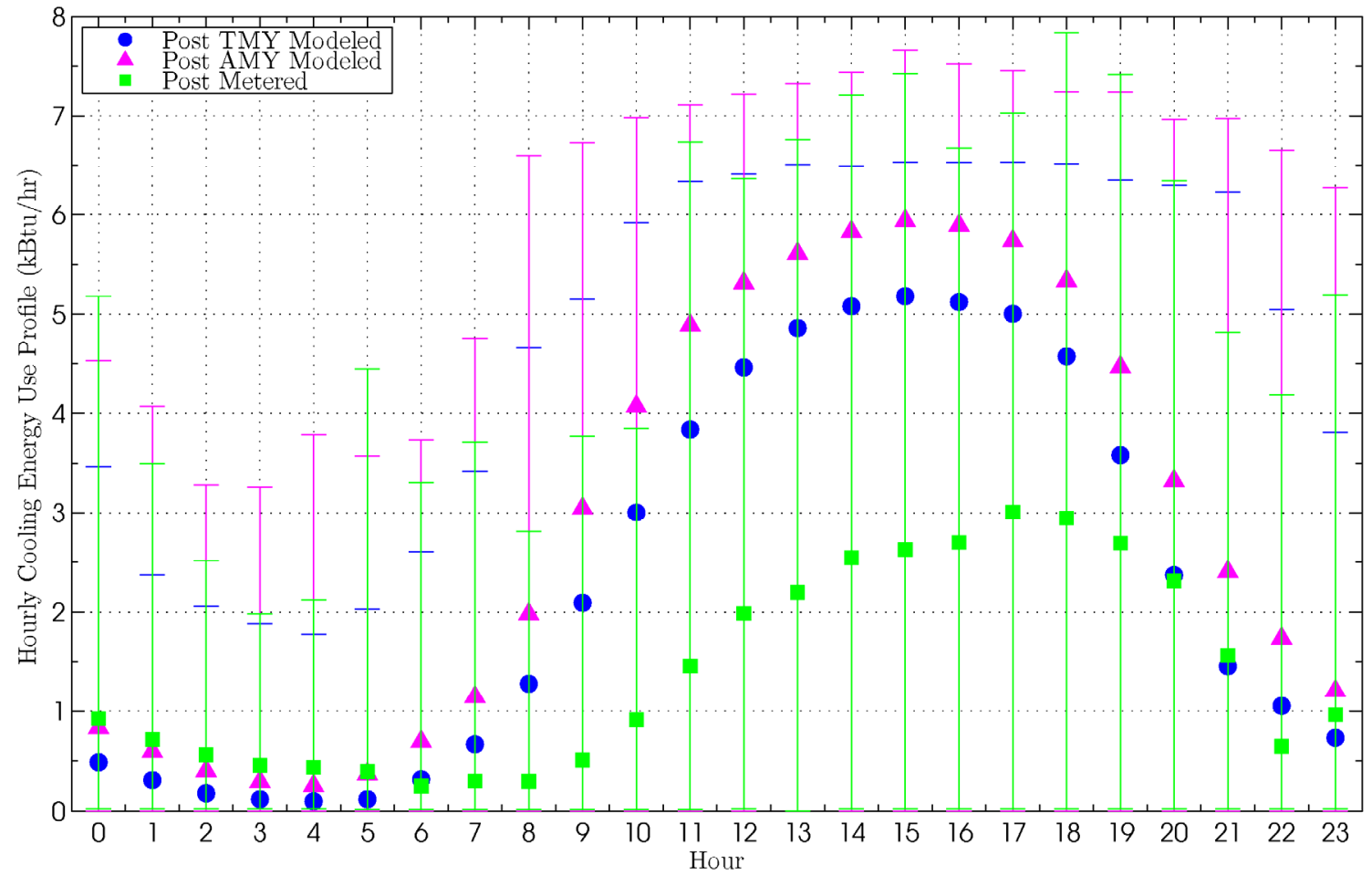

Figure C.28. PNW-3 hourly cooling energy use profile comparison. 


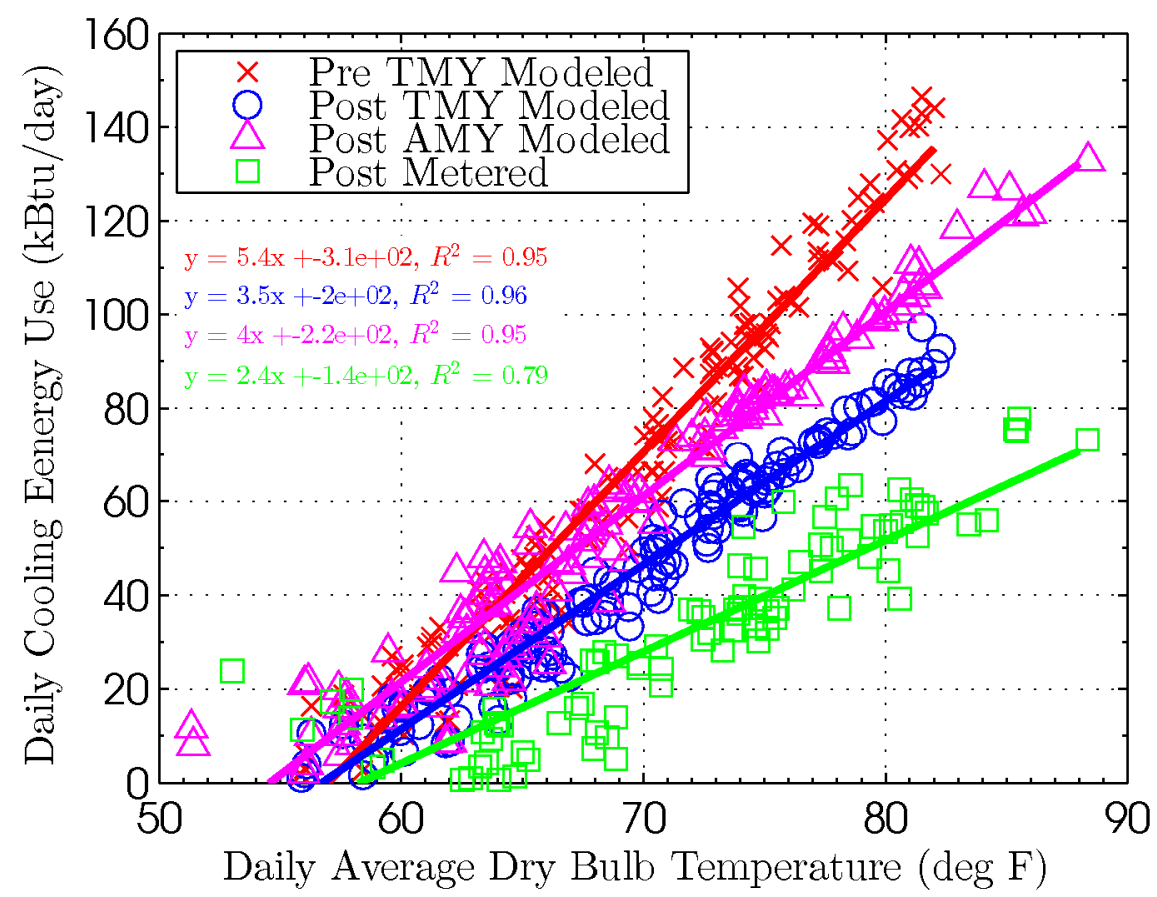

Figure C.29. PNW-3 daily cooling energy use and dry bulb temperature comparison.

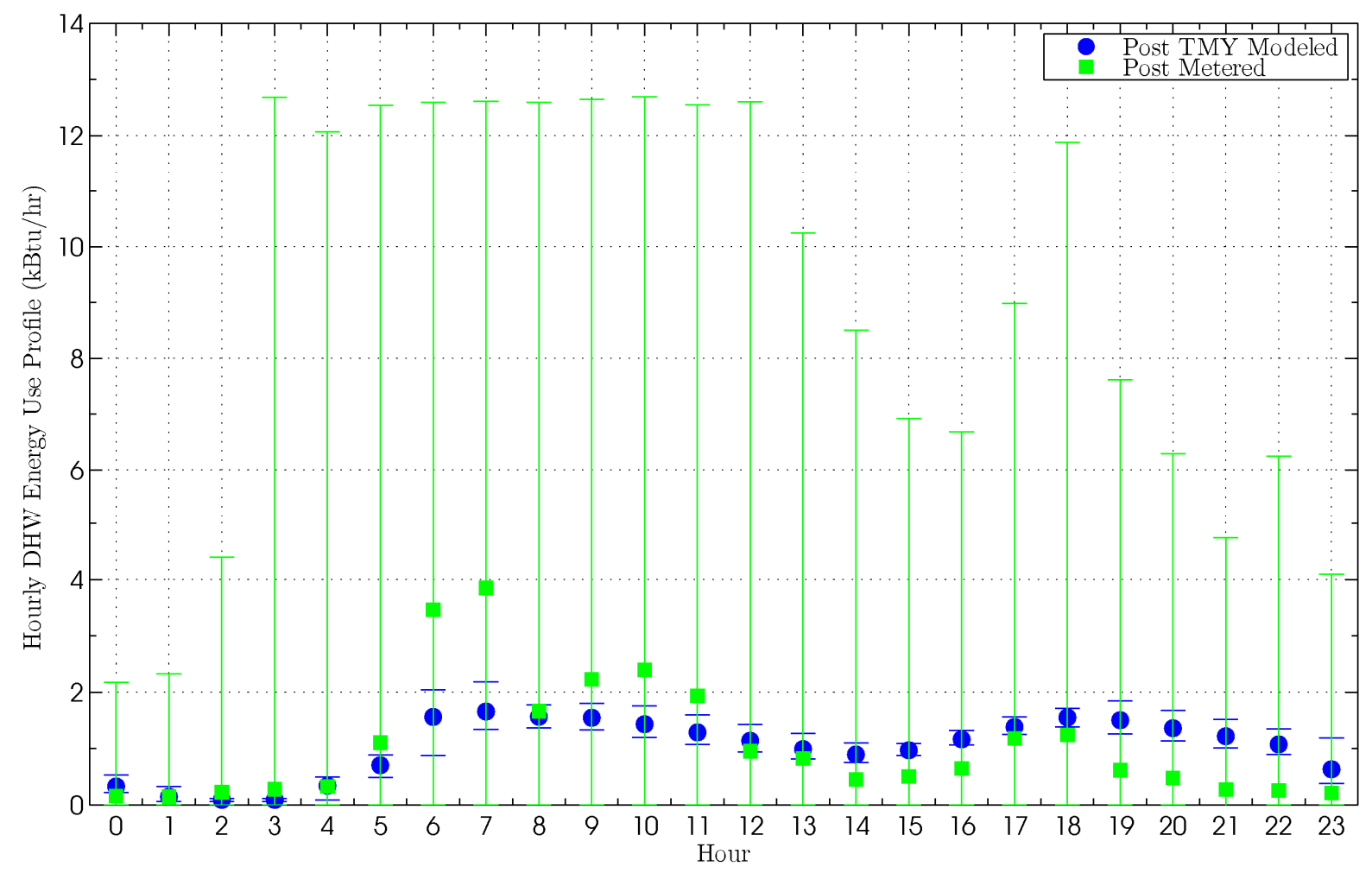

Figure C.30. PNW-3 hourly DHW energy use profile comparison. 


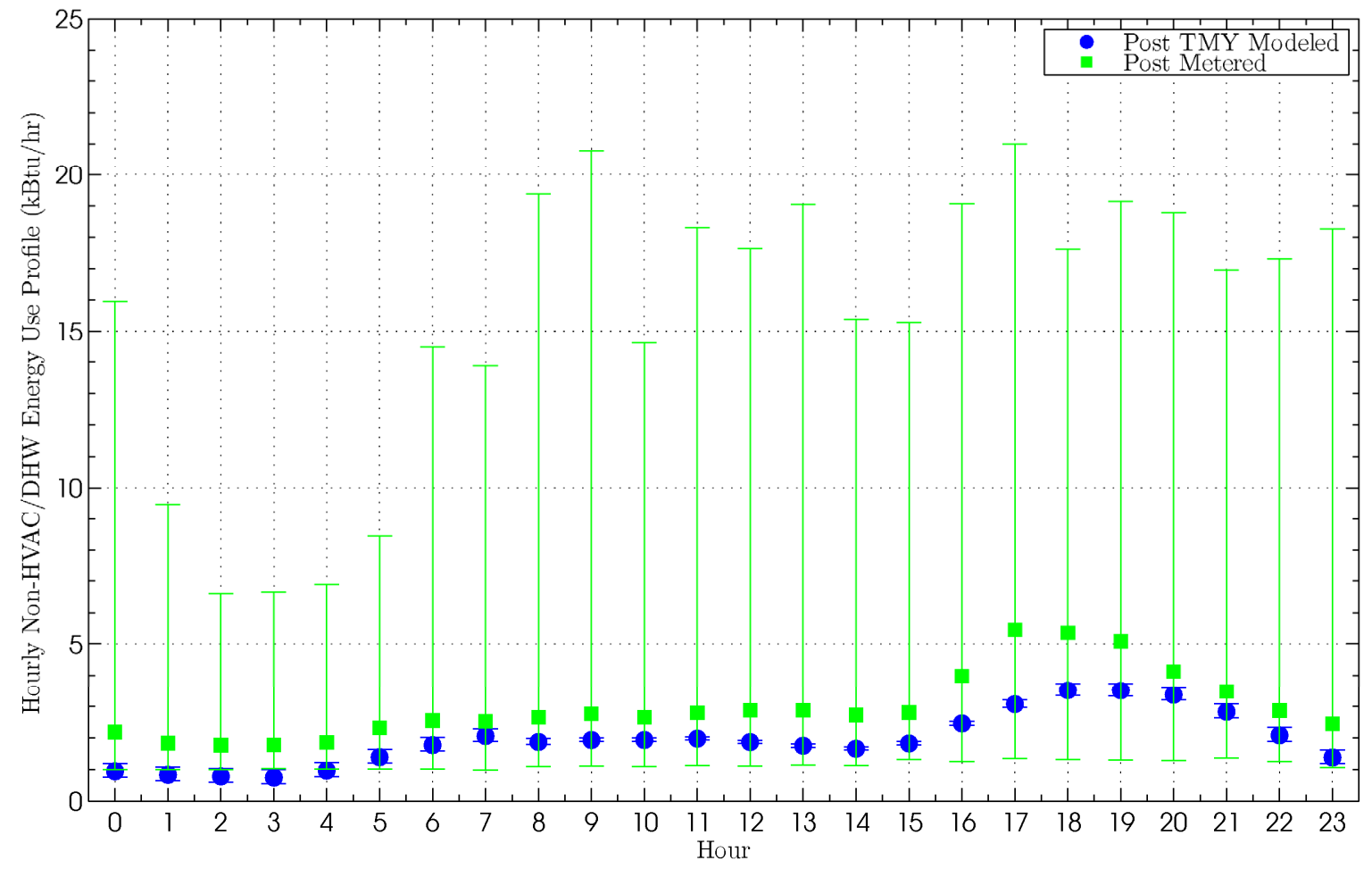

Figure C.31. PNW-3 hourly energy use, excluding HVAC and DHW, profile comparison.

\section{C.4 PNW-4 Home}

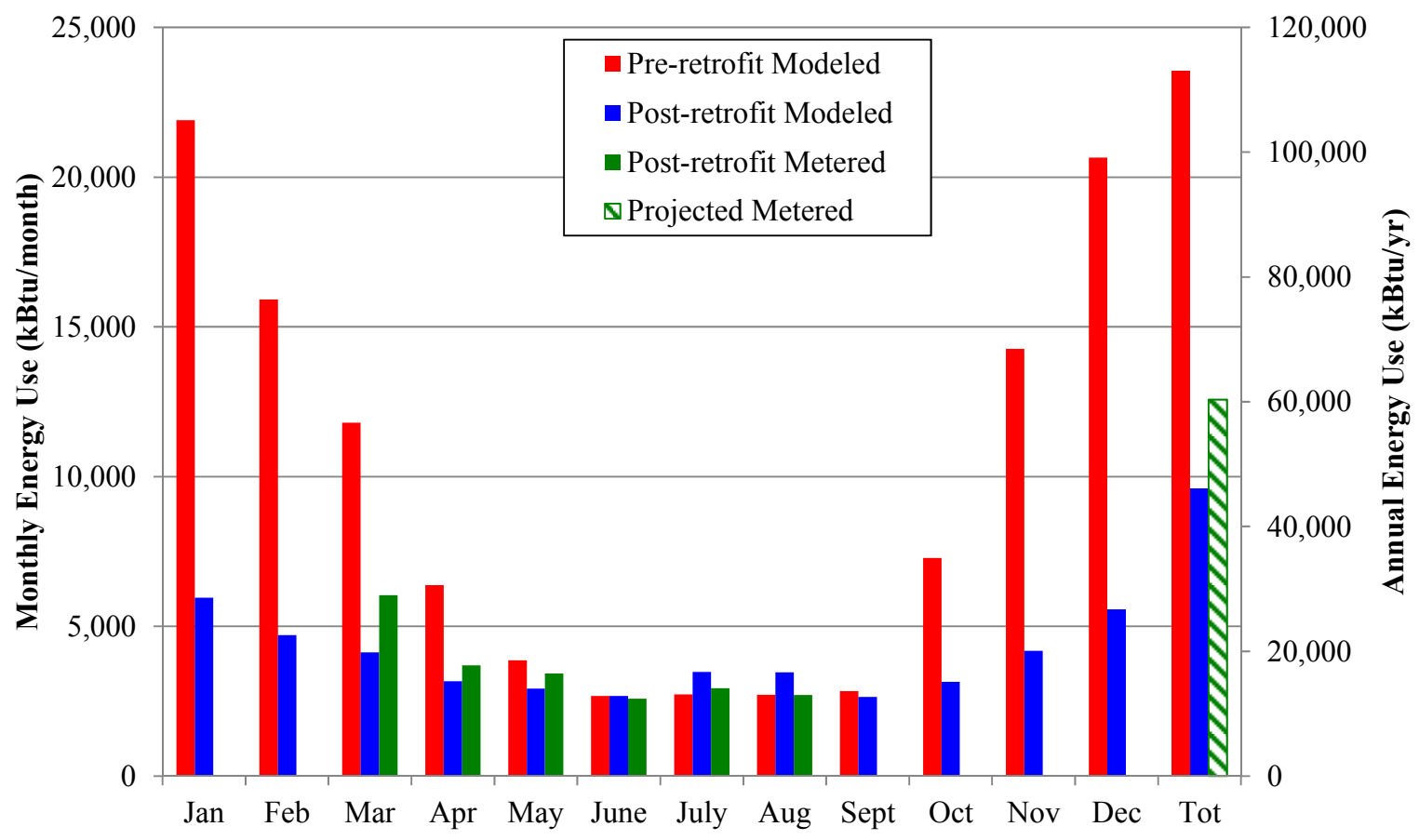

Figure C.32. PNW-4 monthly and annual pre-retrofit modeled, post-retrofit modeled, and metered results. 


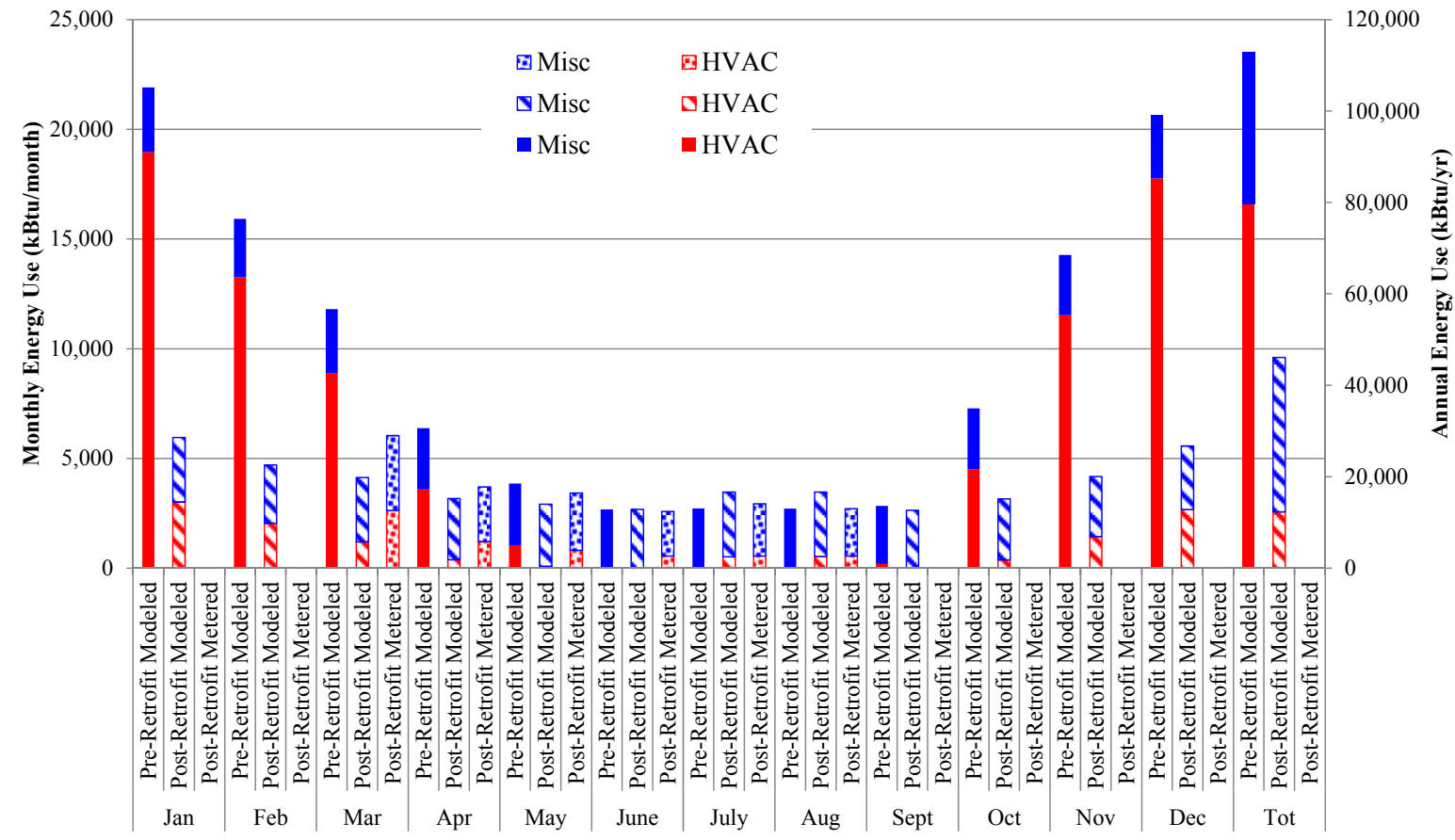

Figure C.33. PNW-4 monthly and annual pre-retrofit modeled, post-retrofit modeled, and metered results disaggregated by end-use.

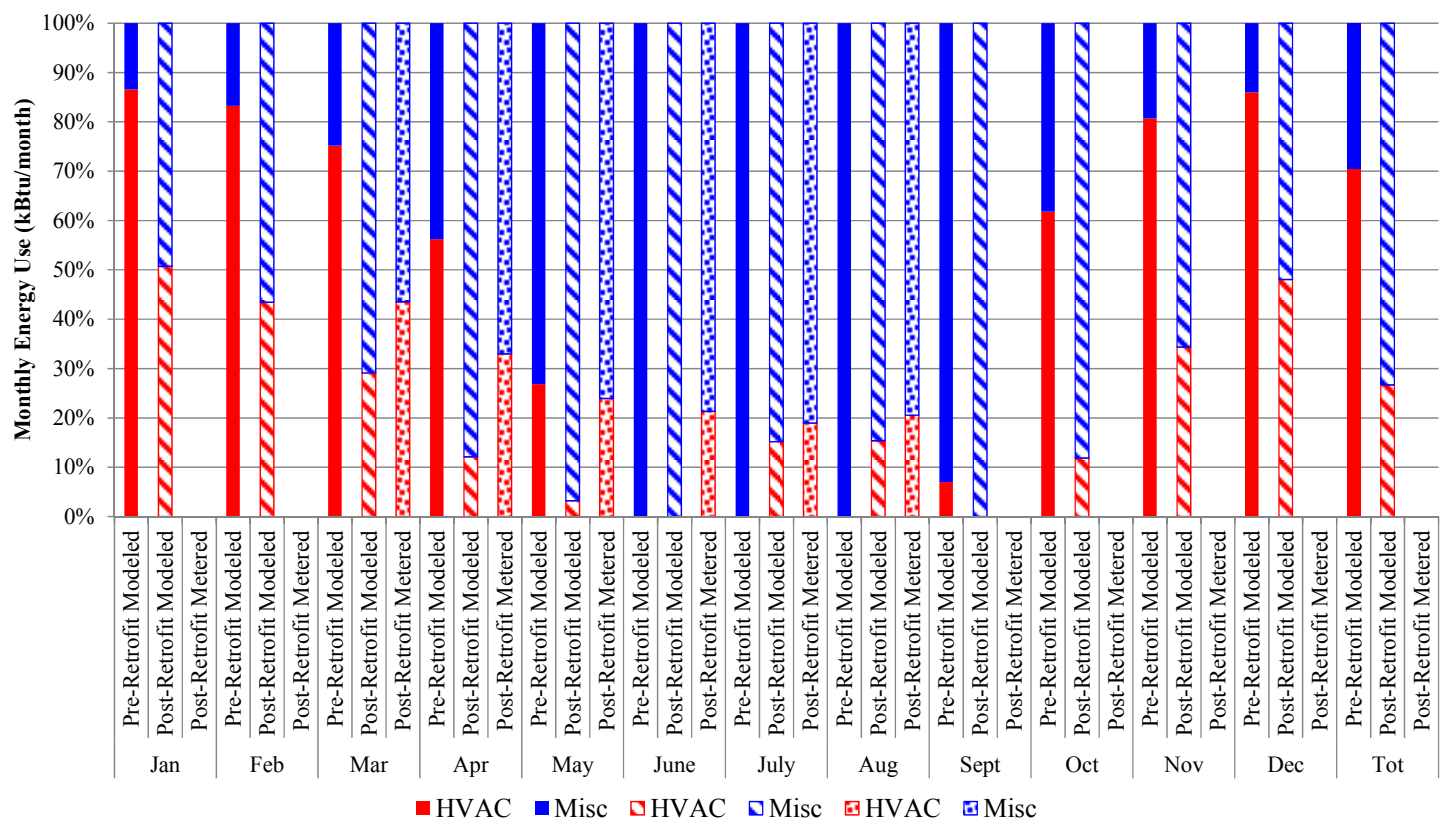

Figure C.34. PNW-4 monthly and annual pre-retrofit modeled, post-retrofit modeled, and metered results percentage by end-use. 


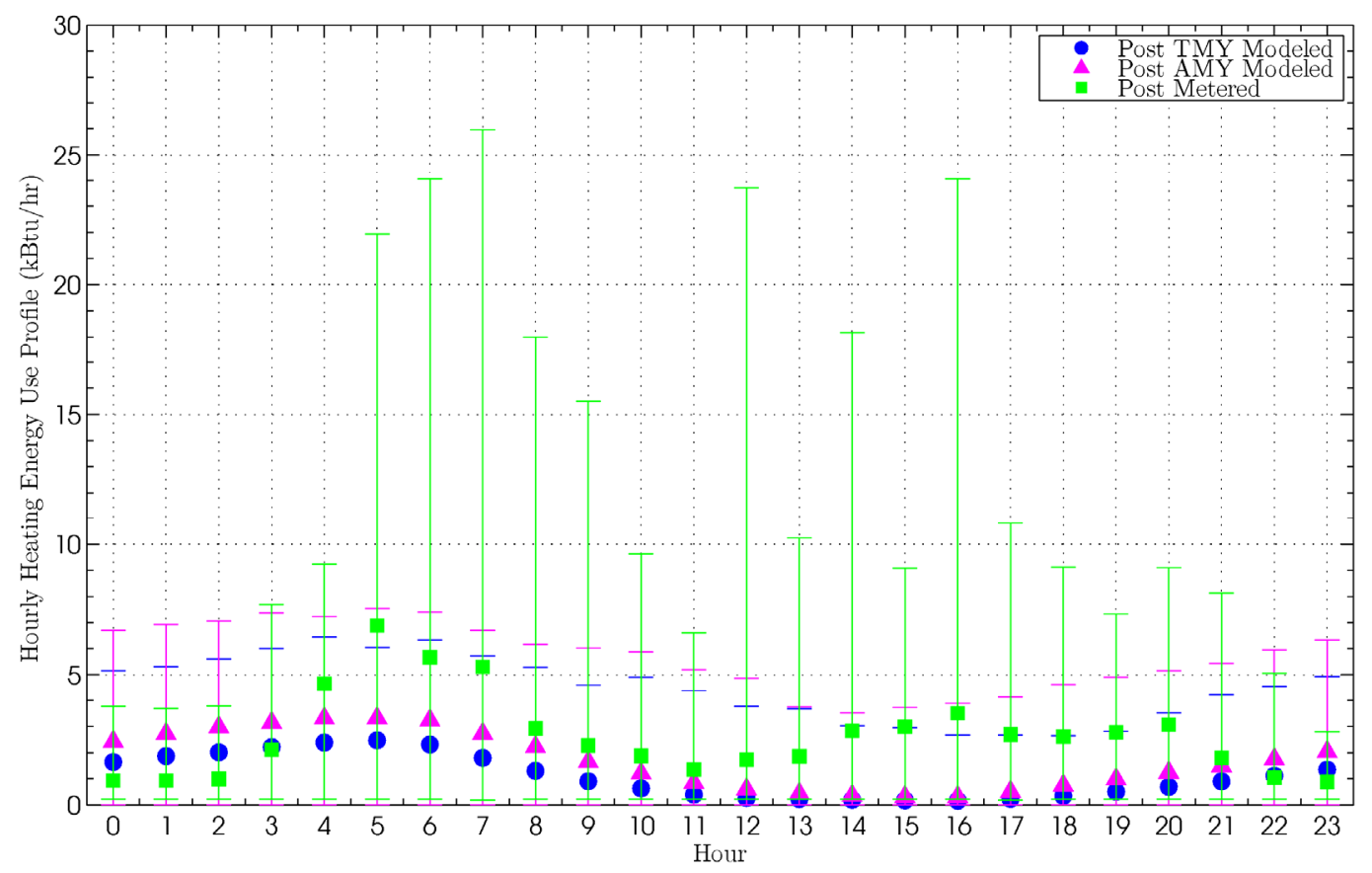

Figure C.35. PNW-4 hourly heating energy use profile comparison. ${ }^{1}$

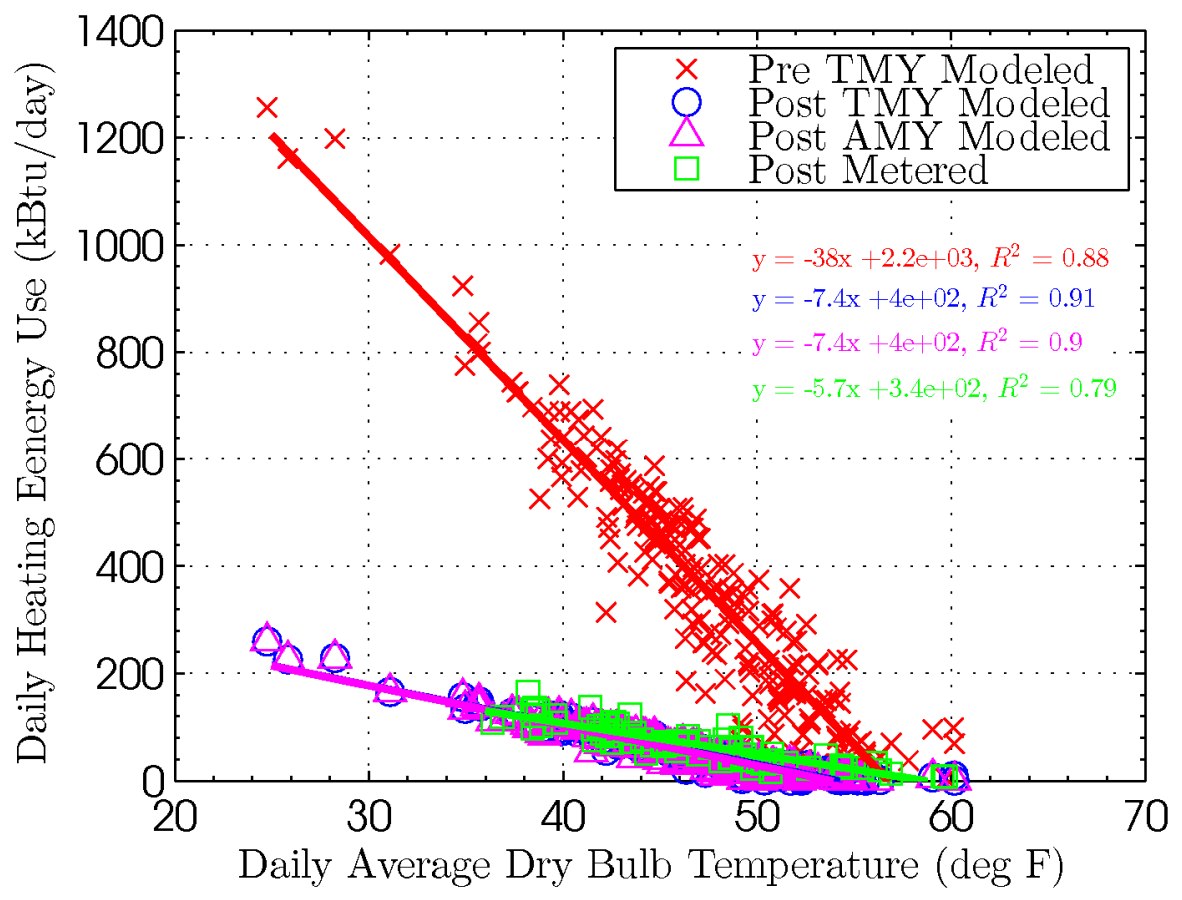

Figure C.36. PNW-4 daily heating energy use and dry bulb temperature comparison.

\footnotetext{
${ }^{1}$ The error bars in all hourly profiles presented in this report represent the maximum and minimum values observed during the given hour and not the standard deviation. This presentation provides insight into the maximum load observed for the equipment monitored.
} 


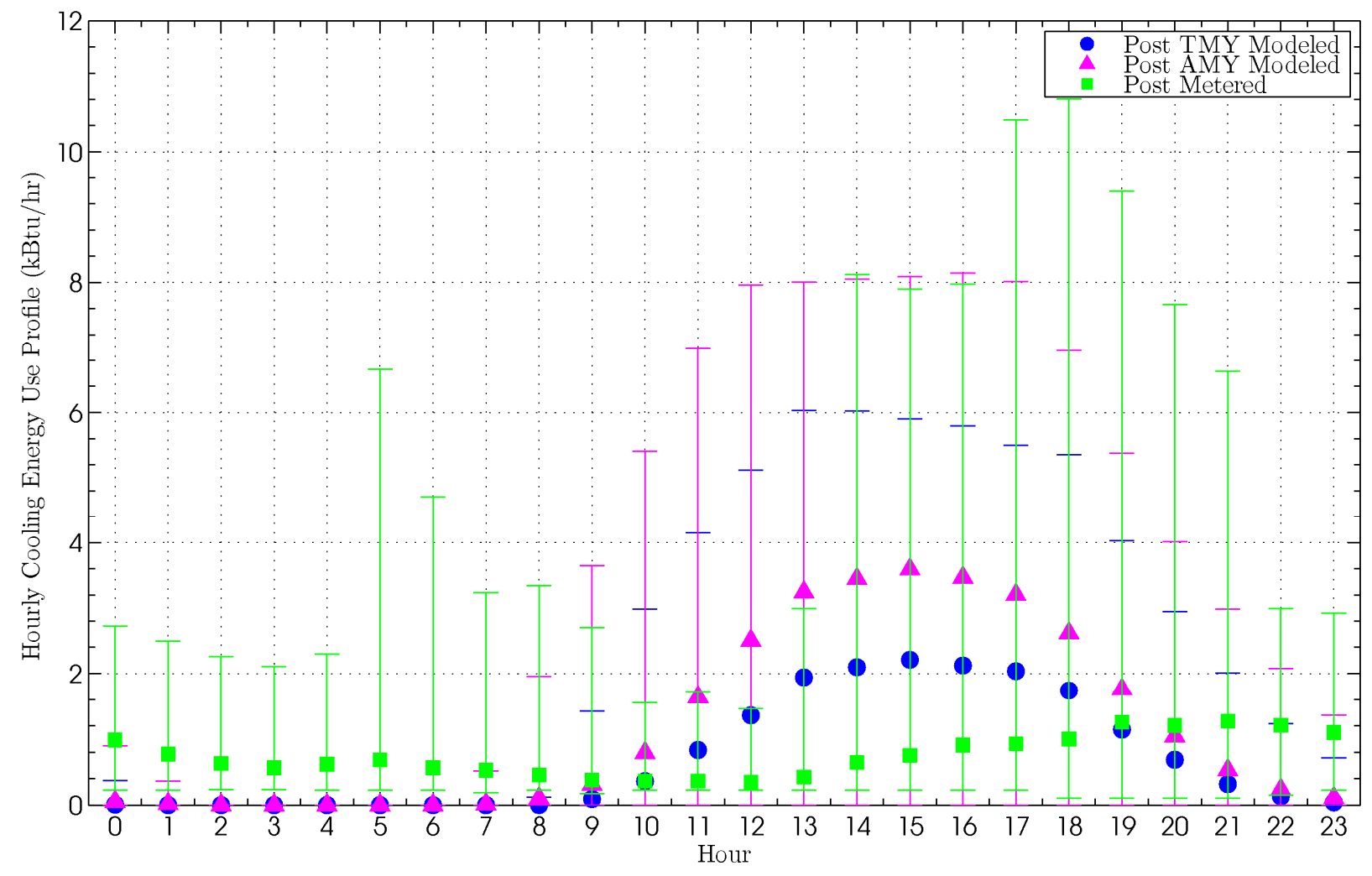

Figure C.37. PNW-4 hourly cooling energy use profile comparison.

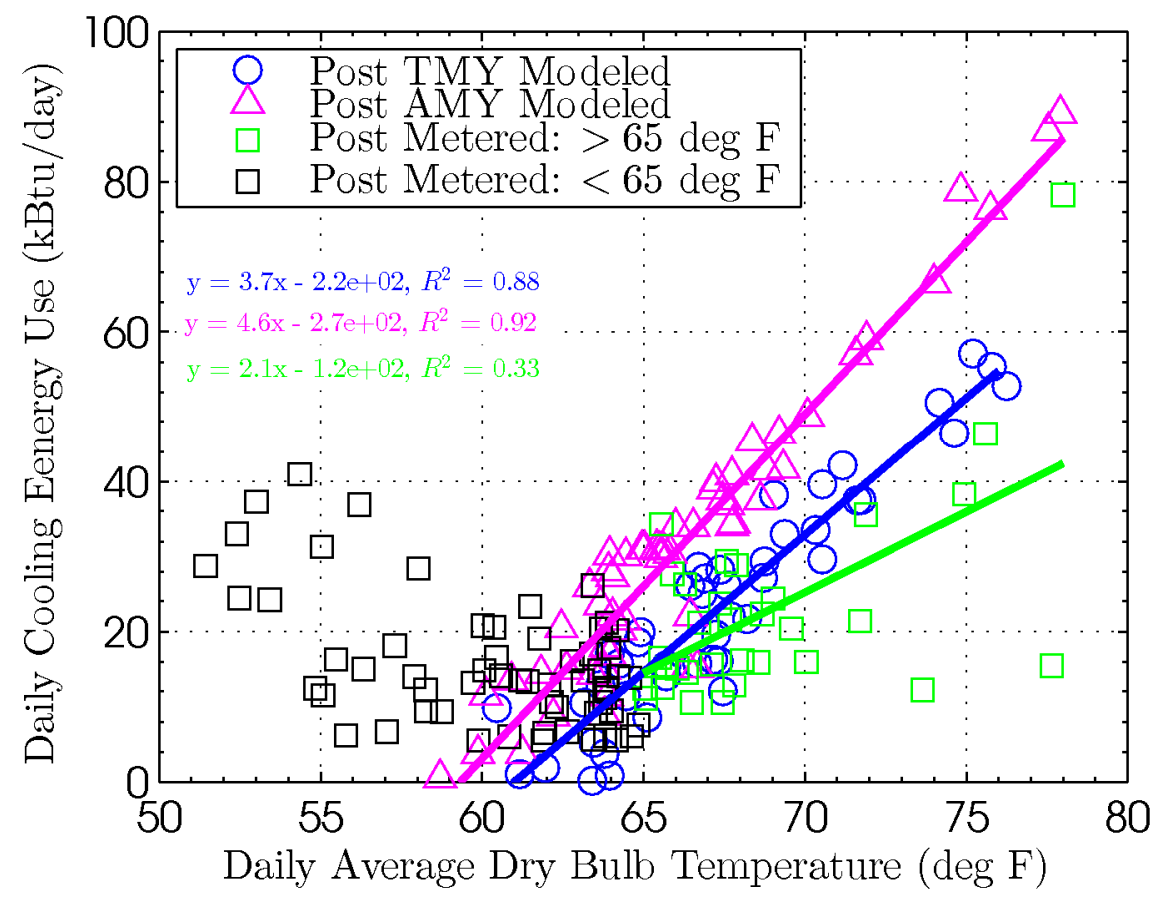

Figure C.38. PNW-4 daily cooling energy use and dry bulb temperature comparison. 


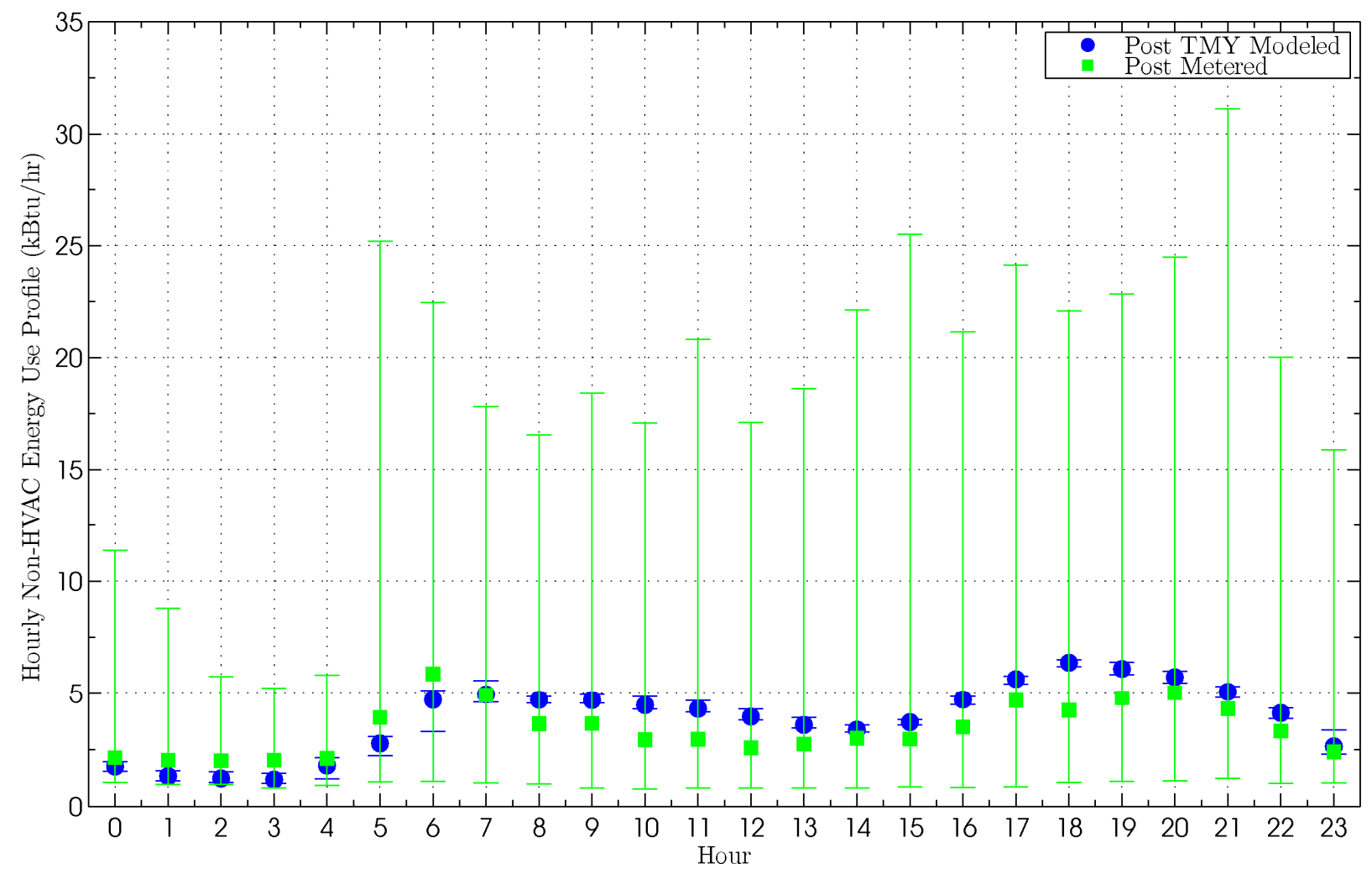

Figure C.39. PNW-4 hourly energy use, excluding HVAC and DHW, profile comparison.

\section{C.5 PNW-5 Home}

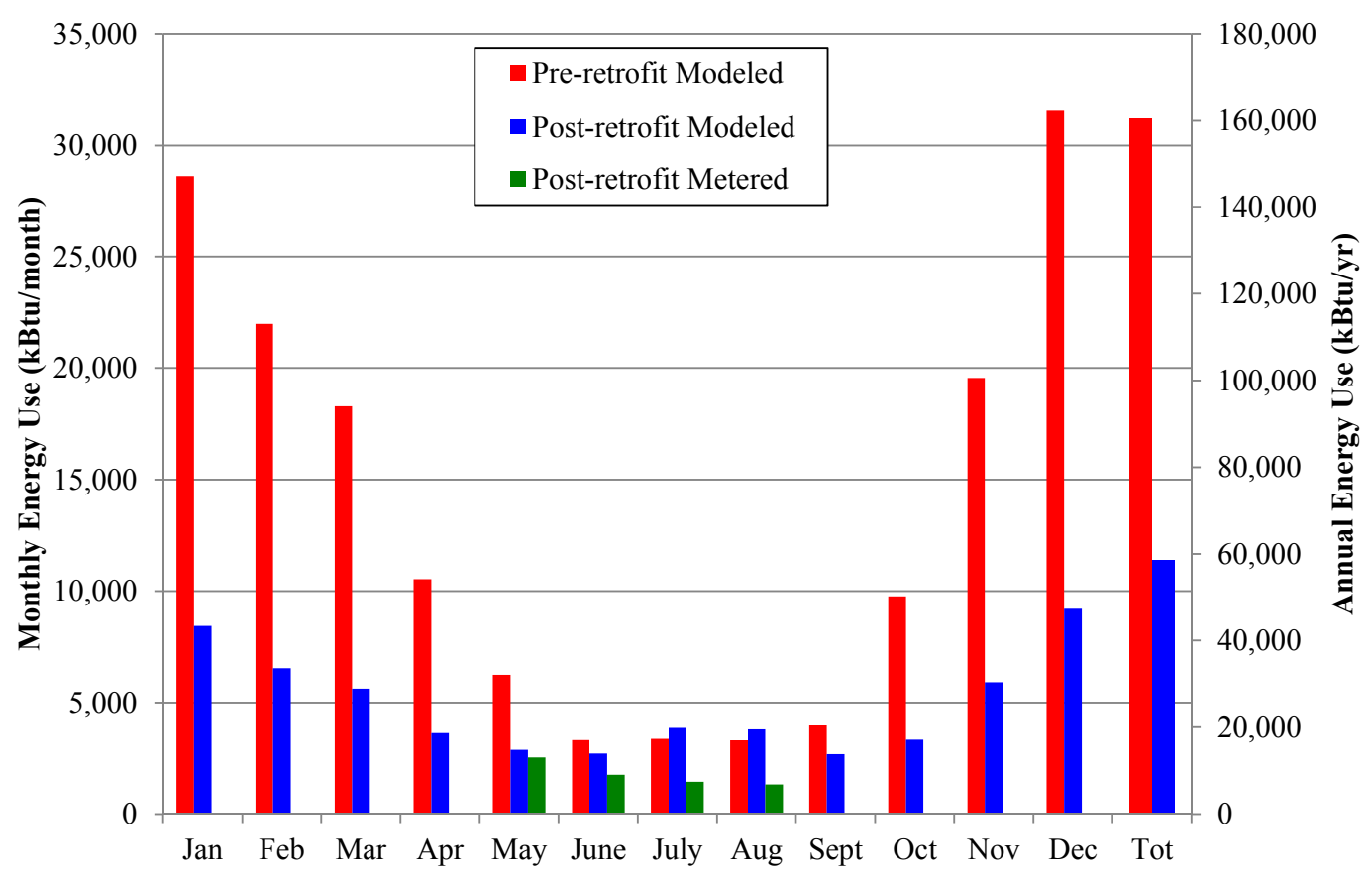

Figure C.40. PNW-5 monthly and annual pre-retrofit, post-retrofit, and metered results. 


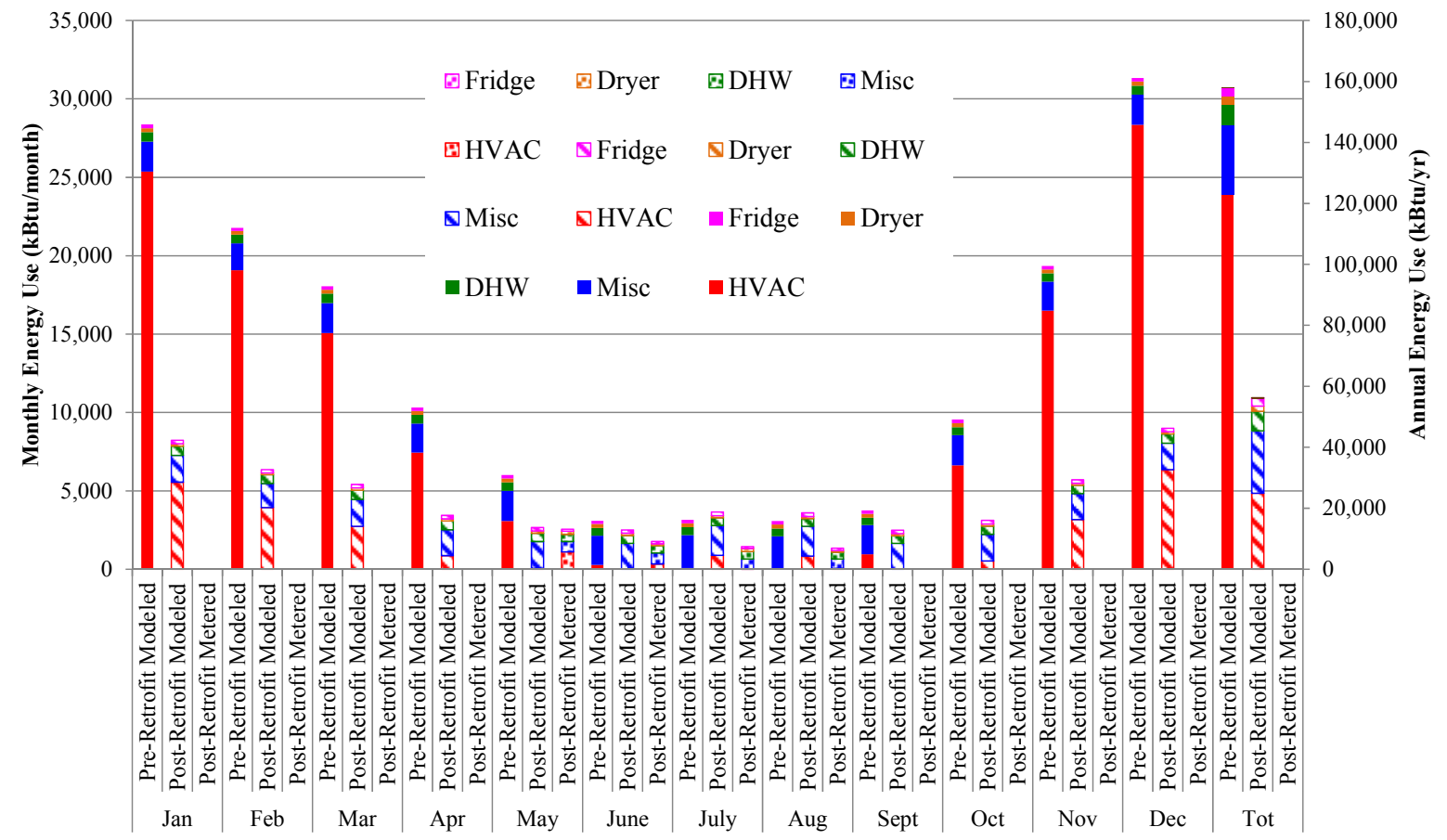

Figure C.41. PNW-5 monthly and annual pre-retrofit modeled, post-retrofit modeled, and metered results disaggregated by end-use.

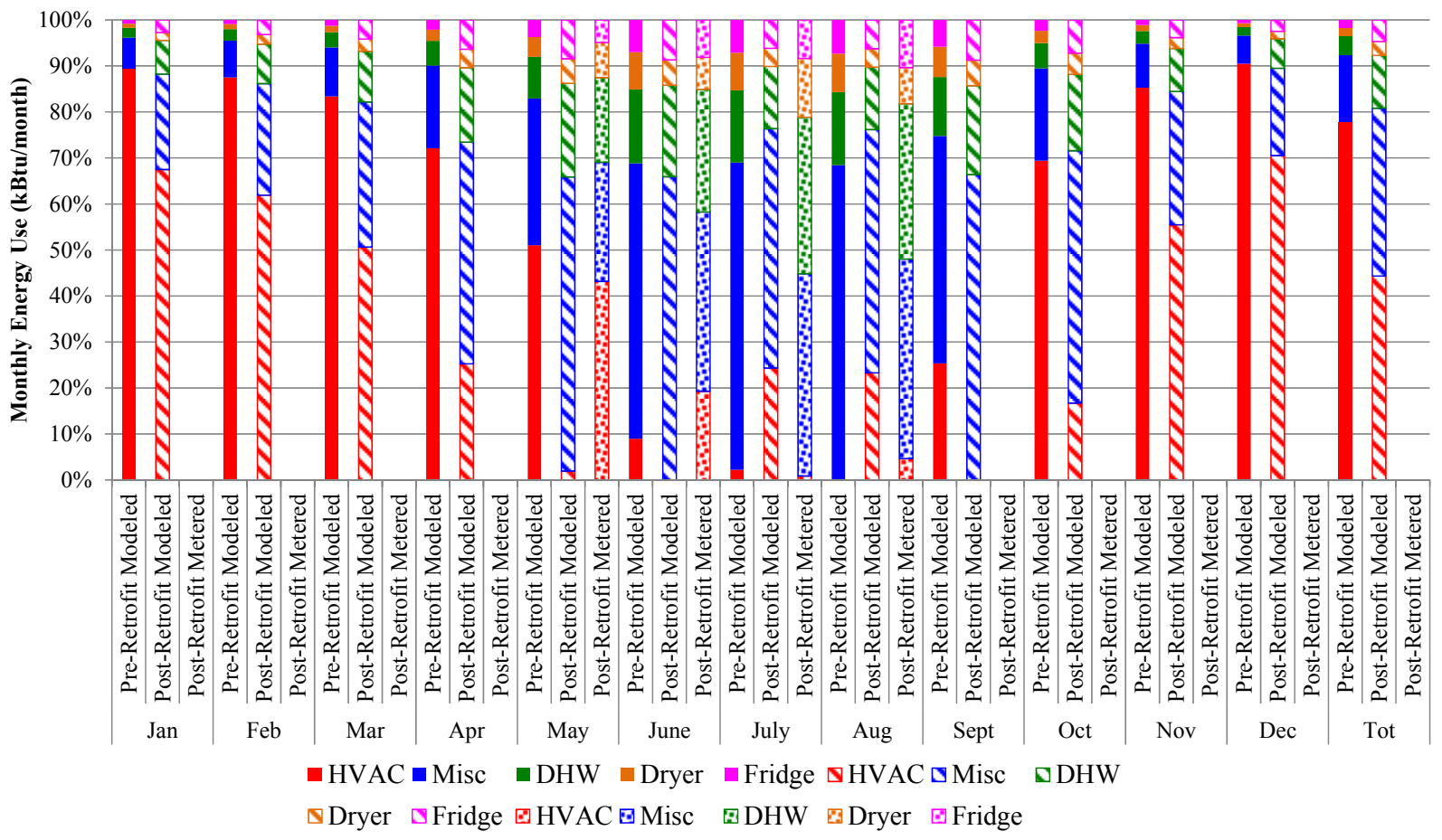

Figure C.42. PNW-5 monthly and annual pre-retrofit modeled, post-retrofit modeled, and metered results percentage by end-use. 


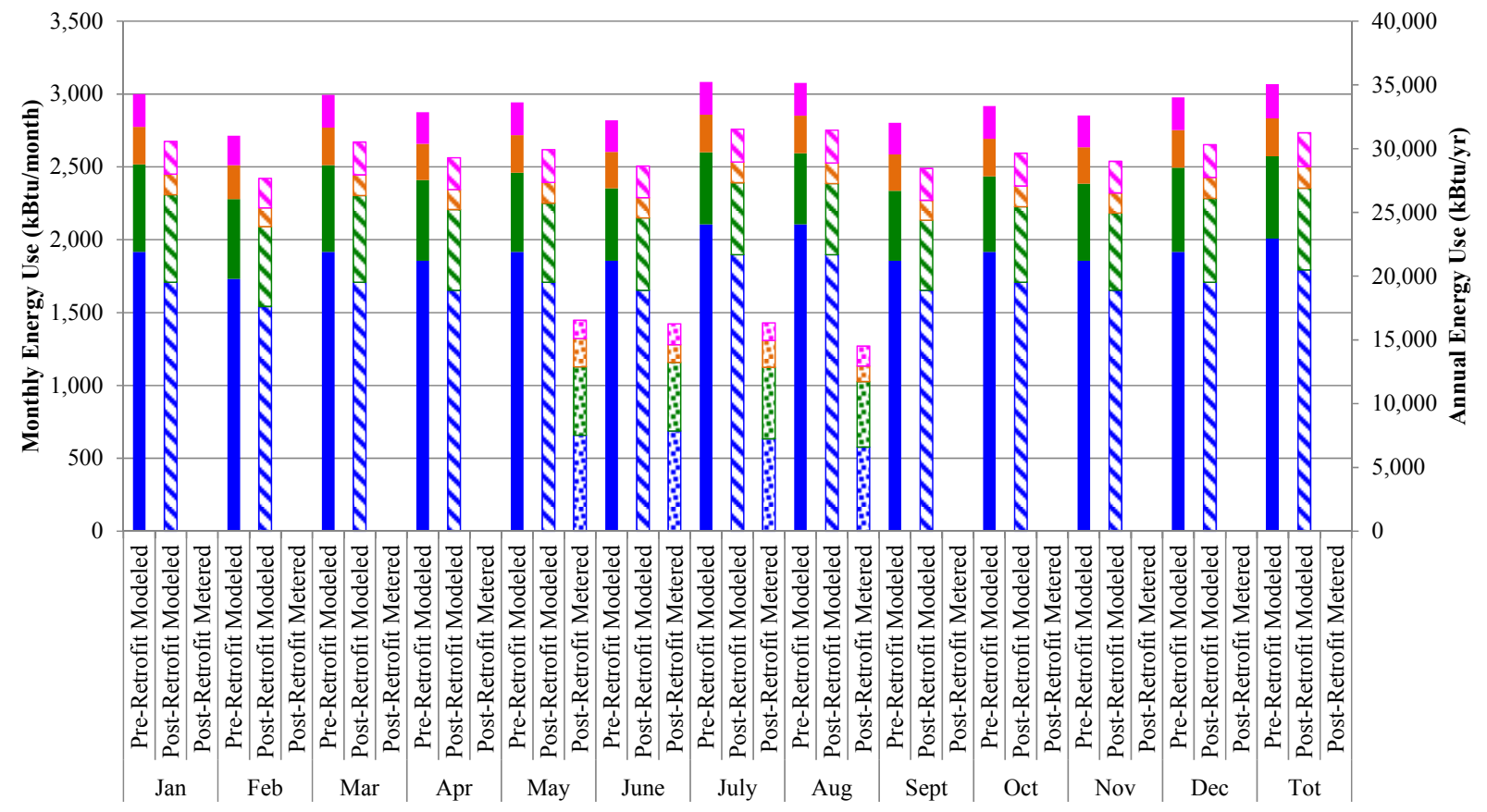

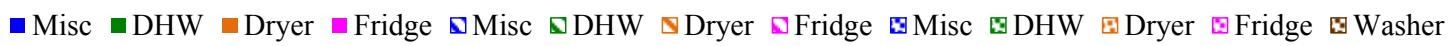

Figure C.43. PNW-5 monthly and annual pre-retrofit modeled, post-retrofit modeled, and metered results disaggregation by minor end-use.

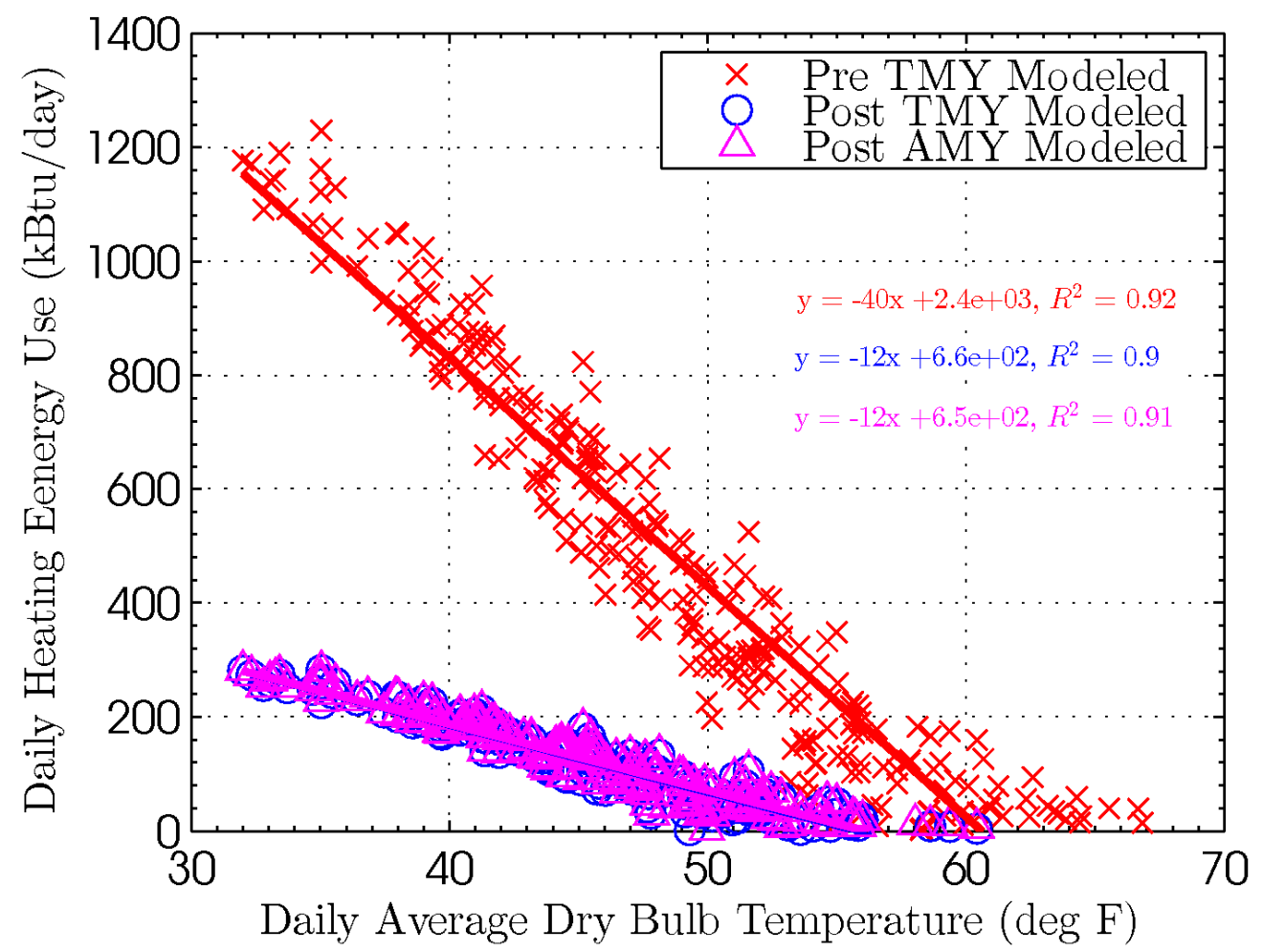

Figure C.44. PNW-5 daily heating energy use and dry bulb temperature comparison. 


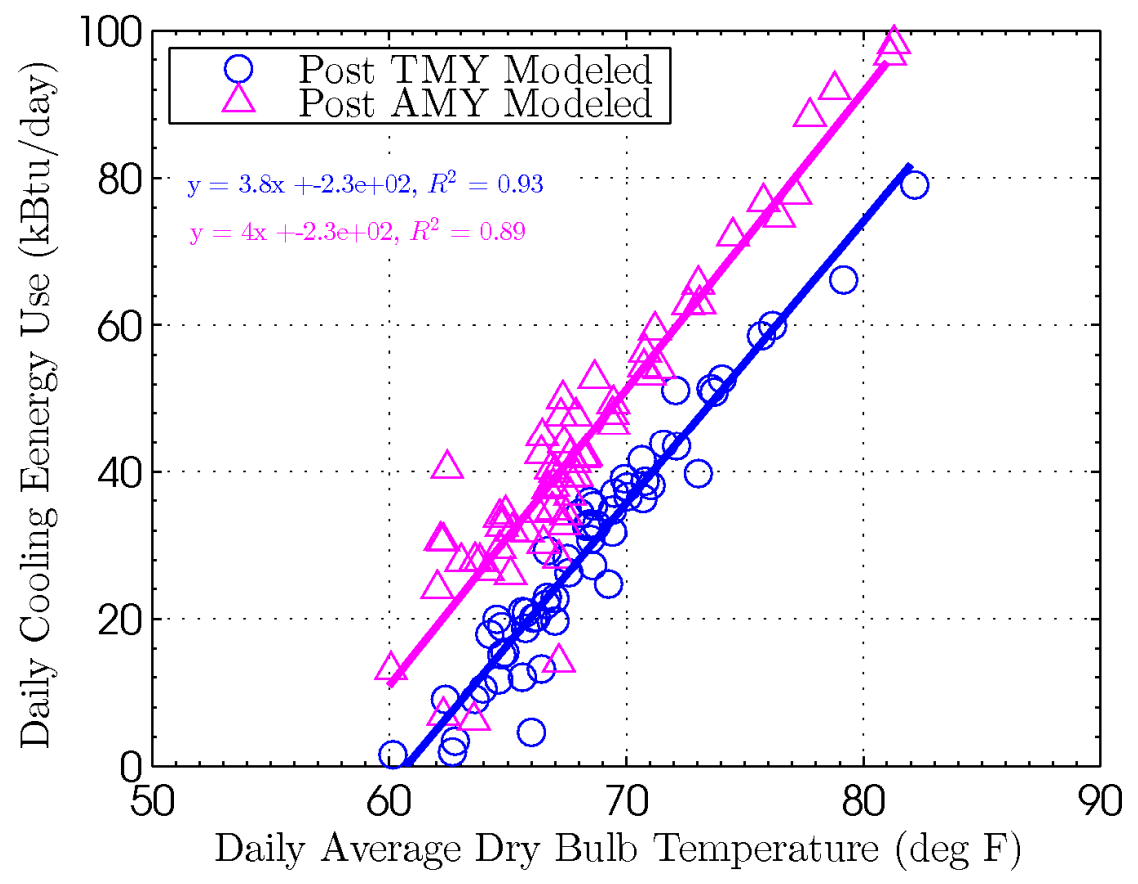

Figure C.45. PNW-5 daily cooling energy use and dry bulb temperature comparison.

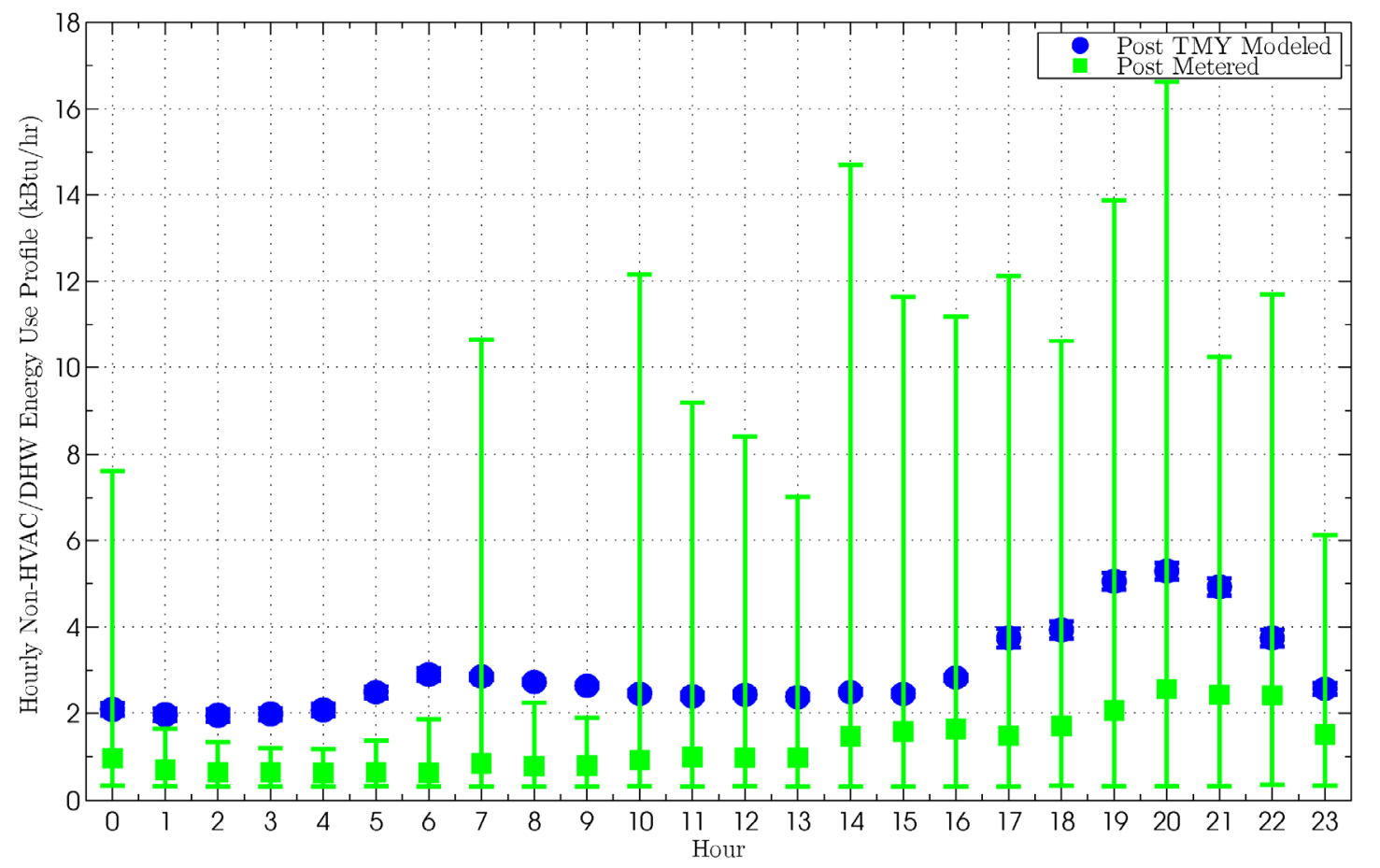

Figure C.46. PNW-5 hourly energy use, excluding HVAC and DHW, profile comparison. ${ }^{1}$

\footnotetext{
${ }^{1}$ The error bars in all hourly profiles presented in this report represent the maximum and minimum values observed during the given hour and not the standard deviation. This presentation provides insight into the maximum load observed for the equipment monitored.
} 


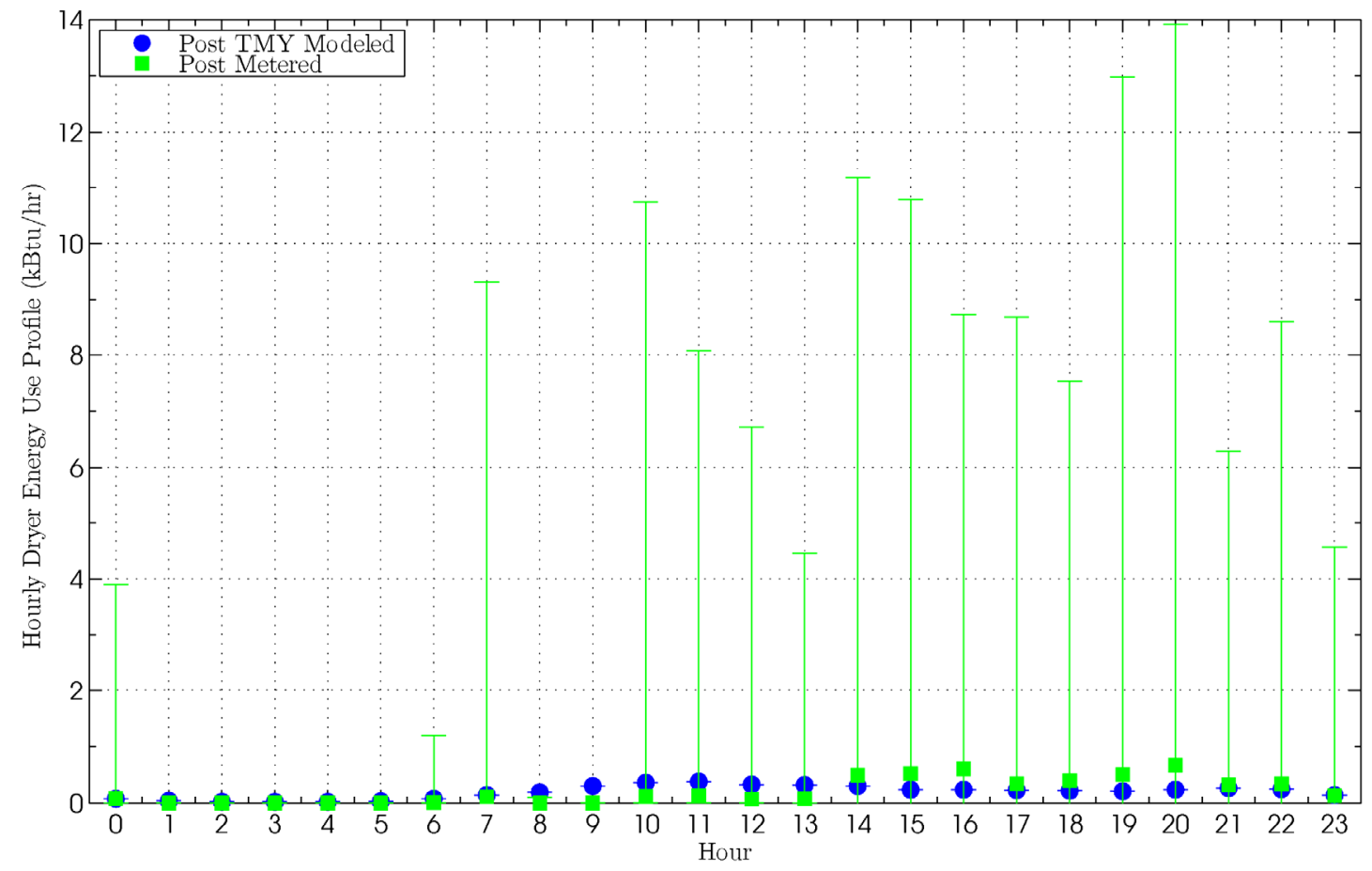

Figure C.47. PNW-5 hourly dryer energy use profile comparison.

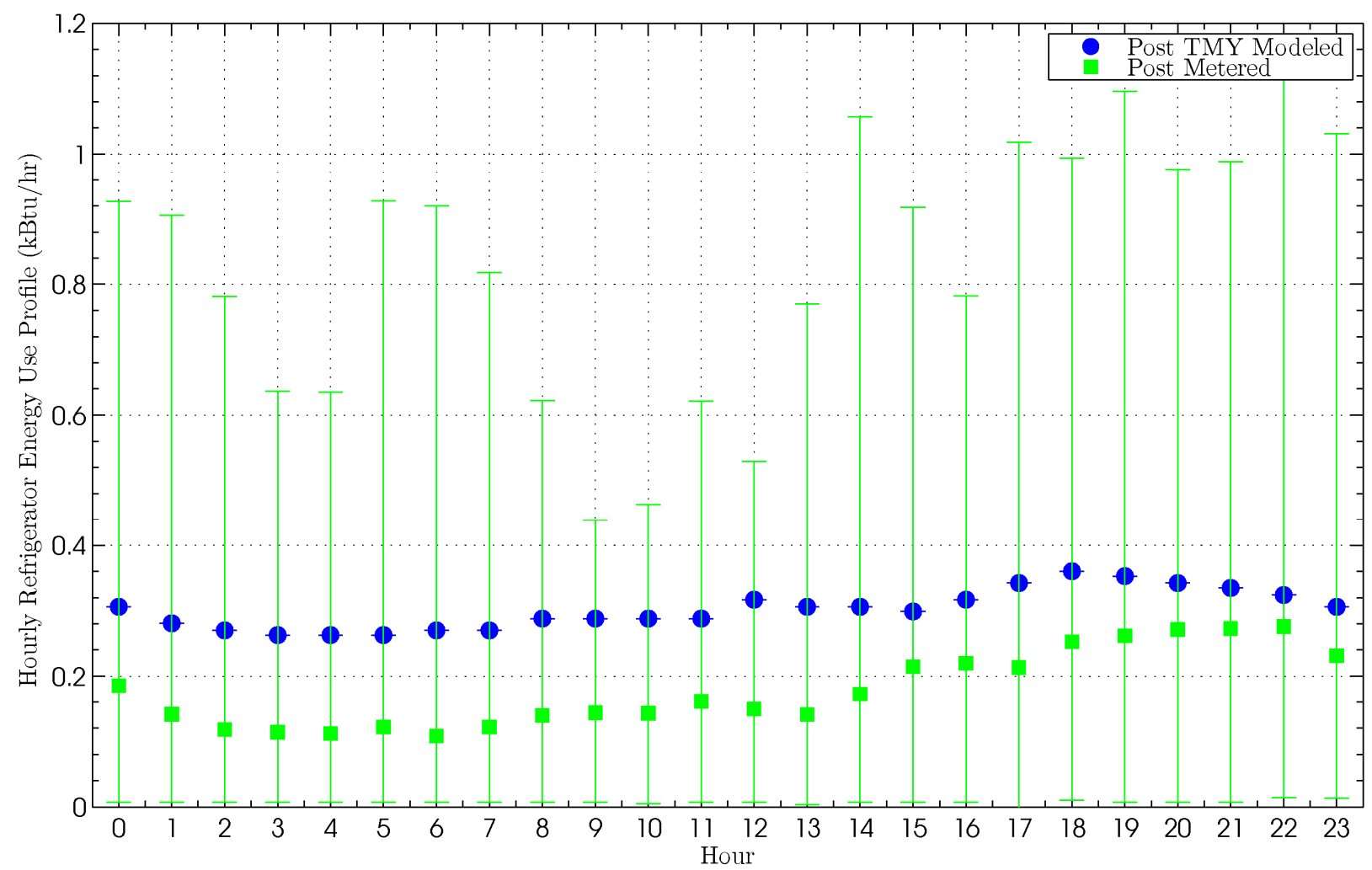

Figure C.48. PNW-5 hourly refrigerator energy use profile comparison. 


\section{C.6 PNW-6 Home}

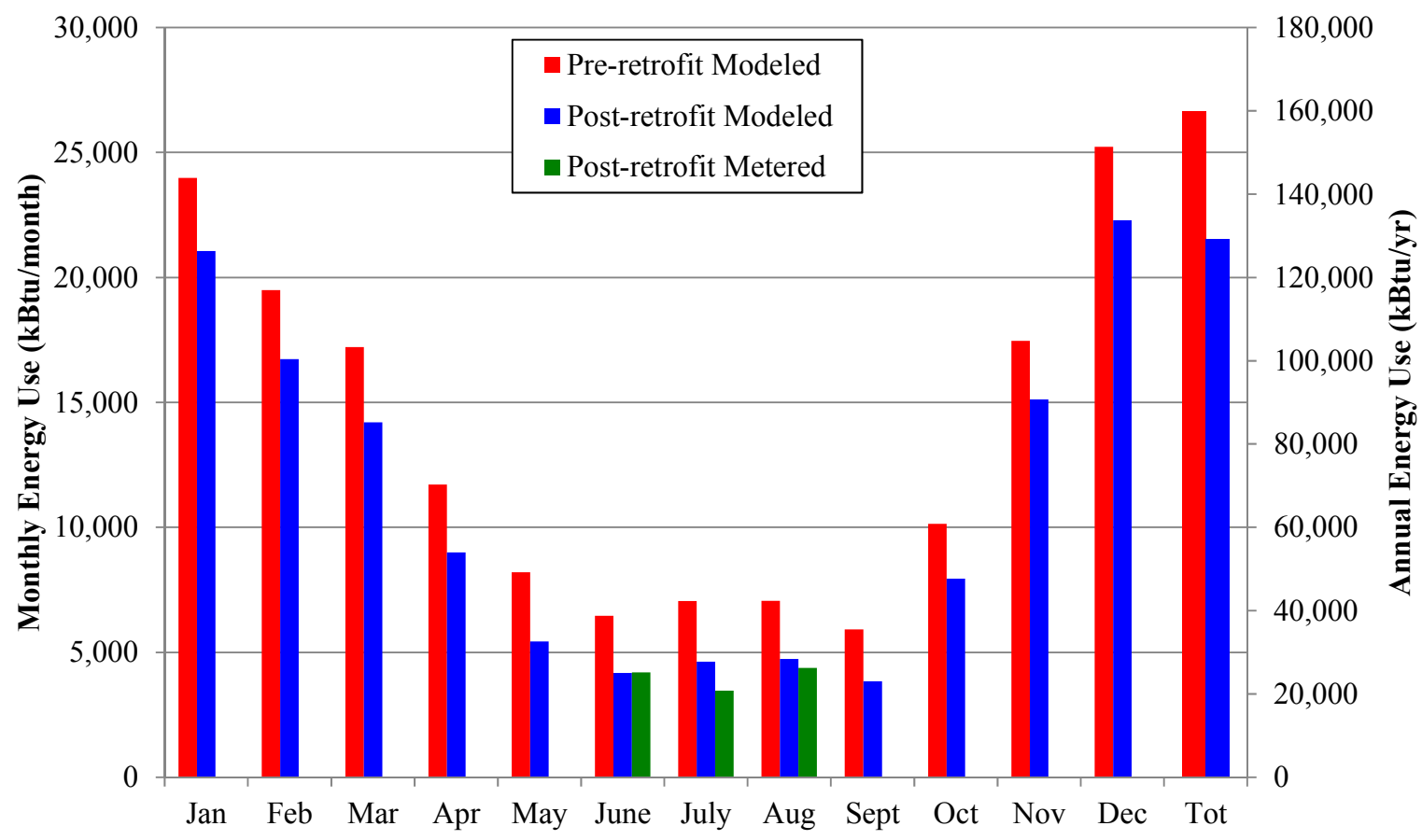

Figure C.49. PNW-6 monthly and annual pre-retrofit modeled, post-retrofit modeled, and metered results.

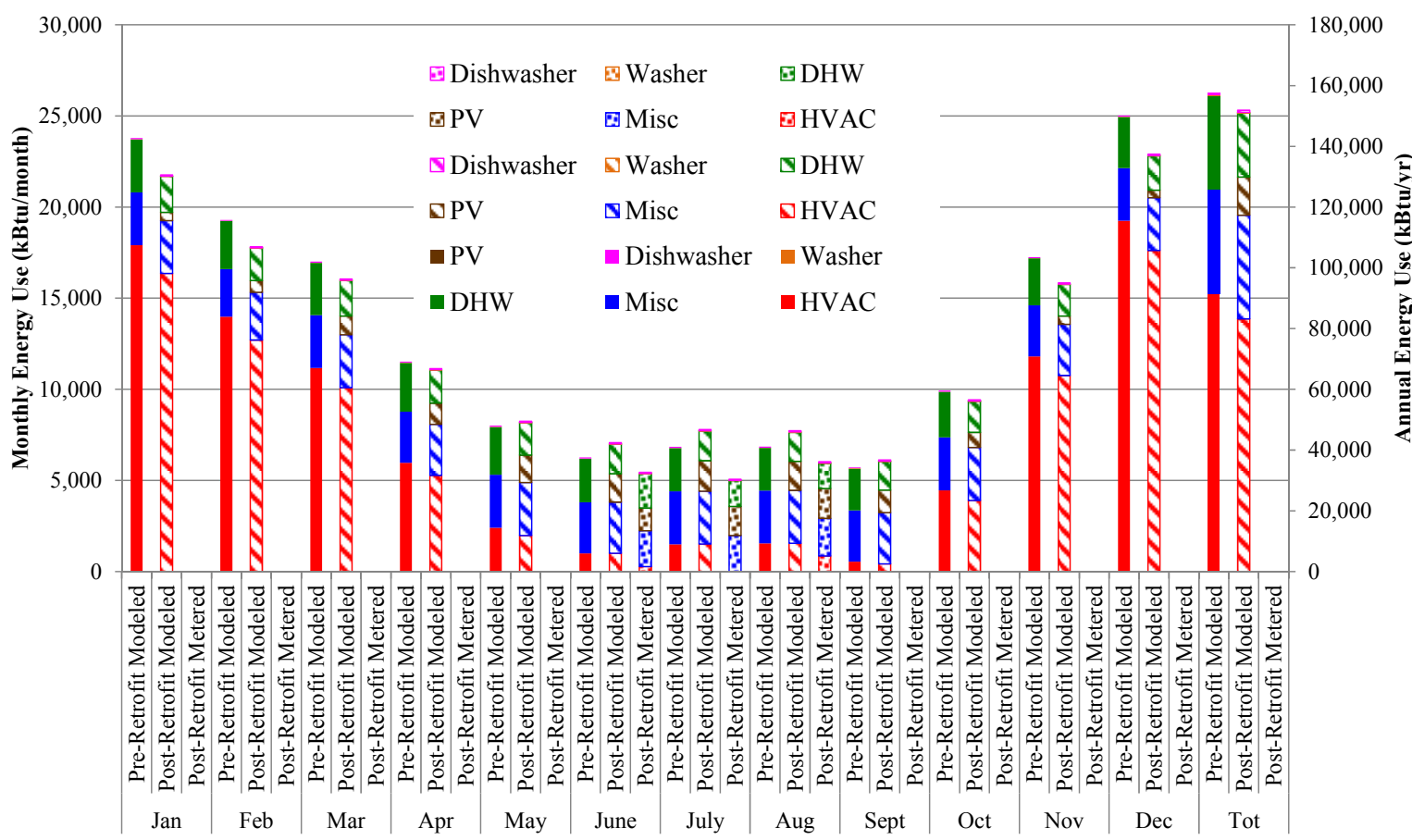

Figure C.50. PNW-6 monthly and annual pre-retrofit modeled, post-retrofit modeled, and metered results disaggregated by end-use. 


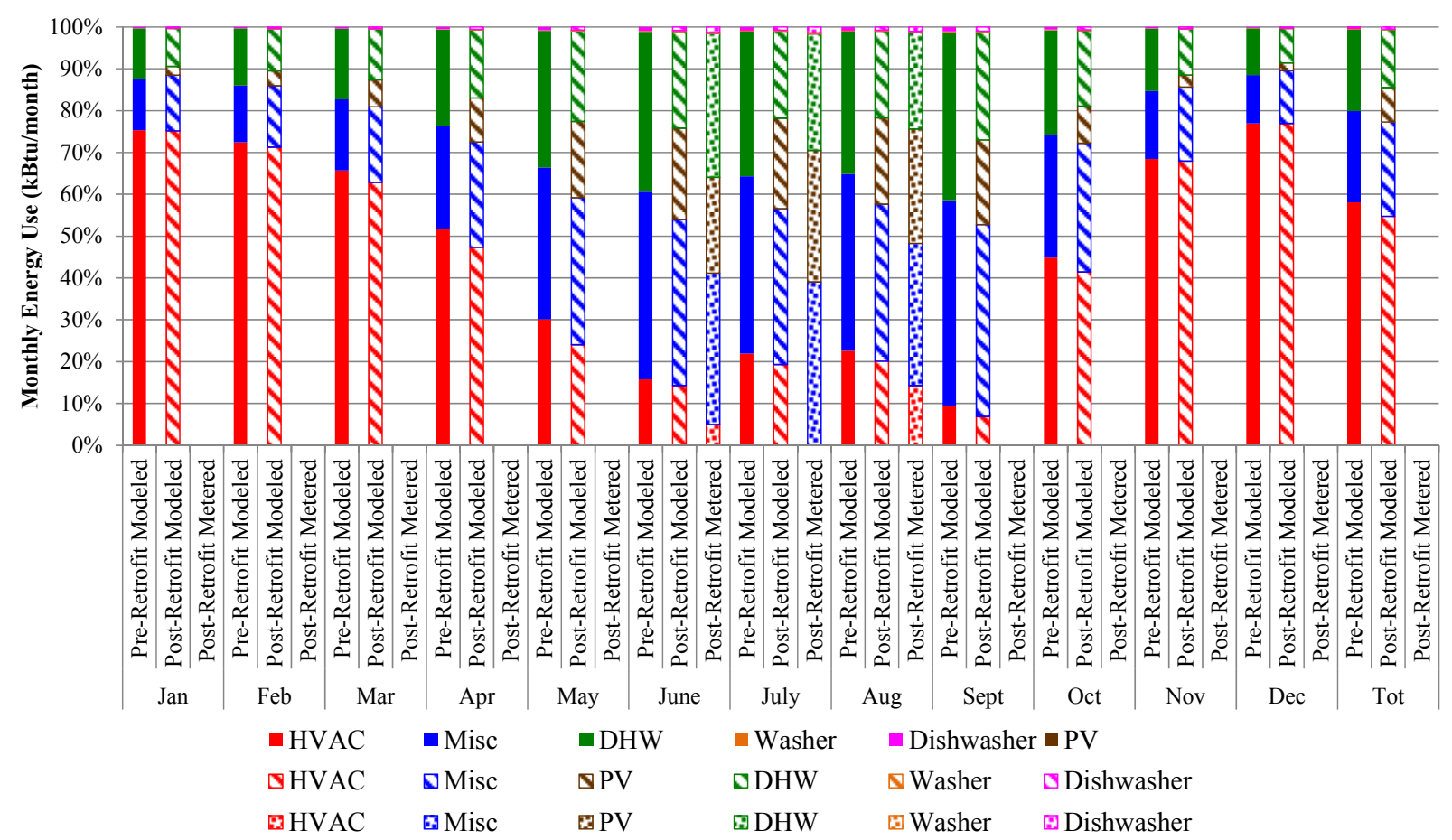

Figure C.51. PNW-6 monthly and annual pre-retrofit modeled, post-retrofit modeled, and metered results percentage by end-use.

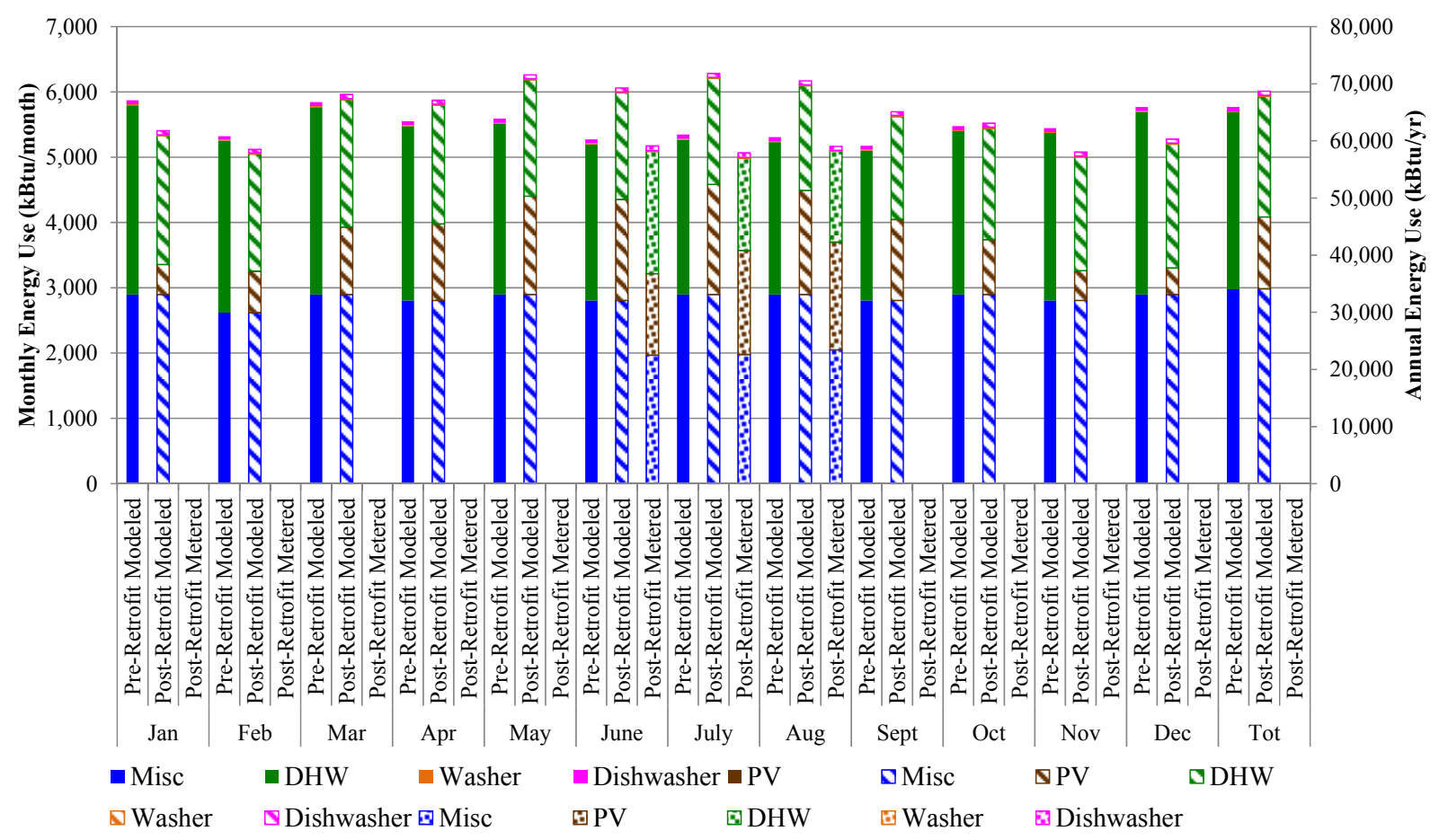

Figure C.52. PNW-6 monthly and annual pre-retrofit modeled, post-retrofit modeled, and metered results disaggregation by minor end-use. 


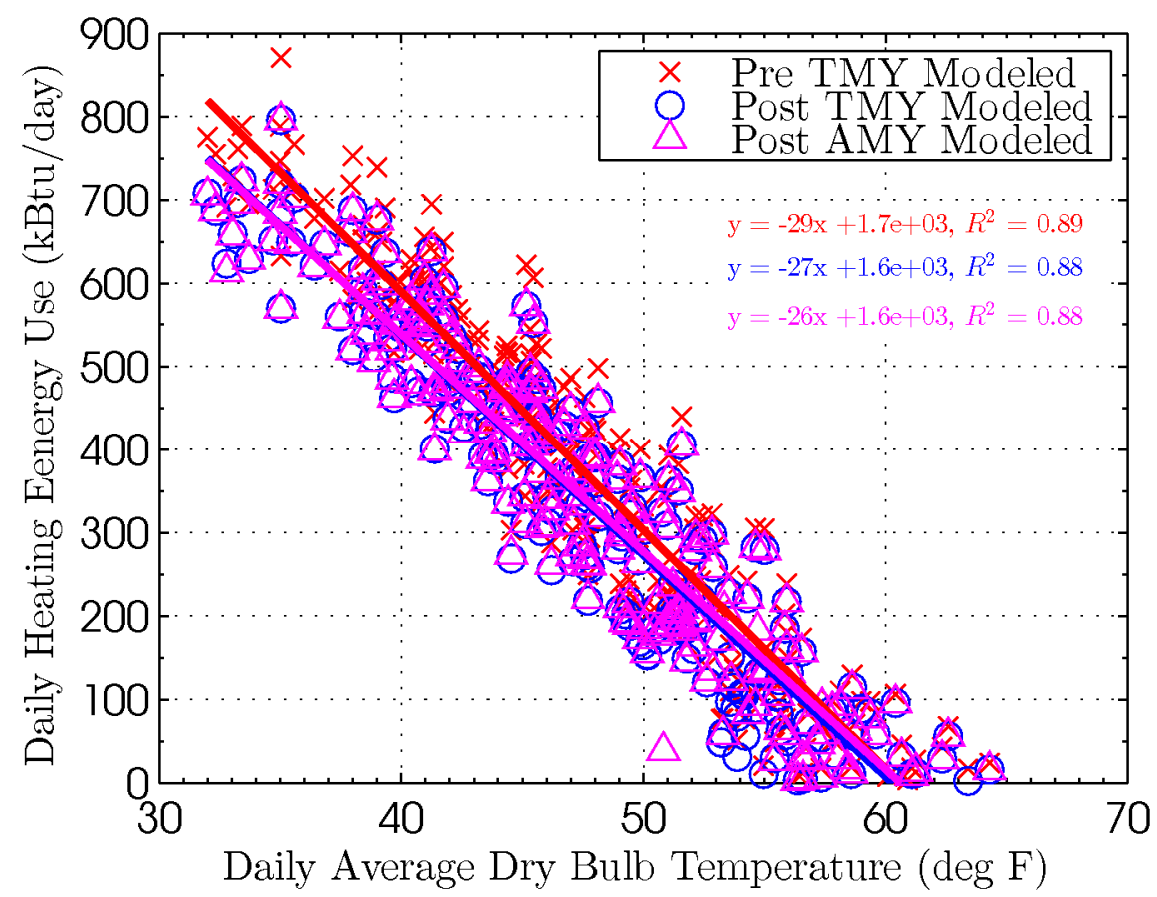

Figure C.53. PNW-6 daily heating energy use and dry bulb temperature comparison.

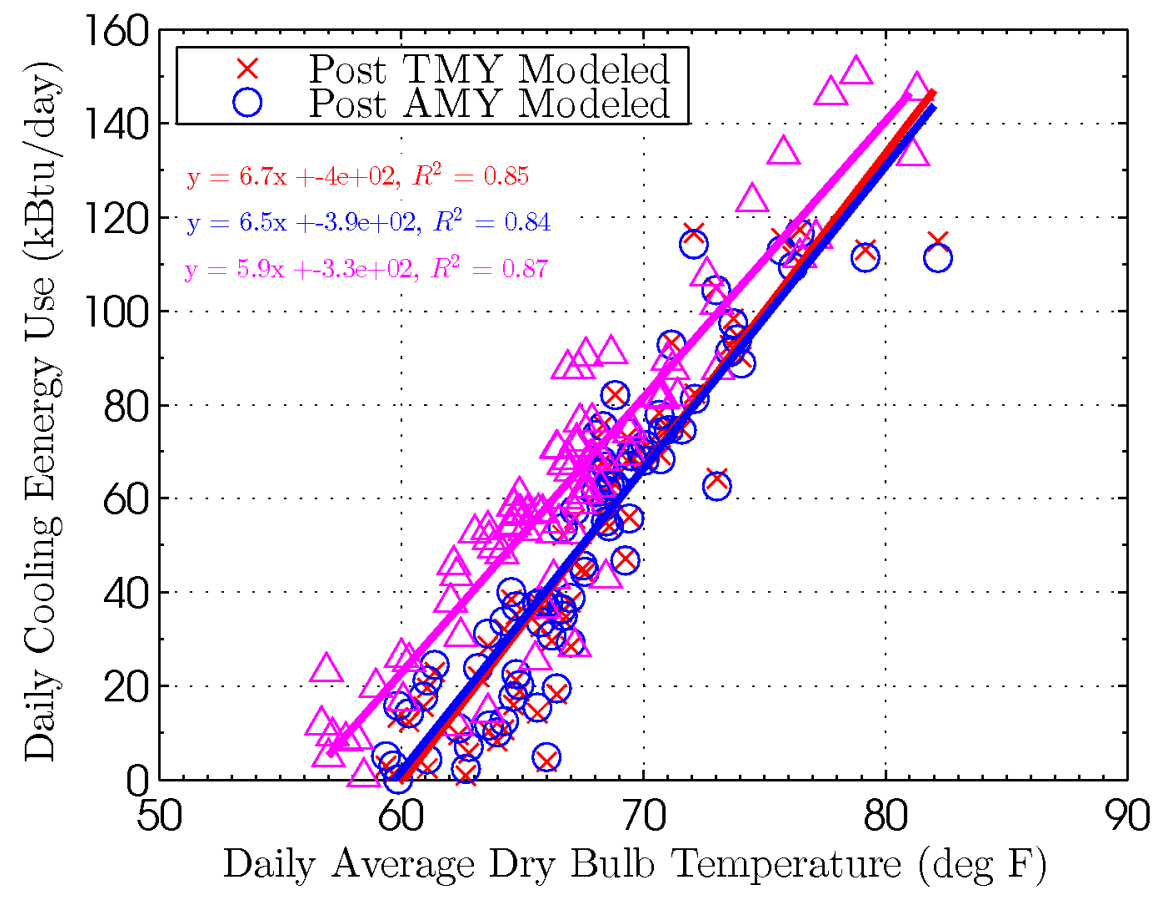

Figure C.54. PNW-6 daily cooling energy use and dry bulb temperature comparison. 


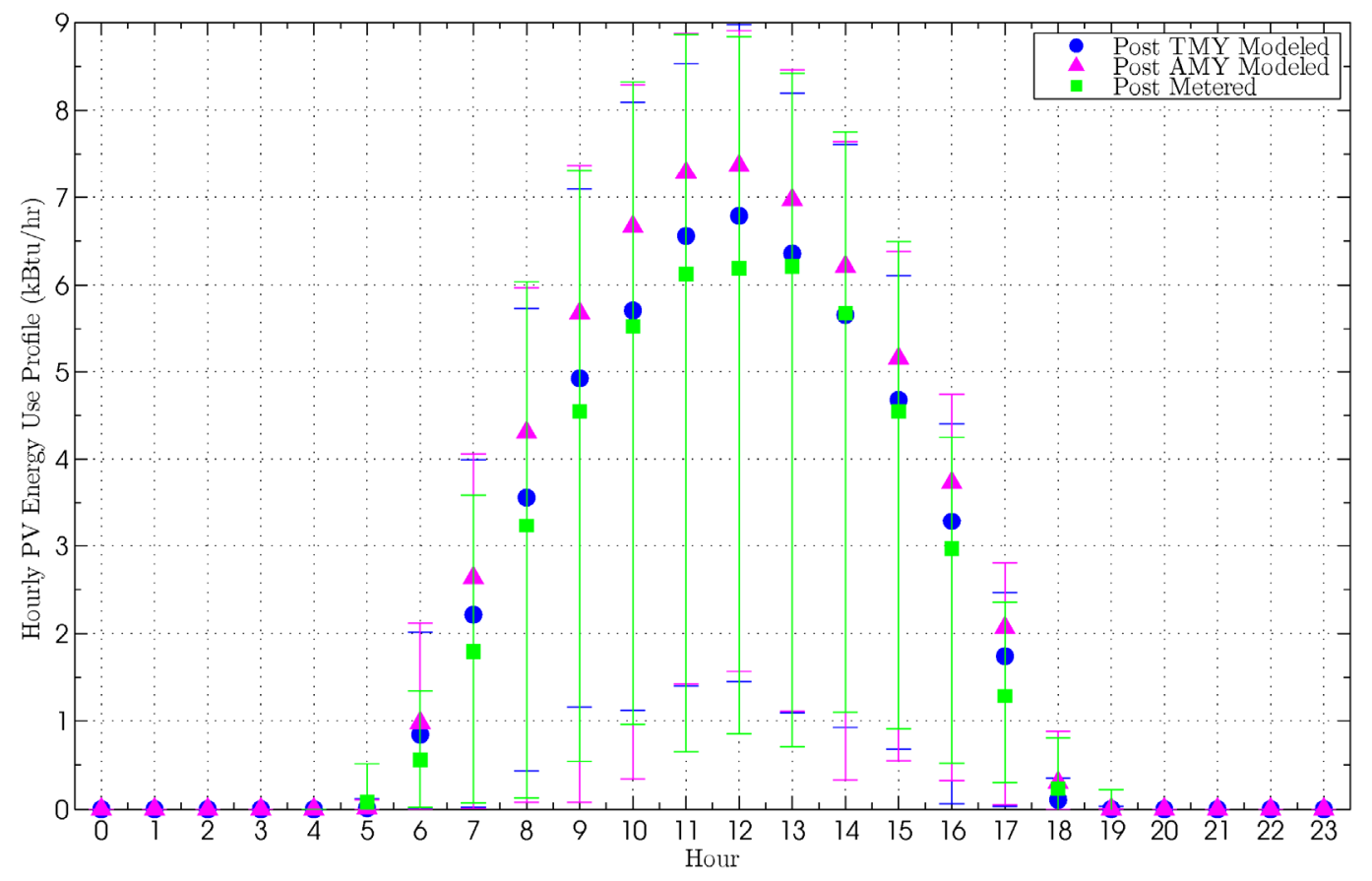

Figure C.55. PNW-6 hourly solar photovoltaic (PV) energy generation profile comparison. ${ }^{1}$

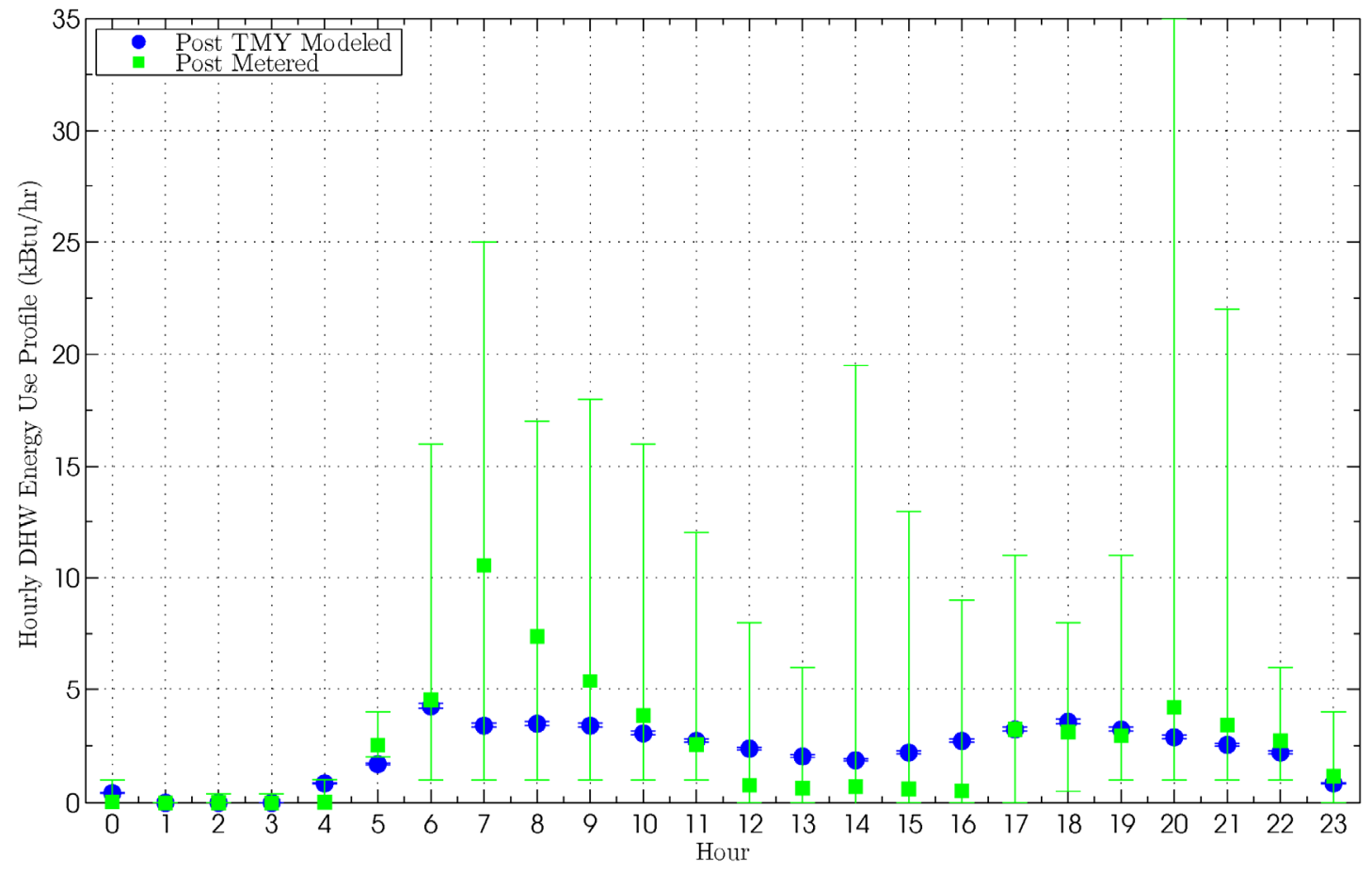

Figure C.56. PNW-6 hourly DHW energy use profile comparison.

\footnotetext{
${ }^{1}$ The error bars in all hourly profiles presented in this report represent the maximum and minimum values observed during the given hour and not the standard deviation. This presentation provides insight into the maximum load observed for the equipment monitored.
} 


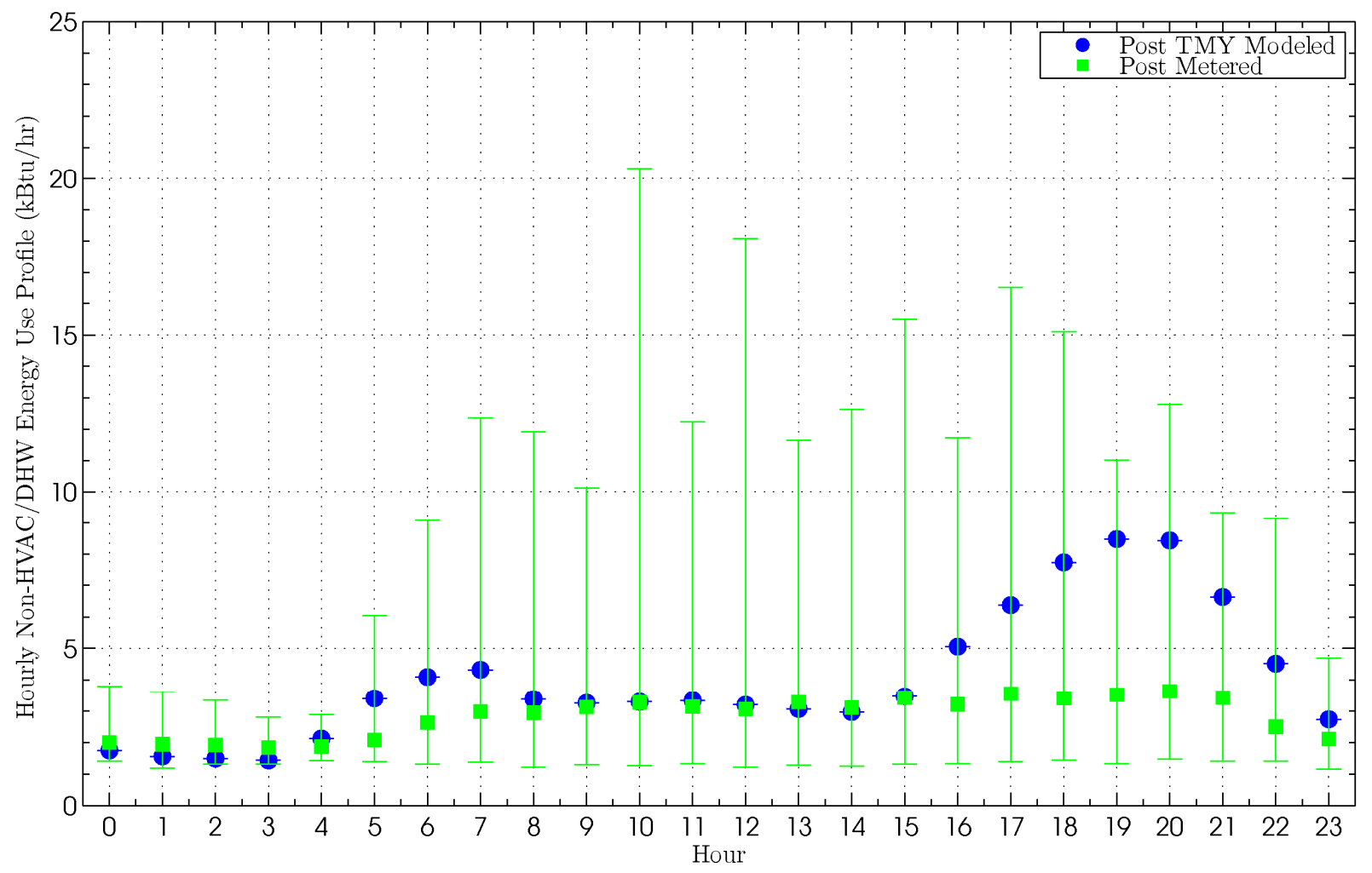

Figure C.57. PNW-6 hourly energy use, excluding HVAC and DHW, profile comparison.

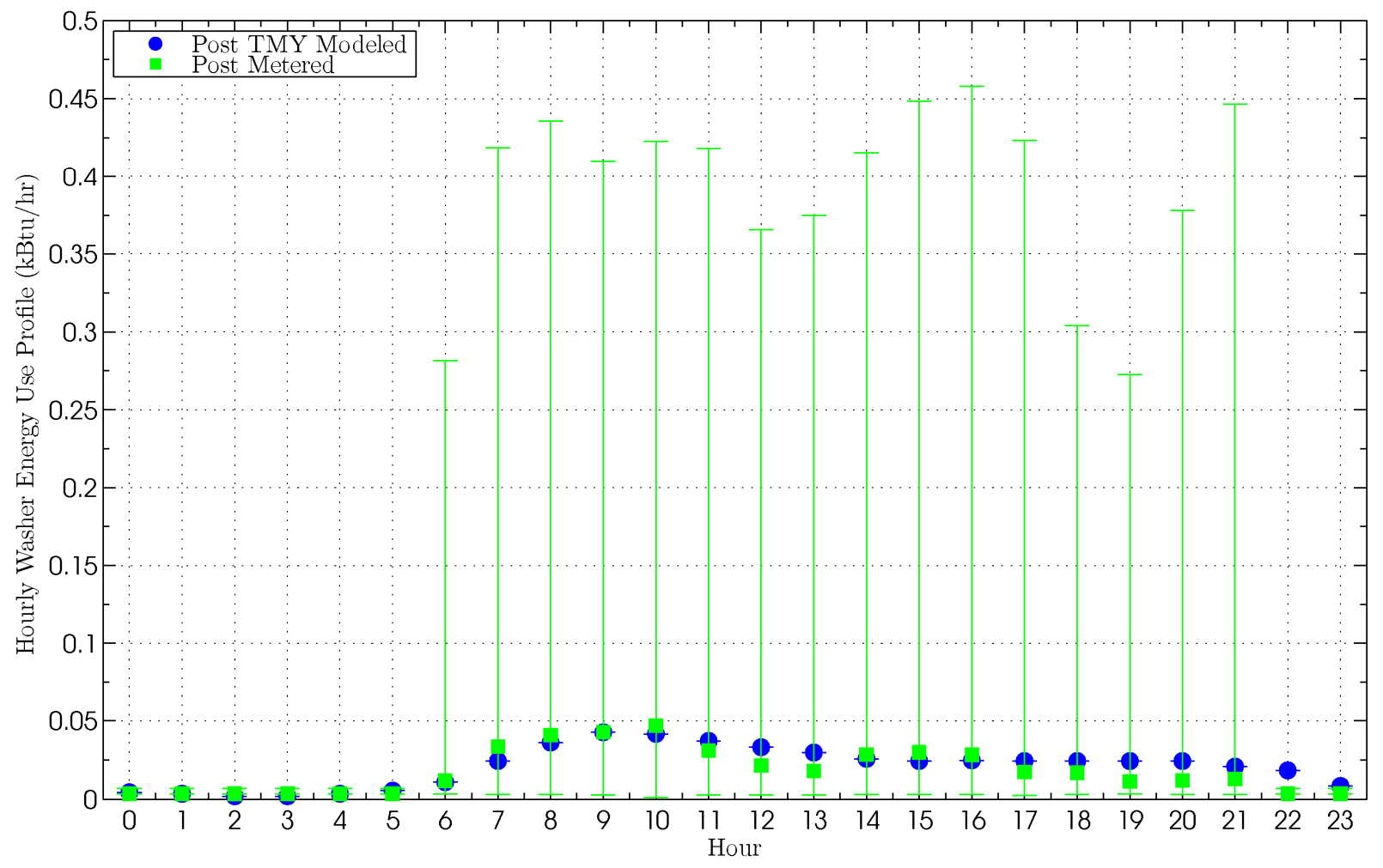

Figure C.58. PNW-6 hourly washer energy use profile comparison. 


\section{C.7 PNW-7 Home}

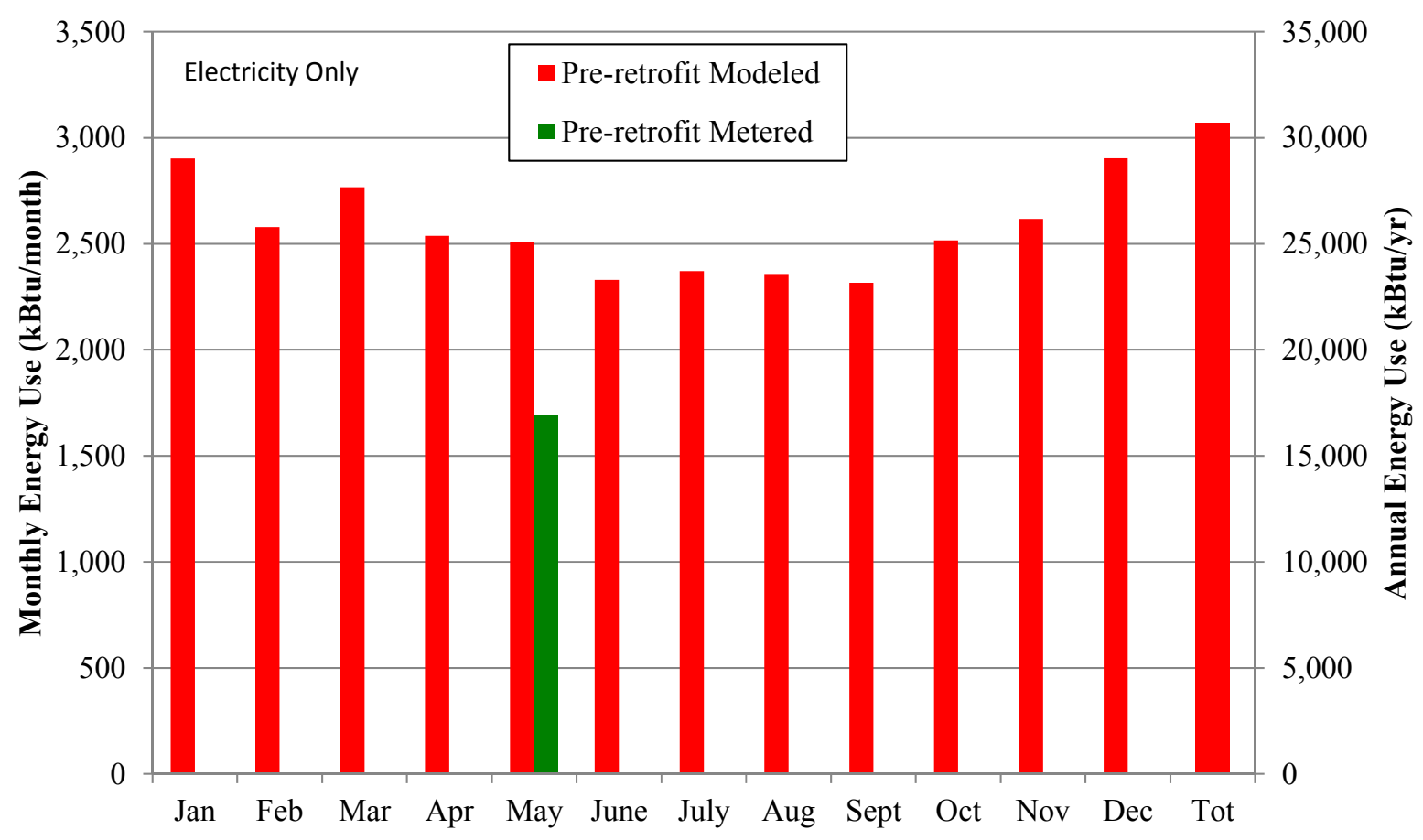

Figure C.59. PNW-7 monthly and annual pre-retrofit modeled and monitored results.

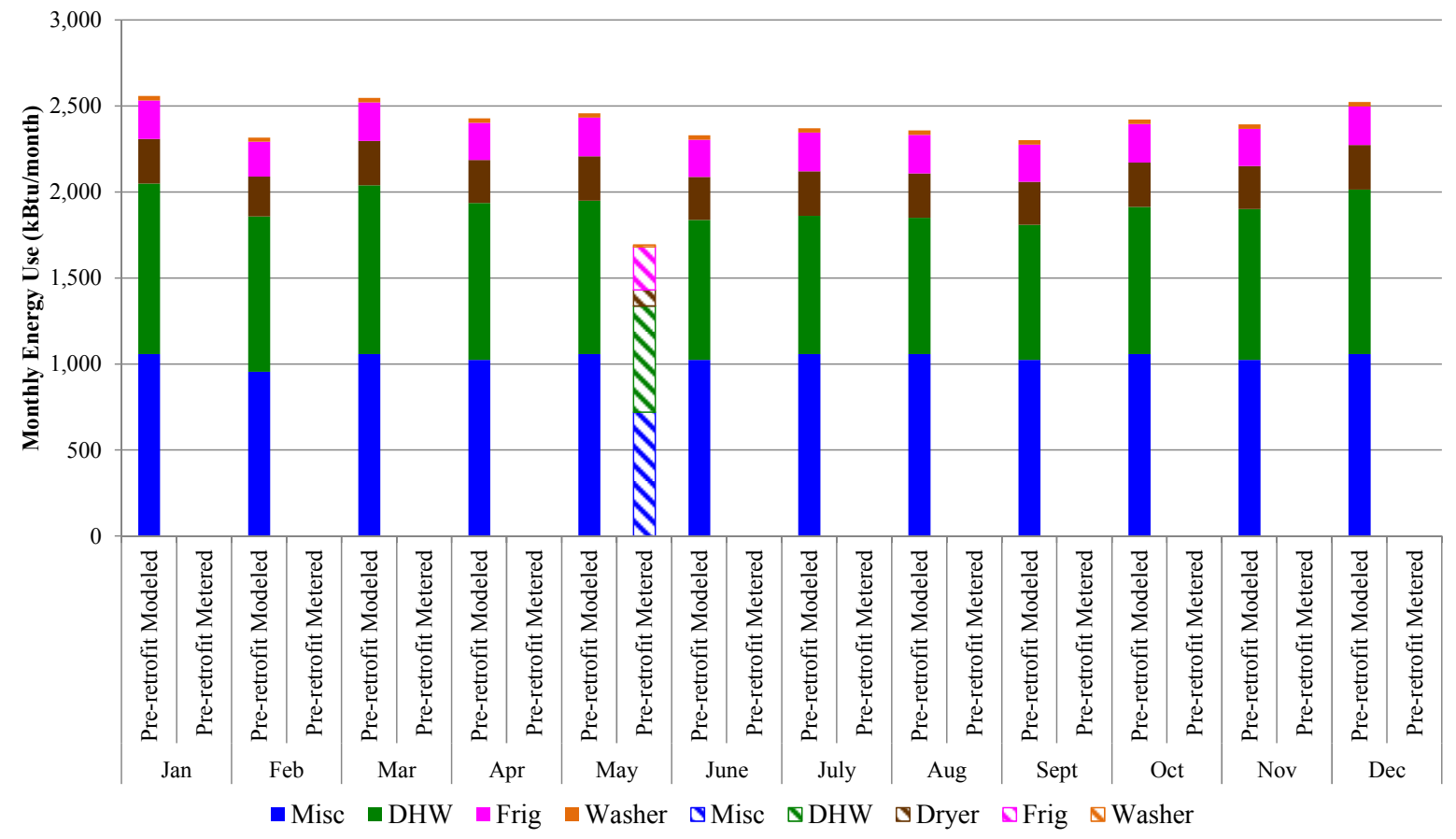

Figure C.60. PNW-7 monthly and annual pre-retrofit modeled, post-retrofit modeled, and monitored results disaggregated by end-use. 


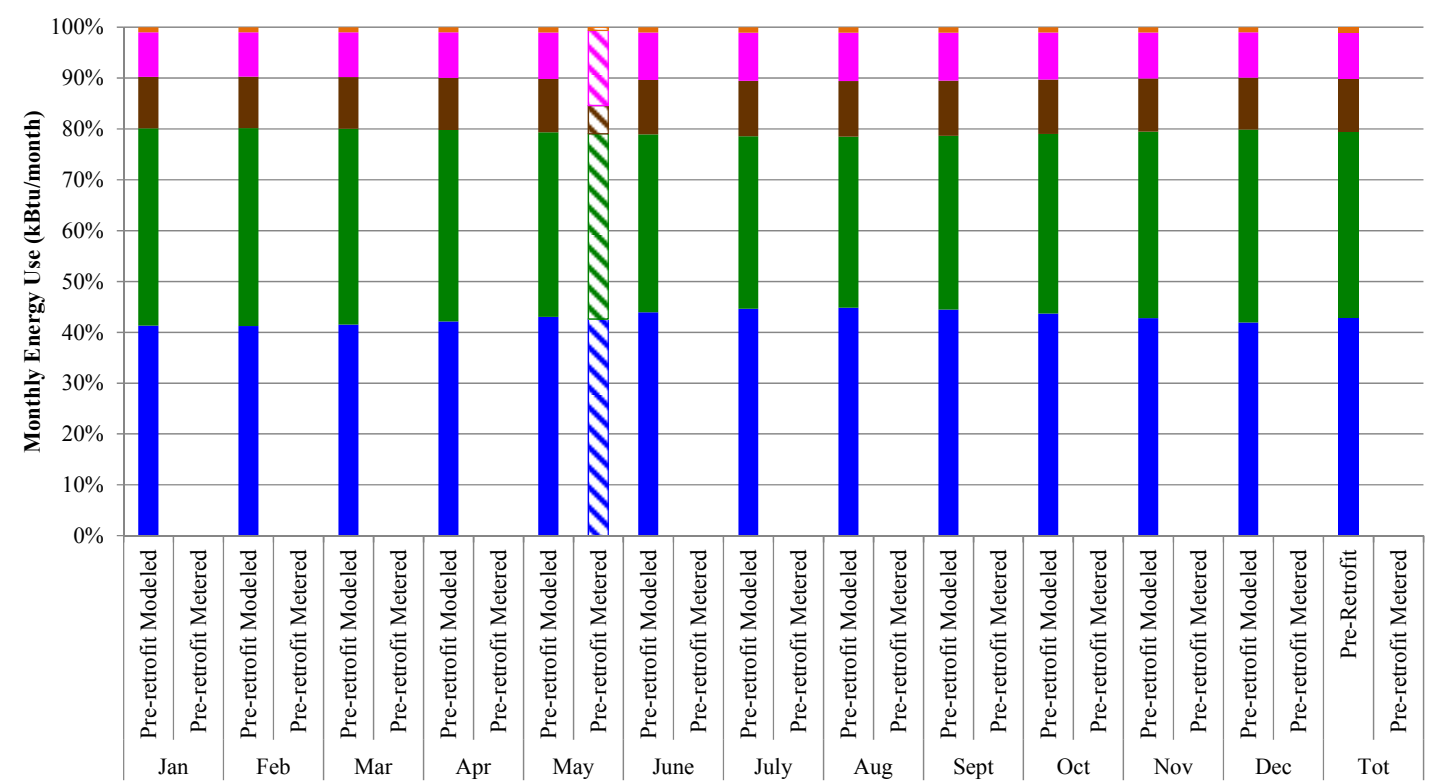

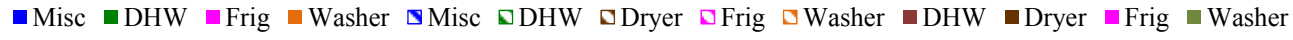

Figure C.61. PNW-7 monthly and annual pre-retrofit modeled, post-retrofit modeled, and metered results percentage by end-use.

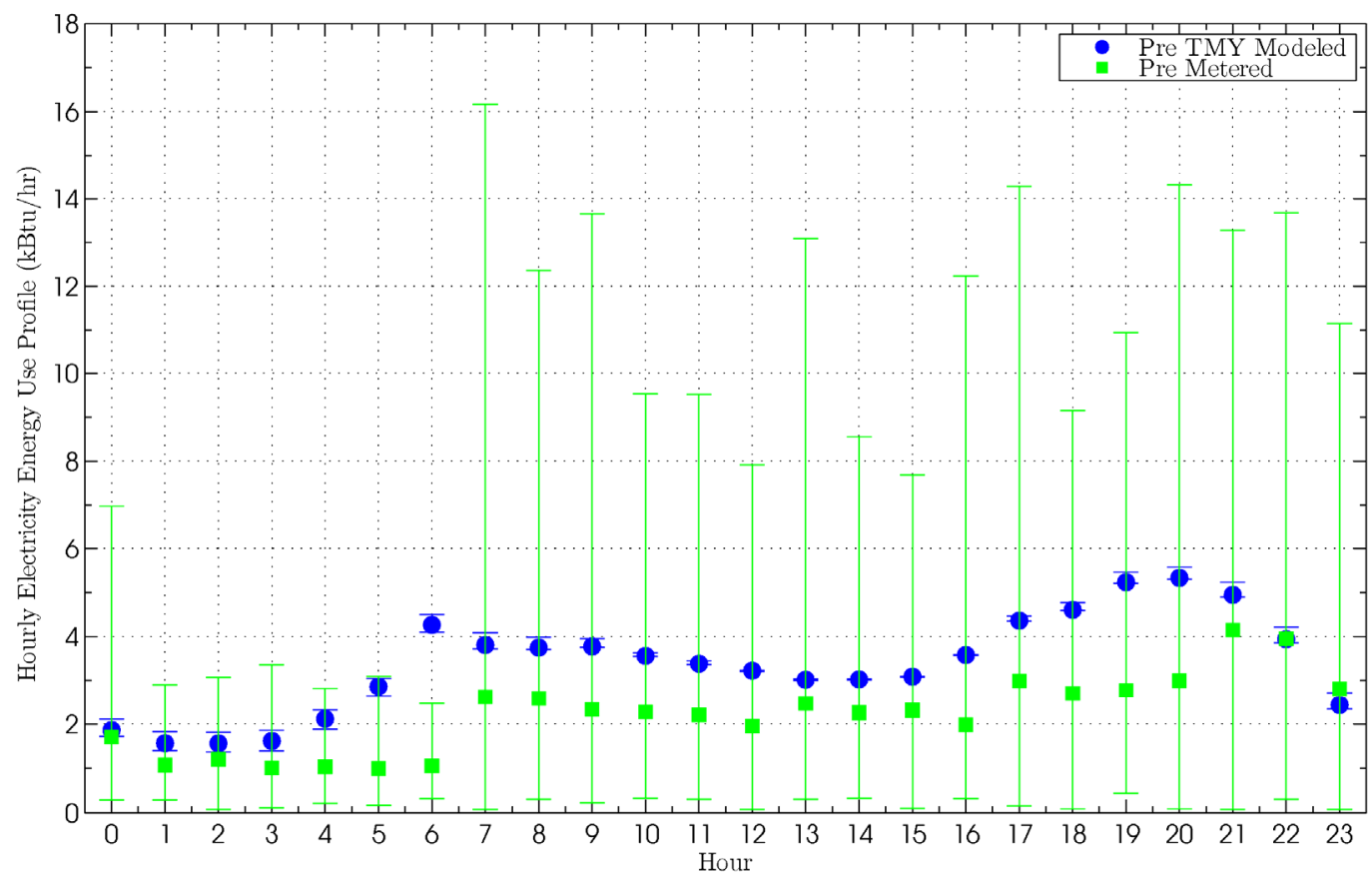

Figure C.62. PNW-7 hourly electricity energy use profile comparison. ${ }^{1}$

\footnotetext{
${ }^{1}$ The error bars in all hourly profiles presented in this report represent the maximum and minimum values observed during the given hour and not the standard deviation. This presentation provides insight into the maximum load observed for the equipment monitored.
} 


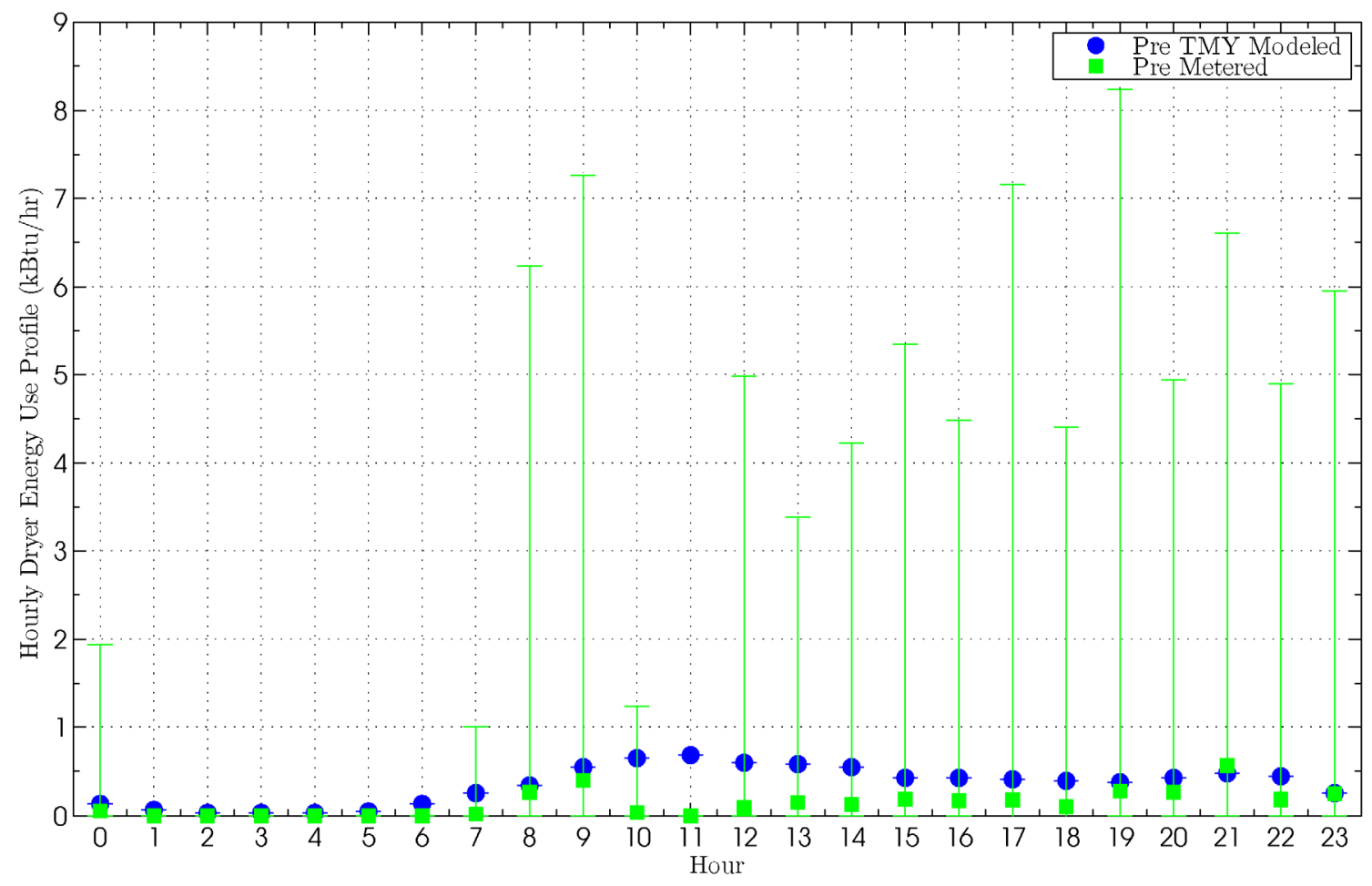

Figure C.63. PNW-7 hourly dryer energy use profile comparison.

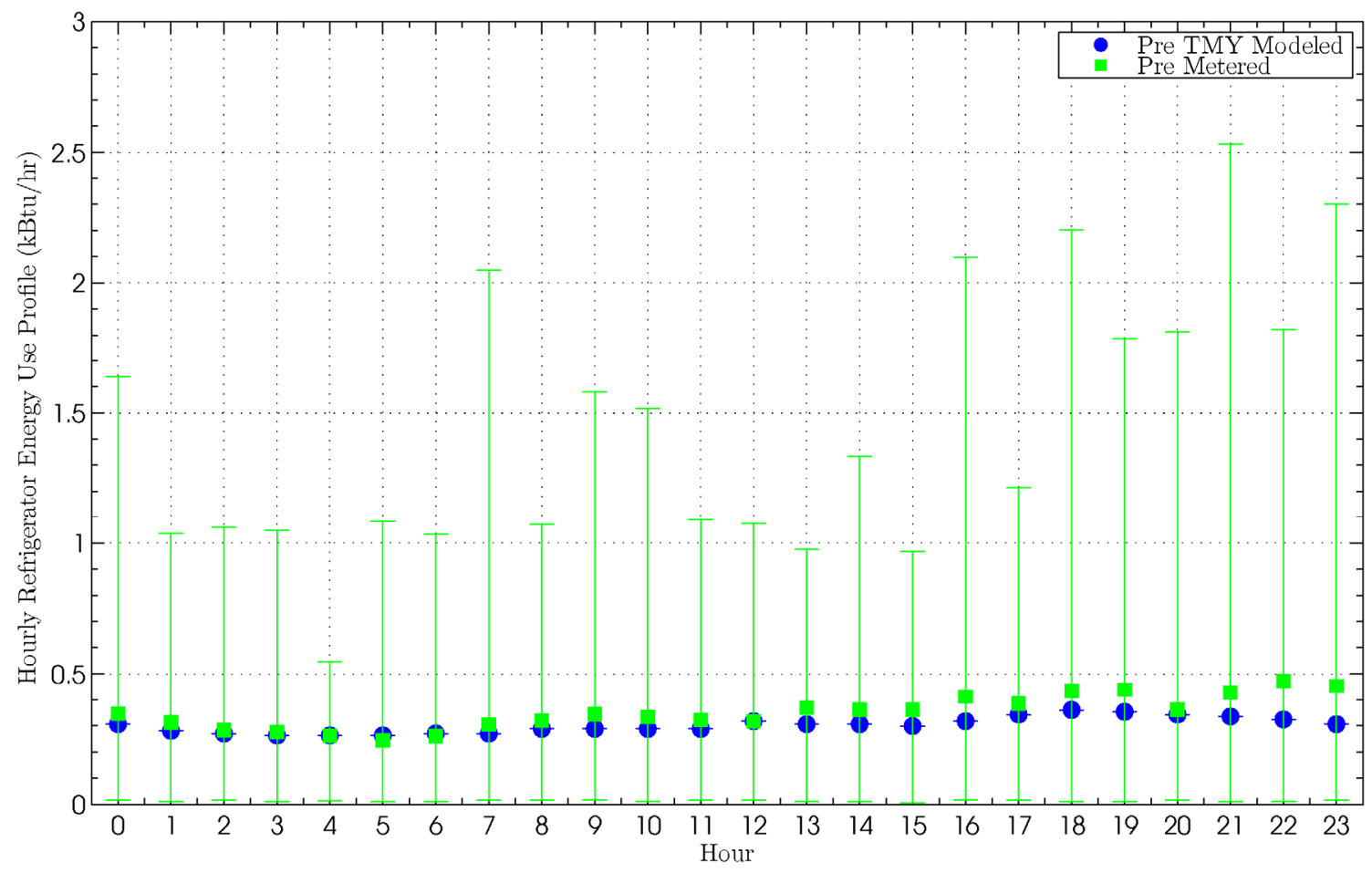

Figure C.64. PNW-7 hourly refrigerator energy use profile comparison. 


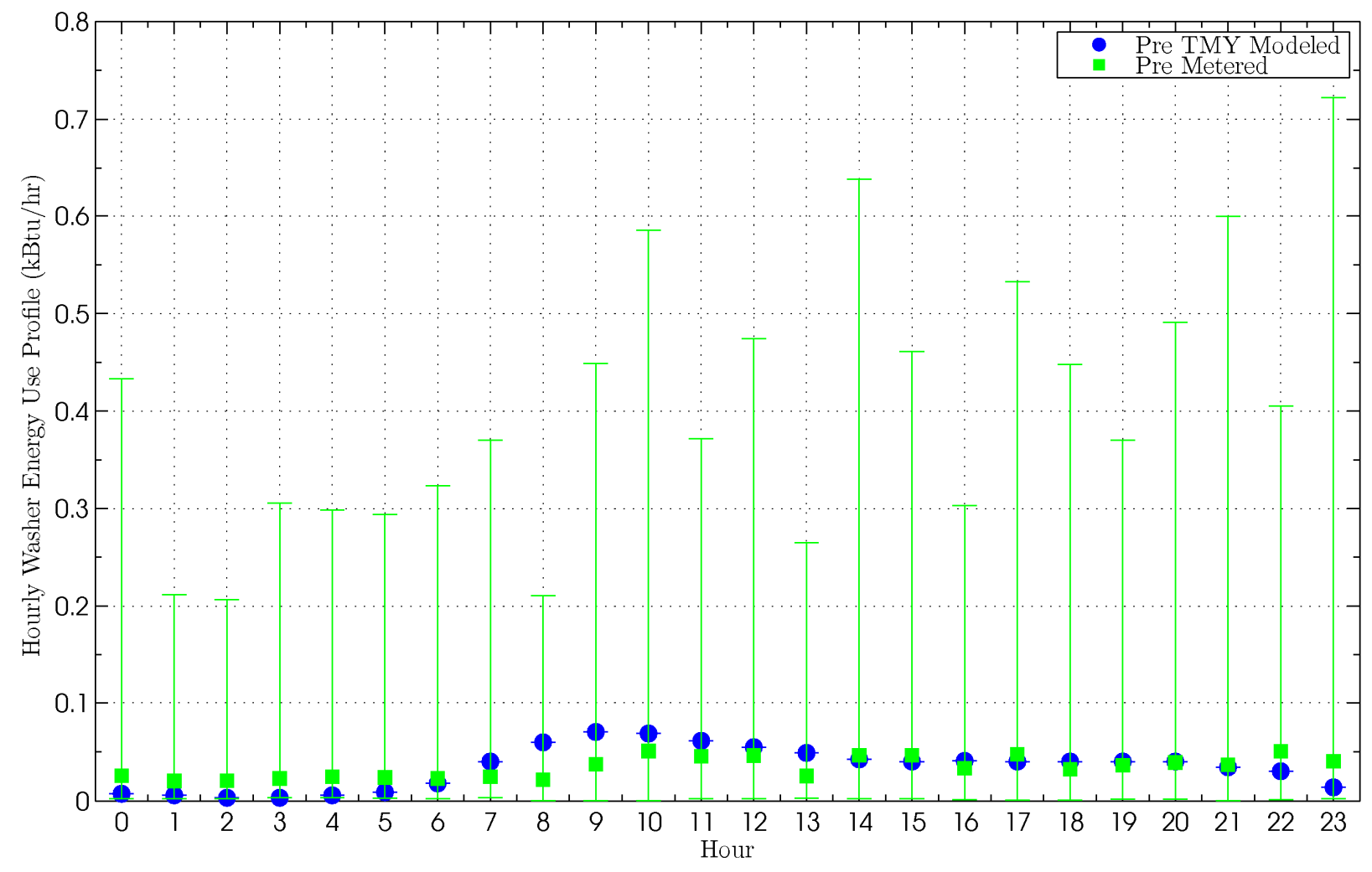

Figure C.65. PNW-7 hourly washer energy use profile comparison. 


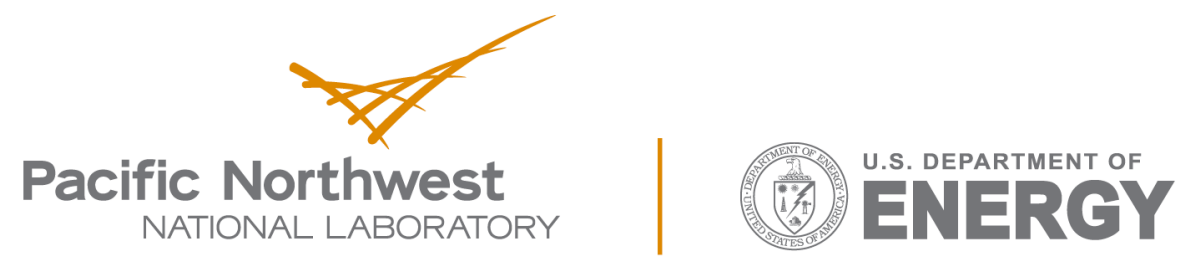

Proudly Operated by Battelle Since 1965

902 Battelle Boulevard

P.O. Box 999

Richland, WA 99352

1-888-375-PNNL (7665)

www.pnnl.gov 